Ana Francisca de Azevedo, Ricardo Nogueira Martins,

Marta Rodrigues, Mónica Santos (Eds.)

\title{
GEOGRAPHICAL IMAGINATIONS
}

Book of Proceedings IV International Meeting in Cultural Geography, Geographical Imaginations 27-28 September 2012- Guimarães, Portugal
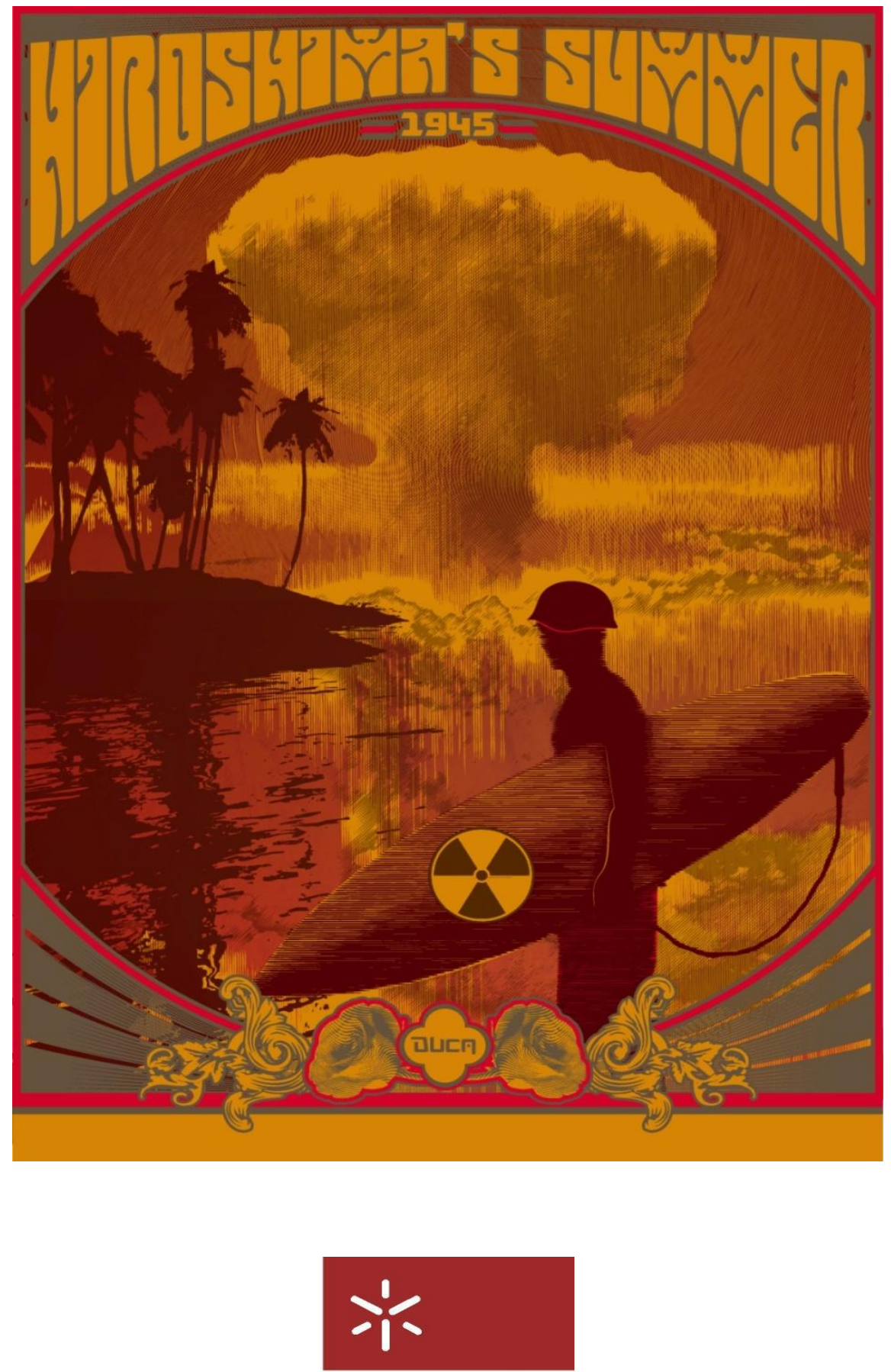

Universidade do Minho

Departamento de Geografia 
Ana Francisca de Azevedo, Ricardo Nogueira Martins, Marta Rodrigues, Mónica Santos

(Eds.)

GEOGRAPHICAL IMAGINATIONS

Book of Proceedings IV International Meeting in Cultural Geography, Geographical Imaginations 27-28 September 2012- Guimarães, Portugal 
Title:

Geographical Imaginations

Editors:

Ana Francisca de Azevedo, Ricardo Nogueira Martins, Mónica Santos, Marta Rodrigues

\section{Authors:}

António Alberto da Silva, Camila Nunes, Carolina Vieira, Dalila Barros, Dariane Rossi, Eduarda Ferreira, José Horta, Juliana Costa, Karina Fiorovante, Lucas Panitz, Maria João Silva, Michael Lent, Romy Hofmann,

Cover Image:

Fernando Lopes

ISBN:

978-989-97394-2-0

Year of Edition:

2013

Editor:

UMDGEO - Department of Geography of University of Minho

Campus de Azurém

4800-058 Guimarães

Portugal

Collection:

Books of Proceedings

Number:

All rights reserved. 
Alterity as a reaction against globalization

Michael Lent

"The birth of tragedy" and its theoretical contribution to art and music in geography

Carolina Deconto Vieira

Spaces of transgression and normativity in Pedro Almodóvar's Filmography

Karina Eugenia Fioravante

Collaborative webmapping: creating layers of lesbian visibility

Eduarda Ferreira

Francis Bacon and the body beyond the representation

Camila Xavier Nunes

Space, Literature and Representation: Identity Construction in 19th Century Portugal

José Horta

Representations of space, musical practices and transborder territorialities among Brazil, Argentina and Uruguay

Lucas Manassi Panitz

Art(F), Juvenile, Mature, Dedicated is looking for space (M) for mutual and all-round arrangements. Enriching geography classes through artistic practice

Romy Hofmann

Place, Flavors and musicality

Dariane Raifur Rossi

Birds, Ecology and Landscape: Linking science and art with elementary school children Maria João Silva, Dalila Barros, António Alberto Silva

Spatial Representations of Squatter Settlement in visual narratives of Brazilian films: a comparative cinematic landscape analysis of Black Orpheus, City of God and Elite Squad | \& II 
GEOGRAPHICAL IMAGINATIONS 


\section{Alterity as a reaction against globalisation}

Michael Lent, University of Lincoln

mlent@lincoln.ac.uk

Spatial Praxis

Fragmentation and mobility towards a singular Other

The geographer Yi-Fu Tuan denotes the symbiotic relationship of space/place when he explains, 'what begins as undifferentiated space becomes place as we get to know it better and endow it with value. ${ }^{11}$ In the last fifty years, artists developed a discourse of earthworks and sitebased arts that have sought to transform landscape. Ultimately, I argue, this transformation of landscape may lead to a spatial disappearance into place, as when Baudrillard warns: 'By their exceptional faculty for knowledge, human beings, while giving meaning, value, and reality to the world, at the same time begin a process of dissolution ('to analyse' means literally 'to dissolve'). ${ }^{2}$

By considering Husserlian strategies of adumbrational theory, this paper is an enquiry into the experience of unfamiliar spaces - those ripe with meaning. In order to uncover and produce an imagining of space, this investigation seeks to explore site without colonising, physically altering, or hastening its dissolution.

Alterity is in danger. It is a masterpiece in peril, an object lost or missing from our system... ${ }^{3}$

There is a crisis of alterity in which otherness is threatened by its opposition to a system of exchange. An artistic effort towards radical alterity is a practical one. It combines experience of real space with strategies of asyndetonal fragmentation and mobility as a production of perception of the world as Other. This strategy advances discovery of the adumbrational potentialities of site, ultimately breaking the cyclical system of exchange that causes everything to disappear.

I suggest a rethinking of the way we utilise space-a radicalised and unique praxis. For centuries, artists focused first on the representation of space and later on the viability of siteboth acts towards disappearance. Contemporary practices engage in the production of art as entertainment, capital, or at least as something slick. This has left the body count of site (amongst many other elements) in the wake of art's murderous utility.

\footnotetext{
Tuan, Y.-F., 2005, Space and Place: The Perspective of Experience, University of Minnesota Press, Minneapolis. p. 6.

2 Baudrillard, J., 2009, Why hasn't everything already disappeared? Translated by A. Willaume. Seagull Books, London; New York. p. 11.

Baudrillard, J., 2009, Why hasn't everything already disappeared? Translated by A. Willaume. Seagull Books, London; New York. p. 11.

${ }^{3}$ Baudrillard, J., 2008, Radical Alterity, Semiotext(e), Los Angeles, CA.
} 


\section{GEOGRAPHICAL IMAGINATIONS}

...the visual arts have remained by the wayside as the entire culture is now being threatened by the extermination of space... ${ }^{4}$

I suggest the extermination of space is more precisely a transfiguration of site into a known and utilised place. It represents a movement into realised place, and a disappearance of the original space that once was. It has been consumed as a product into the system of difference and absorbed into homogeneity. Rather than a mediated practice whereby previous artists respond to space as commodification, I propose a different practice. One that preserves (and produces?) the alterity of unnamed space as an act towards singularity - a singular space that resists the urge towards homogeneity.

Video stills of Project

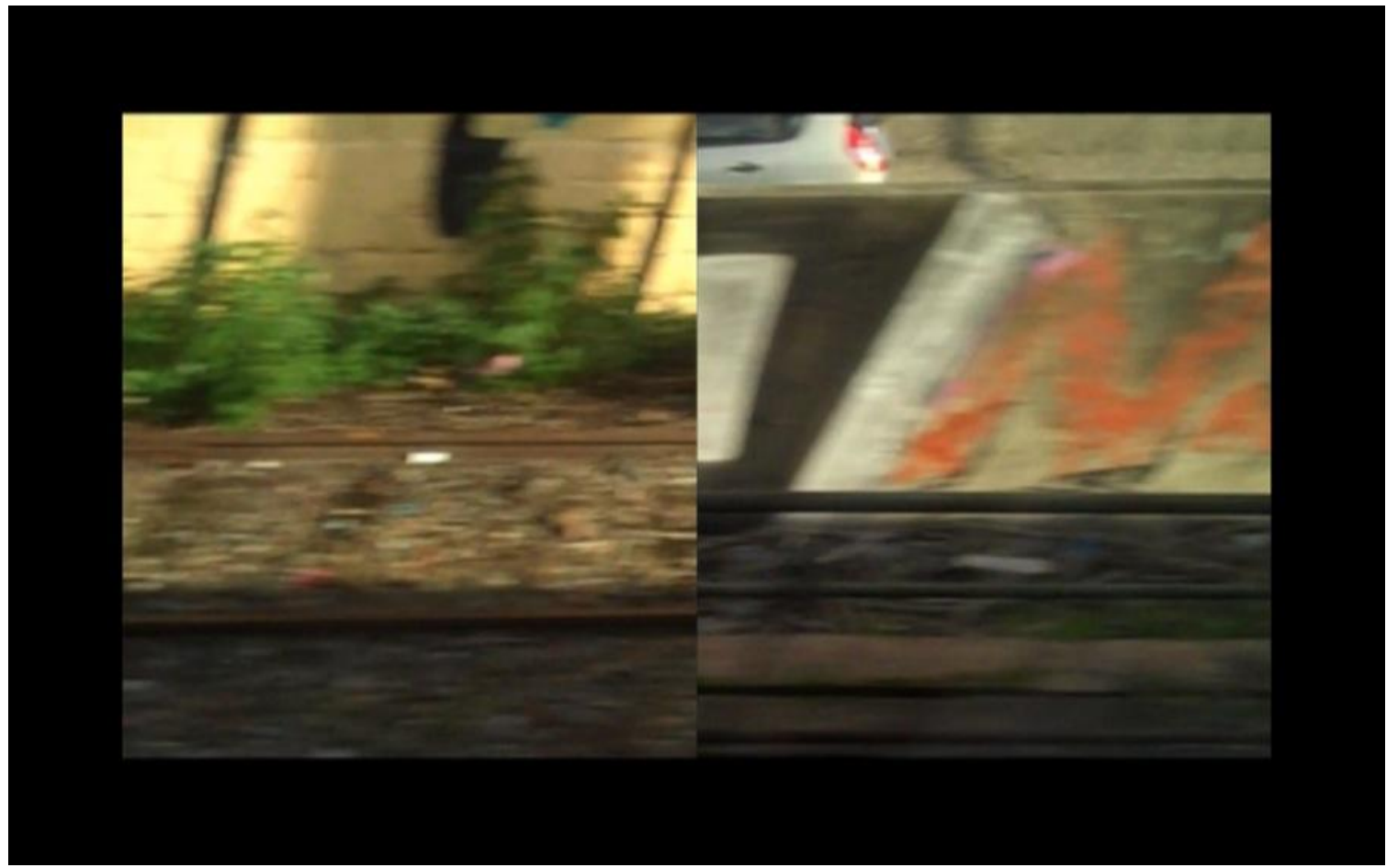

${ }^{4}$ Virilio, P. \& Lotringer, S., 2005, The Accident of Art, Semiotext(e), New York. P. 29 


\section{GEOGRAPHICAL IMAGINATIONS}

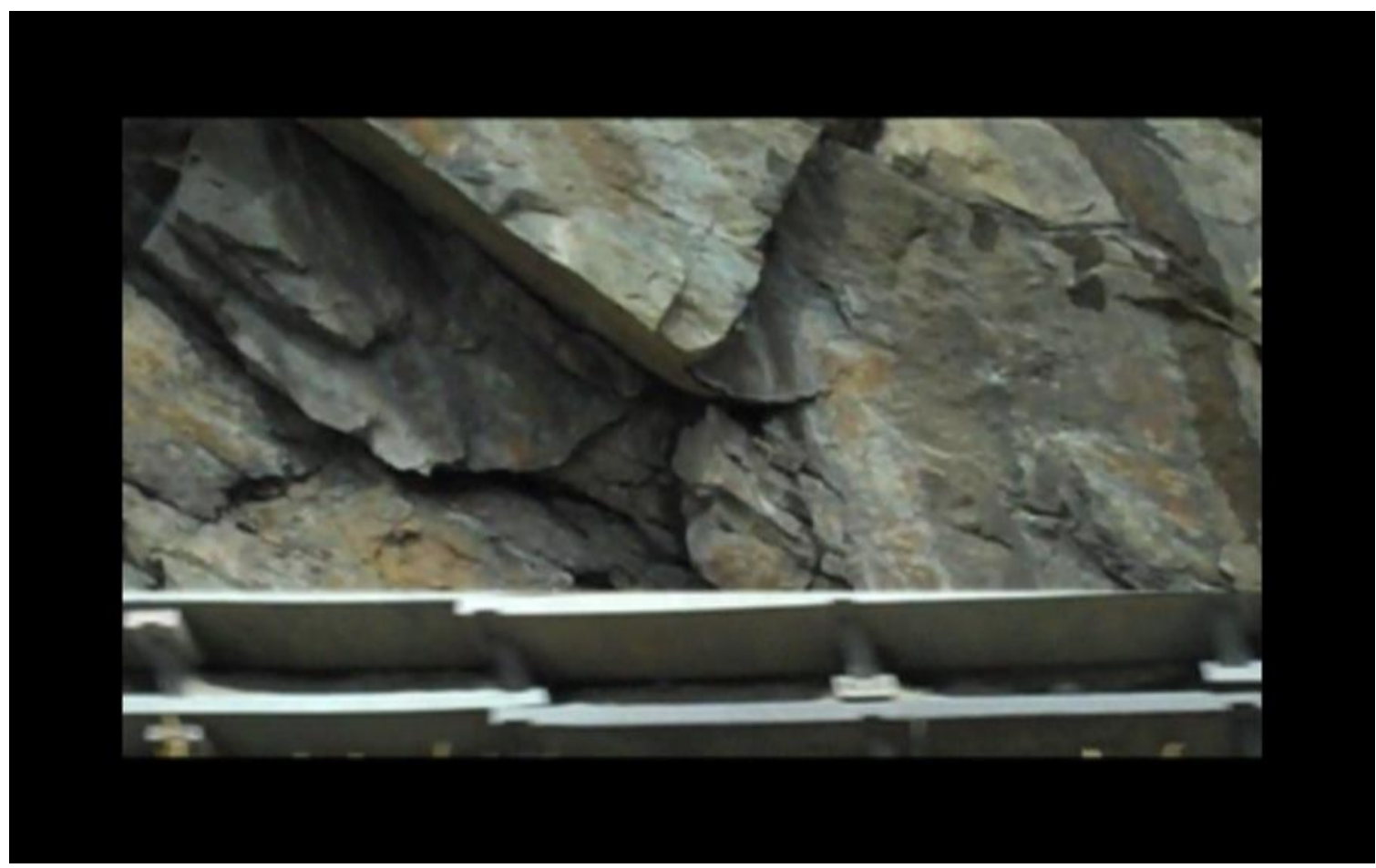

\section{Alterity as a reaction against globalisation}

Alterity is in danger. It is a masterpiece in peril, an object lost or missing from our system... (Baudrillard, \& Guillaume,

There is a crisis of alterity in which globalised meaning is threatened by its opposition to the system of exchange. An artistic effort towards radical alterity is a practical one. It combines experience of real space with strategies of fragmentation and mobility as a production of perception of the world as other. The goal of which is to break the cyclical system of exchange that causes everything to disappear. First, this practice must be based on real space; anything else would be purely conceptual and already disappeared. Virtual worlds are simulacra, unsatisfactory imitations, or pure imagination. They are remnants of what has disappeared, or rather, what never was. Fragmentation and mobility are strategies towards discovering some of the potentialities of real space (which I discuss further later), without causing its dissolution.

I am suggesting a rethinking of the way we utilise space. This is a radicalised and unique praxis, as artists for centuries have focused first on the representation of space and later on the viability of site—-both acts towards disappearance. Again Baudrillard:

By their exceptional faculty for knowledge, human beings, while giving meaning, value, and reality to the world, at the same time begin a process of dissolution. 


\section{GEOGRAPHICAL IMAGINATIONS}

It is through representation that the world begins to disappear into concept, but further, contemporary practices engage in the production of art as entertainment, capital, or at least as something slick. This practice has left the body count of site (amongst many other elements) in the wake of art's murderous utility. In accordance with Baudrillard, Sylvère Lotringer identifies the crisis during his conversations with Virilio in The Accident of Art:

...the visual arts have remained by the wayside as the entire culture is now being threatened by the extermination of space... (Virilio \& Lotringer, 2005:29)

I suggest the extermination of space is a transfiguration of site into a known and utilised place. It represents a movement into realised place, and a disappearance of the original space that once was. It has been consumed as a product into the system of difference and absorbed into homogeneity. Rather than a mediated practice whereby previous artists respond to space as commodification, I propose a different practice. And one that preserves (and produces?) the alterity of unnamed space as an act towards singularity - a singular space that resists the urge towards homogeneity.

The agency of previous artists made a significant impact on the spaces they interrogated and left evidence of this engagement. They worked by sometimes altering or transforming sites in a very literal sense, but just as often by colonising space as overanalysed sites of utility and homogenised dissolution. Instead, I propose a practice that preserves the singularity of the unfamiliarised site. Concurrently and surprisingly, the new spatial praxis I propose of radical alterity also provokes spatial dissolution into a system of difference. This provocation is an interrogation of site to uncover and imagine meaning and potentiality and is different in that its endgame is not to subsume or to conquer. As alluded to by Baudrillard earlier, we might court this dissolution, perhaps enabling an investigation of the moment just before naming and knowing - the moment before disappearance. This is the moment where the ability to discover is most intense.

Here I suggest that in order to "play the game" in which space disappears (or is consumed through place), but without causing its dissolution, practical strategies must be employed. Two specific strategies emerge, namely fragmentation and mobility; they are each intertwined in a spatial praxis that explores the experiential meaning of space without causing it to slip away. Virilio starts to hint at these specific strategies, while also warning of this territory:

Particular selection of what is seen, recording insignificant facts that gradually transforms the true object into a sort of background against which another designation of meaning suddenly 


\section{GEOGRAPHICAL IMAGINATIONS}

emerges, a background which would be already a kind of dissolving view...all is calm, and yet: this world as we see it is passing away (Virilio, 1991:37).

Here, Virilio might provide a very literal studio method_recording insignificant facts and making particular selections of what is seen. I advance that he cautions against creating a kind of work that serves as the background to the colonisation of a forward object. When documentation is transformed into the purely abstract; the original space will have long disappeared into the concept. Instead, I submit that this recording must still have, at least, an intuition of the real or even the familiar. Experiential investigation is paramount, as it presents a resistance to something succumbing to the virtual. Fragmentation removes the linear trajectory of the familiar, preserving this intuition and mystery, while at the same time altering supposed meaning captured in the system of difference. Whilst the ultimate end goal of this practice ("the game") might suppose itself to be singularity, it is the act towards radical alterity, only, with which this practice is engaged.

Paradoxically to this praxis, singularity might not be achievable, but it is here that we begin to investigate what a praxis concerning disappearance alongside an investigation of singularity and alterity might look like.

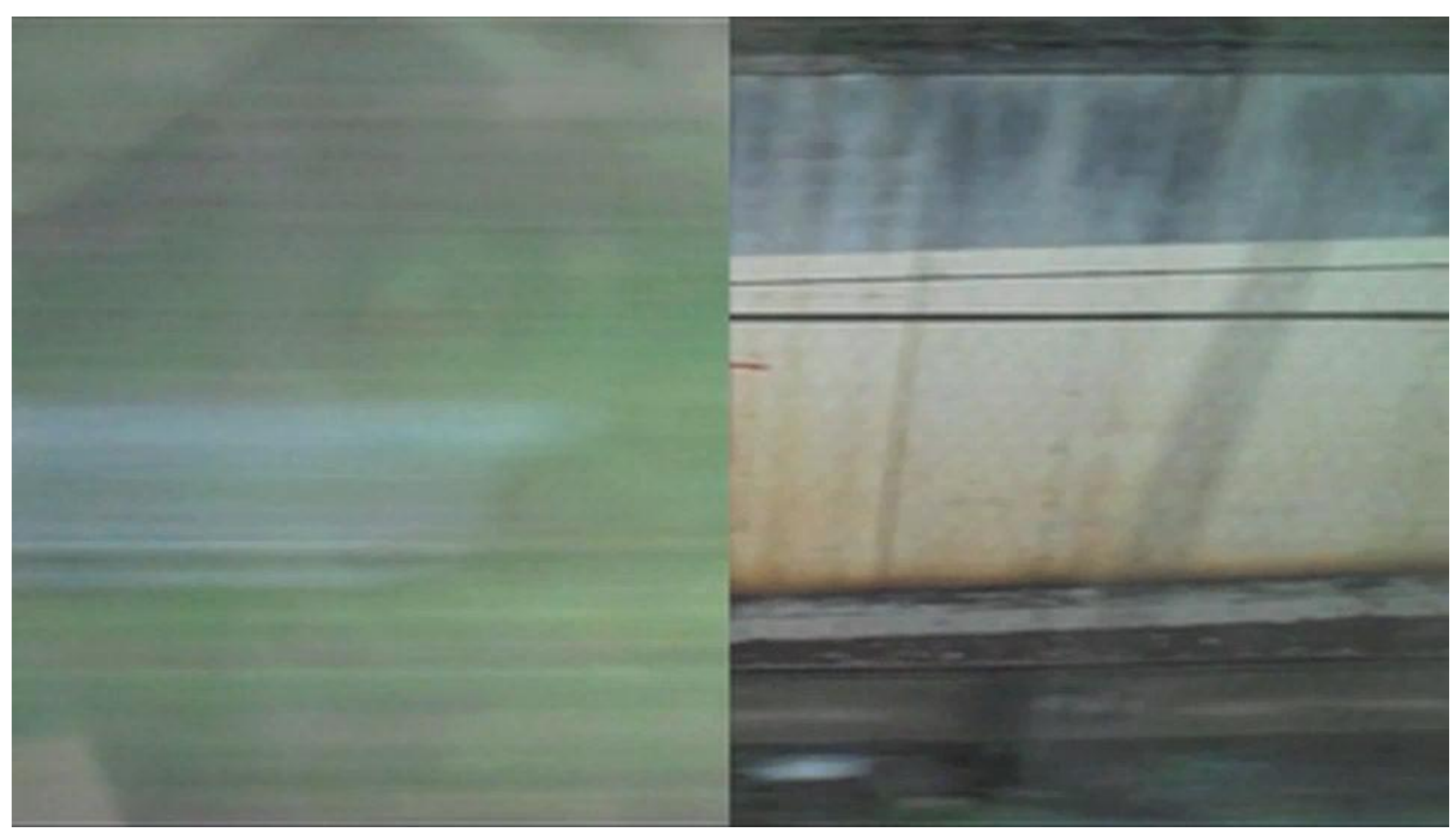

\section{Spatial Praxis}

To practice space is thus to repeat the joyful and silent experience of childhood; it is, in a place, to be other and to move toward the other.

- Michel de Certeau, The Practice of Everyday Life (de Certeau, 2008:110) 


\section{GEOGRAPHICAL IMAGINATIONS}

\section{Fragmentation and mobility towards a singular other}

Which strategies might be employed towards the knowing of space? This research is an endeavour apropos of an experiential cartography of space. In a sense, a return to cartography as it was initially imagined as a guide to ways of moving through locations. Not simply as a map of endpoints in journey, but rather an interrogation of the interstitial space encountered while moving throughout the landscape; an experiential map of journey, rather than a conceptualised notation of city-state boundaries. This movement through location is a type of spatial praxis and one that works as an effort towards recording and reordering momentary glimpses of space viewed in transit as Virilio mentioned. This research offers a different cartography, one that is based on the original function of maps. Rooted in alterity, this return is a cartography of praxis and a rejection of a contemporary practice that seeks to have all space disappear.

In The Practice of Everyday Life, de Certeau explains that maps originated as visual documentation of journey. He notes the post-Enlightenment transfer in the function of cartography.

...if one takes the "map" in its current geographical form, we can see that in the course of the period marked by the birth of modern scientific discourse (i.e., from the fifteenth to the seventeenth century) the map has slowly disengaged itself from the itineraries that were the condition of its possibility. The first medieval maps included only the rectilinear marking out of itineraries (performative indications chiefly concerning pilgrimages), along with the stops one was to make (cities which one was to pass through, spend the night in, pray at, etc.) and distances calculated in hours or in days, that is, in terms of the time it would take to cover them on foot. Each of these maps is a memorandum prescribing actions (Ibid, 2008:120).

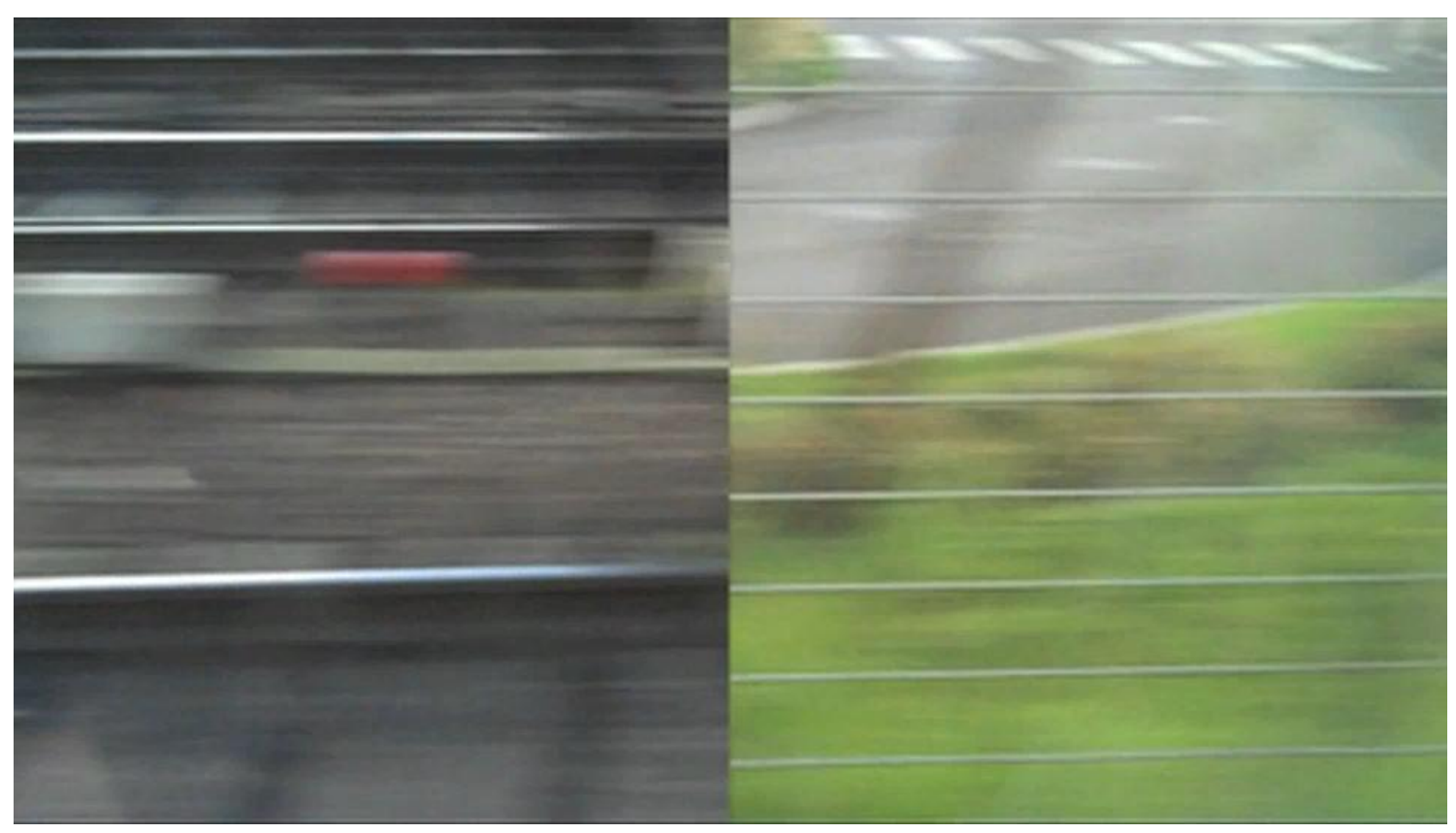




\section{GEOGRAPHICAL IMAGINATIONS}

Cartography is a visual template to spatial encounters-a template which once included the potentialities of spatial experience. However, it has been subjugated to a recording of geopolitical and conceptualised boundaries. Maps are redrawn to denote world events in which one people overthrow or separate from another. Cartography now offers opportunities for surveillance. Global positioning systems communicate navigational demands that focus only on which ways to go, ignoring the sites in-between. Landscape is sick. The consequences of this subjugation have led to war, colonisation, sequestration, and notably, disappearance of space. These medieval maps, as de Certeau posits, suggested an active mobility. They offered an itinerary to experience space that one moved through, a temporal itinerary, and one that focused on the possibilities of movement and the possibilities of encounter. This offered a potentiality of discovery of the world encountered, and one that is slipping away vis-à-vis an effort of knowing eventually leading to disappearance. The richness of imagery recording (or prescribing) journey has been lost since Enlightenment, as geopolitical boundaries shifted into focus. Instead, the delineation of city-states became the centre of concentration, towards the agency of a kind of conquering or mastering of the land and location. Not just of the landscape itself (for agricultural reasons, etc.) or its people, but moreover it presided over the loss of potentiality of experience and possibility. Rather, space imposed itself as an idea as opposed to an experience. Lines were drawn, encircling places and property as well as connecting routes of trade. A rush to explore the ends of the global was prompted by a desire to claim and name.

...the map gradually wins out over these figures; it colonises space; it eliminates little by little the pictural figurations of the practices that produce it (lbid:121).

The practice of space, a "pictural figuration" of the perceptual journey, is lost. In its place, the focus of spatial study, exploration, viability, turns not towards utilising space as a function of movement, of experience, but rather towards geopolitical colonisation and naming, something changes. Globalisation is the disease of spatial colonialism. Its symptoms are the manageable familiarity of the world. A current shift towards homogeneity, not only of culture and capital, but also of space itself, to make all equivalent, interchangeable, and exchangeable-using maps as a guide to an unmitigated apprehension of the world. Through this pervasive apprehension, space disappears from what it once was - a site of potentiality - into the dissolution of what is already known. Space is transformed into knowable place, becomes valued, and part of a system of exchange. No longer sites of experience, space instead becomes a place to consume (or place becomes space consumed?). Paul Virilio begins to describe this problem, when he asks-and answers, "...what is the danger of globalisation? There is no perspective" (Virilio \& Lotringer, 2005:74).

The effort towards owning or naming all location on a global scale is an effort towards familiarity, claiming, and a marking of meaning. It annihilates the possibilities of experiential discovery. Everything becomes mapped and understood. Through this, we destroy any notion of the 


\section{GEOGRAPHICAL IMAGINATIONS}

other-the unfamiliar site of potential discovery. A globalised mapping of space destroys-not the pseudo-produced exoticism of the tourist-but an other of possibilities that is in direct opposition to what is already known. The Other represents potentiality of discovery in our unfamiliarity, it hinges on its infinite adumbrational qualities. It presents something that is not simply different, and therefore comparable and easily knowable, but an unknown element or what can be made out of bounds. However, simple difference allows only for a hastening of disappearance by providing a doorway into exchange. Baudrillard discusses a system of difference that is easily organised into a structure of meaning. However, he reveals a phenomenon called radical alterity, which he defines as essentially a process by which something becomes hyper-other, or more other than simply just different. In this case, the radically alterior avoids the system by which everything is known and communicable. This "super-other" opposes its own disappearance.

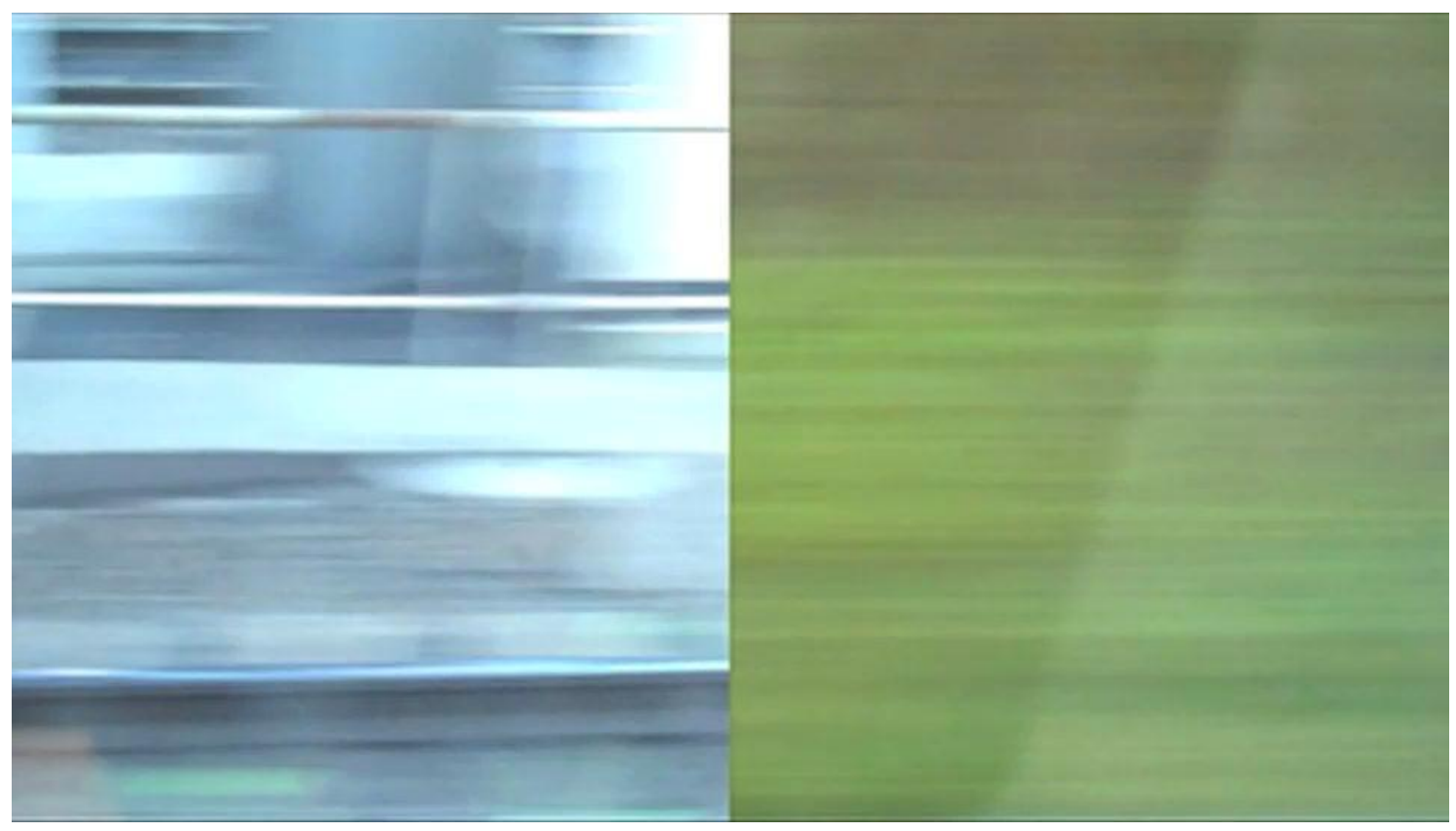

The end effect of radical alterity is to create a Singular object (or event, or space), defined as something that has no exchange value (symbolic or otherwise) and is irreducible to an equivalent meaning or sign. A solitary object, which can never be fully realised or known, one, that presents possibilities of discovery. A singular object that is immune from dissolution. The Singular, by its definition, opposes homogeneity and globalised accumulation of exchangeable place - a site that has already been known, named, and valued. A praxis towards radical alterity is an effort to create a singularity of space that has no exchange value, and thus resists dissolution. Or rather, is impossible to exchange (for meaning, or symbolic meaning). Radical alterity is an effort towards keeping space from slipping away. Baudrillard alludes to this praxis:

Singularity and alterity is a double game... (Baudrillard, 2002) 


\section{GEOGRAPHICAL IMAGINATIONS}

Here, Baudrillard suggests that the effort is two-pronged. Singularity is the end goal by which the process of radical alterity seeks to achieve, ultimately. In a world, which Baudrillard might suggest, that is well on its way to disappearance; we are tasked with a challenge to this system. The spatial praxis that I propose is a component of this game, an active participation.

What is the problem, then, with this disappearance of space? It is a symptom of a cultural shift towards globalisation (as evident in post-Enlightenment cartography) in order to annihilate the otherness of space. Space itself disappears. Without alterity, the homogeneity of the world takes over. There is no longer any room for possibility and therefore discovery, and as Baudrillard notes, the world continues its trajectory in a vegetative state (Baudrillard, 2009). Baudrillard explains that difference is not the same thing as otherness. Difference is an attempt at finding an exchange value in the other, to search for what is familiar in what is different, to make comparable. To subsume the other into this system that analyses things in relation to each other (thus giving value and making them exchangeable, at last leading to their dissolution). When all meaning is uncovered, there is nothing left to experience-all that remains is a flux of exchange like ocean currents. Things, recognisable only in their similarities and the differences of what came before, or already. Baudrillard notes the contrast between otherness (the alterior) and simple difference, when he asserts that the system of difference is

"...symbolically speaking, truly a matter of life and death." (Baudrillard \& Guillaume, 2008). He describes this conflict by comparing it to textual discourse, as de Certeau also does, as this significance is understood through the exchange of meaning and value in language.

...otherness is not the same thing as difference. One might even say that difference is what destroys otherness. When language is broken down into a set of differences, when meaning is reduced to nothing more than differentiation, the radical otherness of language is abolished. The duel that lies at the heart of language - the duel between language and meaning, between language and the person who speaks it - is halted. And everything in language that is irreducible to mediation, articulation or meaning is eliminated - everything, that is, which causes language at its most radical level to be other than the subject (and also Other to the subject?) (Baudrillard, 1993).

Wherein lays the problem to bringing the other into this system of difference? The other itself disappears into analysation and transforms into the familiar (perhaps vis-à-vis its comparable difference). Cartography is a visual representation of meaning, which like language, guides understanding. Both represent a loss and desire of real spaces in the world affected (and dissolved) by efforts to know such as globalisation. The system of difference is an effort towards a global homogeneity. This is the goal of globalisation, to give meaning and value to everything, converting it into a commodity (promoting exchange).

Again, Baudrillard explains the problem: 


\section{GEOGRAPHICAL IMAGINATIONS}

One of the strategies of this new order of the world is to transform singularities into differences. As differences they are able to be integrated into the global. As singularities they cannot. It's an immense attempt of this global world to reduce and annihilate all singularities in order to be integrated into an undifferentiated world. This world of differences, this culture of differences is an alibi for a culture of indifferentiation (Baudrillard. \& Guillaume, 2008).

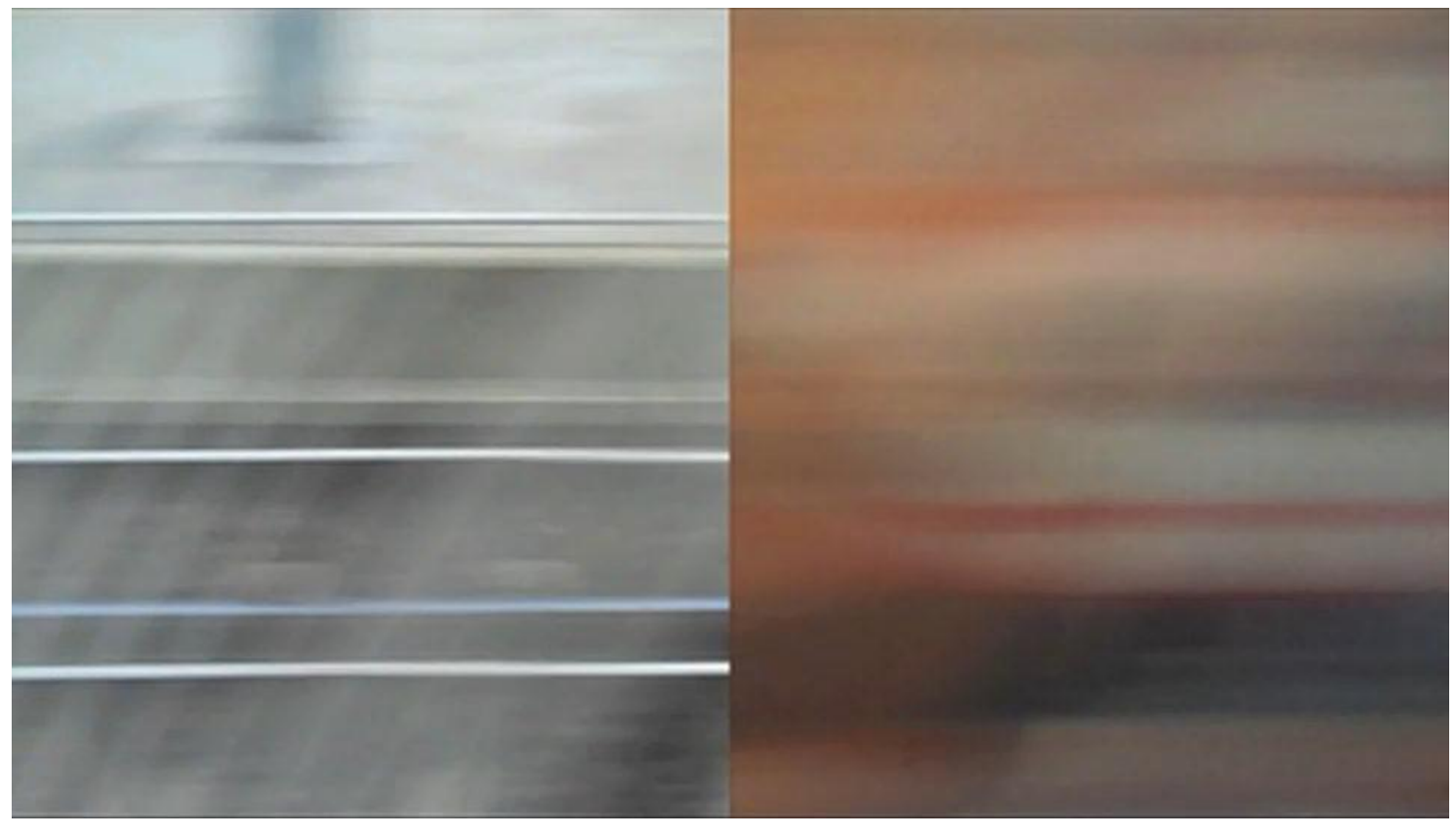

This is a practice that runs counter to the one I am suggesting. A praxis that is already happening all around us. An intense desire to place a value on everything, an effort to name and know every thing and every where, causes the very subject of our desire to disappear into hyperreality. A culture of indifferentiation presents a world without possibility; within it, any notion of discovery has been annihilated by uniformity and absorption.

Baudrillard goes further to suggest a practical solution to this globalisation, and specifically a strategy for artists.

...we can oppose this paradigm of the totality of globalization, where all differences can be integrated, but as differences, not as singularities.... you must create your underground, because now there's no more underground, no more avant-garde, no more marginality. You can create your personal underground, your own black hole, your own singularity (Baudrillard, 2002). 
GEOGRAPHICAL IMAGINATIONS

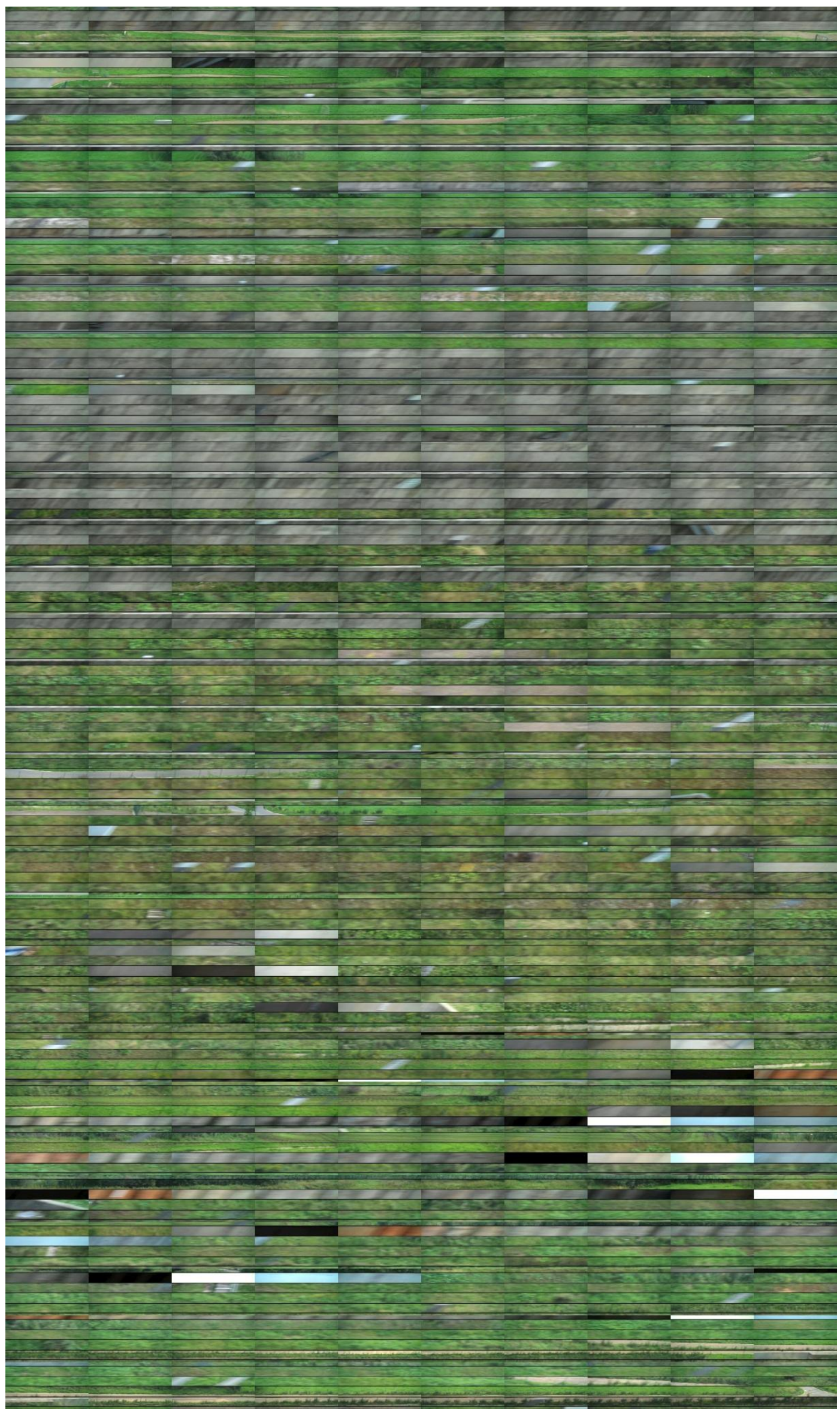




\section{GEOGRAPHICAL IMAGINATIONS}

Singular objects resist annihilation and absorption into the system of difference, they remain as they are - full of possibility - as ripe objects pregnant with unfolding horizons of meaning. I suggest that the spatial praxis I propose, specifically an artistic one, is an effort towards radical alterity. This practice seeks to alter the perception of space to make what is experienced unfamiliar-a radical other. This is where a praxis of this sort might begin, as an effort to see parts of the world as they are, or could be, without them slipping into the globalised dissolution of space.

\section{References}

Baudrillard, J. \& Guillaume, M., 2008. Radical Alterity. Los Angeles: Semiotext(e).

Baudrillard, J., 1993. The Transparency of Evil. London: Verso.

Baudrillard, J., 2002. Between Difference and Singularity: An open discussion with Jean Baudrillard (lecture). Europäische Universität für Interdisziplinäre Studien (European Graduate School).

Baudrillard, J., 2009. Why Hasn't Everything Already Disappeared? Translated by A. Willaume. London: Seagull Books.

de Certeau, M., 2008. The Practice of Everyday Life. Berkeley: University of California Press.

Virilio, P. \& Lotringer, S., 2005. The Accident of Art. Los Angeles: Semiotext(e).

Virilio, P., 1991. The Aesthetics of Disappearance. Los Angeles: Semiotext(e). 
GEOGRAPHICAL IMAGINATIONS 


\section{GEOGRAPHICAL IMAGINATIONS}

\section{"The birth of tragedy" and its theoretical contribution to art and music in geography}

Carolina Deconto Vieira, Universidade Federal do Paraná

carolinadeconto@gmail.com

\section{Introducing Wagner, Schopenhauer and Greek Tragedy - The conceptual triad of "The Birth of Tragedy"}

In order to discuss the works of Friederick Nietzsche, it is necessary to keep in mind that they cannot be either impartial or linear. As we keep track with the author's biography, it is possible to realize how close his life and his ideas were bound. Therefore, it is not possible to dissociate his emotions, his impressions and specially his deceptions and journeys from his philosophical biography. He does not commit to a total metaphysical or moral scheme (for he doesn't believe in any) and he also doesn't seek the truth (for he doesn't believe in one). Instead, he does try to find the origins of the deepest foundations in philosophy.

Having this in mind, it is wise to be aware of the risks to discuss the first and most (self)criticized book written by the philosopher. Studying "The Birth of Tragedy", at a first glance, is a controversial decision. Nietzsche himself has several restrictions towards the book as a whole. Both the preface to the second edition and the chapter in "Ecce Homo" (his philosophical autobiography) points a distance towards Schopenhauer, the first great influence on his views concerning Art. On the latter, he leaves no doubt: "it smells offensively Hegelian, and in just a few phrases it is tainted with the doleful scent of Schopenhauer" (Nietzsche, 2007:45)

In spite of its bad reputation, the book - especially the ideas that Nietzsche pointed out as worthy of mentioning in Ecce Homo ${ }^{5}$ - is still broadly discussed ${ }^{6}$. Its insights towards Art metaphysics - specifically about the Apolline and Dionysiac forces - present a resonance of ideas with his contemporary authors such as Schlegel, Hoffman and even Hanslick, Wagner's antipode - as well as with posterior authors such as Heidegger, Adorno, Focault, Deleuze and Maffesoli. (Safatle, 2006)

As mentioned on Ecce Homo, the book was written during a war:

[...] you would never dream that it was begun amidst the thunder of the Battle of Wörth. I thought through these problems outside the walls of Metz, on cold September nights, in the midst of serving as a medical orderly [...] (Nietzsche, 2007:45)

On the preface to the second edition, "An Attempt to Self-Criticism", it is seen that Nietzsche had been elaborating some considerations about the Greeks and he finished the book at the

${ }_{5}^{5}$ The concept and the psychological profile of Dionysius and the denouncement of Socrates as the killer of tragedy and the dyonisian force in art (NIETZSCHE, 1999:46)

${ }^{6}$ See "Cadernos Nietzche" as an example. 


\section{GEOGRAPHICAL IMAGINATIONS}

same time that the Franco-Prussian war was reaching its end with the peace treaties on Versailles. On this preface, he highlights the merit of his inner battle. Sixteen years after the publication of the first edition, he mentions that it is very important "to look at science through the prism of the artist, but also to look at art through the prism of life." (Nietzsche, 1999:44) In other words, it is necessary to deconstruct our dogmatic views on the truth revealed by the hermetic science through the multiple interpretations of artworks.

It is accurate to say that Nietzsche had two inspirational characters on "The Birth of Tragedy": the composer and conductor Richard Wagner and the philosopher Arthur Schopenhauer, author of "The World as Will and Representation". Guided by his self-claimed youthful ardor and melancholy, by his will of independence and boldness (and at the same time showing deference to Wagner), Nietzsche investigates the Greeks' taste for tragedy. He considered a paradox that such a prosperous society enjoyed to feel and display pessimism on their best works of art.

He claims that, unlike a fearful Christian society (of which he makes an intentional oblivion), the Greeks had the courage to look at the horrors of existence with their eyes open. Through tragedy, many important lessons and knowledge were spread. The spectacles were so important that even the poor had their entrance paid to watch them. Many aspects of life were learned through freer forms of knowledge other than the proto-scientific method taught by Socrates, the "rational man".

Nietzsche had affirmed that the Greek tragedy molds are reborn on the works of Richard Wagner. The philosopher dedicates a great deal of hope on the "new Renaissance" of art through "Wagnerianism". He claims that European culture is decadent and German music would have the power to rescue it from a cultural and philosophical mediocrity settled by Socrates (and Plato). Later on, on his preface, he regretted having such thoughts. In his opinion, he claims that his optimism and hope were premature (Nietzsche, 1999) and they have ruined the book. He affirmed that Romanticism does not quite translate the Dionysiac spirit on his true form.

His change on the subtitle of the book from "and the spirit of Music" to "Hellenism and pessimism" denotes this drastic change: he changes the focus of the book from a Wagnerian treaty to the pessimist aspect of Attic tragedy and centers on Ancient Greece. Nietzsche links the theme of tragedy to life and puts it as a force that drives individuals to live a full life without fearing the "ugly" and the "metamorphosis".

The pair of aesthetic forces inspired by the gods Apollo and Dionysius has an origin on Schopenhauer, to whom Nietzsche and Wagner held great admiration at the time. The philosopher reveals himself as a disciple of the latter God, because this was the relegated god on the eyes of the Socratic "rational man". Starting from the Schopenhaurian concept of will"

${ }^{7}$ The will on Schopenhauer's metaphysics is opposed to representation, which is our view and interpretation of phenomena and objects of the world, i. e., they
are presented according to our perception. On the other hand, the will is an impulse without conscience, free, with no aims. It is the pure reality and its activity. The will carries an ontological reality behind the fragmentations we make upon our reality. Within this metaphysics, music has an extremely important role, for it 


\section{GEOGRAPHICAL IMAGINATIONS}

and his art metaphysics that puts music as the best immediate mediator, Nietzsche explores the psychological issue of tragedy and based on that, he transposes these considerations on the status of $19^{\text {th }}$ century German culture. Through his self-criticism, he points on his past belief that the only way to make it somewhat relevant to history was through the return of Dionysius on the spirit of art creation and through the eviction of Christian moral, especially its pejorative and Aristotelian views on Art. However, as mentioned before, he deliberately omitted Christianity on this work.

Inspired on Attic Tragedy and the works of Richard Wagner, Nietzsche evoked a cultural renewal under the foundation of Ancient Greek values, more specifically on pre-Socratic Greece. He had sought to understand what was beyond the plenitude of tragedy and he concluded that the balance Apolline-Dionysiac pair was the key to these great events.

Succinctly, we can describe the Apolline as the aspect that provides conceptual features (on art, it is done mainly through poetry) and the aspect of being carried in a dream/illusion consciously. We tend to be visually carried away by painting, architecture and sculpture. On the other hand, the Dionysiac force brings horror, the manifestations of will, emotions, inebriation, the loss of individuation and the destruction of the "truth" shown by the truth guided on the "Apolline illumination" (among other things, Apollo was the god of resplandecent light).

Tragedy, on Nietzsche's view, consisted of the fullest artistic manifestation that existed on ancient Greek context: the combination of dance, music and poetry approached Mythology, Literature and History. The philosopher admired this presentation of knowledge (instead of focusing on formal and objective views of reality): the Greek wisdom had a bond with art, not science. One of the central issues of the book lies on the Dionysiac aesthetic force of deconstruction and loss of individuality. This ecstasy and inebriation were important tools for the Greeks to incorporate and surpass the dilemmas approached on the staged tragedies: the collective suffering (induced by music) was ceased by the "return" of Apolline forces (induced by poetry and theater), which was able to make individuals "return to their senses". This balance between seeing and feeling would teach the Greeks more than any rational, non-scientific method.

The culture of archaic Greece, Nietzsche claims, was not just "artistic" in the sense of production, but it was in some sense fundamentally based on and oriented to art. Neither theoretical science shaped truth nor a formally codified religion shaped morality. Art was extensively integrated into all aspects of life and was perceived to be of fundamental significance. Art told the archaic Greeks who they were and how it was best for them to act.

is the maximum expression of the will and the "essence of the world". The composer, then, is seen as the wisest of all men because they can reveal the most source of frustration and suffering (the will is the source of desire in Schopenhauer's opinion), he changes it, converting it into the will of power: this will would drive men to concretize what is brewed inside their conscience, despite of moral values that could restrain it. 


\section{GEOGRAPHICAL IMAGINATIONS}

To sum up, it is important to highlight some literary characteristics of the text. In terms of discourse, Nietzsche preferred shorter chapters (from three to five pages). The concepts are not a set of monoliths that cannot be changed: they are traced through poetical language and the usage of allegories and historical data is a recurrent challenge to overcome.

One very interesting point of the book is that it is possible to read the book in a double perspective because of its preface, "An Attempt of Self-Criticism": first, upon the point of view of the young Nietzsche, a soldier at the battlefield who was writing during a war. The second glance can be seen by an older Nietzsche who became 16 years older and tougher intellectual.

The first five chapters, which concern us the most due to the presentation of our most important conceptions (Apolline and Dionysiac), present a similar sequence of argumentation: a dialectal analysis of tragedy (or any other form of art) that results on the conflict of Apollo and Dionysius through a different starting question. The main argument is that tragedy is the result of this aesthetic conflict. Success in tragedy consists in combining appropriately the most deeply Dionysiac music with the most highly articulated and pleasing Apolline illusions. After that, he endorses his theory discussing the differences among some Greek poets and writers and, in the end, he praises Wagner and his commitment to a "total art" and to a cultural renewal in Germany.

Nietzsche also strongly affirms that it is possible to find wisdom out of the scientific (rational) knowledge. This principle is fundamentally important for this article because it allows us to see how art is relevant to learn about reality: it shows us a different point of view through several perspectives: from the artist's social, historical, political and spatial context to his or her perceptions and feelings.

Art enable us to comprehend, to sympathize and "taste" another space-time. From poetry to music, we can extract reality from art because there is no other source of inspiration other than that. It is the fundamental resource for art, even when we want to confront it throughout abstractions. (Adorno, 1997) Considering that "the problems of working with music" are far from being solved (Safatle, 2006) it is crucial to think upon this complex "object". Philosophy of music still has a lot of issues to clarify and music has also a fine discussion potential in Geography and other sciences.

\section{Nietzsche's diagnosis of art: the necessary balance between Apollo and Dionysius}

Nietzsche's starting point of "The Birth of Tragedy" emphasizes the importance of balance of the aesthetic forces that were a metaphor of Apollo and Dionysius's godly powers. The first is responsible for the individuation principle (or, as described by Schopenhauer, principium individuationis), which is the part of our perception responsible for limiting shapes and concepts from chaos and a blurred, unified reality and from the shapeless and a-conceptual will. It is the organizing principle that associates, for example, an object with a word, taming our view in 


\section{GEOGRAPHICAL IMAGINATIONS}

distinctive shapes and concepts ruled by precise and individual limits. The Apolline art is mainly seen in all forms of art that depend of light (for Apollo is the god of the Sun) and our visible spectrum.

Apollo is also the god of configuring ${ }^{8}$ powers because he is the god who rules the form, the proportions and the harmony of the "beautiful appearance" of things and dreams. Painting, sculpture and even poetry carry a heavy Apolline trait in Nietzsche's view because they carry distinctive concepts and shapes that are spatially or linguistically arranged. They privilege harmony on colors, shapes and perspectives. They are capable of generating illusions because we adopt some images as if they are reality themselves.

The myths about Apollo show him as this god of beauty, of shining light and dreaming experiences. He enables the contemplation of art through an "illusory" perspective as if we lived on a stage play: we see reality dramatized differently from reality; however, it has elements taken from reality itself. The difference lies on the presence of "beauty": people feel attached the same way they do not want to wake up from a pleasant dream: "the individual man, amidst a world of torments, remains impassive and serene." (Nietzsche, 1999:30) Nietzsche states that these wistful shapes are necessary for us to survive and justify life; however, in order to appreciate truly these forms, it is necessary to develop artistic sensibility. It is on Apollo's domains to represent "the happy need of dreaming experience". (ibidem:29)

Through the book's presentation, Apollo has a double role and they are much related to each other when it comes to metaphysics. As mentioned before, he was entitled to beauty, light (the necessary condition to see) and dreams. Nietzsche makes a bridge with the principium individuationis - the principle that maintains the individual aware of his distinctiveness from other objects and reality itself. Apollo also enables the view of Maya ${ }^{9}$. Schopenhauer describes "the Veil of Maya" that comes along with the individuation: Maya is the illusion view we have from a fragmented reality. Young (1992:33-34) states that the Nietzsche's "Apolline", Schopenhauer's "representation" (as described on The World as Will and Representation) and Plato's "idea" are conceptually close to each other.

Even though Nietzsche criticizes the excess of Apollo in European art throughout the book, there is a moment when the discourse is different. When he talks about the lyric poets and music, he gives credit to symbolic power: "In order to express the Will's appearance in images the lyric poet needs all the stirrings of passion, from the whisper of inclination to the fury of madness" (Nietzsche, 1999:35). He later credits lyric poetry with virtues of Dionysiac forces.

According to Gontijo (2006:3), he is the "god of life, metamorphosis, lack of measures, death, sex, pain and music". We can call him god of life because he is genuinely agrarian, originally conceived to explain the abundance of life from soil in its most primitive ways. He is also related

\footnotetext{
${ }^{8}$ To configure, in this case, is to give shape or image (figure) of something.

${ }^{9}$ in Hinduism and Sikhism, the principal concept which manifests, perpetuates and governs the illusion and dream of duality in the phenomenal Universe
} 


\section{GEOGRAPHICAL IMAGINATIONS}

to death and sex because we lose track of individuality during these events and reality becomes mingled with the (un)consciousness.

As a persecuted god, Dionysius is also associated with pain and suffering of existence. According to Greek mythology, he spends his time running away from Hera, Zeus's wife because he is a living memory of his extramarital relation with a mortal. Under the eminent risk of death, Dionysius values and celebrates life, assimilating happiness and inebriation due to his overcoming of suffering and Hera's pursuit through innumerous metamorphosis. Nietzsche emphasizes the importance of enduring and overcoming pain in order to celebrate life and the liberation from anguish of our existence's vicissitudes. Although the philosopher calls himself as a disciple of Dionysius, he recognizes some of the flaws of the excess of "his" god: they can lead to irrational "voluptuousness and cruelty" as well as "witches' drunkenness" (Nietzsche, 2007:35)

If Dionysius could be described in words, we would use "intoxication", "capture", "ecstasy" and "inebriation". The Dionysiac forces reside on the overcoming of quotidian consciousness of Apollo, that is, to go on the opposite direction of individuation and look at reality as it is: conflicted, painful, horrifying and filled with uncertainties. For Nietzsche, we must all accept the challenge of dealing with all of these conflicts in order to grow. We must learn from suffering using our willpower.

Greek tragedies often have this dialectical relation of delight and suffering. The hero tries to put his life together, even when complications arise. The chorus and Music play an important role, for they are the key to liberate the individual from his Apolline individuation. However, the latter is also important because it transforms the abstract and diffuse Dionysiac experiences into intelligible symbols. Dyonysius shows behind the existing reality we perceive and live, revealing it beyond representations of the immediate, individual perception: "[...] when the Dionysiac excitement arises, they drag and annihilate the individuals and it induces a 'return to nature"' (Nietzsche, 2007:30).

On Dionysiac inebriation, the forms are not distinguishable and one loses track of him or herself. There is a passage on the book that describes it:

[...]Not only is the bond between human beings renewed by the magic of the Dionysiac, but nature, alienated, inimical, or subjugated, celebrates once more her festival of reconciliation with her lost son, humankind. Freely the earth offers up her gifts, and the beasts of prey from mountain and desert approach in peace. The chariot of Dionysos is laden with flowers and wreaths; beneath its yoke stride panther and tiger. If one were to transform Beethoven's jubilant 'Hymn to Joy' into a painting and place no constraints on one's imagination as the 


\section{GEOGRAPHICAL IMAGINATIONS}

millions sink into the dust, shivering in awe, then one could begin to approach the Dionysiac. (ibidem:31)

Nietzsche has noticed that through Attic Tragedy, which had been balanced between the Apolline and Dionysiac, men could seek justifications to live. One of the most impacting affirmations of the book is that "[...] our highest dignity lies in our significance as works of art for only as an aesthetic phenomenon is existence and the world eternally justified' (ibidem:33). Castro (2008:129) sees this as a reply to a pessimist and ascetic Schopenhauer: art provides us reasons to live and experience the world.

Another divergence concerns the role of tragedy itself: Schopenhauer had thought of it as an undeniable proof that living was suffering and it was necessary to conform with this condition of anguish; men should try to eliminate their will and urges and observe them from a "safe distance" and the Attic tragedy was a good mean to do that.

In an opposite way, Nietzsche recurrently affirmed that tragedy was precisely the artwork that had sought redemption of suffering; it had sought for solutions, new points of view and the justification (and reaffirmation) of life. Through tragedy, Greeks had become more optimistic for they overcome all the Dionysicac horror and pain through the reconstruction and individuation of reality through an Apolline perspective.

It is noticeable how Nietzsche starts to sketch two key concepts of his philosophy: übermensch - in short words, the man that constantly overcomes himself with open eyes towards reality and does not surrender to illusions of another-worldliness - and will to power, a psychological driving force in humans. Achievement, ambition, the striving to reach the highest possible position in life through knowledge and the overcoming of everything that leads to weaknesses. (Reginster, 2006)

He criticized the mere admiration of figures: without learning to be happy despite of suffering, happiness becomes superficial and naïve. Euripides (ca. 480 - 406 BC), one of ancient Greece's most well known playwright, was criticized by Nietzsche because, like Wagner, he was more concern with popular approval than quality. The philosopher asked: "Why should the artist be obliged to accommodate himself to a force which is strong only by virtue of its numbers?" (Nietzsche, 1999:57) Because of this urge, Nietzsche thought that art became shallower and the Greeks were trapped in a world of beauty, dreams and comedy. This simplistic and incomplete art was reproduced for ages, even after the death of Socrates or any other Greek philosopher. Videira (2006) points that up until the $18^{\text {th }}$ century; music was a mere servant to "paint" feelings. It was also at the mercy of text and preconceived forms that represented those feelings. This aesthetic approach to music started to change only in the $19^{\text {th }}$ century, when the conflict between formalists (like Eduard Hanslick) and their opposite, like Richard Wagner, for example. 


\section{GEOGRAPHICAL IMAGINATIONS}

On "Apolline vanity", the preservation of individuation and sight is kept. Socrates's motto "Know thyself" and the maintenance of control and measures are important Apolline traits on art. However, Nietzsche again emphasizes the importance of Dionysius when he explains that deep within the boundaries, this god shows the bottom of the abyss of the self. Within pain and ecstasy, knowledge can be grasped, which scared Apolline Greeks like Socrates.

The tragedy genre, as mentioned, was lost with time and Apollo took over a more predominant role. This can be explained by the victory of the Dorians (one of the 3 biggest ethnic groups in Ancient Greece) on Attica before the Peloponnese War. This event, known as the Dorian invasion $^{10}$, wiped out a developing culture focused on Dionysius cults and brought up the Apolline to Ancient Greece during its Dark Ages.

Later on, tragedy became less Dionysiac due to the influence of Euripides ${ }^{11}$, who was a close friend of Socrates, one of the most ferocious critics of the "wild" and "irrational" tragedies written in the "old ways" (i. e., in Aeschylus passionate style). Before tragedies became plays staged on theaters, they were a mixture of cult and theater, where actors, who wore goat masks, sang in a unison chorus, marking the loss of individuation. Music was a very important, if not fundamental, vehicle of bonding and agency of spectators (Nietzsche, 1999:21). Castro (2008) describes the Dionysiac roots of tragedy.

Tragedy was born out of music, specifically from the praising chants to Dionysius, sung by a group of people who would run over the forest as satyrs, which were natural-fictional characters with goat feet and small horns. In ecstasy, with their faces painted with sap from different plants and their forehead cover by flowers; these hybrid creatures wandered on the woods, singing, dancing and playing rustic flutes. The chorus of satyrs, transformed (metamorphosis) in actors and spectators, saw a visible spectacle spring around themselves, but just for those who participated on the Dionysiac excitement.

(Castro, 2008:139)

Afterwards, with the "Apolline intervention", the cults became plays and the public remained seated, appreciating the representations, the dialogues and the visual displays. Instrumental music was virtually excluded and the chorus became a less central part of the spectacle.

\footnotetext{
${ }^{10}$ According to Greek historiography, the Dorian invasion brought a rupture on the culture that had been developed by the Mycenaean Greeks (1600 B.C. to 1100 B.C.) since the Bronze Age, who already worshipped Dionysius in rural festivities. The outcome of this invasion was the beginning of the "Dark Ages" of the Ancient Greece. All the cultural traits and development of the Bronze Age was destroyed and replaced by the Dorians, who brought the cults to Apollo, which later on became more sophisticated and mingled with the early cults of Dionysius, generating the Attic Tragedy. (For more information about Ancient Greece, see Gagarin, 2010)

${ }^{11} \mathrm{He}$ served for a short time as both dancer and torch-bearer at the rites of Apollo (op. cit)
} 


\section{GEOGRAPHICAL IMAGINATIONS}

Nietzsche affirms that Socrates (c. $469 / 470$ BC - 399 BC) was one of the murderers of tragedy (along with his friend, Euripides). On Nietzsche's view, he was a new kind of man: he urged for logical explanations, for an objective and scientific knowledge of reality. On his own words:

To penetrate to the ground of things and to separate true knowledge from illusion and error was considered by Socratic man to be the noblest, indeed the only truly human vocation, just as, from Socrates onwards, the mechanism of concepts, judgments and conclusions was prized, above all other abilities, as the highest activity and most admirable gift of nature. (Nietzsche, 1999:74)

This "rational man" has the need to eliminate the mysteries of existence and find the truth. The book mentions several times how this conception of a rational world has a close relation to Hellenic pessimism and the dramas lived by those ancient Greeks.

The book also proposes that true art has the virtue of balancing Apollo and Dionysius on its manifestation. In order to defend these points of view, Nietzsche criticizes Homer, calling him an old dreamer and naïve artist due to his hermetic narrative and style:

Homeric 'naivete' can be understood only as the complete victory of Apolline illusion; it is an illusion of the kind so frequently employed by nature to achieve its aims. The true goal is obscured by a deluding image; we stretch out our hands towards the image, and nature achieves its goal by means of this deception. (ibidem:25)

On the other hand, he praised Archilocus, the "bellicose server, warrior of muses" (ibidem:27) due to his spontaneous and sometimes raging and wild themes. While Homer was considered the teacher of Greece, Archilocus was a soldier, and poetry was an unfit and "unnecessary" skill on the Greek army.

What makes Archilocus so different from Homer is that he makes a musical instead of a visual imitation with poetry. Homer, on the contrary, keeps his language and discourse as close as possible from the truth about reality, describing facts as accurate as he could. Lyricism is closer to a Dionysiac force because he attempts to get closer to nature and the "natural self", therefore, "incoherent" and illogical. Lyric poetry would be as close as we can get to the shapes and the subjectivity of will through words. However, poetry is also filled with representations and Apolline concepts, forms and ideas. In fact, using words is one of the most common ways to establish boundaries among objects. (Idem) He exemplifies this impetuous art with Beethoven, 


\section{GEOGRAPHICAL IMAGINATIONS}

who was one of the first composers who broke with classical music from the $17^{\text {th }}$ and $18^{\text {th }}$ Century ${ }^{12}$.

In Nietzsche's opinion, only Music can rescue the true Dionysiac spirit. It expresses symbolically internal conflicts and pain. "Compared to Music, all appearances [images, sight] are nothing but symbols. That is why language [...] will not be able to manifest exteriorly the deep, intimate essence of music." (ibidem:56) The Dionysiac spirit does not require words and imagery to be evoked. In fact, on his "An attempt to self-criticism", Nietzsche dirges he had not sung the Dionysiac instead of using words and concepts to describe it.

\section{The "problem of Music" and Music Geography}

The reading of "The Birth of Tragedy" makes us aware of the aesthetic forces of Apolline and Dionysiac in Art. Like Michel Foucault, Nietzsche starts a point about an issue with no apparent relation with the actual discussion he wishes to do. He makes a study about the origins of Greek Tragedy, aiming to do something very different: to analyze, criticize and make a change proposal on Germany's $19^{\text {th }}$ century culture through Wagnerian values.

These goals raise a question: is it possible that Art can change individuals or even disclose conflicts that are not easily detected through sight and the formal and "official" discourse? Smith (1997) believes so and she mentions 3 examples: the Italian patrons' Renaissance musicians, who were heavily encouraged to sing about their local identities and places; the national(ist) brass bands from England and the Hip Hop from large cities (rap would also fit on this category).

The point I would like to support here is that music is studied in an Apolline parameter in Geography, i. e., relying on the visual, the symbolic and the representational. As Duffy (2005:6) points out, "most studies examining music as a social practice have retained visually and textually base frameworks and methodologies". Action and involvement are essential to understand the Dionysiac. On Nietzsche's words (Nietzsche, 1999):

To comprehend this complete unchaining of all symbolic powers, a man must already have reached that height ofself-abandonment which seeks symbolic expression in those powers: thus, the dithyrambic servant of Dionysos can only be understood by his own kind! (ibidem:21)

The performative and active aspects of music considered as a secondary aspect to be considered and even listening is considered a "passive" activity. Adorno (2009:131) explains

\footnotetext{
${ }^{12}$ The musician was the author of some artworks which were heavily criticized by spectators. Two famous examples are the fourth movement from Symphony n. 9 (Ode to Joy) and the Great Fuge, originally the last movement of his String Quartet n. 13 (op. 130). Due to his agent's request, he composed another finale for the quartet. The fugue, then, became a spare single piece (op. 133) and was one Beethoven's favorite compositions. In the end of one of the presentations of the original op. 130, the public had asked for the encore of the two middle movements. In reply, Beethoven said "And why haven't they asked the fugue's encore? It should be played alone! Cattle! Asses!" (Solomon, 2003:35)
} 


\section{GEOGRAPHICAL IMAGINATIONS}

that we have this false impression due to the fact that we cannot stop listening the same way we can close our eyes or even turn our head in another direction if we want to stop looking at something. The listening activity induces the Dionysiac and the loss of individuation. In a concert hall, for example, people are carried away by the experience of listening to loud music with others.

Although music followed by lyrics is carried with a heavy load of Apolline (which Nietzsche spent most of the book criticizing), it is also necessary to note that the "absolute music" - which is often associated with Classical Music - Nietzsche took inspiration to write about Dionysius is becoming more restrict and inaccessible to public through mass media. It is necessary then, to adapt or even review what Apolline is or Dionysiac: that would mostly depend on the musical, historical, social and spatial context. There are also other factors to be considered, such as the presence of cinema and other technologies that have changed the course of art.

As an example, we can mention Hip Hop: one of the recurrent themes of lyrics was the social conflict and police violence towards black and poor population. However, many listeners seem to have forgetten about it and some artists (considered to be on the niche of Cultural Industry) to endorse capitalist and sexist values. Nevertheless, despite of the lyrics' themes, Hip Hop has a strong Dionysiac effect on people due to its rhythm and electronic beats, noises and notes. Another example of such a display of lack of measures are some rock concerts, where a large group of people enjoy very loud music with others, singing as a choir and sometimes engaging on mosh pits, a restricted area, usually near the stage, where people (men, usually) start clashing and pushing their bodies against each other.

Even with the wide-ranging decline of instrumental music on behalf of cultural industry production of easy music ${ }^{13}$, that is, Adorno's Leicht Musik (Adorno, 2009:199), we cannot discard the philosophical and ontological heritage given by Nietzsche on this book. Safatle (2007:15) mentions that "Nietzsche values Music as an art capable of exposing what images and concepts cannot handle."

For that reason, music is much beyond a successive series of melodies and harmonic cadences: its extramusical contents are as important as its aesthetic aspects; however, the first is not expressed directly through the latter. Videira (2006:17) shows Eduard Hanslick's ${ }^{14}$ controversial thoughts about it: the effects of music upon feelings and imagination are not its primary goal and it also does not contain predefined forms that manifest happiness, anger, sadness and peace. The interaction between music and the individual is unique to each person. In other words, music has no homogenous effect on people and should not be considered a universal language. The feelings that musical stimuli inspire come from the listener's consciousness, not from the composer.

\footnotetext{
${ }^{13}$ Short-duration songs ( 3 to 5 minutes) with lyrics and repetitive harmonic cadences, as well as a identifiable chorus. ${ }^{14} 19^{\text {th }}$ century aesthetician and music critic, one of the most ferocious critics of Wagner.
} 


\section{GEOGRAPHICAL IMAGINATIONS}

Even though Hanslick is considered a formalist and conservative, he carries an anthropological and relativist point of view when he says that the musical experience depends on the individual's background. Duffy (2005:681) states a similar point. She says "What a musical performance signifies is dependent on the social and cultural contexts attributed to these sounds". The author also mentions that such evoked feelings are not necessarily positive: they can deceive, creating a social coherence that may have the power to hide conflicts and different narratives. National anthems are a good example of this effect. They are constantly used to inflame patriotism among people who are singing it. In a certain sense, just like the Greek tragedy's chorus, people lose their individuation and shortly give in to a collective existence of nationhood.

It is necessary to overcome the "uninterested beauty" that common sense (and Kantian aesthetic) makes about music. Another myth that needs to be clarified is Hegel's legacy: he clearly mentioned his discomfort about music because he relied on the objectivity of words when it comes to expression of ideas. (Safatle, 2006:13)

This prejudicial thought not only brought indifference and oblivion towards the study of music on social sciences and humanities, but also diminished music to a frivolous and shallow entertainment. According to Hegel (apud Videira,2006:85), "sound is certainly an externalization and an externality, but an externalization that immediately disappears when it is externalized. When the ear starts to assimilate it, it suddenly disappears." Duffy (2005) explains that music is difficult to investigate in an objective science because it deals with emotional and individual experiences that are ephemeral and difficult to express in words. This is why we need to go beyond musical pre-established representations given by critics, essays or musical programs: they are one of the many musical experiences.

We should try to incorporate and comprehend the Dionysiac experience of listener(s) rather than an Apolline analysis of the music expert, who will definitely speak on behalf of others without actually knowing who they are. If Apollo goes towards representations, we should go beyond them and try to get as close to "our objects" as we can in order to shorten the gap between science and reality.

Adorno (1997) regards Hegel as one of the great disseminators of the idea of Art's death during the $19^{\text {th }}$ century, when Romanticism was breaking several of rules and protocols in music and painting, for example. Hegel said that art was becoming self-destructive and it could die from its deconstruction and its sentimental drive.

During that time, for the first time in centuries (literally), romantic artists were trying to overcome the "uninterested interest" on the reproduction of reality and tried to work with the bottom of appearances: Schopenhauer named it will and Nietzsche would probably call it a Dionysiac pulse. From that moment on, artworks were allowed to be linked with the artist's individuality. 


\section{GEOGRAPHICAL IMAGINATIONS}

However, feelings were out of Hegel's aesthetic projects which, in Adorno's point of view (Adorno, 1997:3), failed to see that art's substance could be this very same transitory, moving values: once certain practices had become "fashionable", they would have lost their revolutionary and innovative sense, which is fundamental to be included under his (strict) sense of Art.

The lack of trust towards musical works is somewhat dissipated and clarified in Adorno. He clearly points out a link between art and reality: "There is no aesthetic refraction without something being refracted; no imagination without something imagined". Yet, this correlation has a very short limit because even though art takes its substract and (re)sources from reality, "[...] one paints a paint, not what it represents" (Adorno, 1997:4). Having this in mind, art has also the power to (re)construct reality's values. It is possible, through art, to construct new worlds that are opposites of reality as an inverted or distorted mirror from the artist's perspectives.

The same way Nietzsche defended that Attic tragedy had knowledge as valuable as the "Socratic truths", Adorno states that through artworks it is possible to find what he calls truth contents on the refractions of reality created by the "obstacles" ${ }^{15}$ of the artist. We must take into account both the artwork itself and the socio-spatial-political context around it. We cannot interpret art on a literal basis: art is not a creation of lies about reality. A free expression comes from or about it. Art and reality are related, however, they may antagonize without a clear solution for their conflicts. Such is the spirit of contemporary Art (Adorno, 1997:2009).

In order to search for more "Dionysiac" alternatives within cultural geography, the approach of Non-Representational Theory (NRT) seemed an interesting approach to explore. As an exploratory epistemological movement itself, NRT seeks to engage with spaces through action and everyday activities focused on practice and a living space. Instead of relying on representations of space - which also culminate on the creation of expressions like "place" and "territory" - that lead to its discretization in fragmented and totalitarian parts, this 1990s approach, led by Nigel Thrift and the School of Geographical Sciences in Bristol, United Kingdom. (Anderson and Harrison, 2010) embraces the idea that space is produced every day and there is no permanent "essential" set of characteristics bound to it.

Some authors disagree with the term Non-Representation because it may suggest a full breakup with the representation theory. Lorimer (2005:84) states that the primary goal of NRT is to promote the "multifarious, open encounters in the realm of practice that matter most". On the author's opinion, NRT came up as a response to the latest criticism Cultural Geography has been through, which had been done in several occasions (see Duncan, 1980; Jackson, 2000;

\footnotetext{
${ }^{15}$ The metaphor of diffraction seems potentially accurate to explain how reality is shown through art. The real physics event occurs when waves bend around small obstacles, or when waves spread out after they pass through small openings, which means, in other words, the alteration of a wave (in our metaphor, reality) when it goes across different environments (in our case, the artist's consciousness)
} 


\section{GEOGRAPHICAL IMAGINATIONS}

Mitchell, 2000; Nash, 2002 and others) during the last 30 years. Even though a New Cultural Geography arose from the criticisms of Sauerian tradition, many other problems arose, among them the lack of political engagement (resulting in an naïve subjective individual contemplation) and the authoritarian posture of the scientist when he deals with "the represented" (Sahr, 2009).

NRT has been characterized in several words and characteristics, but I would like to pinpoint two of them. The first one was defined as "slow motion" geography, as if trying to grasp all the "insignificant" details of reality that go unnoticed on a "serious" attempt to understand space or even on a representational study (Beyer and Steyaert, 2011). They believe that NRT

[...] entails a rethinking of space as processual and performative, open-ended and multiple, practiced and of the everyday [...] this entails a move from representational strategies of extracting representations of the world from the world to embodied apprehensions of the everyday performing of space (Beyer and Steyaert, 2011:47)

The second definition of non-representation is, in fact, its context: it is a reaction towards the landscape-dominated cultural geography's discussions (Lorimer, 2005). The same author mentions the importance of listening as one of the new "scapes" that are calling the attention of geographers.

We hear how music is an effective medium to orchestrate personal remembering and an affective one when - without warning or preprogramming - it renders us speechless, charges our body or transports us somewhere else. (Lorimer, 2005:87)

This theoretical breakthrough is, in some sense, Dionysiac because it seeks answers not on representations, not on the safe journey of the gaze and the legitimate and organized discourse of the scientist, but on everyday action. NRT seeks to go beyond spatial representations in order to grasp the multiplicity of everyday action that builds up space in a continuum set of practices. Instead of trying to fragment space into separate entities that are bound with identities, this approach embraces the multiplicity and multidimensionality of reality, accepting that multiple identities and trajectories share the same piece of reality. (Massey, 2008)

Duffy (2005) emphasizes that listening is not just an introspective activity: it involves several actors, objects, practices and networks. It is necessary to look at the process of music-making, music-playing and music-listening. They carry meanings and, among them, spatial (geographical) imaginations that may involve identity matters or conflicts. Art communicates non-verbally and it has the power of agency and engagement. If we keep on studying art 


\section{GEOGRAPHICAL IMAGINATIONS}

exclusively on an Apolline and aesthetic angle, we may fall into an equivocal interpretation of artwork's potential relations with reality and society (Adorno, 1997:6).

Artworks, then, are no mere fruition of the artist's creativity and imagination. It has a social, material, historical, geographical and cultural context. The refraction of several aspects of reality that we disregard sometimes are clearly exposed through artistic expression. Music, specifically, brings the ineffable into sounds we decode into feelings or/and political messages, for example.

Adorno (1997) believes that art makes our mind break up with the sense of mental selfpreservation of the accurate view of reality, the principle of sese conservare ${ }^{16}$, which is similar to the principle of individuation. Art tears up the veil of Maya (also cited by Nietzsche and Schopenhauer). This disruption and reconstruction are done outside the realms of "reality", i. e., on people's creativity. Artworks seek their identity through difference. In technical terms, art presents new layers ${ }^{17}$ of reality and space.

To sum up, we would like to reaffirm that music is not a naïve pastime of introspective moments or an environmental catalyst of emotions. Even without helping lyrics to interpret the artist's mind, it materializes and "eternalizes" (even if registered only by scores) a specific context. The more art assimilates social and political values, the less free and spontaneous it becomes on its aesthetics. Knowing this may help us find testimonials of how free ideas were exposed and how intense were cultural wars (Mitchell, 2000) during a certain period.

Smith (1997) points out that sound forms should be brought up to Geography's discussions, that this same science should accept the challenge of getting out of its Apolline comfort zone of the gaze and open its ears to music. However, as I sought to demonstrate, this should be done analytically, critically and actively. I also believe that music should be more discussed upon its intramusical aspects - harmony, rhythm, timbre and melodies - however, without abandoning extramusical aspects such as the political, social, spatial and even economic context, the composer's biography, the venues and events, musical performance, dissemination and so on.

Under this epistemological debate, instrumental music deserves a special care, since it communicates through non-communication. It needs a specific methodology to be analyzed. In order to do so, more research on hybrid studies of Geography, Music, Sociology, Aesthetics and Philosophy need to be done. This essay is just a brief and humble call for this particular need to expand the theoretical field of Music Geography in order to grasp the geographies and cultural politics within music.

\footnotetext{
${ }^{16}$ The conservation of self-identity. This term was used by Schopenhauer on "The World as Will and Representation

${ }^{17}$ The term layer is commonly used on GIS softwares, especially ArcGIS.
} 


\section{GEOGRAPHICAL IMAGINATIONS}

\section{References}

Adorno, T., 1969. Aesthetic Theory. Translated from German to English by R. Hullot-Kentor. Continuum: New York.

Adorno, T., 2009. Introdução a Sociologia da Música: doze preleções teóricas. Translated to Portuguese by Fernando de Moraes Barros. São Paulo: Editora UNESP.

Anderson, B. and Harrison, P., 2010. The promise of non-representational theories. In: B, Anderson, ed.1980. Taking-place: non-representational theories and geography. London: Ashgate, pp.1-36.

Beyes. T. and Steyaert, C., 2011 Spacing organization: non-representational theory and performing organizational space. Organization. [e-journal] 19(1), pp. 45-61.Available through: SAGE database <http://library.sage.edu>. [Acessed 28 July 2012].

Castro, C. M., 2008. A inversão da verdade - Notas sobre "O nascimento da tragédia". KRITERION. N. $\quad 11, \quad$ p. $127-142 . \quad$ Available through <http://www.scielo.br/pdf/kr/v49n117/a0749117.pdf> . [Acessed 5 May 2012].

Duncan, James., 1980. The Superorganic in American Geography. Annals of the Association of American Geographers, Vol. 70(2), pp. 181-198.

Duffy, M., 2005. Performing identity within a multicultural framework. Social \& Cultural Geography, 6(5), pp. 679-692.

Gagarin, M., 2010. The Oxford Encyclopedia of Ancient Greece and Rome. Oxford: Oxford University Press.

Gontijo, F. B., 2007. O Apolíneo e o Dionisíaco como Manifestações da Arte e da Vida. Existência e Arte. N. 2. Available trough <http://www.ufsj.edu.br/portalrepositorio/File/existenciaearte/Edicoes/2_Edicao> . [Accessed 18 February 2012].

Jackson, P., 2000. Rematerializing Social and Cultural Geography. Social \& Cultural Geography,1(1), pp.9-14.

Lorimer, H., 2005. Cultural geography: the busyness of being 'more-than representational'. Progress in Human Geography, 29, pp.83-94. Available Through < http://www1.geo.ntnu.edu > [Accessed 1 September 2012].

Massey, D., 2008. Pelo Espaço - Uma nova política de espacialidade.Translated from English by Rogério Haesbaert. Rio de Janeiro: Bertrand Brasil. 


\section{GEOGRAPHICAL IMAGINATIONS}

Mitchell, D., 2000. Cultural Geography: A Critical Introduction. London: Blackwell.

Nash, C., 2002. Cultural Geography in crisis. Antipode, 34(2). Available Through < http://dx.doi.org/10.1111/1467-8330.00241> [Accessed 28 January 2011].

Nietzsche, F., 1999. The Birth of Tragedy and other writings. Translated from German by Ronald Spiers. Cambridge: Cambridge University Press.

Nietzsche, F., 2007. Ecce Hommo - How to become what you are. Translated from German by Duncan Large. New York: Oxford University Press.

Reginster, B., 2006. The affirmation of life: Nietzsche on overcoming nihilism. Cambridge: Harvard University Press.

Safatle, V., 2006. Nietzsche e a Ironia em Música. Cadernos Nietzsche,21. São Paulo: Ed. Unijuí, pp.7-29.

Sahr, W. D., 2009. Portos e Sertões - Reflexões sobre uma Geografia Cultural à la Bresilienne. In: Mendonça, F., Lowen-Sahr, C., and Silva, M., ed. 2009. Espaço e Tempo: Complexidades e desafios do fazer e pensar geográfico. Curitiba: ADEMADAN, pp. 261-288.

Smith, S. J., 1997. Beyond Geography's Visible Worlds: a Cultural Politics of Music. Progress in Human Geography, 21(4), pp. 502-529.

Solomon, M., 2003. Late Beethoven: music, thought, imagination. Los Angeles: University of California Press.

Videira, M., 2006. O Romantismo e o Belo Musical. São Paulo: Editora UNESP.

Young, J., 1992 Nietzsche’s Philosophy of Art. Cambridge: Cambridge University Press. 
GEOGRAPHICAL IMAGINATIONS 


\section{GEOGRAPHICAL IMAGINATIONS}

\section{Spaces of transgression and normativity in Pedro Almodóvar's filmography}

Karina Eugenia Fioravante, Universidade Federal do Rio de Janeiro

karina_frr@hotmail.com

\section{First acknowledgments}

This paper discusses the role of space in Pedro Almodóvar's filmography. It is, most of all, an attempt to elucidate how cinema can be an interesting field to geographic studies. Many things were already discussed having as basis the films created by Almodóvar. The perspectives are plural and numberless methodologies and thematics have been explored. Sociology, Anthropology, Psychology and History, among other disciplines, have already demonstrated interest towards Almodóvar's films. Despite this, to Geography the theme remains unexplored what gives the possibility to look into his filmography in a new and authentic way.

The interest of this paper is to analyze a particular question: the spaces of transgression and normativity. To do so, it was elected as focus two particular films of the Spanish filmmaker: "Tie me up! Tie me down!" (1990) and "All about my mother" (1999). Both films represent very strongly the notion of transgression and normativity and its relationship with space. I do not intent to bring here a final and ultimate categorization of Almodóvar's filmography. On the contrary, one of the most important objectives of this paper is to demonstrate the richness of his films to geographic analyses, and also, elucidate that they can be problematized through a vast number of methodologies and theoretical approaches.

This paper is constructed by the following way: first, we discuss some thoughts about the potentiality of cinema to geography. We intent to explore and analyze the most relevant concepts, methodologies and theoretical approaches used by geographers. In the second subsection of the paper, we bring some notes regarding the filmography of Almodóvar in order to provide a contextualization of the two films covered in this paper. Finally, we dive into the images of "Tie me up! Tie me down!" (1990) and "All about my mother" (1999) to understand the representations of transgression and normativity and their connection with the space constructed by the cineaste.

\section{Some thoughts on the potentiality of cinema to geography: concepts, methodologies and theoretical approaches}

Since the last two decades we can observe an increase number of researchers interested in the images of cinema. This interest is seen through works that investigate the most diverse themes by multiple methodologies. In geography, these authors are supported by the New Cultural Geography, especially through its proposition of singularity and symbolism. Authors such as Aitken and Dixon (2006) discuss the increasing interest of geographers on the relationship between geography and cinema. They even propose that, in these days, we can relate to a new subfield, called "Geography of Film". 


\section{GEOGRAPHICAL IMAGINATIONS}

It is not our goal here to question the legitimacy of this affirmative. An extensive reading and epistemological reflection would be necessary to conduct a discussion of this proportion. Anyway, if we do a simple search on the engines currently available, we can observe a growth in the number of researches related to the theme. This leads us to consider the rich interconnection between geography and cinema. In the same way, it shows the desire to fill a gap, legitimizing a subject field.

In fact, the history of geographical science shows that the interest towards the images, and also by the cinema, is much older than we usually think. The very idea of geography as a science that produces images of the world is ancient. The importance of cosmographies throughout its construction, while institutionalized field, is very evoked by geographers. Cosgrove (2008) points out that the cosmographies were a central element in the scales configuration of geographic vision, i.e., the images were associated with the existing order in the world, producing thus an intelligible form of places seizure.

Azevedo (2009) reminds us that the rapprochement between geographers and cinema took place since the creation of the last one at the end of the 19th century. It is complicated to periodize the birth of cinema. The first cinematographic exhibition occurred simultaneously in the US and in Europe, but it is customary to point out that it comes up with the invention of the cinematographe by the Lumière brothers in France.

The so-called "First Cinema" was quickly embraced by geographers. Due to the lack of narrative structure and no fictional perspective, it was an excellent way to show the reality. The first films showed depicted scenes of everyday life. The images of workers leaving factories, of people shopping and feeding babies were common in the early days of the cinema display.

Therefore, the first approaches between geography and film came from educational interests. The movies - and its hitherto unquestioned verisimilitude with reality - were used as educational support for teaching geography. They enabled a "trip" to the field of interest. According to this perspective, they showed more accurately the social and natural dynamics since they were built from the idea of movement and shape. This made them more suitable than other imagetic forms, as photography and painting for example (Aitken \& Dixon, 2006).

The notion of mimicry with the reality was the main feature which encouraged the geographers in using this type of media tool. It is valid comment that the discussion around the issue of reality is still current among researchers of film theory. It is difficult, or even incoherent, to point out a point of view that overlaps in some way another one. In fact, this debate still generates heated discussion between theorists and scholars who are interested in visual issues.

The debate is wide, however, there seems to be a consensus among the authors towards the fact that the motion pictures of cinema belong to the domain of representations. This proposal raises some possible ways of analysis. In the first of them, we noted the discussions that movies are "windows to the reality", i.e. they replace the real by a reliable representation of it. According to Gomes (2008) this conception is compliant to that of positivist science, which seeks to reach the truth from identified approaches with the real. 


\section{GEOGRAPHICAL IMAGINATIONS}

This stance has been challenged, and even parodied by theorists as Jenks (1996). According to others, representations do not copy the reality, they create it. However, Gomes (2008) warns that if took to extreme this proposition can be problematic, since we lost our point of reference, which ends up being conceived only as a product of our imagination. In fact, both concepts are problematic. A third way seems to be more consistent to be agreed with: to think images or in this case, the cinema, while creator of its own reality, consistent in its own narrative structure. Gomes (2008:193-194) states that,

What can we say anyway is that representations create their own frameworks, systems, loaded by the inks of each time and soaked in the contexts of each place or social group. The representations expresses the choices throughout principles of signification that are unique, and also transient, ambiguous and polymorphic, or, as we like to say currently, complex.

In this paper, we agree with the position of Gomes (2008). It is not our interest here to assess how much the narrative constructions of Almodóvar approaches a possible reality. Rather, we seek to understand how his cinematography, in particular the two elected movies, brings meanings and symbolisms arrangements by themselves.

This position is shared by some researchers, engaged with the New Cultural Geography. These authors are bringing important collaborations to geography and film studies. In fact, this subfield of geography has incorporated in its agenda the topic, questioning it primarily from the concept of landscape. It is important to state that this is not the only possibility, not even the only concept used, but it is undoubtedly the most current one.

The concept of landscape can be used from many perspectives, and each one of them draws a specific path of dialogue with the cinematographic language. In geography, the concept has always shown visual potential and is not suspect it is one of the most used by geographers' filmgoers. In fact, since the year 1920, if not before, the interpretation of the landscape is one of the primary goals of geography.

It is worth remembering that the concept has undergone many transformations over the time. Since Sauer at the latest poststructuralist contributions, landscape was rethought and the scope of the concept discussed, questioned and enlarged. The movies' landscapes, or saying otherwise, the role of landscapes in film productions has also been constantly re-imagined.

The most common studies seek to interpret the urban landscapes in films (Costa, 2005a \& 2005b; Harper, 2010; D ' Lugo, 2010 \& Clarke, 1997; Bruno, 2002, among others). The cinematic landscape helps to understand the construction of materiality and subjectivity in movies. As Escher (2006) remembers, the landscape is seen as part of the characters' psiqué. Others choose to discuss the notion of landscape as built and constructed from a bias of cinematic realism. There are still the futuristic or imaginary landscapes of science fiction movies, 


\section{GEOGRAPHICAL IMAGINATIONS}

the textual landscapes, etc. In sum, the positions are multiple and, depending on the focus of interest, the approaches are endless.

In their collection on themes of geography and culture, Corrêa and Rosendahl (2009) have dedicated a volume to mediatic forms, including the cinema. The authors argue that it is a social creation that expresses views of the world. That it, it can not only be analyzed as it should from the perspective of spatiality. Azevedo (2009) states that with the ownership of films as theme by geographers, a new challenge was put into human geography. The challenge of revealing the meanings present in the cinema can leverage our knowledge of places according to her.

The author asserts that we can observe two major trends in geography and cinema studies. The first one is related to the studies which focus on landscapes, as already stated earlier. The methodologies used in these approaches tend to have a more interpretive character, associated with the history of art and aesthetics, for example. A second trend is the development of sociocultural studies, which focuses on the analyses of the underlying policies in each film. The methods are mostly qualitative analysis and sociological approaches.

This is a general idea, and we should not fail to pay attention to the fact that, as it presents as a model, is not universal. In fact, the film theory is wide and there are many investigative possibilities. Since the institutionalization of the studies in the late 1970, starting with the creation of cinema departments in USA, there appear new guidelines, visions, languages and systems of meanings.

One of the main features of some works that are being developed, especially after the decade of 1980 , is the constant emphasis on the importance of critical thinking beyond the simplistic descriptions. Geographers have been driven to rethink old concepts, propose new theories and original methodologies, which realize their object of study from a geographic view. Turner (1997) is emphatic and summarizes excellently the discussion about the potential of cinema. In his words,

Although studies on cinema are established in institutions all over the world, we are now at a crucial stage of its development. The cinema is revealed not as much as a separate discipline, but as a distinct set of social practices, a set of language, an industry. The current approaches come from a broad spectrum of disciplines - Linguistics, psychology, anthropology, literary criticism and history - and serve a series of political position - Marxism, feminism and nationalism. But it was clear that the reason why we want to study cinema is because it is a source of pleasure and meaning to a lot of people in our culture.

Following the same guideline, Martin (2011) asserts that it seems irrational to neglect an art that is, socially, the most influent in our time. In fact, turning back to cinema is, at least, to waste a full package of themes that can be easily related to geography. Since the audiences' aesthetic experience until the formal construction of cinematic space, it is possible to observe a large 


\section{GEOGRAPHICAL IMAGINATIONS}

agenda of possible interest. One of the possibilities is the role of space, and how it influences the entire filmic narrative structure.

As Aitken and Zonn (2004) remind us, one of the primary measures of films' success is related to its ability to sustain meaning. In other words, its capacity to be understood by the audience and also to create a possible dialogue between the projected images and the public at the theaters. We may easily affirm that the space created by the film is not a simple frame within which a subject is located. It is more. The role of space is essential to build an intelligible atmosphere to the audience, and in the same level, it unfolds in a variety of ways, many significations and meanings that may appear to be hidden in the narrative.

In early movies and early researches we may observe that the space was conceived as a mere background, predisposed simply to link the actor's dialogue with the spectators. It was static and did not have any major importance. Fortunately, when filmmakers discovered the camera's creative power, they started to realize the huge signifying potentiality of space. Hopkins (1994) goes forward and insists that if the construction of space is at the core of human geography, the notion of cinematic space is a fundamental concern to geography, especially to those who are interested in visual issues.

It is clear that space is fundamental and carefully imagined and materialized by the films' productive crew. It is also of the utmost importance to this paper to consider that the space is not innocently constructed. On the contrary, it represents closely the intentions of the filmmaker and therefore is full of symbolism, always aiming to support or not a bunch of elements.

In this paper we analyze the role of space in Almodóvar's two elected films regarding the notions of transgression and normativity. Our question is related to understand how the filmmaker creates certain spaces to be able to aboard these two practices. It is not our goal to try to reveal some deep and intimate intention of Almodóvar. What guides our interests is the aim to understand how and why the spaces were constructed by this way and which are the implications of these choices regarding the entire narrative plot. This is what we are going to discuss forward. Firstly, it seems valid to bring some considerations of Almodóvar's filmography and aesthetic positioning in order to better contextualize our main concern in this paper.

\section{3. "After all, the essential is to survive and keep the passion": some notes on Pedro Almodóvar's cinematography}

Pedro Almodóvar is known by building his plots based on some features that can provide a characterization of his entire filmography. These elements such as the exaltation of feminine, the denial of gender norms, prostitution, violence and others, were already explored by a great number of researchers. In this work, we intent to explore other sides of his filmography, the spaces of transgression and normativity. However, it is of the utmost importance to bring some considerations in order to provide a deeper view of his aesthetic style. 


\section{GEOGRAPHICAL IMAGINATIONS}

The filmmaker, born in the Spanish city of Calzada de Calatrava in the decade of 1950, was never able to study cinema due to the fact of the humble origins of his family. In the 70's, he moved to Madrid and quickly became involved with theater groups and independent bands. Almodóvar experienced the whirlwind of political and cultural renewal of Spain after the fall of Franco, and like all artists from the avant gard cultural scene, built his own style of artistic representation. Saying in other words, it is possible to affirm that Almodóvar created his own aesthetic school, a truly mixité of all sorts of elements.

Technically and generally, it may be said that movies are produced by photographs, an immense set of separated images printed on film reel, but when rounded together, give the impression of movement. We can also say that it consist of sequences, i.e. smaller units within it recognized from their role in the narrative. Each sequence has scenes, sets of images that have consistency and temporal-space unit (Xavier, 2008).

Similarly, some technical notions are very important when we analyze a movie in a consistent manner. Among them, the formal issues of the cinematographic language, as a background, framing, depth of field and perspective, to name a few, are vital. It may seem curious the need on considering in a geographical analysis a significant amount of elements that are typical of film language, and therefore foreign to geography.

However, the tools used at the time of film construction, such as positioning of the camera, the light, the framing of a particular character or even the music that accompanies it, have meanings, and must necessarily be considered. Otherwise, these are the elements which give singularity to cinema, and should therefore not be overlooked. In this case, we assume that they also give some interesting notions of a particular cineaste.

Of course, some filmmakers are easily recognized, for instance, by the preference for one type of plan. The longshots of New York City which we commonly see in Woody Allen's productions proves that. Similarly, the filmic genders provide a characterization not only related to the imagetic material, but in the same degree, of its founder. It can be said that the genders are narratives conventions that are organized into coherent, and mainly, recognisable typologies. It is common to hear that Hitchcock is the "father" of the suspense film or that Tarantino's movies are as good as bloodiest.

Obviously, in Pedro Almodóvar's cinema we may perceive some elements which, in bigger or less intensity, characterize his production as a set. These features were very well synthesized by Gomes (1996) when the author discusses the postmodern cinematographic aesthetic, commonly associated with the Spanish filmmaker production. In the words of the geographer,

Two filmmakers are regarded as leading figures of post-modernity in the cinema, David Lynch and Pedro Almodóvar. They have in common an aesthetic attitude quite distinctive, represented by the unexplainably of scenes that do not add any meaning to main storyline; an almost cartoonish exaggeration (characters and 


\section{GEOGRAPHICAL IMAGINATIONS}

situations implausible); a certain revival given by wardrobe, music and dialogs; a recourse to irony as privileged communication mode; Anyway, as a result, a "disorganized" scenario. (Gomes, 1996:22)

These characteristics give an overview, not only of Almodovar, but also of other filmmakers that have been characterized by a new form of aesthetic identified with the propositions of postmodernism. Avoiding misconceives on this matter, as formerly discussed on the subfield called "Geography of Film", a convenient approach of postmodernity and the cinema also require a full work.

Postmodern or not, Pedro Almodóvar has a differentiated way to write, shoot and assemble. It is challenging and at the same time dangerous to opt for a single aesthetic to frame his productions. Even the filmmaker makes a point of saying that it is difficult to hold to formal issues, once he feels free to experiment and mix techniques of Cinéma Noir with elements of comedy, for example.

Almodóvar has similarly perform a very interesting connection with other arts such as dance, classical theatre and photography. This intertextuality is also perceived from the frequent evocation to other works or classical figures of cinema. Maybe this plurality and certain disrespect by formalisms is the very reason of the richness of Almodóvar's films. And, certainly, is the reason for the high level of complexity that we embrace when we have our eye on his filmography.

His entire filmography is compost by eighteen films produced since 1987. In fact, it is used to say that Almodóvar filmography can be divided in two particular moments. The first, related to his eight initial films ${ }^{18}$, the filmmaker is heavily influenced by the aesthetics of the so-called movement La Movida Madrileña. This countercultural movement arose in the post-Franco Spain, a context in which young artists sought greater freedom of expression after a period of nearly four decades of closure and artistic limitations. In its aesthetic we can observe some very peculiar features that can be easily identified in Almodovar's filmography: explosions of flashy colors, exaggerated costumes and parody elements combined with the lack or total breaking of narrative linearity.

"Tie me up! Tie me down!" was shouted in this context. Very briefly, the whole narrative turns around the history of Ricky, a young man who after leave a sanatorium institution wishes to meet again with Marina, a pornographic actress with which he had a court romance a few years before. Absolutely fascinated by the woman and disappointed with the lack of opportunity to talk to her, he decides to kidnap and chain her in a bed until she learns to love him.

The second moment ${ }^{19}$ represents a phase of greater maturity of the filmmaker along with the need to express a singular creativity in his films. In this phase we can observe the exaltation of

\footnotetext{
${ }^{18}$ This period is related to the following films: Pepi, Luci, Bom and Other Girls on the Heap (1980), Labyrinth of Passions (1982), Dark Habits (1983), What Have I Done to Deserve This? (1984), Matador (1986), Law of Desire (1987), Women on the Verge of a Nervous Breakdown (1988) and Tie me up! Tie me down! (1990). (1999), Talk to her (2002), Bad Education (2005), Volver (2006), Broken Embraces (2009) and The Skin I live in (2011).
} 


\section{GEOGRAPHICAL IMAGINATIONS}

female issues, controversial topics in controversial plots, where laugh and cry seems to be essential. "All about my mother" was created in this phase of Almodóvar's career. It tells the history of Manuela, a mother whose son was killed by a car accident and which travels to another city to try to find his father, a transvestite. Along the way, she meets with others transvestites and end up becoming the assistant of the actress who was involved in her son's death.

This movie was already our focus of interest in other paper where we explore deeply the gender's performances spatialities (Fioravante \& Rogalski, 2010). In the same way, we will occasionally refer to this theme, since this thematic is really strong and guides, in many ways, the entire filmic narrative and scenarios.

\section{Transgression and Normativity: the role of space in "Tie me up! Tie me down!" and} "All about my mother"

In this subsection, we will analyze how Almodóvar constructed the spaces or scenarios in his films in order to be able to represent the features of transgression and normativity. First, we need to clarify what we are considering to be the practices related to these two features. For transgression, we will assume any sort of positioning that goes against the instituted normalization. It is very important to remember that we are not considering here the possible similitude with any kind of law that might be associated with our "reality". On the contrary, the films were analyzed taking in account only its own internal plot and coherence.

In fact, some elements and spaces that we, regularly, consider typical scenarios where the subjects must follow some rules, in the films this dynamic are completely subverted. The opposite is the same. The films were entirely considered as creators of internal realities and thereby as creators of spaces designed to hold - or not - certain practices.

In the same way, the concept of space is central in our reflection. We assume that it is a primary condition to development of filmic narratives. This concept had multiples approaches since the institutionalization of geography as a science, and has been (re)imagined and (re)valorized according with the scientific context. Understood as a matrix, symbolic, field where all sorts of claims are posed (Corrêa, 1995), this concept was many times strictly related with the evolution of geographical science.

To this work, we will assume space as constructed by two categories, one physical material and one symbolic. Also, as produced by the distribution of things and elements, as well as, by the actions that is orientated according to this distribution (Gomes, 1997).

Indeed, both films could be analyzed from numberless choices. In our reflection we decide to divide them into two distinctive scenarios, or saying in another words, two spaces. We always will refer to a public space that is, generally, differentiated from a private scenario. This choice is related to the fact that this indention seems the most appropriate and intelligible path to approach this paper's thematic. 


\section{GEOGRAPHICAL IMAGINATIONS}

"Tie me up! Tie me down!" is a dichotomic film. It is clear we can observe two very different spatialities which signify the characters' practices in a differentiated way. As mentioned previously, the main feature in the history is the kidnapping of a character, Marina. She remains recluse in an apartment that is, in fact, the space where almost the entire narrative gets developed.

We may start our reflection with the discussion of this space, a private space, which holds not only the practices of transgression, but also shows itself as soaked in normativity as long as the filmic narrative is presented. There are some really interesting formal features that we can observe during this passage from transgression and normativity. In fact, when the two main characters start to coexist with more intimacy we can observe the changes in the scenario.

In the beginning of the film, most precisely when Marina is kidnapped we can observe that the space was constructed to materialize every single aspect of austerity. The image we present bellow represents precisely the scenarios within which the characters interacts.

Figure 1. "Tie me up! Tie me down!” - Pedro Almodóvar (1990)

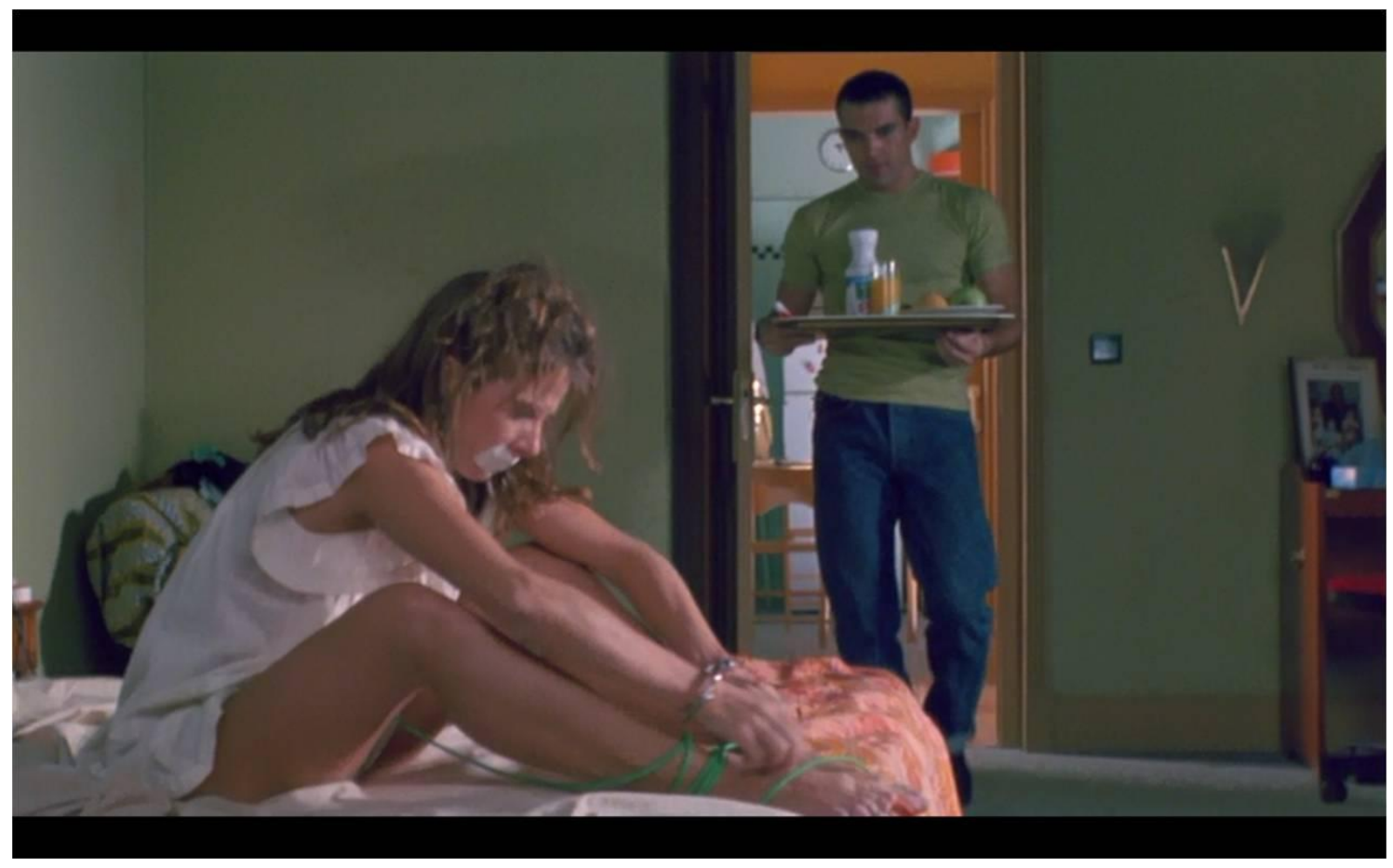

If we take a deep look in the image presented above, we may realize some elements that confirm our formerly discussion. For instance, if we pay attention to the colors that Almodóvar used to build the space, we will not the absence of hot color, such as red or orange for example. Costa (2011) argues that the color's use may reveal some associations with physical, psychological and aesthetics features.

The room where Marina is caged is cold. It is mostly composed by blue objects with green walls. This combined with the fact that she is completely tied up with ropes, gives the assurance that such space was built to represent all the repression and agony the character is involved. 


\section{GEOGRAPHICAL IMAGINATIONS}

Also, it is interesting to observe that the filmmaker do not make use of any kind of physical object that can, in any sense, indicate a possible connection between the characters. Almodóvar does exactly the opposite of that. He uses metaphors of cinematography language to express really deeply the enormous separation between Ricky and Marina. As Martin (2011) remembers, there are many ways a filmmaker can utilize to exacerbate the image signification. As we told before, "Tie me up! Tie me down!" is an interesting film to analyze how much the space can be fluid. The first scenarios represent the insulation, especially by Marina. Throughout the film, the two characters start to develop a more intimate relationship. It is impressive to note how the ambiance changes in the same degree as Marina and Ricky begins to me more close to each other.

The space colors and lighting is differentiated. Even the plan utilized are different, mostly closeups to indicate a deeper connection that is being construct by both. The image below represents this change in the filmic space.

Figure 2. "Tie me up! Tie me down!" - Pedro Almodóvar (1990)

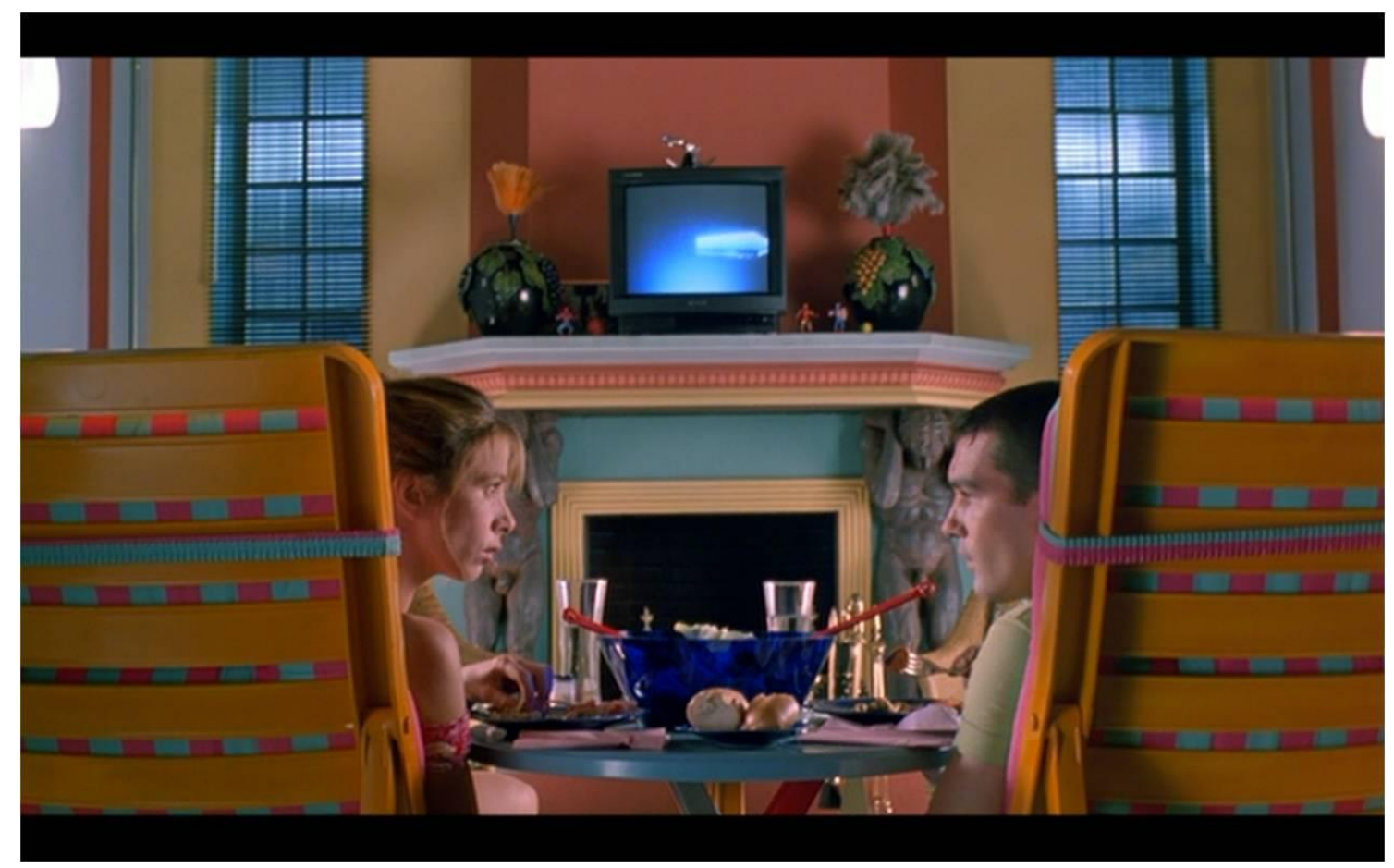

The image represents a classic scene in which a couple talks during a meal. The objects are colorful, hot, which indicates happiness and trusting. What once represented a space of transgression, of violence, now is configured as a scenario of normativity or even regularity. In fact, as long as the narrative plot in passing, Ricky remains tying Marina to a bed, but we can no more qualify such practice as transgressive, seen that this becomes normal and acceptable in the film context. 


\section{GEOGRAPHICAL IMAGINATIONS}

Massey (1999) affirms that it is important to conceive the space as product of interrelationships, i.e. built through interaction raging from global until the intimately small. In the same way, she argues that the space is the sphere which allows the coexistence of multiplicity, where different trajectories coexist. Finally, and this point is extremely coherent to our reflection, to understand the space as always in construction. This definition is interesting when we realize that the filmic space was entirely conditioned by the characters performances. In the same way, the space acted as a material scenario that influenced completely the character's acting. Indeed, the performances and the scenarios were entirely interconnected.

In "All about my mother" (1999) we may observe the opposite. Generally, all the practices of transgressions occur in public spaces. Putting in another words, these transgression do not happen in private scenarios, they took place mostly in urban spaces. The film is probably one of most geographical of Almodóvar's career. The main character Manuela constantly moves from Madrid to Barcelona and her entire life, as presented in the film, is completely conditioned by these two cities.

In Madrid, we observe very normative spaces related with Manuela's daily performance. When her sun dies, she travels to Barcelona to find his father. In this point of the narrative we do not have any element that may indicate any characteristic regarding the father character.

But when Manuela arrives in Barcelona, Almodóvar presents some symbolic images that give us a clear assumption towards that matter. She arrives at night in Barcelona. In this sequence, Almodóvar gives us a general panoramic of the most known touristic points of the city. It is important to observe that these scenes were shouted with a dark lightning. This choice reveals the cineaste's idea to present to the public a transgressive Barcelona, a city where he will introduce to us the obscure side of Manuela's life.

In the same way, the filmmaker shows the character within a taxicab, staring outside to the streets, looking for someone. The subsequent image clearly represents the scenario Almodóvar was introducing to the audience. It represents a prostitution spatiality, which we will consider as a space where practices of transgressions occurs. 


\section{GEOGRAPHICAL IMAGINATIONS}

Figure 3. "All about my mother" - Pedro Almodóvar (1999)

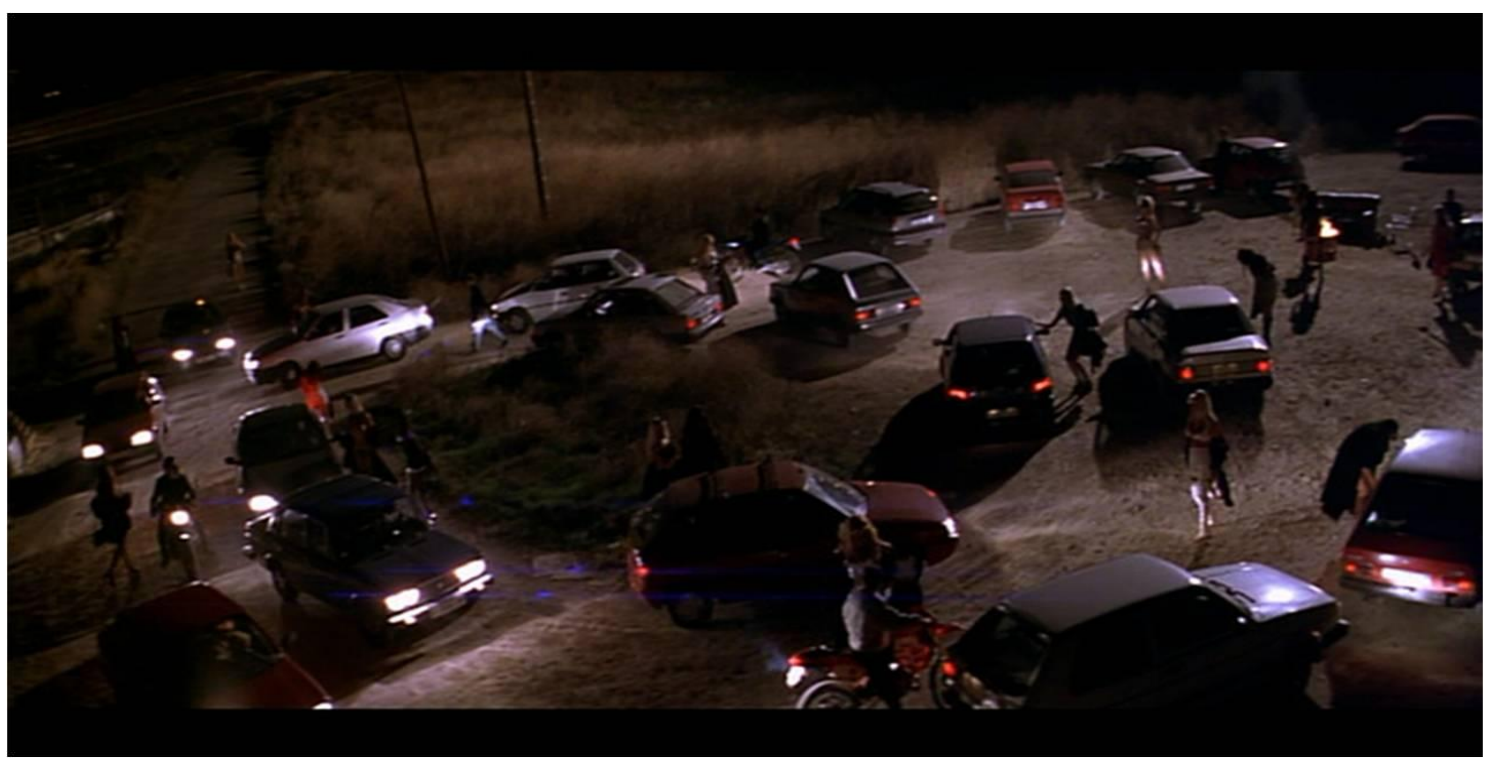

The image presented above is very interesting in the sense that they can provide a panorama of Almodóvar' scenarios of transgression in the entire film. In fact, in other sequences the character Manuela experiences other spaces such as the one represented by the image above. These spaces represent the obscure, the transgression. Even the colors used to construct the spaces are, generally, tonalities of black. In a certain way that created the symbolism of fear, reclusion and, of course, hidden practices.

Even the chosen plan represents a singular intention of the filmmaker. Aumont et al (1995) affirm that the selection of a certain type of plan or shot is full of signification and intentions. Almodóvar opted in present the spaces of transgression through the so-called "long shot", introducing the scenario where the sequence is passed. In the same way, the use of this type of plan represents a contextualization of all the features implied in the entire space.

According to Martin (2011) we must always remember that the cinema's images are not only composed by the frame we are looking at. They are more. There are always some elements that will evoke other space. What is interesting is the fact that all spaces of transgression present some particularities that enable us to characterize them as such. In other sequences of the movie, we can clearly observe the same use of lighting, mostly dark, and also, the use of the same plan type. This reveals the absence of possibility to criate a deeper interaction between the characters belonging to that scenario with the audience.

Theoretically, it is interesting that Almodóvar have chosen such scenarios to bring practices of transgression, seen that we can qualify them as public spaces, otherwise, places which are characterizable by the respect of certain general norms (Gomes, 2002). In fact, it is possible to say that in public spaces the normativity must be prevalent, in order to ensure the maintenance of the social contract which secures even the status of public of this space. It is, most of all, a space where we all exercise the difficult art of coexistence. 


\section{GEOGRAPHICAL IMAGINATIONS}

As we told before, we can analyze both films dividing their scenarios into two spaces. In "All about my mother", the private scenarios represent the spaces of normativity. The image we see below is a clear example of such space, the scenario of Manuela's house. It is interesting to observe the women's performance in this sequence in order to understand how experiencing a private space can alternate their own identities construction which becomes more fluid than within other spaces.

Figure 4. "All about my mother" - Pedro Almodóvar (1999)

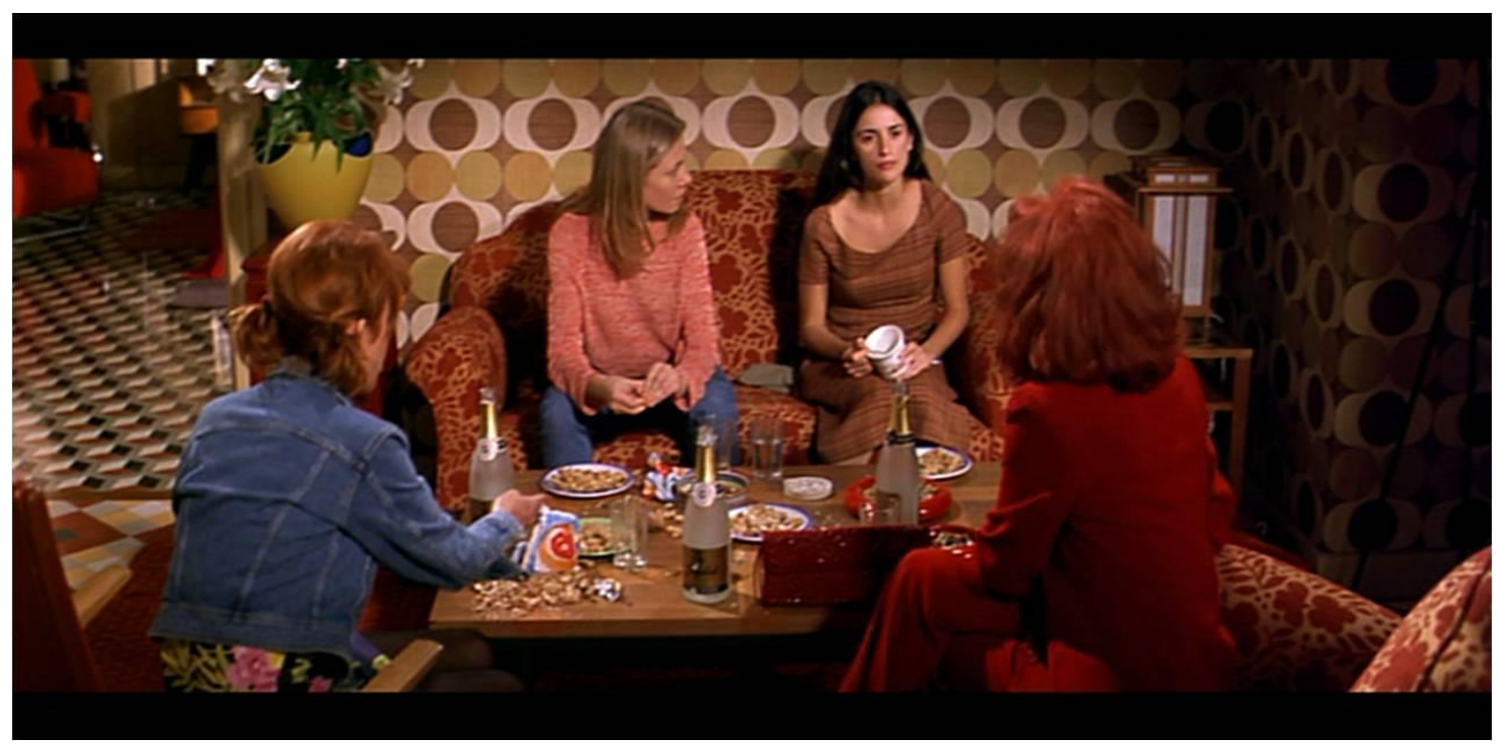

The figure represents a scene from the film that takes place in Manuela's house, where are gathered four of the main characters that constitute the plot. We can observe that these four women have completely spatial performances differentiated among themselves. Almodóvar brings the mother, the nun, the professional and the transvestite. Before we continue we would like to clarify that we have included the transvestite character "Agrado" in this analysis, because despite the biological body, her gender performance is feminine.

As we told before the entire film passes within two cities, Madrid and Barcelona. In Madrid, it is possible to affirm that the spatialities are mostly normative. Manuela's entire existence is correlated with spaces such as a hospital and a house. In theses spaces, the character has a ruled life, where her evidenced characteristic is her condition of mother. In other way, Barcelona represents the transgressions. In this space, Manuela has a daily experience in scenarios of prostitution, violence and denials of gender norms. However, the sequences in Manuela's house represent the spaces of normativity, since in this scenarios, Almodóvar did not brought any practice of transgression. Even the character Agrado, a transvestite, is seen in this scenario as a regular women.

Working with images, such as those produced by cinema requires the application of certain tools that can give an account the concept of succession, since, as points Costa (2008), the 


\section{GEOGRAPHICAL IMAGINATIONS}

movies are products of experience spaces narrated through movement, in which the analysis of meanings and senses is extremely dense, and must consider the movement of scenes and images. We must consider that when the composition of a scene, or scenario, changes, the essence of the events changes, which therefore implies a differentiated design of its geography. In both films we may, easily, perceive that. When the characters are experiencing alternate spatialities, their performance is altered. Even the features that may qualify their identities are changed. Saying in other words, when the character Agrado is presented in a prostitution space, her identity as a transvestite is evoked. When she is in private spaces, such as Manuelas' house or the theater, she is shown as a simple woman. We could continue and give many other examples of such conditioning that the space imposes to the characters. In the same way, how the characters performances changes the space.

In her discussion about the imaginary, politics and territory, Castro (1997) clarifies in a dense and coherent manner the importance of images as a possibility to enlarge the thematic agenda and the empirical field of geographical discipline. According to the geographer, the use of images has been increasingly common in most varied lines of research, which shows the same way, an effort of geography to move away from simplistic analytical processes. The space is then designed as an inexhaustible source of signs and symbols which are relevant to addressing the complexity of the real, as well as to broaden our knowledge about the space.

\section{Final Words}

Geography has dedicated limited interest towards the visual issues, neglecting the fact that the images are present in the vast majority of social relations (Rose, 2001). In the same way those images gain a considerable amount of importance on the construction of imaginaries geographies which (re)signify and gain amplitude in problems of space symbolization (Berdoulay \& Gomes, 2010).

In this paper we have shown how rich can be the interconnection between Cinema and geography. In one hand, Cinema involves the production of meanings (MacDonald, 1994). By the other hand, geography in this paper is seen as a science capable of unfolding the meanings created by a precise physical arrangement. Otherwise, there is always a geographic problem when the spatial order somehow implicate in a specific phenomenon configuration (Gomes, 2010).

We can, in effect, treat cinema in the same way we treat other thematics that were already strongly and profitably explored by geography. The simple idea that film production, development and consumption are physical activities, i.e. it must be located in space, gives a considerable importance to geography. It is also useful to remind the fact that with the new theoretical approaches brought by the New Cultural Geography, the geographers are also capable to contribute with symbolic perspectives. 


\section{GEOGRAPHICAL IMAGINATIONS}

To materialize this discussion we have chosen one particular cineaste whose films provide the possibility to elucidate the importance of filmic space. Transgression and normativity were two features chosen to exemplify one possible road to achieve it. It is of the utmost importance to defend that they are not closed, or even ultimated. Geographical thinking can, if not must to, contribute with cinematographic theory through a larger amount of concepts, approaches and methodologies. We dare to affirm that this contribution can be, indeed, endless.

One conclusion to be drawn is that, interestingly and happily, cinematographic theorists have been paying more attention to the importance of space and its role in the filmic narrative structure. Simultaneously, geographers have realized how much they are able to contribute with cinematic problems. The scope is huge. It goes from economic questions related to the moment of filmic production and distribution to phenomenological approaches regarding the gender representations in cinematic places, for example.

Castro, Gomes and Corrêa (1997) elucidate that geography has always been strongly associated with the idea of exploring, discovering. These discoveries, done formerly by cosmographers, emphasized the adventure provide by the encounter with the unknown. The adventure to explore, to discover has not ceased, only presented a profound change in its direction. The "new worlds" are no longer represented by unknown lands or places never visited before. Rather, are extracts of our daily life discovered from new ways of looking into old propositions.

Indeed, our geographical discovering is now related to the idea of rethink old perspectives to conceive new aspects, new positioning and approaches. The idea of discover remains, just with different pretensions and instruments. Other themes in different contexts are explored. In our case we choose the moving images produced by a camera that can, undoubtedly, hold a vast range of questions and possibilities to geographical analysis.

\section{References}

Aitken, S.C. and Dixon, D.P., 2006. Imagining geographies of film. In: Erdkunde, Dezember 2006, pp. 326-336.

Aitken, S.C. and Zonn, L.E., 1994. Re-presenting the place pastiche. In: AITKEN, Stuart C.; Zonn, L.E. (Orgs). Place, Power, Situation, and Spectacle: a Geography of Film. Maryland: Rowman \& Littlefield Publishers, pp. 3-25.

Aumont, J. et al, 1995. A estética do filme. Rio de Janeiro: Papirus.

Azevedo, A.F., 2009. Geografia e Cinema. In: Corrêa, R.L. and Rosendahl, Z. Cinema, Música e Espaço. Rio de Janeiro: EdUERJ, pp. 95-127.

Berdoulay, V. and Gomes, P.C.C, 2010. Introduction: Image et espace public: la composition d'une scène. Paris: Géographie et Cultures, v. 73, pp. 3-6. 


\section{GEOGRAPHICAL IMAGINATIONS}

Bruno, G., 2002. Atlas of Emotion. Journeys in art, architecture and film. New York: Verson.

Castro, I.E., 1997. Imaginário Político e Território: natureza, regionalismo e representação. In:

Castro, I.E., Gomes, P.C.C. and Corrêa, R.L. Explorações Geográficas. Rio de Janeiro: Bertrand Brasil.

Castro, I.E., Gomes, P.C.C. and Corrêa, R.L., 1997. Explorações Geográficas. Rio de Janeiro: Bertrand Brasil.

Clarke, D.B., 1997. Introduction: previewing the cinematic city. In: Clarke, D.B. (Org). The cinematic city. London: Routledge.

Corrêa, R.L., 1995. Espaço: um conceito chave da Geografia. In: Castro, I.E., Gomes, P.C.C. and Corrêa, R.L. (Orgs). Geografia: conceitos e temas. Rio de Janeiro: Bertrand Brasil.

Corrêa, R.L., Rosendahl, Z., 2009. Cinema, Música e Espaço. Rio de Janeiro: EdUERJ.

Cosgrove, D., 2008. Geography and vision: seeing, imagining and representing the world. London: I.B. Tauris \& Co Ltda.

Costa, M.H.B.V., 2005a. Geografia Cultural e cinema: práticas, teorias e métodos. In: Rosendahl, Z. and Corrêa, R.L. (Orgs). Geografia: temas sobre espaço e cultura. Rio de Janeiro: EdUERJ, pp. 43-78.

Costa, M.H.B.V., 2005b. As paisagens urbanas e o imaginário fílmico. In: Valença, M.M. and Costa, M.H.B.V. (Orgs). Espaço, cultura e representação. Natal: EdUFRN, pp. 81-96.

Costa, M.H.B.V., 2008. Cinema e arquitetura: percepção e experiência do espaço. In: Revista Cidades, v. 5. N. 7, pp. 63-78.

Costa, M.H.B.V., 2011. Color in films: a critical overview. In: Crítica Cultural (Critic), v. 6, n. 1, pp. 333-346.

D'Lugo, M., 2010. Landscape in Spanish Cinema. In: Harper, G. and Rayner, J. (Orgs). Cinema and Landscape. Chicago: The University of Chicago Press, pp. 117-130.

Escher, A., 2006. The geography of cinema. A cinematic world. In: Erdkunde, Dezember, pp. 307-314.

Fioravante, K.E. and Rogalski, S.R., 2010. Da Geografia às imagens do cinema: uma discussão sobre espaço e gênero a partir de Pedro Almodóvar. In: Expressões Geográficas, 07, ano VII, p. 11-31. 


\section{GEOGRAPHICAL IMAGINATIONS}

Gomes, P.C.C., 1996. Geografia e Modernidade. Rio de Janeiro: Bertrand Brasil.

Gomes, P.C.C., 1997. Geografia fin-de-siècle: o discurso sobre a ordem espacial do mundo e o fim das ilusões. In: Gomes, P.C.C., Castro, I.E. and Corrêa, R.L. (Orgs). Explorações Geográficas. Rio de Janeiro: Bertrand Brasil.

Gomes, P.C.C., 2002. A condição urbana. Ensaios de geopolítica da cidade. Rio de Janeiro: Bertrand Brasil.

Gomes, P.C.C., 2008. Cenários para a geografia: sobre a espacialidade das imagens e suas significações. In: Rosendahl, Z. and Corrêa, R.L. (Orgs). Espaço e Cultura: Pluralidade Temática. Rio de Janeiro: EdUERJ.

Gomes, P.C.C., 2010. Um lugar para a geografia: contra o simples, o banal e o doutrinário. In: Fioravante, K., Pereira, R. and Rogalski, S.R. (Orgs). Geografia e Epistemologia: ciência viva e dinâmica, aberta e plural. Ponta Grossa: UEPG, pp. 9-26.

Harper, G., 2010. Introduction - Cinema and Landscape. In: Harper, G. and Rayner, J. (Orgs). Cinema and Landscape. Chicago: The University of Chicago Press, pp. 13-28.

Hopkins, J., 1994. A mapping of cinematic places: icons, ideology, and the power of (mis)representation. In: Aitken, S.C. and Zonn, L.E. (Orgs). Place, Power, Situation, and Spectacle: a Geography of Film. Maryland: Rowman \& Littlefield Publishers, pp. 47-65.

Jenks, C., 1996. Visual culture. Londres: Routledge.

MacDonald, G.M., 1994. Third Cinema and the Third World. In: Aitken, S.C. and Zonn, L.E. (Orgs). Place, Power, Situation, and Spectacle: a Geography of Film. Maryland: Rowman \& Littlefield Publishers, pp. 27-44.

Martin, M., 2011. A linguagem cinematográfica. Rio de Janeiro: Brasiliense.

Massey, D., 1999. Spaces of politics. In: Massey, D., Allen, J. and Sarre, P. (Orgs) Human Geography Today. Cambridge: Polity Press.

Rose, G., 2001. Visual Methodologies. An introduction to the interpretation of visual materials. Trowbridge: Cromwell Press.

Turner, G., 1997. Da sétima arte à prática social - uma história dos estudos sobre cinema. In: Turner, G. Cinema como prática social. São Paulo: Summus, pp. 36-50.

Xavier, I., 2008. A janela do cinema e a identificação. In: Xavier, I. O discurso cinematográfico: a opacidade e a transparência. Rio de Janeiro: Paz e Terra, pp. 17-25. 
GEOGRAPHICAL IMAGINATIONS 


\section{GEOGRAPHICAL IMAGINATIONS}

\section{Collaborative webmapping: creating layers of lesbian visibility}

Eduarda Ferreira, Unversidade Nova de Lisboa, e-GEO

e.ferreira@fcsh.unl.p

\section{Introduction}

This paper reports the work in progress of the last phase of the research project "reconceptualising public spaces of (in)equality: sensing and creating layers of visibility". The objective of the research project is to explore the potential of public authoring and collaborative web mapping to promote the agency and empowerment of people who experience discrimination and it is organised in three phases: 'mapping the landscape' - to map physical and online spaces of lesbian and gay visibility in portugal and to explore same-sex displays of affection in public spaces; 'sensing the landscape' - to identify significant dimensions of space and places that relate to lesbian and bisexual women's social identities through collaborative maps based on bio data, on-site emotions, personal experiences and significances; and 'creating landscapes' - to explore how creating and sharing digital layers of lesbian visibility on collaborative web maps can disrupt a hetero pervasive reality and impact social identity and belonging.

Space and social identities mutual relation of constitution and reproduction, lead us to the understanding that space reflects power relations and hegemonic discourses, and that inequality can perpetuate itself through the ways space is organized, experienced, represented and created (Massey, 2005; Mitchell, 2000; Smith, 1991; Valentine, 2001).

This research addresses sexual identities because spatial visibility is a particularly important aspect of their constitution and reproduction (Mitchell, 2000; Valentine, 2001). Discriminated minority groups, such as lesbians and gays, experience power inequalities in their everyday lives, and their spatial invisibility contributes to their disempowerment (agency for fundamental rights, 2009). The research focuses on lesbian and bisexual women because of the specificities of the interrelation of women and public spaces (Valentine, 1993) and the scarcity of research on lesbian issues when compared to gay issues (Ferreira and Silva, 2011).

The methodological approach of 'creating landscapes' is centred on structured workshops: 'collaborative web mapping' and 'layers of visibility'. On the 'collaborative web mapping' workshop a collaborative web map of portugal was produced, based on georeferenced data created by lesbian and bisexual women, and on the 'layers of visibility' workshop a web map with positive lesbians' experiences on public spaces was created and made accessible on web browsers and directly on location with mobile devices (tablets, mobile phones).

\section{Space and sexual identities}

Space and social identities are mutually constituted. Space is an essential part of the constitution and reproduction of social identities. Moreover, social identities, meanings and 


\section{GEOGRAPHICAL IMAGINATIONS}

relations produce material and symbolic or metaphorical spaces (Cloke, Philo \& Sadler, 1991; Massey, 1999; Smith, 1993).

Geographical space is not an objective structure but a social experience imbued with interwoven layers of social meaning. These meanings shape the way spaces are produced and used, and how spaces can feed back into shaping the way in which people categorize others and identify themselves (Smith, 1991).

As doreen massey (2005:107) argues, because space emerges through relations which are active practices, material and embedded, space is made of a dynamic simultaneity, constantly disconnected by new arrivals, constantly waiting to be determined (and therefore always undetermined) by the construction of new relations. Space is always under construction and in a process of becoming.

To theorise space as the product of social relations, leads us to the understanding that public space is not an emptiness which enables free and equal speech. Public space, from the greatest square to the smallest public park, is a product of heterogeneous and sometimes conflicting and unequal social identities/relations. Identities are produced within the complex power-geometry of social/spatial relations, and in turn the way in which individuals experience and imagine spatiality reshapes the power-geometries of social/spatial relations (Massey, 2005).

Social identities (such as class, gender, sexuality and race) are socially constructed, not taken for granted as given or fixed, and therefore they can be contested, resisted and (re)negotiated (Valentine, 2001; West \& Fenstermaker, 1995). The power-laden spaces in and through which life is experienced are highly contingent on the way particular identities become salient or foregrounded at particular moments. Individuals maintain multiple identities in different spaces and in one space but at different times. Social identities are neither stable nor passively received understandings of social differences; therefore it is not possible to explain inequalities through a single framework. Intersectionality, as spatially constituted and experienced, supports the understanding of the intimate connections between the production of space and the systematic production of power (Valentine, 2007).

This research focuses on lesbian and gay sexual identities because of their strong relation to spatial dimensions. Sexual identities depend to some extent on particular spaces for their production, and space is also produced through the performance of identities. Spatial visibility has been and still is particularly important in the development of lesbian and gay civil rights movements (Mitchell, 2000). An individual's sexual identity may be read as lesbian or gay from the space they occupy, or a person may only feel able to "come out" and identify as gay in a lesbian or gay space (Mitchell, 2000; Valentine, 2001). Pride marches, self organized neighbourhoods with lesbian and gay friendly ambience, specific public places announced to be safe and discrimination-free, and the negotiation of place-related identities (sexual orientation disclosure only in specific places), all have a common attribute: space. 


\section{GEOGRAPHICAL IMAGINATIONS}

Sexual orientation has an additional relevant characteristic for this research - the possibility of invisibility. People can decide not to disclose their sexual orientation, and invisibility is a common option on a context of social discrimination (Ferreira, 2008). Although there have been significant legal steps towards equality in the european union, discrimination on grounds of sexual orientation is still a widespread reality. Lesbians and gays invisibility is simultaneously a consequence and a cause of inequalities in their everyday lives, and contributes to their disempowerment (agency for fundamental rights, 2009).

\subsection{The pervasive invisibility of lesbian and gay sexualities in public spaces}

Sexuality is a process of power relations which mediates our everyday interactions, rather than a feature of private life (Valentine, 1993:246). Hegemonic discourses, such as heteronormativity, are literally inscribed in space. As an example, relevant to this research, the performance of non-normative identities in public space, such as lesbian and gay sexual identities, disrupts and therefore exposes the way in which the street is commonly produced as "naturally" or "normally" a heterosexual space (Bell, 2001; Valentine, 2001).

The intimate connections between the systematic production of power and the production of space have been uncovered and studied by a diverse range of researchers. In particular spaces, there are dominant spatial orderings that produce moments of exclusion for particular social groups (Massey, 1999; Mitchell, 2000; Smith, 1991; Valentine, 2007).

'mapping the landscape', the first phase of the research project "reconceptualising public spaces of (in)equality: sensing and creating layers of visibility", aimed to map physical and online spaces of lesbian and gay visibility in portugal and to explore same-sex displays of affection in public spaces. The results provided original empirical data on the interrelations of sexual identities and space (Ferreira, 2011). The study focused on behaviours (same-sex public displays of affection) rather than on identity discourses. This approach made it possible to stress the significant relations of sexual orientation disclosure with space, and to uncover some examples of dissonance in the self - identity discourse of lesbians and gays. Public displays of affection are rather common in the portuguese socio-cultural context, a fact which offers a special opportunity for exploring how lesbians and gays negotiate same-sex displays of affection in public spaces.

The research results (Ferreira, 2011), based on semi-structured interviews and an online survey, indicate that same-sex public displays of affection (such as holding hands, hugging, kissing) are not frequent for the homosexuals and bisexuals that participated in this research. The main reasons the participants identified for refraining from public displays of affection, are: a) the feeling of "not being safe" / fear of discrimination; b) the understanding that people in general are not prepared to deal with same-sex public displays of affection and that homosexuals and bisexuals should not confront others (which can be identified as internalized homophobia); and c) the need to take into consideration their partners' attitudes towards same- 


\section{GEOGRAPHICAL IMAGINATIONS}

sex public displays of affection. Only a small percentage of the respondents answered that they had the right to express their affection regardless of other people's reaction or society's respect for diversity. Most of the respondents reported an ever-present feeling of a lack of safety associated with same-sex public displays of affection and the understanding that these behaviours imply the disclosure of one's sexual orientation.

Analysing the results according to age did not reveal any differences. Due to the significant increase of lgbt associations and comprehensive legal changes which have occurred in portugal since 1996 (Ferreira and Silva, 2011) we would expect a higher percentage of younger lesbians, gays and bisexual persons having same-sex public displays of affection. The eurobarometer on discrimination in the EU (European Commission, 2009) can contribute to better understanding these results, as it reveals that the younger citizens perceive the discrimination on grounds of sexual orientation as being more widespread than the older citizens. A greater awareness of the risk of being discriminated can contribute to a more cautious/defensive behaviour in public spaces.

Another noteworthy result is that some of the interviewees who had previously "come out" to their families, friends or co-workers, also reveal avoiding public displays of same-sex affection. These results can be better understood if we acknowledge that the process of "coming out" is a complex and difficult process in which individuals negotiate space/time strategies such as deciding not to have same-sex public displays of affection (Valentine, 1993).

This research (Ferreira, 2011) also explored the relation of the characteristics of public spaces with same-sex displays of affection. Most of the respondents identify isolated public spaces away from "other people's eyes" as safer for same-sex public displays of affection. Public spaces are constructed around particular notions of appropriate sexual comportment, reflecting and reproducing heteronormativity, as they exclude non-normative sexualities, such as lesbian and gay sexualities (Hubbard, 2001). Another clear idea stands out: proximity to place of residence or work limits same-sex public displays of affection given that most of the respondents do not want to be identified as lesbians or gays by people with whom they interact daily. On the other hand, spaces identified as Igbt friendly, like some nightlife areas in large cities characterized by a sense of anonymity, are facilitators of same-sex public displays of affection. An analysis of space/time contexts is interesting. Lesbians and gays may feel comfortable in public spaces that they usually do not consider friendly, but that at specific times become so, such as during pride events or Igbt film festivals. The presence of visible lesbians and gays can transform a heteronormative space into a homo-friendly one (Bell, 2001; Valentine, 2001).

The research results (Ferreira, 2011) point out that if we were to draw a map of friendly public spaces to same-sex public displays of affection, we would have to draw as many maps as individuals; the importance of residence and workspaces dictates the need for personal maps of lesbian and gay visibility; there would be no single map that would meet the specificities of each 


\section{GEOGRAPHICAL IMAGINATIONS}

individual; probably only some nightlife areas in large urban areas would be common spaces to all personal maps.

Research on the experiences of being lesbian, gay or bisexual can contribute to improve our understanding of sexuality as a process of power relations which mediates our everyday interactions.

\section{Participatory geospatial web}

Space representation through maps is a socially constructed form of knowledge that contains different meanings and reflects diverse relations of power (Harley, 1988; Wood \& Fels, 1992). As the ability to map and mark places become more widely available through technology, the power of shaping reality through mapping is increasingly the privilege of many (Barnett, 2003). The rich diversity of media in everyday life and the rapid democratisation of geographic information, enable people to actively participate in space representation through adding and sharing of cartographic content, giving rise to the geospatial web. Due to the increasing sophistication in location-aware portable devices, such as mobile phones, together with web technologies, maps can easily be created, modified, and shared (Silva et al., 2009).

Current web mapping services provides features for users that support the creation and sharing of location-based content and people are increasingly using web maps to connect with each other and with the urban and natural environment in ways that no one had predicted (Roush, 2005).

A wide diversity of research projects on mobile devices and collaborative web mapping are being carried out by universities and research centres. Projects, such as social tapestries (http://socialtapestries.net/) promote a participatory approach to data collection, exploring the potential benefits and costs of collaborative web maps generated by means of public authoring systems. Public authoring is the mapping and sharing of local knowledge using pervasive computing technology to create and support relationships beyond established social and cultural boundaries and the development of new practices around place, identity and community (Airantzis et al., 2008:11). Public authoring proposes that everyday people become the authors of a complementary flow of knowledge, information, memories, stories and experiences that adds local specificity to the more generalised material that can be offered by media companies. Social tapestries projects have focused specifically on how public authoring can support grassroots participatory activities to contribute to an alternative experience where people are presented with the opportunity to be agents, actors and authors (Lane et al., 2005).

Participatory approaches to collaborative web mapping are numerous and participation patterns vary. Goldman et al. (2009) propose three models: collective design and investigation individuals define what, where, and why to map, interpret the data and act on the results; public contribution - participants are actively involved in the collection of data they find meaningful, but not necessarily in the definition of research questions or use of the results; and personal use and reflection - individuals log information about themselves and use the results for personal 


\section{GEOGRAPHICAL IMAGINATIONS}

discovery. Participatory approaches create the opportunities for community and personal discoveries, allowing people to use today's technologies to observe, document, and act on issues that matter to them. It fosters positive changes and empowerment in peoples' lives (Goldman et al., 2009).

\section{Creating landscapes}

The methodological approach of this phase of the research is centred on two structured workshops: 'collaborative web mapping' - a collaborative web map of portugal was produced, based on georeferenced data created by lesbian and bisexual women; and 'layers of visibility' a web map with positive lesbians' experiences on public spaces was created and made accessible on web browsers and directly on location with mobile devices (tablets, mobile phones).

The decision process of designing "creating landscapes" workshops was based on the results of previous research tasks (figure 1). Considering the objective of this phase of the research: to create and to access georeferenced layers of web maps; and the need to use a free and usable software (so that participants could easily collaborate), did not support the choice of a software that enables the creation and access of web maps information both online and on local. The available software with these features is not yet user friendly and/or requires mobile phones with access to the internet (this is not a feature commonly used in mobile phones in portugal ${ }^{20}$ ). Additional constraints were related to the need of using free and usable software compatible with a diverse set of hardware, considering that the participants had to use their own equipments (the research had no funding).

Based on the information shared by the participants on the previous phases of research we became aware of some aspects that had to be taken into consideration, namely: the need to organize an engaging and interactive activity; to ensure that the participants' personal information, and in particular their sexual orientation, was not disclosed publically; and to protect information on participants location for security reasons (on accounts of the discriminatory social context). These aspects led us to opt for a collaborative/shared web map that was visible only to the workshop's participants.

\footnotetext{
${ }^{20}$ State of Communications 2011, ANACOM, available at http://www.anacom.pt/render.jsp?contentld=1127309
} 


\section{GEOGRAPHICAL IMAGINATIONS}

Figure 1 - map of the decision process of designing "creating landscapes" workshops

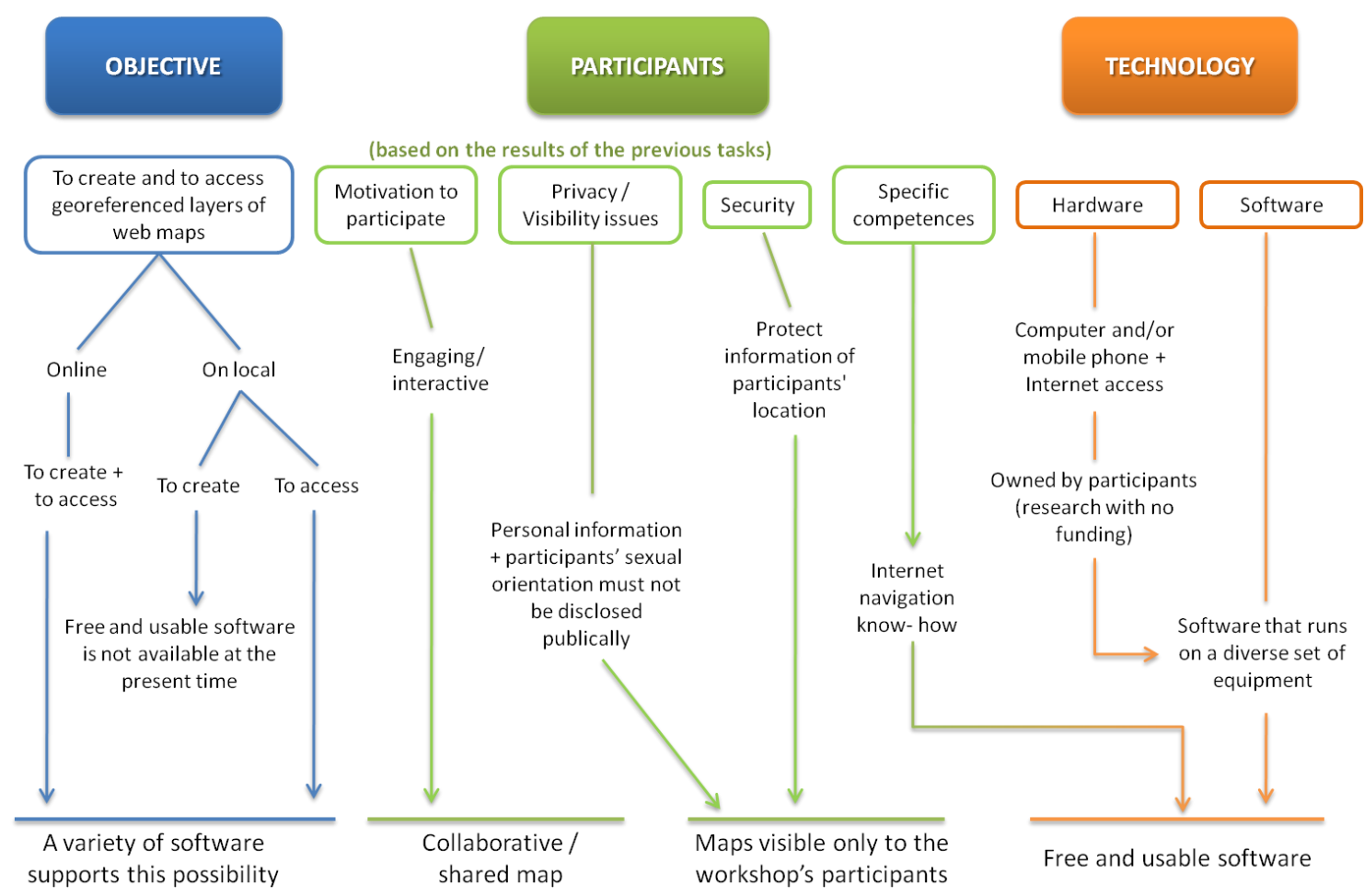

As a result of this decision process the choice was to use google maps with the privacy and sharing settings set to 'unlisted', which allows sharing its content only with selected people who have the map's url ${ }^{21}$. The field work period was from january to july 2012.

\section{1. 'Collaborative web mapping' workshop}

This workshop consisted of a collaborative web map of portugal, based on georeferenced data created by lesbian and bisexual women. The call for participation was explicit that the collaborative web map should be based on impressions, experiences, thoughts, emotions or memories, related to public spaces. A google map "camadas de visibilidade" (unlisted - not accessible through search engines, available only to people who have the map's url) was created by the researcher and participants were invited as collaborators; all collaborators could create placemarks ${ }^{22}$ and/or comment (add content) to placemarks created by other collaborators. The steps of the workshop were: to call for participation on lgbt portuguese mailing lists and on facebook; to create an initial map with some placemarks with information from the previous phases of the research project so that collaborators did not face an "empty" map; to send detailed instructions and regular mails to collaborators (1 per week) to remind that the workshop was running; to make regular backups of $k m$ files $^{23}$ (feature available on google

\footnotetext{
${ }^{21}$ Uniform resource locator (URL) is a specific character string that constitutes a reference to an Internet resource.

${ }^{22}$ Placemarks can have descriptive text, including rich text and HTML, photos and videos.

${ }^{23}$ Google Earth's file format for storing placemarks.
} 


\section{GEOGRAPHICAL IMAGINATIONS}

maps) to record the process of the web map creation; and to publish an online survey ${ }^{24}$ to assess collaborators activity during the workshop. The period of web map creation was 7 weeks.

Initially 24 women accepted the invitation to participate in the 'collaborative web mapping' workshop, however only 14 created (or commented) placemarks. Most of the participants identified themselves as lesbians, live in urban areas, have at least a secondary level of education, and are more than 30 years old. The professional occupation is diversified and in various areas of activity. Two of the participants were unemployed.

The survey to assess collaborators activity during the workshop explored: the clarity of the instructions; frequency of web map visualization; number of placemarks created and/or commented; access with mobile phone; and the effect of their participation on their perception of the spaces where they usually circulate and/or areas that they are familiar with. Based on the results we can conclude that the participants considered that the instructions on how to participate were clear and easy to follow. In what concerns the participants' activities during the 'collaborative web mapping' workshop: 6 participants accessed the web map at least once a week and 8 less than once a week; 9 participants created 5 or less placemarks, 4 created between 6 and 10, and only 1 created more than 10 placemarks; 6 participants commented on placemarks created by others; and only 1 participant accessed the web map on a mobile phone. The main ideas expressed by the participants on the effects of the workshop on their perception of spaces, are related to: the unexpected overall positive content of the placemarks; access to information about country areas where lesbians are more 'visible'; and an increased awareness of the surrounding space.

"it is positive there are not many references to homophobic attitudes; i expected more on this topic."

"i got a clearer picture of areas of the country in which lesbians are visible and perhaps, indirectly, where there are more lgbt people."

"i became more attentive to what is happening around me."

The analysis of the web map produced during the 'collaborative web mapping' was based on the following steps: geo localization - to count the number of placemarks according to their geo localization; transcript - to create a table with the content of the placemarks: identifying the place, type of icon, content (words and/or photos); and to make a list of all the words used in the placemarks; coding - to code each placemark as positive, negative or neutral, according to their content; to code the types of content of each placemark; and to identify all the placemarks related to same-sex public displays of affection; and analysis - to analyse the words used on the placemarks interrelations and the coding results.

${ }^{24} \mathrm{http}: / /$ pt.surveymonkey.com/ 


\section{GEOGRAPHICAL IMAGINATIONS}

The final google map "camadas de visibilidade" ${ }^{25}$ (figure 2), after removing the initial placemarks created by the researcher, had 88 placemarks: 43 in lisbon region (which includes greater lisbon and peninsula of setubal), 14 in porto, 5 in the littoral (considering the entire area of the portuguese littoral with the exception of algarve), 5 in the algarve, 2 in azores, 1 in coimbra; and the rest scattered in the interior areas of the country (mostly with indication of holidays). Notwithstanding that most of the collaborators were from lisbon, the distribution of the placemarks is similar to the results of 'mapping the landscape' (Ferreira, 2011). An interesting data is that there is only 1 placemark in coimbra although 3 participants live in that area. The 2 placemarks in azores are of particular interest since it is one of the geographical areas of portugal that did not have any data on the previous phases of this research. However we may assume that they were created by someone on holidays, since none of the collaborators lives in the azores.

Figure 2 - Final web map of the 'collaborative web mapping' workshop
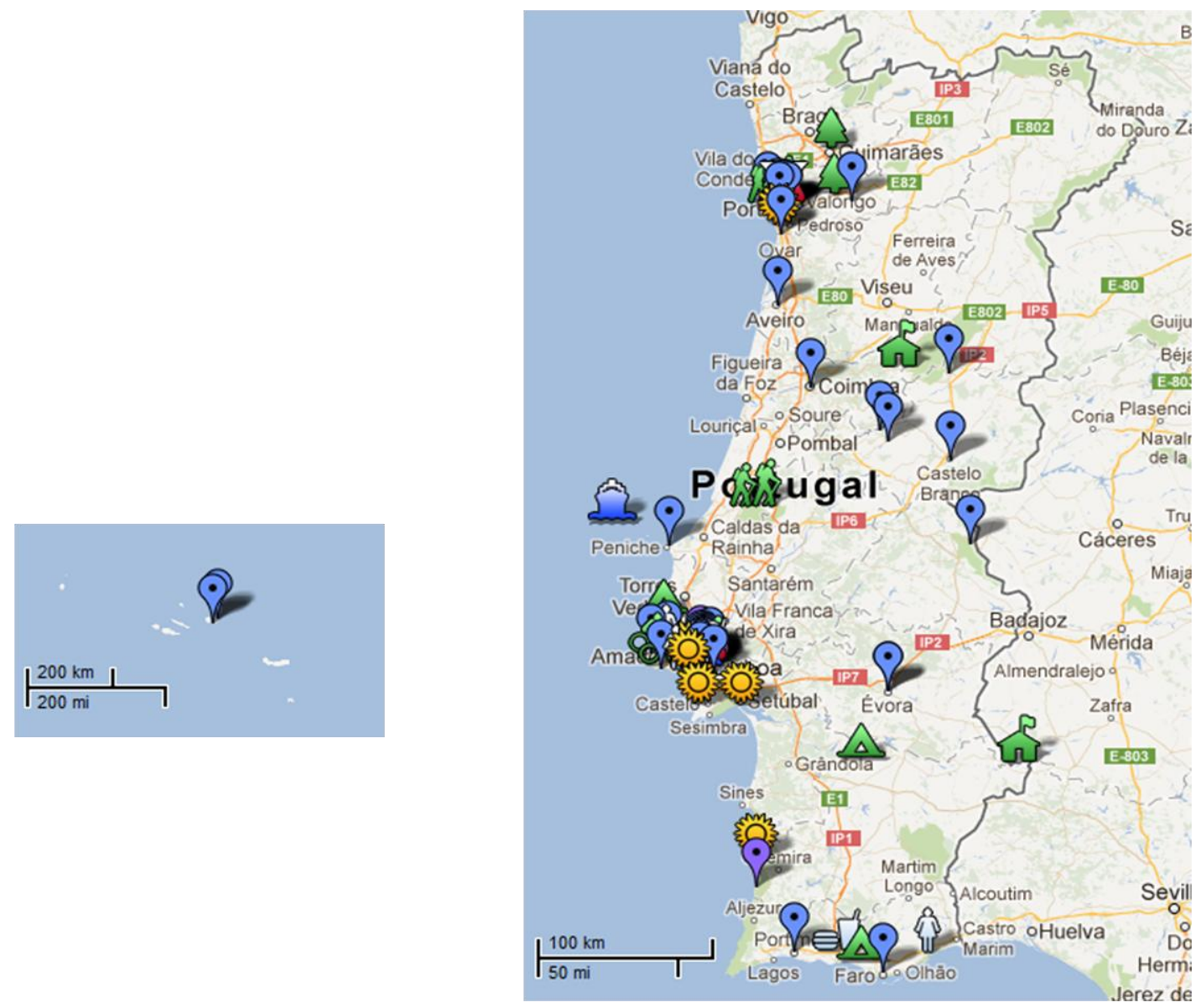

${ }^{25} \mathrm{http}: / /$ goo.gl/maps/dC6I 


\section{GEOGRAPHICAL IMAGINATIONS}

From the 88 placemarks on the web map, 66 (75\%) have text. Most of these placemarks have full sentences or small texts; only $14(16 \%)$ have a single word, mostly the name of the location. These results indicate that participants actually contributed with information to the web map. although the instructions explained step-by-step how to insert photos on the placemarks and how to change the icon, only $7(8 \%)$ have photos, and $43(49 \%)$ of the placemarks use the default google maps icon $\odot$ Out of the 45 changed icons, 12 (14\%) are a woman symbol is, and the rest is quite diverse, from camping tent, train, food, danger signal, tree, sun, etc. We may say that the graphic aspect of the map was not the most important for the participants, words were privileged over images.

In terms of positive/negative/neutral connotations of placemarks, most of them $59(67 \%)$ have a clear positive content, and the rest are equally divided in negative or neutral connotation. These results present a prevailing positive content of the web map.

Although the call for participation was rather general, asking for participants to contribute with: impressions, experiences, thoughts, emotions or memories, related to public spaces, it is noteworthy that $33(37,5 \%)$ placemarks are related to same-sex public displays of affection. These results might be related to the context of the research project; by the time of this workshop the research project was widely publicized on a wiki with information on previous phases' results and current activities, and participants might be aware that the overall objective was focused on same-sex public displays of affection. The fact that $30(90 \%)$ of the 33 placemarks related to same-sex public displays of affection have a positive connotation might seem unexpected. Although, if we consider the fact, based on the content of the placemarks and the results of "mapping the landscape", that most same-sex public displays of affection are usually performed in isolated spaces, away from others' eyes, preventing the occurrence of negative reactions, this result becomes more easily comprehensible.

Analysing the type of content of the placemarks we can further explore these results. The categories used to code the type of content, were: observations: description of something that was noticed or perceived; ideas: thoughts, conceptions or opinions; memories: personal situations experienced; names: just the name of the place; events: reference to specific events; emotions: expression of feelings. According to the content each placemark could have multiple coding, resulting on 172 coding data on 88 placemarks. The graphic 1 presents the results of this process. 


\section{GEOGRAPHICAL IMAGINATIONS}

Graphic 1 - percentage of types of content of the placemarks on the web map

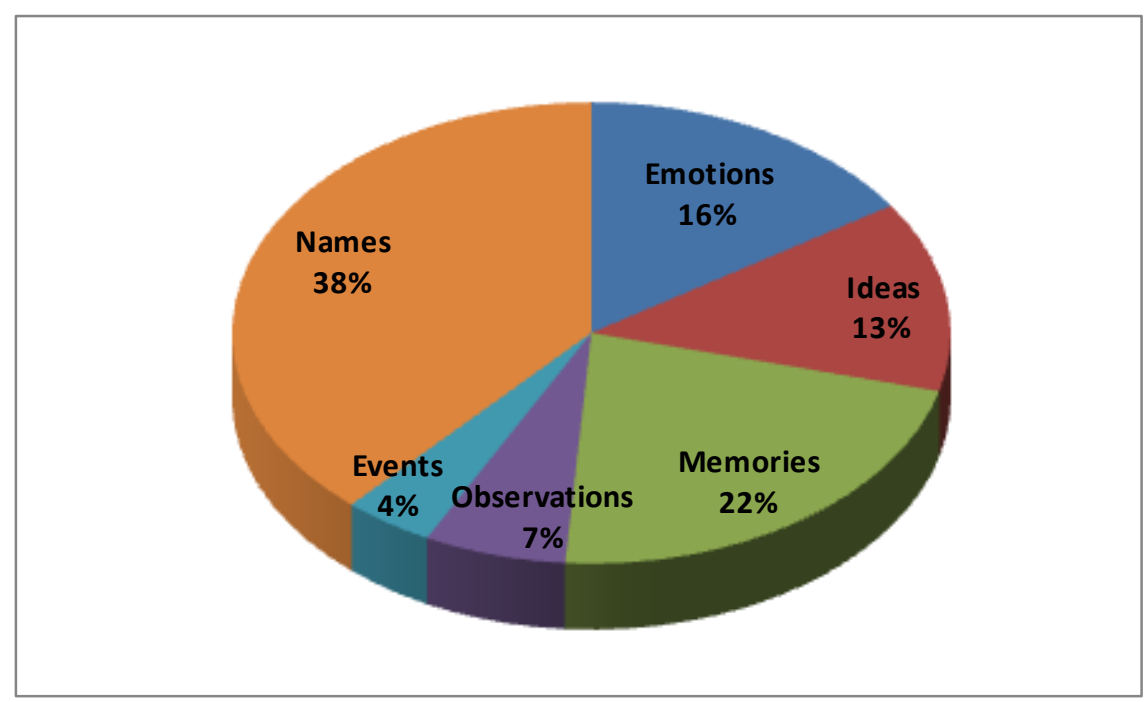

It is interesting to note that participants felt the need to name $(38 \%)$ the places where the placemarks were positioned, notwithstanding that this information was provided by their geolocation on the web map. Besides the name of places, personal situations experienced (memories), expression of feelings (emotions), and thoughts, conceptions or opinions (ideas) were the most frequent type of content. A description of something that was noticed or perceived (observations) and reference to specific events (events) were minor. Participants did contribute with their own experiences, emotions, thoughts and opinions, which was the main objective of the workshop. The collaborative creation of this web map provided a lived representation of georeferenced experiences, emotions, thoughts and opinions of lesbians and bisexual women.

Crossing the information on placemarks related to same-sex public displays of affection with a positive connotation and their geolocation, discloses some interesting results. The percentages of placemarks on specific regions ${ }^{26}$ of the country (lisbon region, porto, coimbra, interior, littoral, algarve and azores) differ when we compare the overall distribution with the 30 placemarks related to same-sex public displays of affection with a positive connotation (sspda+), as illustrated on graphic 2 .

\footnotetext{
${ }^{26}$ See Pg. 11 for the description of these regions.
} 


\section{GEOGRAPHICAL IMAGINATIONS}

Graphic 2 - percentage of types of content of the placemarks on the web map

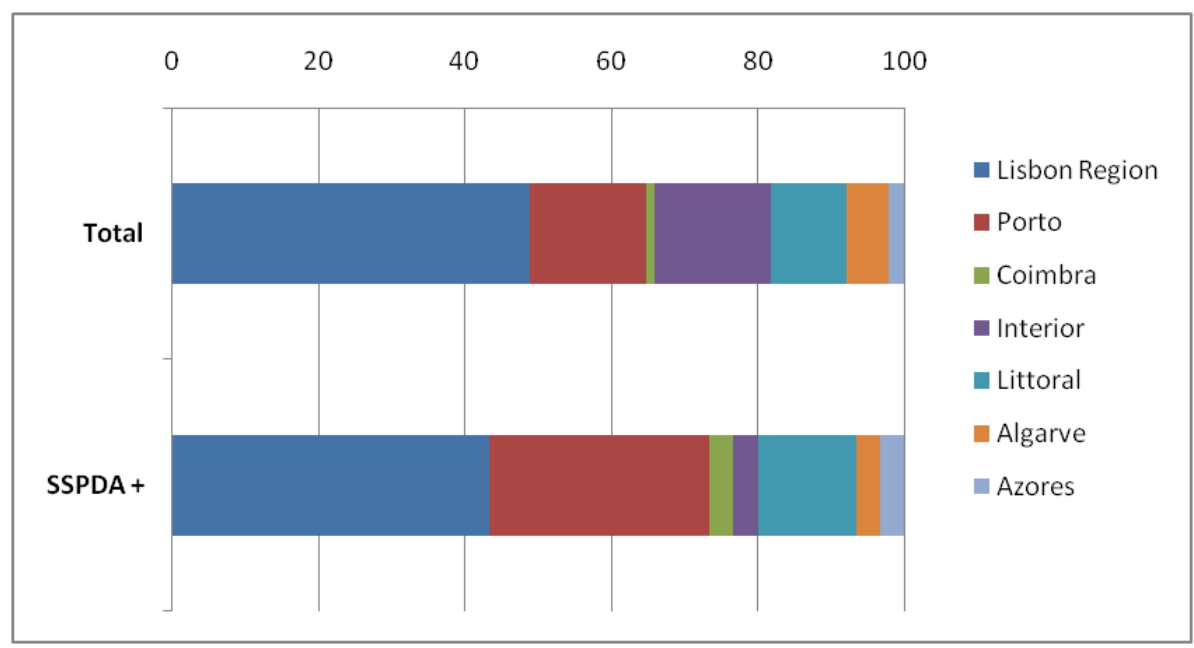

For instance, porto has a higher percentage of placemarks on the universe of sspda positive placemarks $(30 \%)$ when compared to the total placemarks $(16 \%)$, and the interior has a lower percentage (3\% of sspda positive placemarks and $16 \%$ of total placemarks). These data may indicate that georeferenced experiences, emotions, thoughts and opinions of the participants have a different geographical distribution if related to same-sex public displays of affection. Porto relevance on the web map's representation is more significant if we consider positive placemarks on same-sex public displays of affection, and the interior of the country registers the opposite situation. Lisbon region, porto and the littoral are represented on this web map as more friendly to same-sex public displays of affection.

Analysing the words more frequently used on the placemarks (table 1) it is clear that most of the content was related to same-sex relationships: couple(s), girlfriend, dating, kisses and lesbians, are amongst the words most frequently used. These results are in line with the workshop's context and demonstrate that participants did comply with the workshop's objective.

Table 1 - words more frequently used on the placemarks

\begin{tabular}{|l|l|}
\hline Couple(s) & 15 \\
\hline Girlfriend & 15 \\
\hline Dating & 15 \\
\hline To kiss, kisses & 11 \\
\hline Porto & 11 \\
\hline Beach & 11 \\
\hline
\end{tabular}

\begin{tabular}{|l|l|}
\hline Lesbian(s) & 10 \\
\hline Lisbon & 10 \\
\hline Gaze & 10 \\
\hline Lgbt & 8 \\
\hline People & 8 \\
\hline Public & 8 \\
\hline
\end{tabular}




\section{GEOGRAPHICAL IMAGINATIONS}

A particular contribution was quite interesting. In this case it was possible to determine the authorship of the placemarks by the date of their creation and the type of content (given that the placemarks creation was anonymous). This contribution consists on the last 17 placemarks of the web map (on the left sidebar of the google map there is a list with all the placemarks ordered by the day they were created or commented on) and reports a personal history. It illustrates how a web map can tell a georeferenced history; by reading these georeferenced placemarks we can understand the relation of different places with specific episodes of life, states of mind, emotions and individual positionality. We come to understand the path lived by this woman, from her adolescence in a small town characterized by loneliness and oppression, through her university years in porto when her sexual orientation was a cause of distress as well as a trigger to self-awareness and active resistance, passing by some years of suffering and destructive behaviour, the discovery of the independence of having her own house, to a time of change and Igbt activism in the 90's in lisbon. This history fits in the context of the lgbt movement in portugal; it was until the 90's and in lisbon that lgbt associations became relevant and visible.

Summarizing the results we can say that the content of the placemarks indicate that the participants contributed to the web map with their own experiences, emotions, thoughts and opinions related to same-sex relationships. On the online survey participants acknowledged that the 'collaborative web mapping' workshop made them more attentive to the surrounding spaces. The content of the placemarks was mostly positive even when related to same-sex public displays of affection. However the results point to a heterogeneous geographical distribution of positive placemarks related to same-sex public displays of affection. Lisbon region, porto and the littoral are represented on this web map as more friendly to same-sex public displays of affection, in concordance with the results of the previous phases of the research. The collaborative creation of this web map provided a lived representation of georeferenced experiences, emotions, thoughts and opinions of lesbians and bisexual women, and one particular example illustrated how a web map can tell a georeferenced history.

\section{2. 'Layers of visibility' workshop}

A web map with positive lesbians' experiences on public spaces was produced by the researcher with information from 'collaborative web mapping' workshop and made accessible on web browsers and directly on location with mobile devices (tablets, mobile phones). The decision about the area of the map of 'layers of visibility' workshop, parque das nações in lisbon, was made based on information gathered on the first phase of the research "mapping the landscape". This particular area of lisbon has some characteristics suitable for the workshop: it is not identified as Igbt friendly (the objective of the workshop requires a hetero pervasive reality), and it is a cosmopolitan area with lots of people walking by (the cosmopolitism and peoples' presence can provide security - this is particularly important since 


\section{GEOGRAPHICAL IMAGINATIONS}

the map used in the workshop can create the impression of a lesbian friendly area and participants may feel safer to have same-sex public displays of affection).

The placemarks displayed on the map used in this workshop ${ }^{27}$ were selected from all the placemarks created by the collaborators of the 'collaborative web mapping' workshop. The criterion to select the placemarks was related to positive lesbians' experiences on public spaces. Most of the placemarks on the map of 'layers of visibility' workshop (12 out of 16) contain information on positive experiences of same-sex public displays of affection. The placemarks were moved from their original locations (diverse places all over portugal) to ensure collaborators privacy, and their georeferentiation was chosen in order to cover the whole area of parque das nações.

The initial idea was to publish and to gather information on reactions to the map of 'layers of visibility' workshop through facebook. The procedures were: to create a group on facebook (members were selected from portuguese lesbian groups on facebook); to set the privacy level to 'secret group' (only group members can see posts, members by invitation only); to share the "layers of visibility" web map with the wikitude myworld facebook app; and to call for comments on the facebook group about the mapped area (reactions in terms of representation and possible behavioural changes). Wikitude myworld is a feature of the wikitude world browser, announced at the mobile world congress 2012 in barcelona (27 february - 1 march, 2012). Wikitude world browser was the first mobile augmented reality ${ }^{28}$ browser worldwide. It allows the search for points of interest by current position and to view them on a map, list, and on an augmented reality (ar) camera view. With wikitude myworld users can create georeferenced tags to places with descriptions, photos and comments producing an augmented reality (ar) world directly from their mobile device and share it with facebook friends. Places can be created in real time on smartphones or by interacting with a world map via the wikitude myworld facebook $\mathrm{app}^{29}$ on the web. Wikitude myworld is available on android, ios and blackberry handsets. Although wikitude myworld enables the creation and access of information on local (see figure 1 - map of the decision process of designing "creating landscapes" workshops) it requires mobile phones with access to the internet (it is not yet a feature commonly used in mobile phones in portugal ${ }^{30}$ ).

Although the facebook group had 62 members (self identified lesbian and bisexual women), almost no-one commented on the map. Some participants mentioned that they were not comfortable using a facebook app because it requires that the user grants access to personal information. In order to promote participants' reactions to the 'layers of visibility' map it was created an online survey ${ }^{31}$ based on the google maps version.

\footnotetext{
${ }^{27} \mathrm{http}: / /$ goo.gl/maps/jHcp

${ }^{28}$ AR allows the user to see the real world, with virtual objects superimposed upon or composited with the real world. (Azuma, 1997)

${ }^{29}$ Wikitude myWorld Facebook App: apps.facebook.com/wikitude

${ }^{30} \mathrm{http}: / /$ www.anacom.pt

${ }^{31} \mathrm{https}: / /$ sites.google.com/site/layersofvisibility/
} 


\section{GEOGRAPHICAL IMAGINATIONS}

Most of the 23 women who answered the online survey identified themselves as lesbians, live in lisbon region, have at least a graduate degree, and are more than 30 years old. The professional occupation is diversified and in various areas of activity.

It is interesting that not only women from lisbon answered the online survey. Parque das nações is a well known place even for people out of lisbon (this was the site of expo 98 and since then it has been a rather cosmopolitan and touristic area).

The online survey asked some questions about the effect of the web map on: ideas and representation of the area; likelihood to have affective behaviours with another woman in this space; and perception of safety for lesbian and bisexual women. The answers required both the use of a rating scale (from $1=$ not at all to $5=$ completely) and a text.

Graphic 3 - rating scale results (number of answers) of the online survey's questions

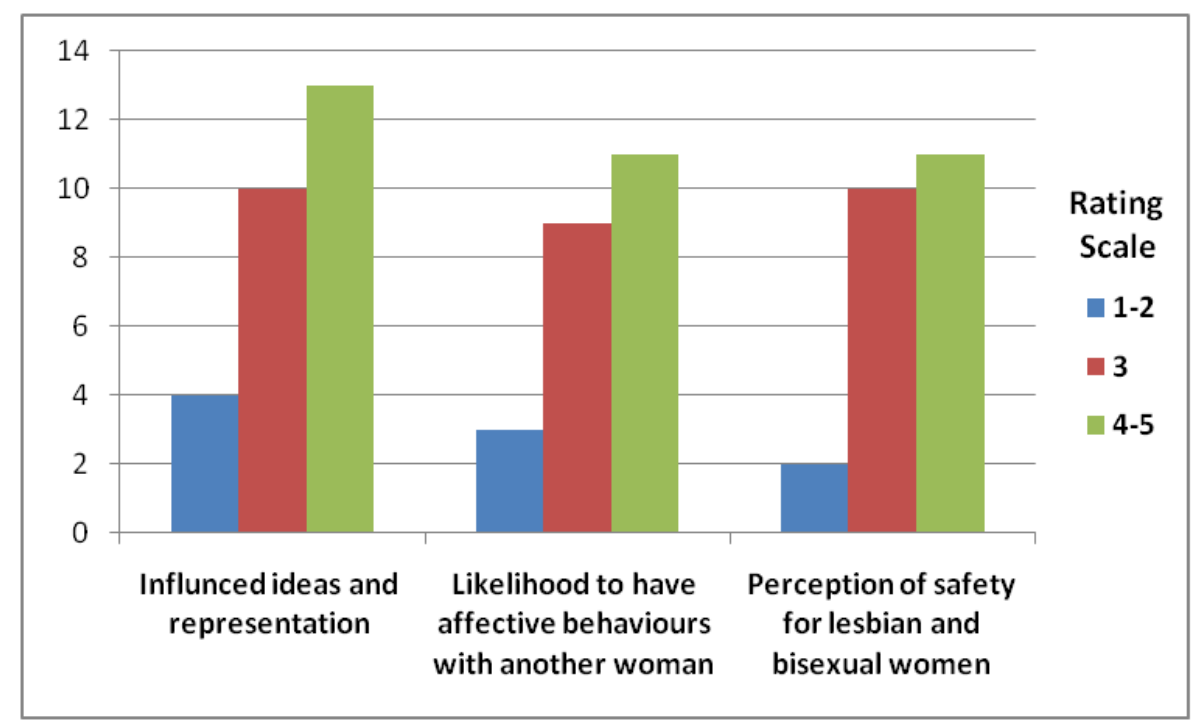

The answers to the rating scales (graphic 3 ) indicate that most of the participants acknowledge the effect of the web map on their ideas and representation of parque das nações, namely that they perceive this space as safer for lesbian and bisexual women, and that it is more likely to have same-sex public displays of affection.

The text answers contribute to better understand the effect of the web map on the participants' representation of parque das nações and possible future behaviour. Some participants explicitly refer to the sense of belonging, safety and joy elicited by the visualization of the web map with positive lesbians' experiences on this public space. The positive emotional reaction to the web map is worth mentioning if we consider that participants (as we all) live in a pervasive heteronormative public space that discriminates non-normative sexual orientations.

It was refreshing and liberating to understand that a space that $i$ know is a space of visibility and affection for people with the same sexual orientation than mine. I feel joy, belonging, freedom. Bisexual, 24 years old 


\section{GEOGRAPHICAL IMAGINATIONS}

One interesting outcome is the increased awareness of the importance of space to lesbians and bisexual women's behaviours. Although the intimate connections between the disclosure of sexual orientation and space have been uncovered and studied by a diverse range of researchers (Valentine, 1993; Mitchell, 2000; Ferreira, 2011) it is worth mentioning that some of the individuals enduring discrimination on grounds of sexual orientation are not themselves aware of this fact.

It seems to me that more people are disclosing their sexual orientation in some areas and it provides a sense of security. I had never thought about the spatial aspects of lesbian visibility. Bisexual, 45 years old

Some participants speculate on the possible reasons for this particular public space to have reports of positive lesbians' experiences, which can point to some scepticism about the reality revealed on the map.

Most of the areas identified on the map, are near the river, which means that only half of the space can have people, restraining the visibility issues. Is this one of the reasons for these behaviours?? At least there no one sees us. On the other hand in this space people may be more absorbed in jogging, cycling or conversations. It is a place frequented by urban people, with a neutral behaviour. It is an area with no apparent risk of adverse extreme reactions. Bisexual, 40 years old

The most evident change on the participants' representation is an increased perception of this space as safer for lesbians and bisexual women. This change is supported by the reasoning that more frequent same-sex public displays of affection can contribute to people's indifference and the corresponding decrease of other's gaze (identified in the first phase of this research as one of the most unpleasant aspects of public space for non-heterosexuals and inhibitor to same-sex public displays of affection).

Because imagining myself surrounded by people who share my ideals can make me feel safer, knowing that there is less likely to be discriminated. Bisexual, 24 years old Given that there is a greater lesbian visibility it is likely to be a safer place. Bisexual, 19 years old

Knowing about the existence of these behaviours among women on this space, $i$ assume that it can contribute to an indifference of "others" towards these behaviours. Lesbian, 40 years old

First, because $i$ do not think people will have any other aggressive behaviour besides staring, then because if more of us do the same, perhaps the gestures become more trivial and less noticed. Lesbian, 40 years old

Another reason for the increased feeling of safety is based on the idea that other people can intervene and support in case of possible negative reactions. This idea is strongly related to a 


\section{GEOGRAPHICAL IMAGINATIONS}

sense of belonging, of being a part of a group of anonymous people that will stand up for you. This kind of feeling is uncommon for most non-heterosexuals in public spaces, if they choose to disclose their sexual orientation, with the exception of Igbt friendly areas or specific time/space events, such as pride marches or Igbt film festivals.

Yes, because $i$ see that there is not as much discrimination as $i$ had imagined, and because the fact that there are more people with the same behaviour than me (affective behaviour with another woman) $i$ think that in this space if there was a case of active discrimination $i$ would feel more protected by this group of unknown people. I imagine that for example before any physical or verbal aggression, $i$ could have reactions of solidarity by same-sex couples who witnessed the situation. Lesbian, 45 years old

Watching and witnessing others experiences feeds our understanding of spaces. Having access to information about other lesbians and bisexual women positive experiences on public spaces can work as a facilitator to same-sex public displays of affection.

Probably $i$ will not be the only lesbian walking around with a girlfriend or wife and if there have been no strong negative reactions to others then it should not be to me. Bisexual, 45 years old

I learned that this space is more welcoming than i thought, because there are other couples at ease, it helps me to feel comfortable too (for kissing, hugging, holding hands). Lesbian, 40 years old

The 'layers of visibility' web map did contribute to change most of the participants' representation of parque das nações, in terms of safety, belonging and increased possibility of same-sex public displays of affection. The most significant change has been the perception of this space as safer for lesbians and bisexual women. One of the arguments for this change in perception is associated with the fact that more frequent same-sex public displays of affection can increase people's indifference to overt lesbians and bisexual women. The increased sense of belonging is particularly relevant and worth exploring in future work, being an uncommon feeling for most non-heterosexuals in public spaces.

Notwithstanding some scepticism about the reality revealed on the web map it is noteworthy that its visualizations has contributed to increase the awareness of the importance of space in lesbians and bisexual women's feelings, attitudes and behaviours.

We are aware that one single experience of being exposed to information on the positive experiences of lesbians and bisexual women is not sufficient to effectively impact peoples' representation, but it can trigger reflection and questioning, which can precede change. However these results support the possibility of using this strategy to promote a non discriminatory public space, in what concerns sexual orientation. Further work is needed to investigate whether these changes endure in time and if the representations and ideas are put into practice and transformed in behaviour. 


\section{GEOGRAPHICAL IMAGINATIONS}

Based on the results of 'layers of visibility' workshop we can assume that this strategy contributes to create landscapes of non-discriminatory public spaces that are more equal and friendly to lesbians and bisexual women.

\section{Conclusions}

Acknowledging that sexuality is a process of power relations which mediates our everyday interactions (Valentine, 1993), and that hegemonic discourses are literally inscribed in public space (Massey, 2005), supports the understanding that the spatial invisibility of lesbians and gays contributes to their disempowerment. Moreover the public expression of non-normative identities, such as those of lesbians and gays, disrupts and therefore exposes the way in which the street is commonly produced as "naturally" or "normally" a heterosexual space (Bell, 2001; Valentine, 2001).

In what concerns discrimination on grounds of sexual orientation there have been significant legal advances towards equality in portugal. A consistent and significant set of legal measures has been implemented, from the decriminalisation of homosexuality in 1982 to the 2010 samesex marriage law. It is a remarkable change, framed by the revolution of 1974 and the accession to the european union in 1986. Portugal has wide-ranging anti-discrimination laws and is one of the few countries in the world to include in its constitution a ban on discrimination on the grounds of sexual orientation. However social discrimination is still a pervasive reality and a number of important areas of legal inequality remain (Agency for Fundamental Rights, 2009).

One of the most pervasive forms of social discrimination is the strong societal pressure to confine and hide lesbian and gay sexuality within private spaces (Valentine, 1993). The results of a recent research conducted in portugal on same-sex public displays of affection indicates that the majority of lesbians and gays tend to confine displays of affection to private spaces (Ferreira, 2011), which supports the understanding that social discrimination on grounds of sexual orientation is a widespread reality in Portugal.

The results of 'creating landscapes' illustrate that lesbian and bisexual women can create new landscapes by sharing and creating geospatial web content with their experiences, emotions, thoughts and opinions on same-sex relationships. Providing a lived representation of same-sex public displays of affection through collaborative web maps and participatory geospatial web can contribute to disrupting hegemonic heteronormativity. Having access to web maps with layers of positive lesbians' experiences in public spaces can affect the perception of safety and belonging and increase the possibility of same-sex public displays of affection. Virtual layers of positive lesbians' experiences on public spaces can facilitate the occurrence of same-sex public displays of affection, and more frequent same-sex displays of affection on public spaces feedsback the way these spaces are perceived on a cyclical process that can contribute to a more equal and non-discriminatory space. 


\section{GEOGRAPHICAL IMAGINATIONS}

\section{References}

Agency for Fundamental Rights, 2009. Homophobia and discrimination on grounds of sexual orientation and gender identity in the EU member states. Wien: European Union Agency for Fundamental Rights.

Airantzis, D. et al, 2008. Participatory Sensing for Urban Communities. Proceedings of International Workshop on Urban, Community, and Social Applications of Networked Sensing Systems - UrbanSense08, Raleigh, North Carolina, 4 November.

Azuma, R., 1997. A Survey of Augmented Reality. Presence: Teleoperators and Virtual Environments, August 1997, pp. 355-385,

Barnett, C., 2003. Culture and democracy: media, space and representation. Edinburgh: Edinburgh University Press.

Bell, D. ed., 2001. Pleasure zones: bodies, cities, spaces: Space, place, and society. Syracuse University Press.

Cloke, P., Philo, C. and Sadler, D., 1991. Approaching Human Geography. London: Paul Chapman.

European Commission, 2009. Discrimination in the EU in 2009 - Special Eurobarometer 317. Brussels: European Commission.

Ferreira, E., 2008. A diferença invisível - Abordagem da orientação sexual em meio escolar. Educação Sexual em Rede, 3, Janeiro 08, APF - Associação para o Planeamento da Família, pp 3-7.

Ferreira, E. and Silva, M. J., 2011. Equality policy in Portugal: the case of sexual orientation. In: J. Motmans, D. Cuypers, P. Meier, D. Mortelmans and P. Zanoni, eds. Equal is not enough: challenging differences and inequalities in contemporary societies. Antwerp: Policy Research Centre on Equal opportunities, University of Antwerp - Hasselt University, pp. 142-155.

Ferreira, E., 2011. Geographies of (in)equalities: space and sexual identities. In: R. Salvador, R., A. Firmino, C. Ponte and E. Ferreira, eds. Proceedings of Geographies of Inclusion: challenges and opportunities. Lisboa: e-GEO. Available at www.geographiesofinclusion.pt.to/

Goldman, J. et al., 2009. Participatory Sensing - A citizen-powered approach to illuminating the patterns that shape our world. Washington: Woodrow Wilson International Center for Scholars. 


\section{GEOGRAPHICAL IMAGINATIONS}

Harley. J. B., 1988. Maps, Knowledge, and Power. In: D. Cosgrove and S. Daniels eds. The iconography of landscape: essays on the symbolic representation, design and use of past environments. Cambridge: Cambridge University Press, pp.277-312.

Hubbard, P., 2001. Sex Zones: Intimacy, Citizenship and Public Space. Sexualities, 4 (1), pp.51-71.

Lane, G. et al., 2005. Urban Tapestries - Public Authoring, Place and Mobility. London: Proboscis.

Massey, D., 1999. Spaces of politics. In: D. Massey, J. Allen and P. Sarre eds. Human geography today. Cambridge: Polity Press.

Massey, D., 2005. For Space. London: Sage.

Mitchell, D., 2000. Cultural geography: A critical introduction. Oxford: Blackwell.

Roush, W., 2005. Social Machines: Computing Means Connecting. Technology Review, 108(8): 44.

Silva, M. J. et al., 2009. Adding Space and Senses to Mobile World Exploration. In: Druin, A. ed. Mobile Technology for Children: Designing for Interaction and Learning, Boston: Morgan Kaufmann, pp. 147-169.

Smith, N., 1991. Uneven Development: Nature, Capital, and the Production of Space. 2nd edition. Oxford: Basil Blackwell.

Smith, N., 1993. Homeless/Global: scaling places. In: J. Bird, et al. eds. Mapping the futures: Local Cultures, Global Change. London: Routledge.

Valentine G., 1993. Negotiating and managing multiple sexual identities: lesbian time-space strategies. Transactions of the Institute of British Geographers, New Series 18, pp.237-248.

Valentine, G., 2001. Social Geographies: Society and Space. Harlow: Prentice Hall.

Valentine, G., 2007. Theorizing and researching intersectionality: a challenge for feminist geography. The Professional Geographer, 59(1), pp.10-21.

West, C. and Fenstermaker, S., 1995. Doing difference. Gender and Society, 9(1), pp. 8-37.

Wood, D. and Fels, J., 1992. The power of maps. New York: Guilford Press. 
GEOGRAPHICAL IMAGINATIONS 


\section{GEOGRAPHICAL IMAGINATIONS}

\section{Francis Bacon and the body beyond the representation}

Camila Xavier Nunes, Federal University of Rio Grande do Sul; University of Minho

camilagauche@gmail.com

\section{Transgressive in life and art}

The job of artist is always to deepen the mystery. Even within the most beautiful landscape, in the trees, under the leaves, the insects are eating each other; violence is part of life. ${ }^{32}$.

Francis Bacon (1986)

Working with bacon's universe - both fascinating and frightening - is to break up the surface and discuss the deeper layers of body materiality and senses. ${ }^{33}$. Lucy Figueiredo (2007)

On october $28^{\text {th }}, 1909$, Francis Bacon was born in the city of Dublin, son of english parents and namesake of the elizabethan philosopher, essayist and statesman - who was a distant relative, according to his mother. In the early twentieth century, Ireland was undergoing major events: the nationalist movement sinn fein boosted the election of several irish representatives in the british parliament who decided to proclaim the unilateral independence of Ireland in 1919. After two years of confrontation, the british signed a treaty in which they recognized the independence of Ireland. Still, the conflicts were far from extinct. The tumultuous Ireland of his childhood inspired his sense of disdain, a recollection that he associated with the hostility of a country in constant conflict and the brutality of an extremist father - "Bacon harbors within himself all the violence of Ireland, and the violence of nazism, the violence of war" (Deleuze, 2007:21) ${ }^{34}$.

His father, Eddy Bacon, whose temper was intolerant and violent, was a veteran of second boer war, reaching the position of captain, later becoming a race horses trainer. His mother Winnie, heiress of business in the mining and steel area, held a position diametrically opposed to her husband's. Francis Bacon was an asthmatic child with several allergies to dogs and horses; and often, during the asthmatic attacks, had to resort to morphine. Due to his fragile health, he was under the care of the family's nurse and was educated at home by private tutors. Since he was a child, he enjoyed dressing well, and this, along with his manner, which was considered effeminate by his father, created a great distance between both. Eddy Bacon made use of violence on the grounds of "making him a man" - whipping his son as one of his horses. In

32 Translated by the author.

${ }^{33}$ Translated by the author.

${ }^{34}$ Translated by the author. 


\section{GEOGRAPHICAL IMAGINATIONS}

response to parental aggression, Francis Bacon made public his secret meetings with employees of the stable.

The family moved several times, alternating their homes between Ireland and England. After the $1^{\text {st }}$ World War, his parents eventually returned to Ireland and Francis Bacon was sent to live with his maternal grandmother and her husband for a time. His only experience with formal education, related to painting, was the time when he attended dean close school (Cheltenham England), between the years 1924 and 1926. Still in 1926, a dramatic event significantly marked his personal trajectory: Francis was surprised by his father wearing his mother's underwear in front of a mirror.

The expulsion of the house seems to have been the cause of unpleasantness, as the relationship with his father was dubious and conflicted - he felt repulsion and attraction of his father. Alone, he went to London to establish a new life, he kept a simple life with the allowance sent by his mother and was an enthusiastic reader of Friedrich Nietzsche. After working in jobs that did not please him, he discovered that his refined taste attracted wealthy men, and he eventually took advantage of this situation. Francis became involved with a former soldier, a close friend of his father, who also bred racehorses. They went to Berlin together, but the former soldier quickly returned to Dublin, as Eddy Bacon was aware of his friend's manly fame, but he did not know about his attraction to younger men.

Once he got enough money, Francis left to Paris, where he lived for a year and a half. The parisian cultural effervescence fascinated him, during the week he used to go out to see art exhibitions five times or more; in 1927, an exhibition of Picasso's paintings awakened his artistic interest, and he began to join a circle of bohemian painters and writers who rejected traditional values, especially in the company of the painter Lucian Freud. During this period, besides working as a painter, he was also interior decorator and furniture and rugs designer - he dedicated himself exclusively to painting from 1933.

His first solo exhibition held in 1945 at the Lefebvre gallery, shocked people and was not well received. The postwar european society was tired of war and its horrors. Bacon was obsessed by the pictorial language and the thematic references of past painters like Velazquez, Michelangelo and Van Gogh. Bacon is a great admirer of Rembrandt because he painted people as if they wanted to say something through their gestures and facial expressions sometimes animalistical expression. The excessive concern that bacon possessed with the light and the color is an indicative of the influence of Rembrandt exercised in his work (figures 1 and 2). 


\section{GEOGRAPHICAL IMAGINATIONS}

Figure 1. Rembrandt - the carcass of an ox (1657)

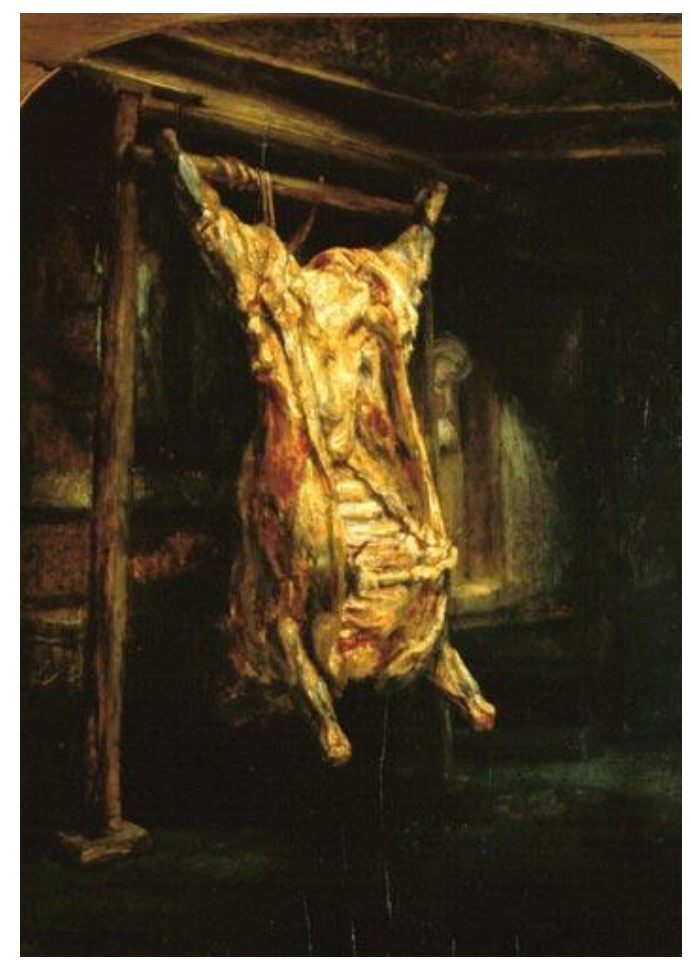

Figure 2. Francis Bacon - figure with meat (1954)

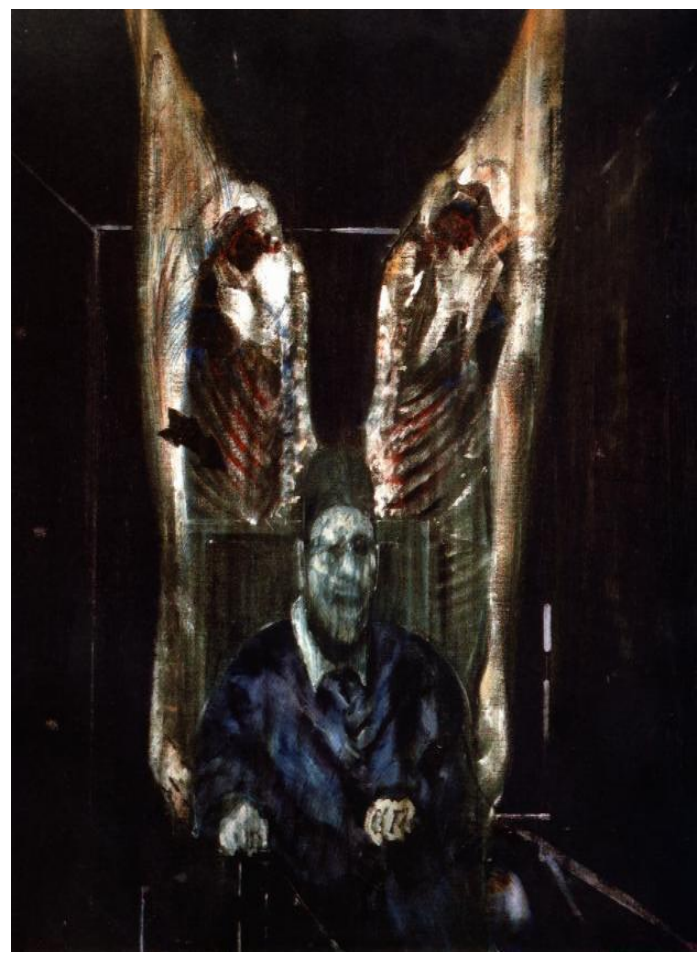

Screens with blood hues, dismembered bodies, sexual perversion, obsession with body representation, especially in physiology and pathology of fluids (blood, semen, urine, bile) produced more disgust than admiration. The violence was present in his works in a visceral 


\section{GEOGRAPHICAL IMAGINATIONS}

manner. Since the beginning of his work as a painter, bacon addressed the horror with extraordinary vigor and a minimum of complacency. This is due to his repressive parenting, the troubled relationship with his father, the socially rejected homosexuality, aspects that are presented in his works through male violence associated with homoerotic tension. The exposed flesh as a metaphor to animality, which modern society insisted to isolate; his transgression was directed to topics such as sex, religion or any other social taboo that, despite of being related to everyday life, still shock. The subject represented and the real subject that serves as a reference to identify with one another in a abstract synthesis: "it is bacon's painting that best demonstrates the indiscernibility between concept and thing" (Carvalho, 2007:10) ${ }^{35}$.

\section{Painting forces: sensation-image and nerve stimulation}

I always think of myself, not so much as a painter, but as e medium for accident and chance. ${ }^{36}$

Francis Bacon (1986)

The power of the painting precisely lies in this ability to directly reach the nervous system without the mediation of the brain, inherent mediation to images that illustrate or narrate something, in which the effect is almost retarded or deferred. ${ }^{37}$

Nuno de Carvalho (2008)

In an attempt to isolate the figure from the viewer's imagination (voyeur), the painter creates an aesthetic environment that resembles a completely empty translucent box as it integrated an extension of its perspective, and from the chromatic surface dissolved the spectator-subject and led him to a passive vertigo (figures 3 and 4).

\footnotetext{
35 Translated by the author

${ }^{36}$ Translated by the author.

${ }^{37}$ Translated by the author.
} 


\section{GEOGRAPHICAL IMAGINATIONS}

Figure 3. Francis bacon -figures in movement (1976) Figure 4. Francis bacon -study for red pope (1950)
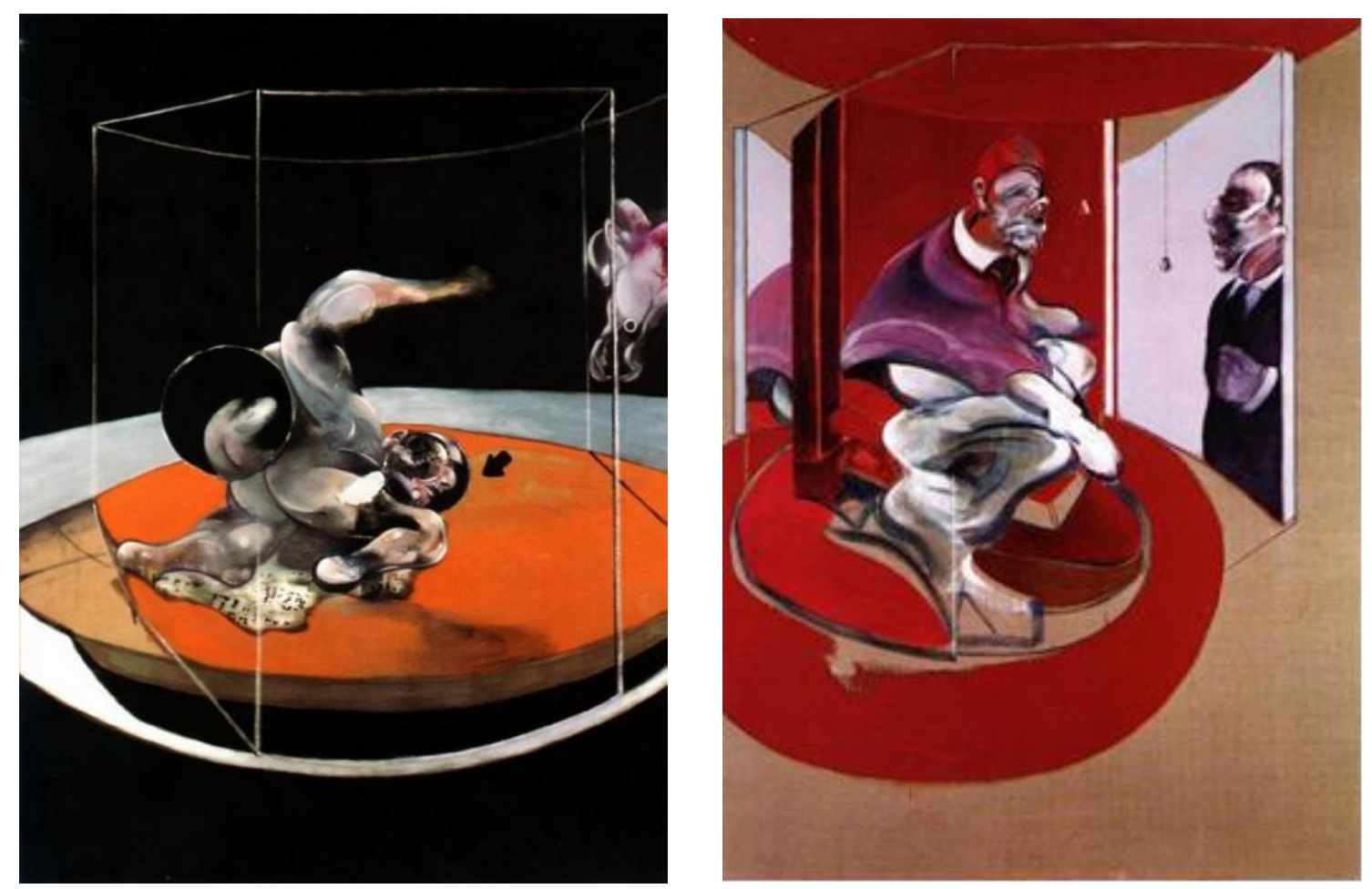

The Francis Bacon's work breaks some paradigms of visual arts when exposing the clash of forces originated by society under two dimensions: the rationalist and the organicist. And, at the center of these forces, bodies lie sustained in acetic and dismembered spaces in the struggle for an idealized stability, but never achieved (Rocca, 2004) ${ }^{38}$. The intersubjective relationship established between artist-artwork-spectator by the sensations aroused, the depth is more to the sensory activated than to the perspective / angle or in the techniques applied - his work is not limited to painting; it is also the intersubjectivity between artist, image and spectator-subject. The art is not only as an object of enjoyment of something linguistically assimilated, but it is a sensory and perceptual experience that affects and destabilizes the individual / the spectator.

The problem that bacon faces in painting is stated in interviews with David Sylvester - a document to which Deleuze frequently resorts and it is constituted from the creation of images that directly reach the nervous system through the violence of a sensation (Carvalho, $2007: 16)^{39}$.

\footnotetext{
38 Translated by the author.

${ }^{39}$ Translated by the author.
} 


\section{GEOGRAPHICAL IMAGINATIONS}

Bacon brings to the human nervous system levels of sensation aroused and situates violence in the flesh -he painted with the intent of outsourcing some internal body images. Bacon moved away from representation and narrative, there were no feelings, but impulses and affectations, because they first act on emotions and then reveal the fact: the existentialism of exposed flesh deterritorializing the representation. His painting was not a means to imitate reality, but a means to expose the most intimate and instinctual needs of the human being, dominated exclusively by the deep brutal force of sensation (Deleuze, 2007). Then, what would the sensation be to Francis bacon? The sensation would be something that passes from an "order" to another, from a "level" to another, from a "domain" to another. It was not the movement that will explain the sensation levels, by contrast, the levels that would explain the sense of movement. But, for the artist, painting the sensation was extremely difficult for not knowing how the paint directly touched the nervous system -the reason that made him destroy many of his paintings.

Therefore, painting the sensation goes beyond the organicist view of body representation which presents it as a fixed and structured object -, it breaks with the illustrative, avoiding the narrative image. The image-feeling is not located on the visuality of the screen, but the sensations it arouses. What was more explored was the "image of pain," without using a narrative that already contains a meaning to be interpreted, but from pictorial elements that arouse a range of feelings - depending on the interactivity the spectator has with his work.

The main contents of the mind arise from the ability to generate neural maps in the brain that are composed of visual, auditory, olfactory, tactile and internal images; they are basic feelings we have of our own body that are directly associated with somatic regulators (basic actions selfregulating organism). As these mappings are realized their own circuits of the nervous system are in process of constant modification, "then the basic principle is that every form of behavior and experience are possible to be associated with different brain structures" (Varela, Thompson, Roch, 2001:33) ${ }^{40}$.

Through internal images that emanate from the body, the conceptual construction is first established in the body from the apprehended experiences, it is in the dialogue body-mind-brain that building-images are established and are the basis for the embodied mind. According to neurologist António Damásio (2000), the brain produces two kinds of body images: images of flesh originated from inside the body (visceral and interior) and images of special sensing waves derived from peripheral sensory organs (retina and/or ear). The internal images are derived from body states that are ongoing, and the representations are closely related to the regulation of body, to survivaland to mind and seized by the sensory-motor apparatus. The subjectivity of human mind is also the capability of creating images resulting from this flow.

The logic of sensation is opposed to a work of representation. If the representation imposes a mimesis relationship between screen space and real space, where the first would seek to reproduce the shapes of

\footnotetext{
${ }^{40}$ Translated by the author.
} 


\section{GEOGRAPHICAL IMAGINATIONS}

the latter, a sensation-image, as Deleuze seeks to glimpse into bacon, the important thing is, rather than reproducing forms, presenting, without the mediation and distance implied in the representation, forces (Carvalho, 2007:23) ${ }^{41}$.

If the brain generates minutely organized representations of any part of the organism, human subjectivity and the consciousness of existence itself would be excluded from the process of creating body images - the sensory-motor system and the abstract reasoning are not instances separate in the human constitution. A suspension of body mapping also suspends mind. Body awareness occurs through the states in which it is located, it does not come in parts. Thought is founded from a stream of images, "we have the perception of a certain state of the body along with the perception of a certain mode of thinking" (Damásio, 2004:96) ${ }^{42}$.

The sensation-image produced by bacon is distinguished from the image-meaning because it does not undergo a work of interpretation that tries to restore a narrative thread or reveal a hidden meaning (Deleuze, 2007). Accordingly, the visual sensation becomes one captured invisible force, the representation beyond representation. What is painted is not the thing, but the feeling that the pictorial space can present - the more intense, deeper the resemblance. The greater the alertness of the cognitive system, the clearer the image processing: "when an organism is engaged with the processing of an object, core consciousness arises, also increasing the chance of engaging with other objects" (Damásio, 2000:356) ${ }^{43}$.

The contact with the world materiality through these invisible forces expands the very materiality of the viewer's body. The sensation-image deflagrates the excess of the body presence itself; bacon's painting converts on a hysterical experiment. Precluding the location of the feeling on the represented (image and viewer) is to put into question the very figurative painting, is to break the violence of clichés. The art work is a being of sensation, nothing more.

\section{The disfigurement as a sensible experience}

The painting puts our eyes everywhere: in the ear, the stomach, the lungs (the painting breathes). This is the double definition of painting: subjectively it invests our eye, which ceases to be organic in order to become a mobile and polyvalent organ; objectively, it puts before us the reality of a body, lines and colors liberated from organic representation. ${ }^{44}$

Gilles Deleuze (2007)

\footnotetext{
${ }^{41}$ Translated by the author.

${ }^{42}$ Translated by the author.

44
Translated by the author.
} 


\section{GEOGRAPHICAL IMAGINATIONS}

Bacon paints the flows and fluids of matter exhibiting, at the same time, its ephemeral, fleeting and perishable sides. Twisting and voluntarily turning the picture, he questions not only the image, but also the painting itself as an art of representation, because it considers the image as being more important than the beauty of the painting ${ }^{45}$.

Beatriz Siqueira (2000)

The intimacy and strangeness are intrinsic elements, since they do not disguise the reality of the broken body or even the imaginary around its fragmented image: in relation to the body's vulnerability that embodies the fragility of human existence, Francis bacon considered himself a "image maker". His works transcend the pictorial issue, and the objective decentralization present in them assume a fall of the subject from his own centrality by the desire to confront the possibility of representing the human in its figurative intensity. Thus, it replaces the representation of a subjective reality for an objective reality's illusion likely to materialize: the human image has little to do with realism; however, it is not a strictly subjective expression, as it shows the distance between the image and the represented thing in its work. The deformation was the only way for the sensation-image to compete with violence as spectacle. It did not portray the horror itself, but the world, the violence, which has always existed (Deleuze, 2007) 46

The modes of representation in the visual arts can be grouped into three main types: the symbolic, the realistic and the individualized mode - in which the attempt to mimesis of the world is replaced by the analysis of the sign producer subject. The work of Francis bacon approached from this perspective: "the importance of human body representation in art and in all ages is the mutation that it has been suffering nowadays, mutation of which bacon is an enlightening example" (Luz, 2000:306) ${ }^{47}$.

The painting as analogical language operates three basic dimensions (surface, color, body) and bacon's painting is marked by three fundamental dimensions (structure, shape and contour) that converge to the color with the goal of reaching the nervous system in a more violent way. For bacon, the color system was itself a system of direct action on the nervous system: "understanding the phenomenon chromatic requires openness to the contributions of the physics of light, optics, physiology, neurology, chemistry, anthropology, sociology, history, etc..."(Guimarães, 2000:105) ${ }^{48}$.

In his disfiguring method, bacon draws the lines from stable forms of a significant, he invents other links -in a move that destabilizes and creates other connections of great aesthetic

\footnotetext{
${ }^{45}$ Translated by the author.

${ }^{46}$ Translated by the author.

${ }^{47}$ Translated by the author.
}

${ }^{4}$ Translated by the author. 


\section{GEOGRAPHICAL IMAGINATIONS}

intensity, he composes images under non-rational marks. Eros and thanatos, the instincts of love and death, direct the shapeless masses of sensations in the imagery composition. A series of the spasms are portrayed by bacon - with its involuntary, violent and sudden contractions involves love, blood, nausea, vomit, excrement, visual metaphor of the body which tries to escape by one of its organs in order to meet the canvas of chromatic intensity again, the material structure.

From the disfigurement, bacon - rather than formal correspondences of classical art - sought to create a zone of indiscernibility between the human and the animal: he engaged in pictorial dissection of the body to expose the weakness of the flesh, to deconstruct stereotypical discourses of masculinity and gender in a kind of self-destruction of the human anatomy - the body does not harbor the idea of itself anymore. The covering rupture that delimits and makes explicit the corporal space discloses, by means of layers, the depressions and the volumes of anterior geography, while it exposes the depth and the body's chaotic and strange framing (figure 5).

Figure 5. Francis bacon - three studies for a self-portrait (1979-80)
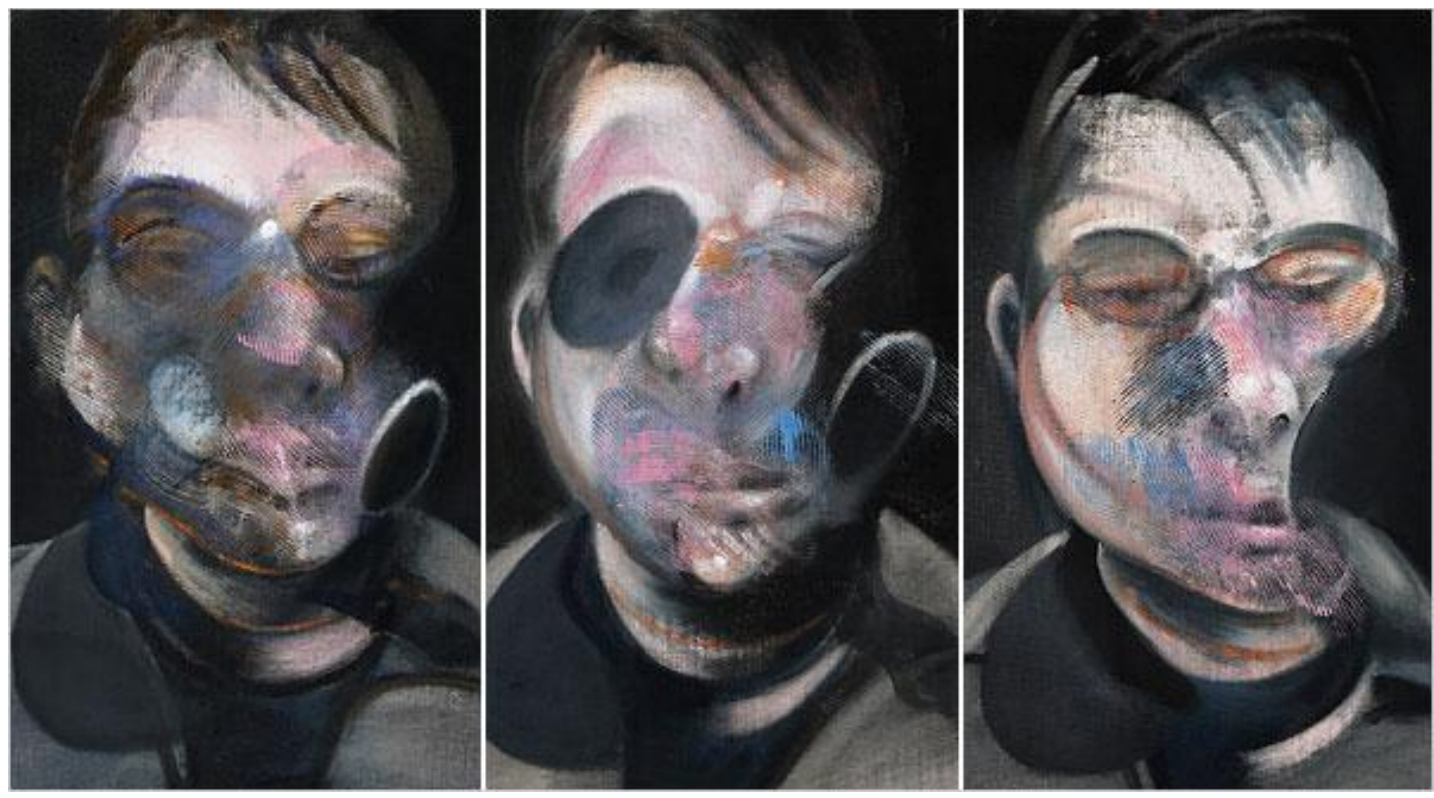

His portraits are disportratis, because they do not identify, but justify a strategy of space occupation by the body due to the fractal virtues that this space offers. The body loses the contours, but remains uncertain of its probable configurations (Silva, 1999:108) ${ }^{49}$.

The deformations are not the result of tortured bodies, but of most mundane postures and gestures possible; the body is glimpsed as a basis for meaning that dissolves in a territory of

${ }^{49}$ Translated by the author. 


\section{GEOGRAPHICAL IMAGINATIONS}

possibilities - "the dichotomies of body and affections rise side by side, pointing to what emanates from this body, in which the skin-case rupture suggests the deconstruction of appearance and the surface" (Figueiredo, 2007:74) ${ }^{50}$. Francis bacon constantly claimed that the shadow was as present as the body. It acquires this presence because it escapes from the body: the shadow is a body that escaped by either point located on the contour. Bacon breaks with the organic representation of classical art by disembody bodies, freeing them from their inertia and the materiality of their presence - "in this sense, it becomes an archaeologist who digs the human body, in a frantic search for what escapes it, for what is hidden beyond the surface" (Figueiredo, 2007:74-75) ${ }^{51}$.

After the advent of photography, modern painting passed through a very complicated situation regarding the break with figuration: the images captured by the camera lens presented the "visuality of the material world" - the photography in social discourse was made for illustrative and documental function. For Francis bacon, the photography could go beyond the representation illustration-representation-narration, as the experiments he performed with photography and painting. Despite nurturing a passion for photography, he gave no aesthetic value to this art; he would prefer the ones that brought the most banal everyday actions and images that were under other means such as radiographies or medical boards (figures 6 and 7). Through photography, he composed portraits of models and studied old paintings. "the photograph, according to the artist, is not limited to a merely analogical function, but it is connotative, constructing new meanings and often functioning as an artifact trigging new ideas" (Figueiredo, 2007:75) ${ }^{52}$.

Figures 6 and 7. Photograph of Francis Bacon's studio at 7, reece mews. 1998, ( P Perry Ogden
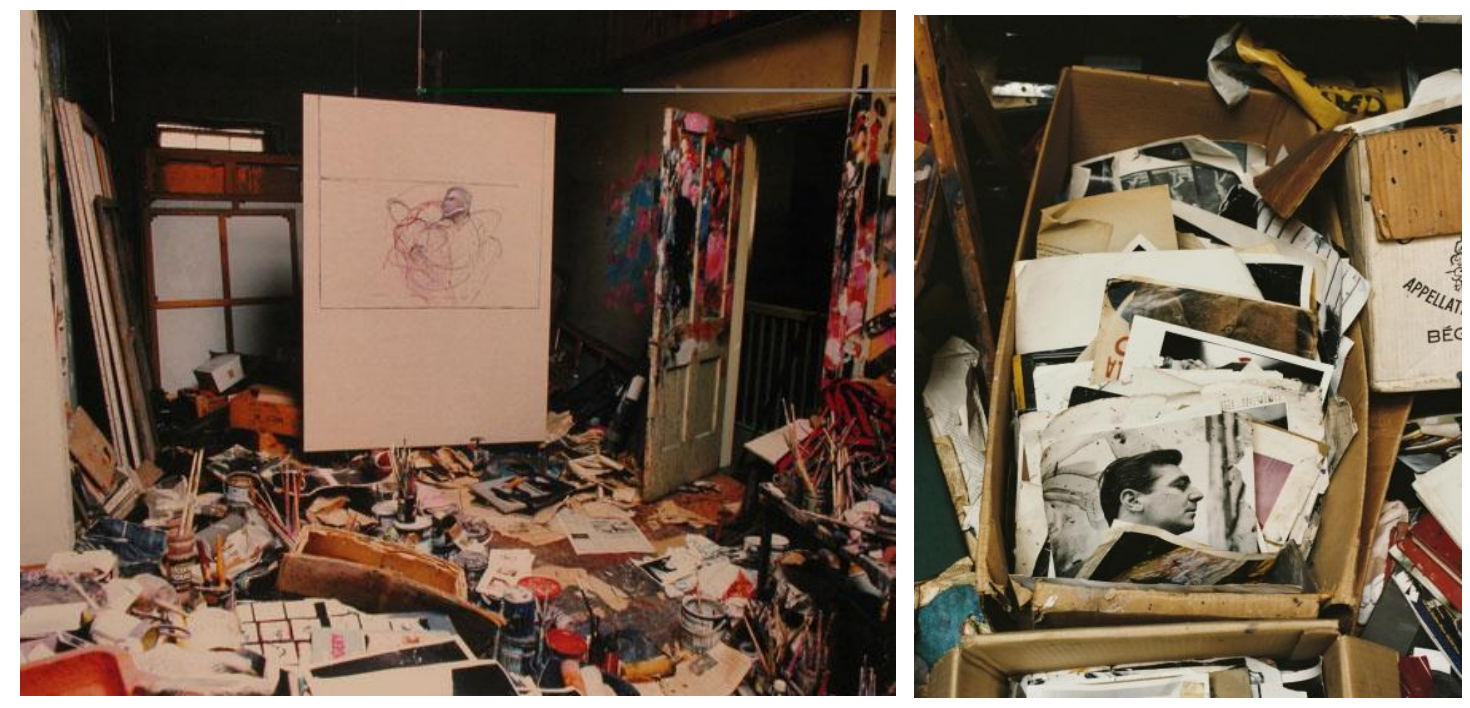

${ }^{50}$ Translated by the author.

52 Translated by the author. 


\section{GEOGRAPHICAL IMAGINATIONS}

In bacon, the person is not only the spectator of things, things that affect the nerves of the audience, which makes it a witness-body. Contemplating bacon's painting is like looking at a mirror and metaphorically see our own afflictions, our own fears: loneliness, failures, humiliations, perversions, oldness, death, unspeakable and threatening disasters (Luz, 1998) ${ }^{53}$. Analyzing bacon's painting is not just a technical issue, but it is also a matter of language: painting the horror as a visual narrative is different from painting horror sensation as a nerve impulse.

The artist claimed that it was necessary to decide between the spectacle's violence or the sensation's - and it is clear that bacon explicitly chose the latter. His painting's task was extracting from the social organization of the face independent and autonomous picturality traits that bring aesthetic intensities and bring to "light and color", creative forces that print to life the power of becoming. How to make visible the invisible forces? Freeing the bodies of their inertia, from the materiality of their presence - pictorially, disembodied bodies. Deconstructing the superficial view of the object and overcome appearance through image distortion is the way the representation-body desecrates itself.

\section{The triptychs: the aesthetic limits of time, space and body}

Art is a method of opening up areas of feeling ... a picture should be a recreation of an event rather than an illustration of an object

I would like my pictures to look as if a human being had passed between them, like a snail, leaving a trail of the human presence and memory trace of past events as the snail leaves its slime. ${ }^{54}$

Francis Bacon (1986)

There are so many movement in bacon's paintings that the law of the triptychs can only be a movement of movements, or a state of complex forces, in as much as movement is always derived from the forces exerted upon the body. ${ }^{55}$

Gilles Deleuze (2007)

The bacon's painting drove an unprecedented pictorial transformation and deconstructed the iconographic meaning of the body through disperser hysteria of conventions and stereotypes. A return to the animality by the desecration of the flesh, through its dissection presents its fragility. His work brought a new order of the pictorial world through what he called "disalienation of clichés" - the screen is not in blank, but it is always filled with cliché. According to Deleuze e Guattari (1995), the color, the line and the surface constitute three representing metaphors

\footnotetext{
${ }^{53}$ Translated by the author.

${ }^{54}$ Translated by the author.
}

${ }^{55}$ Translated by the author. 


\section{GEOGRAPHICAL IMAGINATIONS}

toward an aesthetic signs archeology. They produce a sensation of a tactile view: light is time and space is color. The passage of time by the luminosity's variation and the chromatism that creates new spatialities - the maximum of light unit and color aiming at the maximum of shape division (figures 8,9 and 10).

Figure 8. Francis bacon - three studies for a crucifixion, 1962
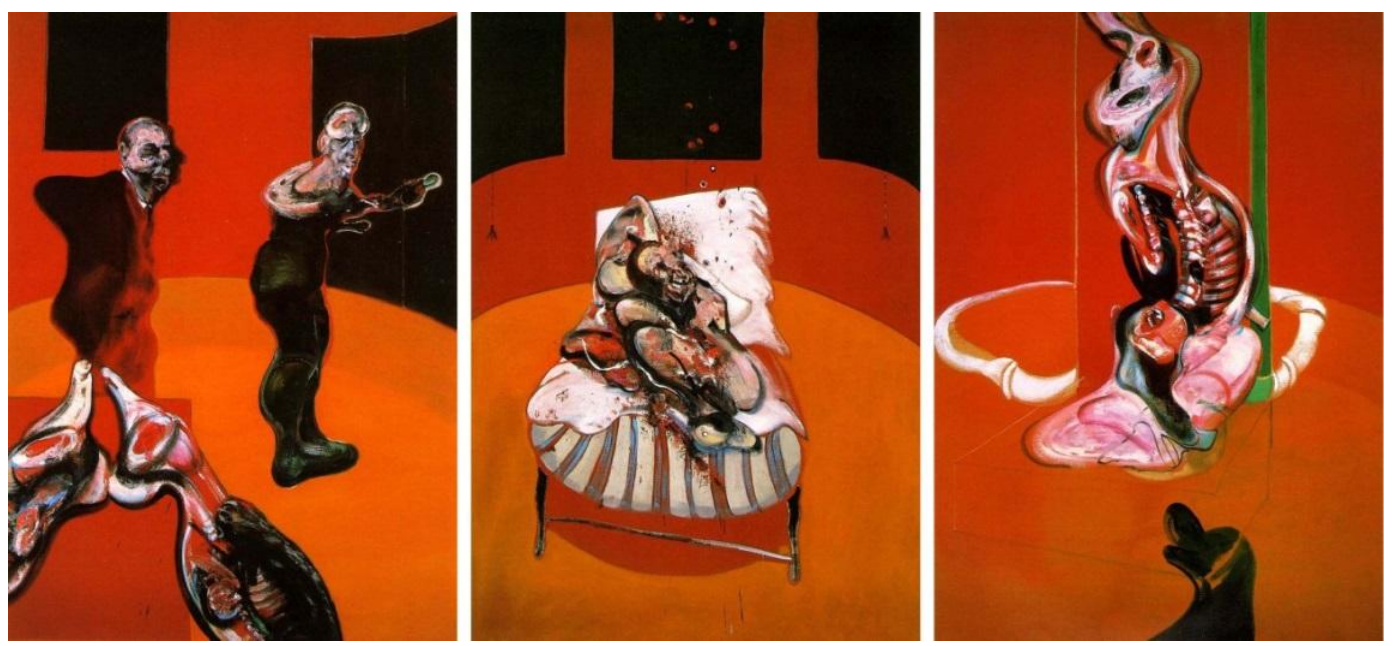

Figure 9. Francis bacon -triptych (1974-77)

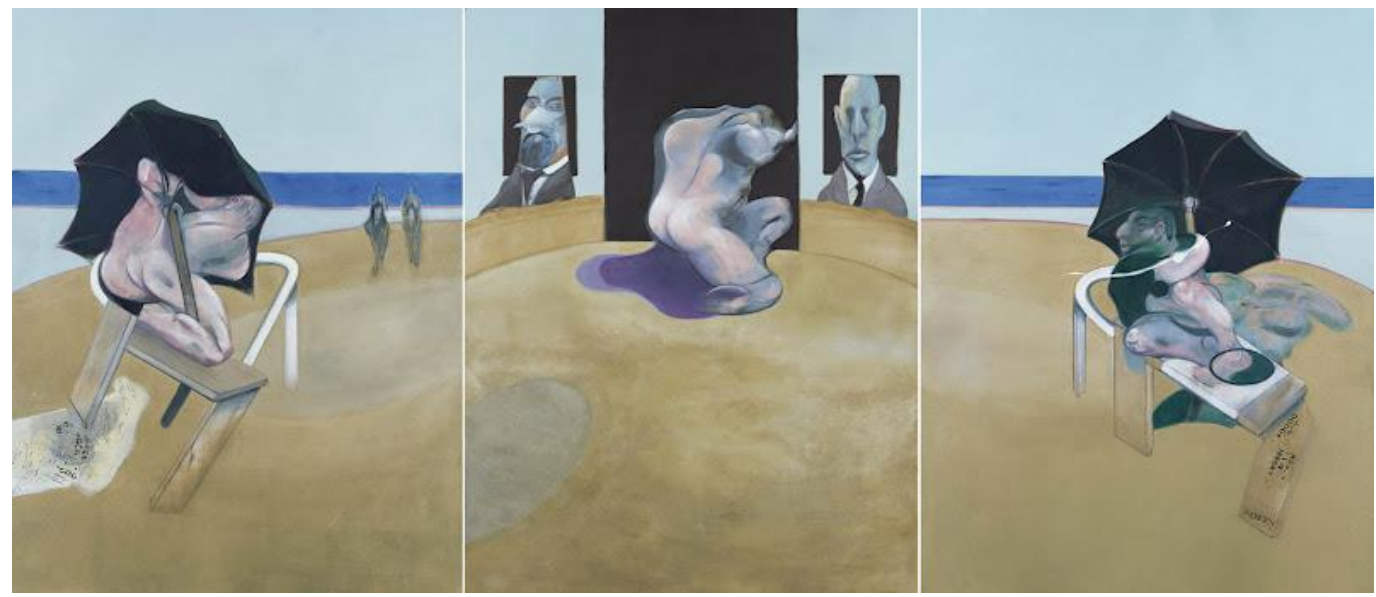




\section{GEOGRAPHICAL IMAGINATIONS}

Figure 10. Francis bacon - three studies for figures at the base of a crucifixion (1944)
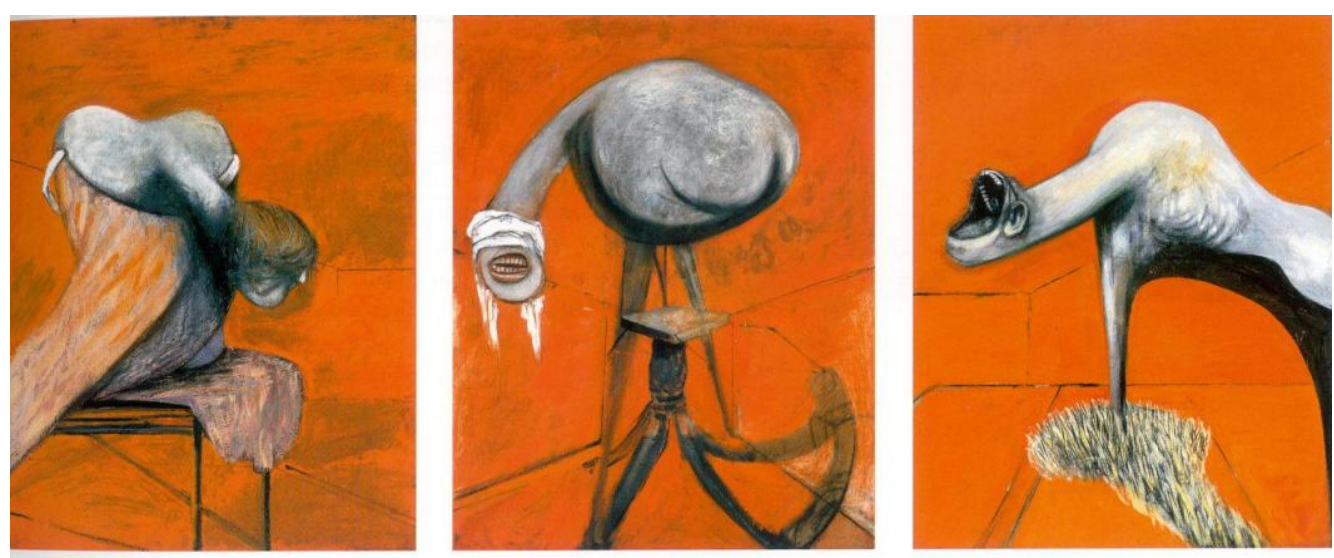

The triptych of three movable frames that coexist as mobiles form a scenographic structure spatial that gives support. There's something moves in happening - "the triptych is undoubtedly the form in which the following demand is posed most precisely: there must be a relationship between the separate parts, but this relationship must be neither narrative nor logical" (Deleuze, 2007:36) ${ }^{56}$. Bacon, when making his triptychs, introduced the notion of a third space: surfaces fall over each other, creating a tenuous depth, combined with a non- purist treatment of color. In his paintings, there was not an ordering through narrative elements: the colors are mixed and do not delimit the object anymore, and bodies are out of balance, state of permanent fall.

The color, line and surface are the place in which the energetic movements of pictorial space circulate, originating to two fundamental tensions: diastole and systole - muscular contraction that changes in a period of rest. The heart impulse as a metaphor for the image that comes to life from the movement pictorially built - series of crucifixions, series of popes, series of portraits, self-portraits, etc. Deleuze (2007) - stresses that there is a diastole in the systole and a systole in the diastole, and it is by the intersection of all these dynamics the pictorial space can capture forces and present sensations. The heart impulse as a metaphor for the image that comes to life from the movement pictorially built - series of crucifixions, series of popes, series of portraits, self-portraits, etc.

\section{Some considerations}

"the art provokes cracks in which the species, the genders and the places have disrupted its contours, providing vivid lines, flows and modes of expression that promote the production of singular modes of existence, unique existences" ${ }^{57}$

Ana Godoy (2008)

${ }^{56}$ Translated by the author.

${ }^{57}$ Translated by the author. 


\section{GEOGRAPHICAL IMAGINATIONS}

"dissected bodies as Rembrandt or tortuous as Francis Bacon, painted as Yves Klin (manifestation of body-art), refurbished, resined and plastinated as Von Hagens, surgically modified as orlan, all these artistic procedures in one way or another are leading the human being to think about new concepts inwhere sciences are hold hands to the arts not only in demand of better days, but also looking forward to disarticulate the humanity and the concepts of ethics in our society" ${ }^{58}$.

Grace Ramos (2005)

The body, throughout the history of human civilization has been the subject of representations as a result of social and hierarchy relations established in the geographic space. In western societies, in particular, the representations and subjective processes are closely linked to the evolution of technique and institution of collective imagination. In western art, the painting was taken as image-concept, unlike the eastern painting, which is not thought of as a representation. For its cultural complexity, the temporal-spatial dynamics generate different investments over the body, investments that can be understood by means of an analysis of the evolution of the techniques of representation in the visual arts and their influence in the composition of new subjectivities.

In classical antiquity, predominates the plastic ideal of the classical aesthetics, the body was glimpsed as artwork resulting from social practices: its forms should be represented with the highest possible realism and the proportions served as geometric patterns meticulously calculated and projected to a scale of the city. The human anatomy and physiology were parameters for the development of technical objects, urbanistic plans and architectural masterpieces, as well as, the body images were bases for analogies that take part in the western thought. In the middle ages, the body was sacralized as a representation of god who created man in his image and likeness. The body distant from the classical ideal of beauty by iconoclastic practices would become unplayable, the concealment of the body was not just by the clothes, but also by the containment of cultural life and the retreat of collective space. The renaissance was an important period of transition from medieval structure for the royal court societies because it allowed a greater social mobility both in referring rises in social and geographical displacements.

Since the renaissance period, the centrality of vision and the production of subjectivities reveal relationships that are established between the subject's body and the systems of meaning and power - which made the space more accurate and geometric and less feasible to religious and mythological conceptions. A pictorial representation was not only lined through the observer's point of view, but also through cartesian principles of rationality, "creating a fixed presence for the subject (observer)". This form of having a perspective about the world has come to focus the

${ }^{58}$ Translated by the author. 


\section{GEOGRAPHICAL IMAGINATIONS}

'truth of the experience' on the eye and resulting technologies, making it the center of what was intended to represent" (Azevedo, 2009:35) ${ }^{59}$.

The renaissance discourse detached the human action of the divine work and gave it autonomy, a concept that has significantly changed the way in which the mankind has change the relationship with its own body: it was gradually settling a perception of the body - more functional than religious - as a product of the knowledge progress of anatomy and physiology. The body as the center of the universe, as the foundation that linked the human environment, a new technical imaginary would bring new representations of the body, the emergence of the public man and new forms of disciplinement of bodies. Maps and chronometers would constitute essential instruments to the enlightenment thinkers who appropriated the renaissance conceptions until the last limits of its operation. The enlightenment conception brought the domination of nature as a necessary condition for human autonomy and spatial organization became an integral part of your design world.

In the modernity, the historical evolution of the concept of the body influenced the way in which the human being had learned, represented and intervened in the space, from the development of science, the question of the health of body and health in urban areas. The diversification of modes of sociability, the consciousness of individuality and the technical development allowed the establishment of relations with other space-time. While the enlightenment proposed to remove the human being from the "darkness" and bring it to the "light" of art and knowledge, scientism aimed to prove that the body was a machine of flesh and bone. In western art, the painting was taken as image-concept, unlike the eastern painting, which is not thought of as a representation. If the classical artist believed in the ability to represent the world through rational principles, in modern art each artist sums up his story in his own way, putting at stake the communication between the material basis and the symbolic field and, consequently, the entire history of western painting: "the vanguards of the early twentieth century drive a disintegration of the human figure: questioning the traditional representation, cubists, expressionists, dadaists and surrealists tear and deform human anatomy" (Matesco, 2009:36) ${ }^{60}$.

The modern practices influenced the culture and scientific thought through a new way of seeing the world, living, thinking and representing reality by numerous and fragmented ways. An epistemological change also alters the conception and the world representation. The rupture of the major paradigms involving modern society can be perceived by the emergence of non-linear narratives and metaphors that reflect the whirlwind of experiences involving contemporary society, which could be observed by anaesthetic renewal.

The twentieth century works were first deprived of their representative function; the art that emerged did not limit techniques and materials in the creative process, which was built as part of the work itself. The contemporary body presents itself as a simulacrum of signs with great ability of incorporating new meanings and shifting new meanings. From the second half of the

\footnotetext{
${ }^{59}$ Translated by the author.
}

${ }^{60}$ Translated by the author. 


\section{GEOGRAPHICAL IMAGINATIONS}

twentieth century, the body is worked beyond the dimensions of painting, sculpture and photography and starts to be represented in actions, performances, sensory experiences, organic fragments, which affirms the notion of literal body as particularity of contemporary art.

Francis Bacon is recognized as the "painter of corporeality"; in his work, he deals almost obsessively with the issue of the human body representation and its ethical-aesthetic, biographical and intersubjective implications. His agencements may be constituted of subjectivities, even if they are influenced by already normalized practices. The western body is the image of its own culture. The function of art, according to bacon, is to dispel false perceptions, the visually stereotype demotions, and, therefore, it was necessary to deconstruct pictorially the image-meaning, the body-representation, and space-materiality.

In contemporary times, the crisis of the classic body and the modern body is inevitable, since the boundaries between nature and culture become increasingly blurred; the bios (life) and the psyche (breath) merge into a single body. The big difference perhaps exist in the way how the image production was reversed: until the mid-nineteenth century images sought represented the everyday life lived, currently our actions are constantly challenged by images that become daily references. The plasticity is more associated with excessive availability of techniques and supports than an ontological characteristic: "body image and representation do not have a single meaning, and we can say that western culture is the result of this polysemy" (Matesco, 2009:09) ${ }^{61}$. The choice of Francis bacon is relevant when we consider the space as embodied experience, not only as a representation. That body is situated, located from their relationship through sensitive representations in those subject and object. The art as vanguard of social events breaks with aesthetic standards, narrative and reaffirms the body as existential basis of culture.

\section{References}

Azevedo, A.F., Desgeografização do corpo. Uma política de lugar. In: Azevedo, A. F., Pimenta, J. R. and Sarmento, J. Eds. 2009 Geografias do corpo: ensaios de geografia cultural. Porto: Figueirinhas, pp. 31-80.

Bacon, F., 1954. Figure with meat. In: Ficacci, I., 2007. Francis Bacon. Lisboa: Taschen. [book].

Bacon, F., 1956. Figures in movement. In: Ficacci, I., 2007. Francis Bacon. Lisboa: Taschen. [book].

Bacon, F., 1950. Study for red pope. In: Ficacci, I., 2007. Francis Bacon. Lisboa: Taschen. [book].

\footnotetext{
${ }^{61}$ Translated by the author.
} 


\section{GEOGRAPHICAL IMAGINATIONS}

Bacon, F., 1979-80. Three studies for a self-portrait. In: Ficacci, I., 2007. Francis Bacon. Lisboa: Taschen. [book].

Bacon, f., 1962.three studies for a crucifixion. In: Ficacci, I., 2007. Francis Bacon. Lisboa: Taschen. [book].

Bacon, F., 1974-1977. Triptych. In: Ficacci, I., 2007. Francis Bacon. Lisboa: Taschen. [book].

Bacon, F., 1944. Three studies for figures at the base of a crucifixion. In: Ficacci, I., 2007. Francis Bacon. Lisboa: Taschen. [book].

Carvalho, N.M., 2008. A imagem-sensação: Deleuze e a pintura. Ph.d. University of lisboa.

Damásio, a., 2004. Em busca de espinosa: prazer e dor na ciência dos sentimentos. São paulo: ed. Cia. Das letras.

Damásio, A., 2000. O mistério da consciência. São Paulo: ed. Cia. das letras.

Deleuze, G., 2007. Francis bacon: lógica da sensação. Rio de Janeiro: Jorge Zahar editor.

Deleuze, G. and Guattari, F., 1995. Mil platôs: capitalismo e esquizofrenia. Rio de janeiro: editora 34.

Ficacci, I., 2007. Francis bacon. Lisboa: Taschen.

Figueiredo, I., 2007. Imagens polifônicas. Corpo e fotografia. São Paulo: Annablume. Fapesp.

Guimarães, I., 2000. A cor como informação: a construção biofísica, linguística e cultural da simbologia das cores. São Paulo: Annablume.

Godoy, A., 2008. A menor das ecologias. São Paulo: Editora da Universidade de São Paulo.

Heidegger, M., 1999. A origem da obra de arte. Lisboa: Edições 70.

Luz, R., 2000. O corpo desfeito por Francis Bacon. Nat. Hum, 2(2), pp. 301-328.

Matesco, V., 2009. Corpo, imagem e representação. Rio de janeiro: Jorge Zahar ed.

Michaud, Y., 2008. Visualizações: o corpo e as artes visuais. In: Corbin, A., Courtine, J. and Vigarello, G. Eds. História do corpo. 3: as mutações do olhar. O século xx. Petrópolis, Rio de Janeiro: vozes, pp. 541-564.

Miranda, J. A. J de., 2011. Corpo e imagem. São Paulo: Annablume. 


\section{GEOGRAPHICAL IMAGINATIONS}

Nabais, J. M., 2009. Rembrandt - o quadro a lição de anatomia do Dr. Tulp e a sua busca incessante pelo auto-conhecimento. Revista da faculdade de letras: ciências e técnicas do património, 7(8), pp. 279-296.

Ogden, P., 1998. Photograph of francis bacon's studio at 7, reece mews. [electronic print] available at: <http://www.perryogden.com/publications/francis-bacon-publications//show/2346> [accessed 18 september 2012].

Peppiatt, M., 2006. Francis Bacon in the 1950s. New Haven: Yale University Press.

Ramos, G., 2005. O corpo como suporte artístico: o homem modificado. Revista Cultura Visual, 1(6), pp.58-65.

Rembrandt, V. R., 1630. The carcass of an ox. [electronic print] available at: <http://images.bridgemanart.com/cgibin/bridgemanimage.cgi/400wm.gls.184330.7055475/3030 2.jpg > [accessed 28 june 2012].

Rocca, A., 2004. Francis Bacon. El cuerpo como objeto mutilado; regresión a la animalidad. In: cyber humanitatis. Revista de la facultad de filosofía y humanidades [online], 0(31). Available: http://www.cyberhumanitatis.uchile.cl/index.php/rch/article/viewarticle/5752/5620 [accessed 9 september 2012]

Siqueira, B., 2000. Ensaio Francis Bacon: um grito suspenso na distorção da imagem in: Escola Letra Freudiana "o corpo da psicanálise", 17(27), pp.51-66.

Silva, P.A., 1999. O lugar do corpo: elementos para uma cartografia fractal. Lisboa: Instituto Piaget.

Sylvester, D.,1995. Entrevistas com Francis Bacon, a brutalidade dos fatos. São Paulo: Cosac Naify.

Varela, F., Thompson, E. and Rosch, E., 2001. A mente corpórea: ciência cognitiva e experiência humana. Lisboa: Instituto Piaget. 
GEOGRAPHICAL IMAGINATIONS 


\title{
GEOGRAPHICAL IMAGINATIONS
}

\author{
Space, Literature and Representation: Identity Construction in 19th Century \\ Portugal \\ José Horta, International School of Braga \\ jose.horta@clib.pt
}

\section{Representations of Irish Space and Identity}

Through the use of different literature venues, both monarchists and republicans defined the Irish as a different race from the English. However, their intentions in doing so were different. Based on physical anthropology, monarchists established a hierarchy and claimed that the Irish race was inferior to the English, thereby justifying the English presence in Ireland (Reis, 1988). The republicans attributed the differences to the attachment to the land, evidence of an Irish sense of place based on rightful belonging, suggesting that the English presence in Ireland was an illegitimate occupation. That sense of place was further emphasised by identifying the West of Ireland and particularly Connaught as the "land of the real Irish" (O Século, 25-05-1882). Johnson claims that the West of Ireland became the cultural heartland of the country and consequently a fundamental element in the construction of Irish nationalism, being exclusive rather than inclusive especially when associated to Catholicism (Johnson in Graham, 1997). Johnson's arguments extend to Portugal and the association of Irish nationalism to place helped the republicans in Portugal to determine equivalent connections and identify spatial niches of cultural heartland such as the regions of Minho and Trás-os-Montes.

Anderson and Connolly identify a political dichotomised organisation of Irish identity after the 1870 s and the 1880 s, the period when the representations of Irish identity were more fiercely contested in Portugal by republicans, monarchists and Catholics. On the one hand there were the Anglican and Presbyterian landlords and tenants, the urban workers and the middle class businessmen. These were brought together by an allegiance to Protestantism and the maintenance of the union, which identified the collective identity of unionism. This unity, however, was weak. Disunity took place at times but cohesion was restored by the violence of 1919-1922. On the other hand there were the Catholic tenants, the landless and the land poor, the farmers and some particular urban groups. These were united by loyalty to historical myth and political symbol, which formed the collective identity of nationalism (Connolly, 1997). Representations of Irish identity in Portugal followed some of these premises but, in most cases, were absolute distortions of the reality. In any case, in a time of Darwinist assumptions and positivist perspectives, they avoided, to a great extent, the temptation of mainstreaming Irish identity into a simplistic racial interpretation.

England's most influential periodicals and newspapers recurrently channelled the depiction of Irish identity to questions of race. They treated the Irish as a kind of an inferior race, "as a kind of a white negro" (MacLaughlin, 1998: 53). The situation in the Portuguese press was quite different. Irish identity, although widely discussed, was never clearly and objectively defined in 


\section{GEOGRAPHICAL IMAGINATIONS}

Portugal. This led to confusion in the Portuguese readership. Catholicism, Protestantism, Celtic ascendancy, the Anglo-Norman influence and an extensive list of traits and characteristics all figured in the disorder. For conservative factions this confusion was useful; it represented chaos and dystopia, ideas that removed the Irish from modernity (Gregory, 1993). Furthermore, the sureness of Irish identity would allow for a defence against the imperial forces of cultural standardisation and colonialism (Lee, 1985). On the other hand representations of the Irish in republican newspapers were incoherent due to the political manipulation of the journalistic milieu by the monarchist governing powers (Franco, 1993). Therefore, it would be naïve and grossly simplistic to assume that there was a clear divide between one or more newspapers that portrayed the Irish in one clearly defined form and the other newspapers that always portrayed the Irish in a contradictory manner. The issue is more complicated than that. Not only was the Irish identity presented differently within the same newspaper, it was also modified over time. Nevertheless, there were certain patterns that were followed by 'O Comércio do Porto' and by 'O Século'. Whether the writers were pro-Irish or pro-British, their analysis of Irish identity was unreservedly spatial. Indeed, in accordance with discourses of racial construction of Irishness, one of the first references to Irish identity in Portugal in the period of analysis indicated the West of Ireland and particularly Connaught as the space of the 'real Irish' within the island (MacLaughlin, 1998). The West of Ireland became a social, political and religious discourse and a propagandistic tool for different factions of Portuguese society including Catholics, liberals and later republicans. Indeed, Elias Regnault in his 1842 book "História dos crimes do governo Inglez desde os primeiros assassinatos da Irlanda até ao envenenamento dos chins" used Connaught as a discourse, alleging spatial segregation carried out by the English in Ireland and conveying distaste for Protestantism and the resilience of Irish identity.

Out of the four provinces which compose Ireland, three were exclusively reserved for the Protestants and the last one for Catholic exile - Connaught. This vast province is separated from the rest of Ireland by the River Shannon. There, plague and carnage emptied and deserted the last asylum offered to the relics of the proscribed nation (Regnault, 1842: 35).

The manipulation of space as an instrument to aid a particular definition of Irish identity was a reality before the 1865 mechanisation of the press industry in Portugal. However, propagandistic books and pamphlets in which that spatial manipulation was already evident were not yet powerful enough for the construction of a widespread Portuguese geographical imagination of Ireland. This only occurred when newspapers embraced the question and influenced public opinion. 'O Comércio do Porto', for example, presented the most severe portrayal of the Irish during the period of analysis, although the representation was not always consistent. The harshest portrayals of Irish identity in this newspaper came from one particular 


\section{GEOGRAPHICAL IMAGINATIONS}

author: Dr E. Oswald. However, Irish identity was not only used for propaganda purposes in the press. Several books were published with the intention of campaigning for or against certain sectors of Portuguese society (Torgal et al, 1998). For example, the liberal Leonce De Lavergne in his 1867 book "Ensaio sobre a Economia Rural de Inglaterra, Escócia e Irlanda" associated the construction of Irish identity with English territorial policies and claimed that the difference between the Irish and the English lay in the administration of the territory. The Irish were frequently described as violent, turbulent and indolent, characteristics provoked by two factors. Firstly, to the frustration caused by non-ownership of the land they loved. Secondly, to the reluctance of England to develop an infrastructure within the island causing geographical isolation and, in turn, recklessness and hostility. Regnault's descriptions of Irish identity were based more on the physical traits of the Irish. He attempted to separate Irish and English identities. Indeed, his references described the Irish ancestors as being corpulent men having "long blonde plaits hanging from both sides of their heads" (Regnault, 1842). His descriptions of the physiognomy of the Irish suggested a hybrid connection between Celts and Normans, intended to separate them from the English, proving that the English were foreign invaders who illegitimately exploited the land.

Consistent criticism of the Irish in 'O Comércio do Porto' was suspended by the Liberal author R. de F., who revealed a different side of Irish identity in the same newspaper. He described England and Ireland as the "domineering (the opulent) and the dominated (the miserable). This difference is the basis for the struggle that has lasted for centuries" (O Comércio do Porto, 2810-1881). Throughout his work the reader is bombarded with pro-Irish and anti-British references. $\mathrm{R}$ de $\mathrm{F}$ attempted to identify other identities similar to the Irish and criticised writers who blamed the situation in Ireland on claimed characteristics of the Irish: their "mental retardation", their "laziness as workers" and their "passionate activity as trouble-makers" (O Comércio do Porto, 30-10-1881). R de F relied again on Mill to argue that no race would accept mistreatment. He claimed that Irish identity was similar to that of ancient Celts and even the Greeks in terms of working commitment.

The Irish are not less able to work than the other French or Tuscan Celts, or ancient Greeks (---). There is no more laborious worker than the Irish in England or America, but he is no cottager. ${ }^{62}$

Divergences between the discourses of the liberal $\mathrm{R}$ de $\mathrm{F}$ and the conservative monarchist Oswald peaked when the No Rent Manifesto was translated into Portuguese in 1881. The No Rent Manifesto, written and signed by Charles Stewart Parnell in Kilmaiham Jail, was widely referred to in the Portuguese press (Bew, 1991). However, the translations published by the two authors in question were very different from each other and from the original. As a result, the

62 In the original: "O irlandez não é menos apto para trabalhar do que os outros celtas francezes, toscanos ou antigos gregos (...). Não há trabalhador mais laborioso que o irlandez na Inglaterra ou na América; mas ahi não é cottager." (R de F, In 'O Comércio do Porto', 30-10-1881). 


\section{GEOGRAPHICAL IMAGINATIONS}

manifesto became an instrument of conflict in Portugal, while Ireland became the battleground for the conflict between old and new Portuguese ideals (Santos, 2007). R de F's translation was a discourse of saviours, heroes, defenders of liberty and human rights who fought for a historically united race. It portrayed the Irish leaders as examples to be followed in Portugal. The translation used by Oswald focused on the manifesto as a discourse of sanguinary rebels geographically spread over the world, representing a global terrorist threat, who disrespected the world and Irish public opinion.

\begin{tabular}{|c|c|}
\hline 'No Rent Manifesto' & 'No Rent Manifesto' \\
\hline As translated by $R$ de $F$ (Pro-Irish) & As translated by Oswald (Pro-British) \\
\hline $\begin{array}{l}\text { "We are all fighting for your country, for your } \\
\text { homes, for your life; a fight that involves all the } \\
\text { memories of your race, all the hopes of your } \\
\text { children, all the sacrifices of your sons under } \\
\text { arrest, (...) for domestic happiness and national } \\
\text { freedom. (...) Stay united in front of the evil and } \\
\text { shameful enemies of our race. (...) Do not pay } \\
\text { any rents and remain passive, firm and fearless } \\
\text { while the armies of England fight hopelessly } \\
\text { against a spirit that soldiers cannot defeat." }\end{array}$ & $\begin{array}{l}\text { "We resolved to voluntarily take action in } \\
\text { Ireland, England and everywhere the English } \\
\text { have any interests. We will actively use } \\
\text { mechanical and chemical means to wage war, } \\
\text { as well as other destruction agents that the } \\
\text { evolution of times may offer us." }\end{array}$ \\
\hline ( $\mathrm{R}$ de F In 'O Comércio do Porto') & \\
\hline
\end{tabular}

The dichotomisation of the Irish rebellious tendencies was common in the representation of the Irish in Portugal, especially until the early 1890s, at which point the monarchist regime restricted the freedom of the republican press (Franco, 1993). Both pro-British and pro-Irish writers sought to define Irish identity as distinct from the English. However, their intentions in doing so differed. Pro-Irish authors asserted that the English were invaders and illegitimate occupiers of Ireland and that the Irish had their own identity, which was inherited from generations prior to the Norman and English invasions of the early second millennium (Foster, 2001). On the other hand, pro-British authors presented Irish identity and its rebellious characteristic as a colonial discourse claiming that the Irish had an identity that was less developed and unsuited to organise a well structured nation (Hall, 1997). They claimed that the Irish had to be controlled and dominated since they could not possibly control their own destiny.

Irish identity as Catholic and Protestant was divided according to spatial criteria. It was grounded in Ireland's territory. According to Portuguese republicans, the Irish space held its constituting elements together. In effect, Portuguese realist writer and consul Eça de Queirós (1845-1900) did not pursue the idea that the Protestant Irish were political or religious enemies of the Catholics but instead saw them as people who shared the suffering that came with living in the same space, enforcing the idea that territorial issues were more pressing and unifying 


\section{GEOGRAPHICAL IMAGINATIONS}

than religious questions for the construction of Irish identity and the respective sense of place (Mitchell, 2000). Since Queirós had no obvious religious persuasion, he did not feel compelled to represent Protestantism as evil and his definition of Irish identity was utterly spatial (Mónica, 2001). He claimed that the Irishman was deeply attached to the soil, "as secure as a tree is by its roots and would often prefer to die rather than abandon the barren strip of land which did not suffice to sustain him" (Queirós, 1970). His descriptions of the harsh nature of Irish soil were recurrent. The Portuguese republican definition of an Irish sense of place was in itself a political discourse and more specifically an anticolonial discourse (Catroga, 1991).

Throughout the 1880s, as had happened with the Irish and Hungarians, the association of the Irish and Portuguese was a strategy frequently used to establish identity connections (Kabdebo, 2001). The views of the Irish and the Portuguese became denigratory but as schemata of racial hierarchy emerged in European thought, these peoples had the advantage of being, at least in most eyes, 'white' (Howe, 2000). However the association was political rather than social. It was a political discourse. That discourse aimed, once again, at attacking both England and the monarchy. The critique of physical anthropology embedded in Darwin's evolutionary theories and their application to England's views of the world was often used to attack the hierarchisation of world races (Livingstone, 1992). According to Portuguese republican authors, including Portuguese republican writer, Jaime Batalha Reis (1847-1935), only monarchist regimes could establish such "in-humane stratification and determine policies according to it" (Reis, 1988). This republican position was, of course, hypocritical since republicans strongly defended Portuguese ownership of the colonies and consequent subjugation of their peoples (Gonçalves, 1917).

The English consider the Irish as an inferior race, not much above blacks or American Indians, considerably below the French, around the level of the Portuguese, Brazilians or Argentineans ${ }^{63}$ (Reis, 1988: 151).

Reis denounced the monarchist use of the category 'race'. MacLaughlin argues that the term 'race' was used as a form of ascribing social inferiority to entire sections of the global population and also to ethnic minorities in nation-building Europe and 'internal colonies' on the Celtic fringe of Victorian Britain (MacLaughlin, 1998). Furthermore, associating Irish and Portuguese identities allowed the republicans to achieve some of their political goals, which aimed primarily at attacking monarchist regimes. Aware of the importance of representation and the impact of images of place in the political arena many authors published and commented on cartoons, particularly those denigrating the image of England and its monarchist regime. Queirós and Reis

${ }^{63}$ In the original: "Os ingleses consideram os irlandeses como uma raça inferior, não muito acima do negros ou dos índios da América, consideravelmente abaixo dos franceses, ai pelo nivel dos portugueses, brasileiros ou argentinos". 


\section{GEOGRAPHICAL IMAGINATIONS}

frequently analysed cartoons published in the English press including 'Dr. Tanner' and 'Punch' (Plate 1).

Plate 1 - Caricature by James Wales and commented on by Reis representing an 'untameable' Irishman observed by John Bull and Uncle Sam

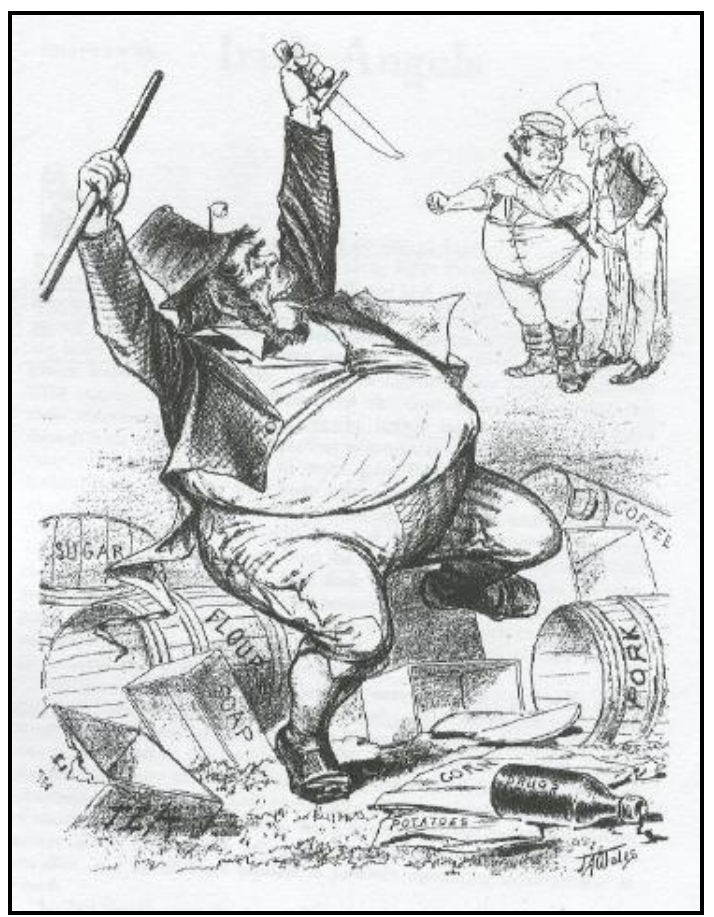

Source: (Curtis et al, 1971: 66)

His analyses of those cartoons aimed at generating hatred for England especially after the 1890 ultimatum (Coutinho, 2003). The cartoons were often socially intolerant towards the Irish and Reis argued that the English targeted both the Portuguese and the Irish, the former were condemned for their race and the latter for their backwardness (Santos, 2007). Hence, the English descriptions of the Irish implied descriptions of the Portuguese. The descriptions of English cartoons suggested what became an Irish-Portuguese identity of irresponsible rebelliousness, debauched happiness, criminal behaviour, childish oblivion and chronic sloppiness.

However, the private and official discourse that Queirós produced for the state was a different case (Queirós, 1979/1994). The representation of Irish identity in those documents was more objective. Since he was protected from the responsibility of influencing public opinion, it was closer to his true opinion (Coleman, 1980). In one consular report he conveyed a different image of the Irish particularly those in America (Queirós, 1994). Again, the discourse was dependent on the recipient and on the intentions of the emissary (Brown et al, 1993). As a personal report to the minister of foreign affairs, Queirós accurately wrote that Irishmen who emigrated to the United States, found employment primarily in municipal companies such as public transport, gas, plumbing and railway (Cousens, 1961). According to him, great construction companies 


\section{GEOGRAPHICAL IMAGINATIONS}

prioritised Irish employees because of certain favourable characteristics of their identity, among them industriousness and submission to all subaltern tasks. However, negative aspects of their identity were also mentioned. He claimed that the Irishman's immoderate use of whiskey made him unwelcome among Native Americans and other immigrants. He also reported an Irish fanaticism leading to quarrelling over religious issues. Queirós disclosed a personal opinion that was incompatible with those expressed in his newspaper articles in which he represented the Irish as almost flawless.

The Irishman is not esteemed [in America]. His intemperance, his bitterness and demands, his political empathies and his extreme Catholicism with dominating yearning make the American population and the powerful German emigrants hostile towards him ${ }^{64}$ (Queirós, 1979: 46).

During the latter part of the nineteenth century the Portuguese republican representation of Irish identity was compared to the Portuguese identity in a clear political attempt to change Portuguese identity itself and consequently modify the political regime. In fact, Irish identity and the English opinion of it were used as propaganda to strengthen republicanism in Portuguese society. Furthermore, they were used to serve the ideologies of Queirós and Reis. Both authors used journalism to communicate particular characteristics they considered lacking in Portuguese society, including nationalism, the belief in ideals and struggle for power (Miné, 1983). Interestingly, Reis and Queirós claimed that it was via the struggles between the English and Irish that the construction of Irish identity was possible, and consequently, that the construction of Portuguese identity could be achieved with similar struggles (Santos, 2007). The peak of representation of Irish identity and its rebellious tendencies in the Portuguese press coincided with the 1891 failed Revolução Republicana in Porto (Coutinho, 2003). The representation of Irish identity by the republican press decreased greatly after the revolution, with the new and harsh press censorship of 1891 (Franco, 1993). Queirós was less involved in the public republican scene, allowing the monarchists and the conservatives a less challenged audience (Cunha, 1993). The path for the depiction of the untamed Irish was now less complicated.

Poverty in Ireland is to a large extent due to the Irish and their bad habits, to drunkenness, to turbulence, to lack of caution, to the huge amount of children they have, to the lack of enterprising and industrious spirit, to the foolish habit nearly all of them have of

\footnotetext{
${ }^{64}$ In the original: "O Irlandez não é estimado: a sua intemperança, o seu espirito asedado e exigente, as suas sympathias politicas, o seu catholicismo com pretenções dominadoras torna-lhes hostis a população americana, e a emigração Allemã que é uma força na União" (Eça de Queirós In a manuscript report sent personally to the minister of foreign affairs Andrade Corvo in Lisbon, 09-11-1874).
} 


\section{GEOGRAPHICAL IMAGINATIONS}

dedicating themselves to agriculture and to carelessness of soil maintenance. ${ }^{65}$

\section{The Role of Religion}

Within the period of analysis, before the development of the press industry in Portugal allowed different ideological factions to use newspapers to transmit their ideals, the publication of books and propagandistic bulletins was a popular strategy (Samuel, 1991). Republicans, aware of the power of books, used translated texts published by foreign specialists in order to emphasise the advantages of republican policies (Catroga, 1991). Lavergne's work was dedicated to the analysis of the harmful rural economic policies of England in Ireland. However, the issue of religion was also addressed. The representation of a geographical divide between Catholics, a rural population, the Protestants and an urban population, implied that Catholics were more earthy, being distanced from the depravity of cosmopolitan life. He represented Protestantism as a "disease that contaminated the sacred Irish soil" (Lavergne, 1867). Although the conflict between the Irish and the English was initially connected mainly to property, it achieved an overwhelming religious dimension with the Reformation (Donnelly, 1975). Protestantism was blamed for turbulence and for hunger and poverty. Lavergne accused the Protestant Church of charging tithes to the poorest of the poor, consequently perpetuating starvation. The tithe as a discourse of religious exploitation served Portuguese republican interests, allowing for the condemnation of the power of religious organisations over people and the administration of the territory (Homem, 1998).

Despite the importance of Regnault's book its primary focus was not on the analysis of the Irish case. However, William Cobbett's 1865 book "Protestant Reformation in England", strengthened Catholic propaganda in Portugal (Almeida, 1968). Indeed, Cobbett's book and in particular its translation was essentially a Catholic propagandistic list of atrocities that were committed during and in the centuries after the Protestant Reformation (Ingrams, 2006). The author argues that a Protestant Inquisition, ten times worse than the one that happened in the mainland, took place while the international community looked on. The translation is more radical than the original text since the translator, Father Souza Amado, intended to use Ireland as an example of what would eventually happen in Portugal if nothing was done to stop the growing march of Protestantism (Almeida, 1968). Amado revealed his own fundamentalist view of Protestantism in the book. The book belittled the image of most Protestant English monarchs and particularly of Henry VIII (1491-1547), describing his "indulgent interpretation of the sacrament of matrimony" (Regnault, 1842). Hence, the translation pointed out that Protestantism was a dangerous malevolence waiting to strike:

\footnotetext{
${ }^{65}$ In the original: "A pobreza na Irlanda deve-se em grande parte aos irlandezes e aos seus maus habitos, da embriaguez, da turbulencia, da imprevidencia, do grande numero de filhos que téem, da falta de espirito emprehendedor e industrial, da mania de se dedicarem todos ou quasi todos á agricultura e do pouco cuidado que prestam á cultura do solo". (Dr E Oswald, In 'O Comércio do Porto', 30-04-1916).
} 


\section{GEOGRAPHICAL IMAGINATIONS}

Protestantism is similar to the voracious and eager tiger who after devouring the prey that falls into his claws, satiated with blood and full of flesh, lays down and rests, allowing others close by to live peaceful and rested, but not for long ${ }^{66}$

Cobbett's work also became a tribute and an acclamation of Catholic monarchists, without reference to the assassinations that took place during the reign of Mary I (1542-1587). Instead, assassinations during the reign of Elisabeth I were detailed and used to darken the image of Protestantism (Boran et al, 2006). The image and description of the beheading of Mary Stuart was used to communicate the "cruelty of Protestantism" (Plate 2). Cobbett wrote that common citizens were forbidden to attend mass and take communion and clerics were forbidden to teach and preach the Catholic faith. Even monarchs and dynasties were not immune to "shedding innocent blood" to guarantee the security and possession of the throne (Cobbett, 1865).

Plate 2 - Print representing the beheading of Mary Stuart during Queen Elisabeth's reign Original Title - "She resorted to her last shist, the legal murder, which was commetted on her haples victim the $8^{\text {th }}$ of February $1587^{\prime \prime}$

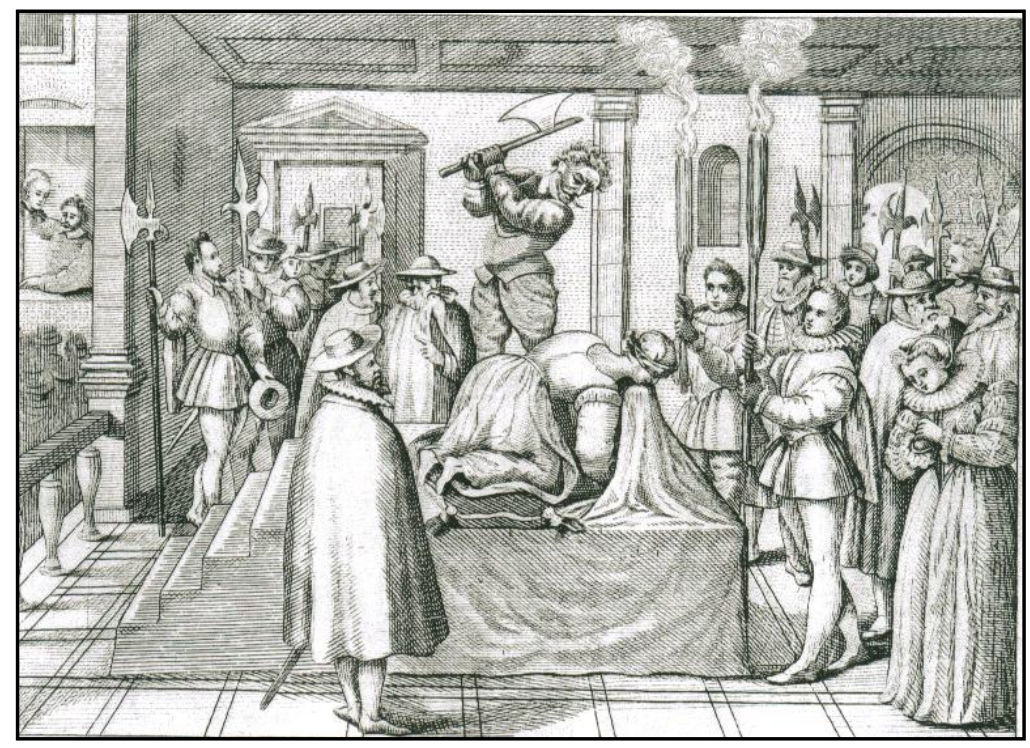

Source: (Cobbett, 1865: 257)

Cobbett's main objective, however, was to attack the institution of Protestantism so that the Portuguese would fear Reformation and the extinction of Catholicism with all its territorial and social implications (Azevedo, 2000). To foster the threat of Protestantism, the case of Ireland was analysed and used to predict events that could take place in Portugal. Accounts of attacks on Catholics were very frequent. Those accounts included situations taking place in Ireland and

${ }^{66}$ In the original: "O protestantismo, similhante ao tigre voraz e sequioso, que depois de ter devorado a victima, que Ihe cahira nas garras, saciado de sangue e farto de carne, se deita socegado e dorme, deixando outras não longe viver pacificas e socegadas: mas não por muito tempo" (Cobbett, 1865: 9). Originally translated from the English by Padre José de Souza Amado. 


\section{GEOGRAPHICAL IMAGINATIONS}

also in mainland Europe where attending mass was forbidden and laws prohibited priests from administrating last rites and accompanying the deceased to the grave, among many other restrictions (Boran et al, 2006). However, the pictorial representations of the Reformation and the actions carried out by the "Protestant Inquisition" in Ireland became more powerfully threatening and contributed more efficiently to a geographical imagination of fear (Cobbett, 1865).

Plate 3 - Print representing persecution of Irish Catholic clerics during the Protestant Reformation

Original Title - "There are some of the means wich good Bess made use of to make her Church"

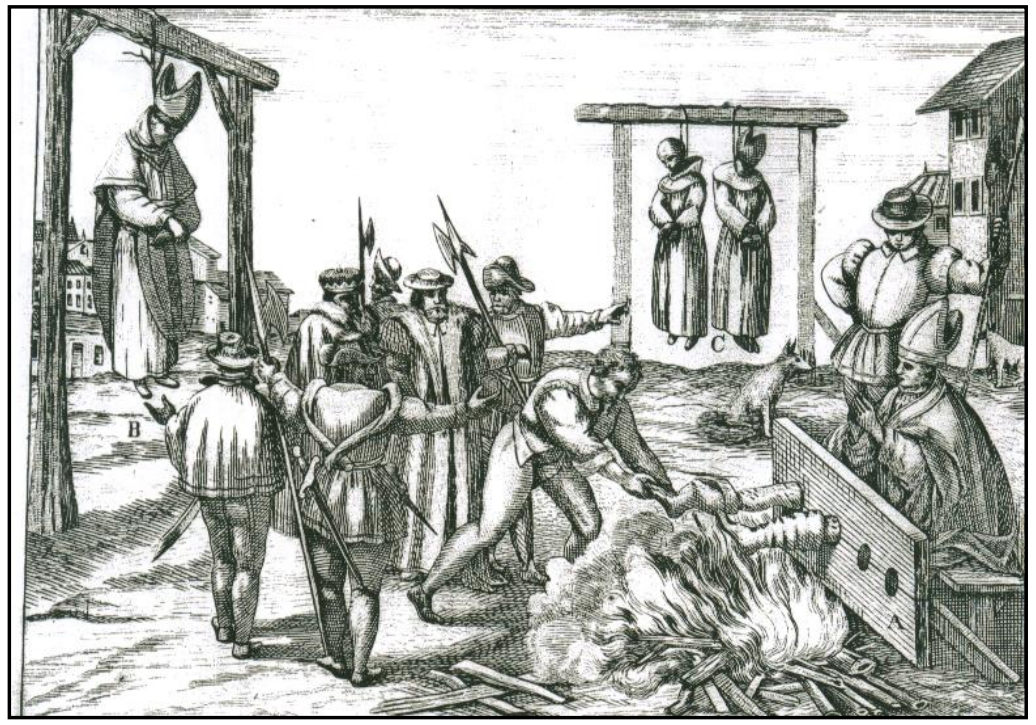

Original Key

A - Dormicio [Dominic?] Hurlen, Irish Bishop, accused of having administrated the sacrament of Confirmation to some boys, was arrested and taunted, as it can be seen, when they filled his boots with olive oil and put fire underneath. Later they removed the boots and the feet flesh was plucked off.

B - Afterwards they hang him and let him there so he would slowly die.

C - Patricio [Patrick] Ochley, Franciscan Bishop of Mayo, and another one from the same order, hung near the ground so they would be devoured by wild animals, which despite the amount of them around did not dare to touch the bodies.

Cobbett claimed that "the event called Reformation impoverished and reviled the majority of the English and Irish people" (Cobbett, 1865). According to him the Reformation was motivated by a "beastly lust brought forth in hypocrisy and perfidy, and cherished and fed by plunger, devastation and rivers of innocent English and Irish blood"67 (Cobbett, 1865: 361). The consequences of the Reformation, he argued, could be seen in nineteenth century Ireland: in its

${ }^{67}$ In the original: "A coisa a que chamaram Reforma, foi gerada por uma lascivia bestial, dada á luz pela hypocrisia e perfídia nutrida, e sustentada com os roubos e devastações e com rios de sangue Inglez e Irlandez". 


\section{GEOGRAPHICAL IMAGINATIONS}

misery, poverty, hunger, and unending hatred. Portuguese republicans blamed Irish misery on English policies, the monarchists blamed the rebellious and indolent spirit of the Irish and Catholic propaganda blamed the Protestant Reformation.

The translation of Cobbett's work had one main objective: to bolster Catholicism in Portugal. Ireland became the spatial illustration of a dreadful prophecy, which was inevitable if the population and the Catholic institution failed to unite. Amado's radicalism even incited him to claim, in his analysis of plate 3, that if Protestants dared to impose their will in Spain or Portugal as they did in Ireland they would be "chopped up into steaks" (Amado in Cobbett, 1865). He claimed that "the word protestant is synonymous with knave, impostor, thieve, robber, slanderer and assassin" (Amado in Cobbett, 1865). His depiction of English Protestantism in Ireland was the bleakest available in Portugal and, unlike Regnault, Amado failed to mention that Catholic Emancipation had taken place 36 years before. He emphasised the need to prevent Portugal and its people turning their backs and the need to resist the threat of "evil Protestantism" (Amado in Cobbett, 1865).

In the light of all this [Catholic persecution in Ireland], much vigilance is necessary in Portugal, especially on the part of the ecclesiastics. If this vigilance does not unveil Protestantism, later the bitter fruit of that carelessness will be harvested; fruit that England and other nations for many years have tasted and God knows what will happen next. With protestants we cannot have compliance or truce. (...) Portuguese Catholics (...) look at what awaits you when indifference descends from your heads to your hearts. ${ }^{68}$

Aware of the threat of Protestantism, the Catholic community in Portugal was attentive to national and international events, particularly in Ireland, that could serve either to promote Catholicism or denigrate Protestantism. The 1879 reported apparitions of Virgin Mary, St. Joseph and St. John Evangelist - along with a lamb, a crucifix and shining stars (Plate 4) - on the southern gable of Knock parish church, County Mayo, did not go unnoticed in Portugal (Connell, 2000). Catholic editor Joaquim António Pacheco published a major book in 1881 with the original text resulting from an investigation of Irish writer John MacPhilpin into the apparitions and translated by Fernando Thomaz de Brito titled "História da Aparição de Nossa Senhora na Egreja Catholica de Knock". MacPhilpin's book was published in Portuguese just one year after the publication of the original text and two years after the event actually took place (Rodrigues, 1992). Suddenly, and despite the fact that the republican press had omitted

\footnotetext{
${ }^{68}$ In the original: "Em vista de tudo isto, muita vigilância em Portugal, especialmente da parte dos ecclesiasticos. Se não houver esta vigilância desmascarando o protestantismo, mais tarde se colherão os amargos frutos d'esta incuria, que a Inglaterra por tantos anos tem saboreado, e que Deus sabe o que ainda será. Com protestantes não póde haver condescendencia, nem tréguas. (...) Olhem os Catholicos portuguezes para isto, e vejam o que os espera, quando o indifferentismo descer da cabeça para o coração" (Padre José de Souza Amado In Cobbett, 1865: 280-256). The use of upper case in the word 'Catholics' and lower case for the word 'protestants' is not a typing mistake but a decision of the author, Souza Amado. It was an intentional form of undermining Protestantism.
} 


\section{GEOGRAPHICAL IMAGINATIONS}

to mention the event, Knock became an important location in the Portuguese geographical imagination, particularly within the Catholic community.

The apparitions could not have occurred at a more opportune time for Portuguese Catholicism. Catholicism in Portugal desperately needed a divine intervention or a bona fide miracle to boost faith following the increasing success of the Partido Republicano which had elected its first deputy in October 1878 and had gained support with the first issue of the newspaper 'O Século' published in 1880 (Tengarrinha, 1965). Hence, the descriptions of the three apparitions, besides images of identity and landscape, focused primarily on the celestial nature of the miracle and its universality. The author described his investigation in loco and wondered at the intelligence of the witnesses of the miracles such as 13 year old boy Patrick Hill who "could not have learnt his prayers and thoughts from anyone in the village but from heavenly interference" (MacPhilpin, 1881).

The apparitions in Knock took place in a rural area (Knock, 1979). Furthermore, they took place in the West of Ireland, in Connaught, which was an area associated with the real Catholic Ireland - pure, hardworking, simple and devoted (Brewster et al, 1999). In fact, references to the untouched nature of the land and of the people in which the apparitions took place were contrasted to the corruption of urban areas and Knock was portrayed as the perfect location for a holy shrine. The apparitions became a religious and nationalistic discourse embedded in space. By referring to the religious hinterland of the miracle, it emphasised the power of the Catholic faith to unite a whole nation.

Plate 4 - Print representing the first apparition in Knock in 1879

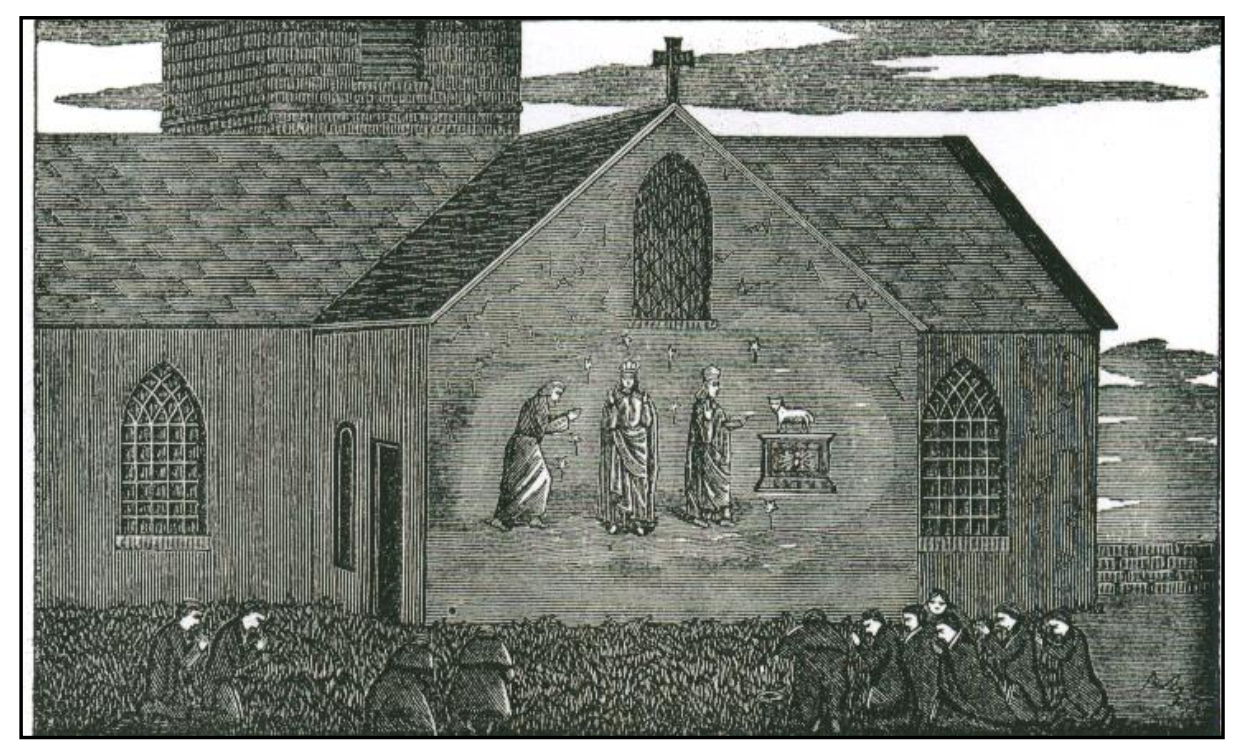

Source: (MacPhilpin, 1881)

The local geography of the events was clearly manipulated by the translator and a plan of the area was described in detail (Plate 5). The fact that the apparitions took place in the Knock 


\section{GEOGRAPHICAL IMAGINATIONS}

church with its orientation north-south, rather than the common west-east, was relevant. The apparitions were said to be seen on the wall of the south gable of the church. This was important for two reasons. Firstly, they appeared in what was considered the holiest part of the church, on the wall of the sacristy in the sanctum sanctorum, thus further validating the visions. Secondly, in what was a clear religious-political discourse of the translator, the wall of the apparitions faced south and thus towards Portugal, which he implied was a sign for the Portuguese to remember their Catholic faith and religious allegiance. Furthermore, the inclusion of the plan of the area revealed the spatial organisation of a gendered educational space. It implied community service and the importance of the Catholic institution for the commendable and modern instruction of society since it was carried out in a structured and organised manner. This manipulation of space in the case of Knock among others had the clear, propagandistic objectives of strengthening the Catholic position in Portugal, which suffered both the increasing threat of agnostic republicanism and the invasive Protestant wave from England and Spain (Azevedo, 2000).

Plates 5 and 6 - Plan and print of the surrounding area of Knock parish church

Original Title - "Plan of the field where the chapel is situated".Original Title - "Exterior of the Chapel"
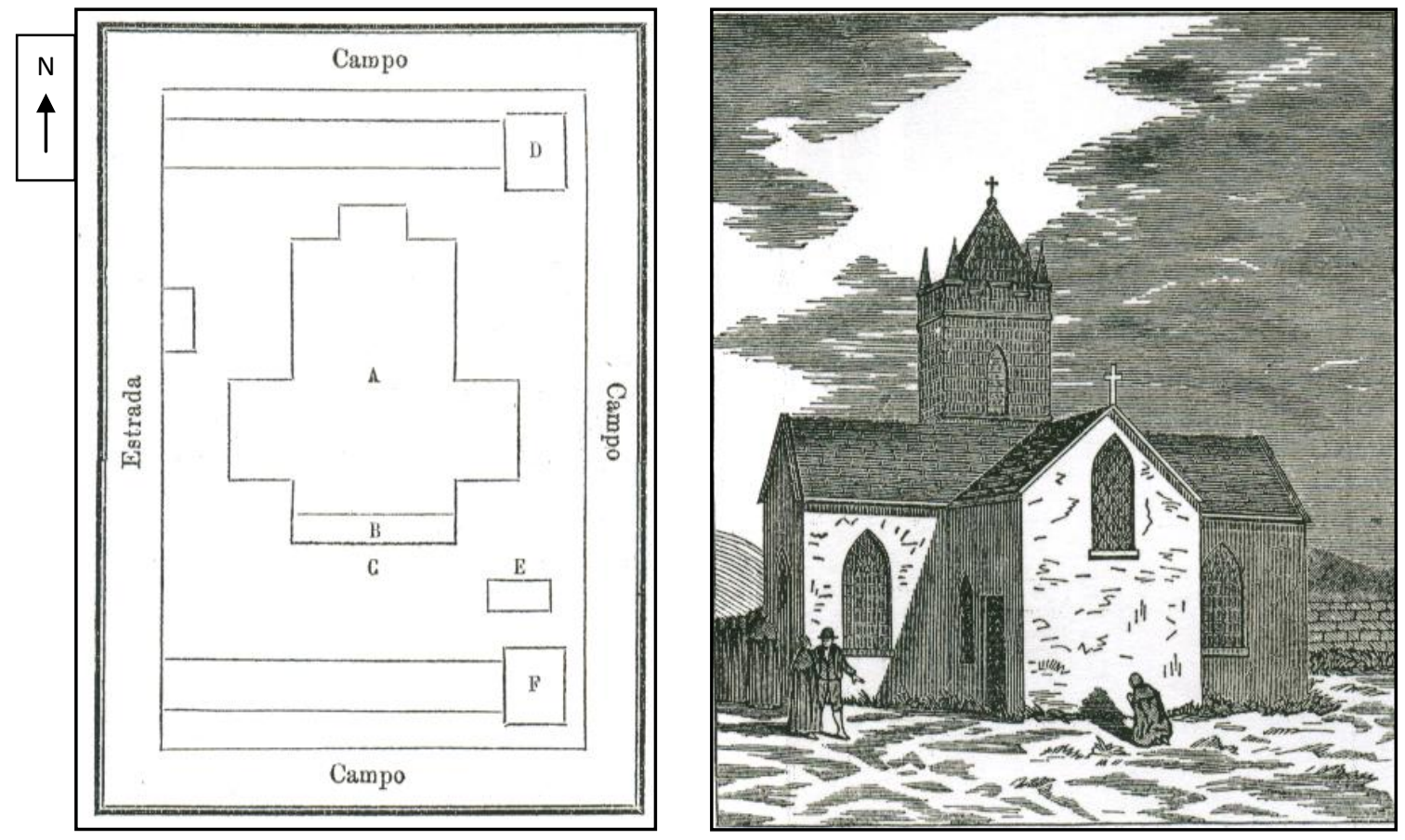

Original Key (Plate 5)

A - Chapel B - Sacristy $\quad$ C - The exterior side of the chapel upon which the apparitions were seen

D - Boys school E - Mr. O'Grady's tomb, father of the priest who order the building of the church F - Girls school 


\section{GEOGRAPHICAL IMAGINATIONS}

Although in reality Protestantism never really threatened the hegemony of Catholicism in Portugal, the power of the Catholic Church progressively decreased throughout the nineteenth century (Almeida, 1968). With the development of the press industry came widespread religious and political propaganda (Tengarrinha, 1989). Republicans and socialists resented Catholic power in Portugal and spoke out violently against it (Coutinho, 2003). Paradoxically, they praised the Catholic convictions of the Irish to attack England and its monarchist regime. On the other hand, the monarchists had a long term connection with the Portuguese Catholic institution and yet criticised the Catholic devotion of the Irish in order to defend England and its policies in Ireland (Homem, 1998).

Pro-Irish author $\mathrm{R}$ de $\mathrm{F}$ dismissed Catholicism as a minor concern. Instead he emphasised the land question because the Irish needed a parliament "more because of the land than the sky" (O Comércio do Porto, 04-11-1881). Furthermore, he accurately pointed out that many of the celebrated leaders of the Land League had been Protestant, emphasising a further separation between religion and land (Connolly, 1998). He minimised the importance of religion in the 'Irish Question', stating that the Catholic Irish sent Protestant representatives to the parliament in London, since it was "difficult to find people with literacy skills" (O Comércio do Porto, 04-111881). The association of Catholicism and ignorance was common practice in Portuguese republican discourse and had two main purposes: to attack both the monarchy and clerics, particularly Catholicism. The situation in Ireland strengthened any attack on the monarchy but could not support criticism of the Catholic Church. For that reason, Irish Catholicism was praised only within its borders and harshly criticised abroad, especially in Portugal.

(...) [in Portugal] the clerical horde is not Portuguese. It is constituted by French, Italian and Irish priests; tolerated by acephalous governments, disguised and hidden in little convents, attracting the belief of noble ladies, opening classes for rich boys, sons of dominant politicians. It is from them that this hallucinating virus exhales, which spreads to permissive provinces that scream and scare women or attract them according to the interests of the creed truly implicit in the criminal code. ${ }^{69}$

Despite the fact that the Irish Saint Patrick's College at Lisbon had closed its doors to students in 1834; it was administered by the Irish Dominicans of Corpo Santo until its final closure in the early twentieth century. The church where they celebrated mass directed, especially, to the Irish community in Lisbon was the Igreja do Corpo Santo (O'Connell, 2000). The remaining Irish priests in Portugal were not glorified by the attempt to portray Irish society as a counter-model to

\footnotetext{
${ }^{69}$ In the original: "(...) [em Portugal] o bando clerical não é portuguez; compõe-se de padres francezes, italianos e irlandezes; tolerados por governos acephalos, em conventiculos disfarçados, agremiando as fidalgas, abrindo aulas para os meninos ricos, filhos de políticos dominantes: é d'elles que sae esse vírus allucinador que se estende ás províncias permissionarias que berram e espantam as mulheres ou as attrahem conforme os interesses da seita cuja moral está verdadeiramente implícita no código criminal" (Theófilo Braga, In 'O Século', 19-04-1882). Theófilo Braga would become the first president of the Portuguese Republic in 1910.
} 


\section{GEOGRAPHICAL IMAGINATIONS}

Anglicisation (Canny, 2001). Instead, they were demonised because they personified the reactionary fight of Clericalism that in the name of religious feelings exploited the "ignorance of the masses and the idiot ingenuity of the rich aristocracy" (O Século, 19-04-1882). According to Braga, Irish priests in Portugal were oblivious to the cares of civil society due to their celibacy, with no notion of fatherland and afraid of science because it attacked the "fantasies of the miracle" (O Século, 19-04-1882). The resulting representation of Irish clerics in 'O Século' and in 'O Comércio do Porto' presents interesting dichotomies: in 'O Século' Irish Catholic priests were presented as a positive force in Ireland but a negative presence in Portugal. According to 'O Comércio do Porto' Irish priests were a negative force in Ireland but a positive presence in Portugal. This reinforces the importance of space for the representation of Irish religiousness since Irish priests were demonised or glorified depending on their location.

\section{Conclusions}

The representation of Ireland, and particularly of its identity, in Portugal was spatial. In other words, events in Ireland acquired spatial meaning and became actual discourses. In fact, a multitude of Irelands and a variety of Irish identities existed in Portugal because different ideological interests used the press to divulge their ideas (Pires, 1996). They described an Irish identity that, according to the republicans, should be admired and celebrated as an example and, according to the monarchists, should be avoided at all costs. Republicans and monarchists asserted those versions of Irish identity, more intensely until the failed Revolução Republicana on 31 January 1891 (Coutinho, 2003). After that date, as a reflection of the 1891 press censorship which was aimed mainly at republican press, their representations became more similar, especially after the establishment of the republican regime in 1910 and with the First World War (Marques, 1972). In any case, within a critical geopolitical framework, it becomes clear that Irish identity in Portugal was particularly different from that in England, the United States and in the Anglicised world in general (Foster, 1993). Portugal reflected a peculiar form of 'transnational Irishness' based on conflictive discussions of colonialism and religion within the forming nation-state (Arrowsmith, 1999). The republicans in particular defended the empire as a keystone of Portuguese identity but when representing Ireland, at least until the establishment of the republican regime, portrayed an image of themselves as the most enlightened liberals, critics of imperial expansion and colonial subjugation.

The republicans saw Ireland as the perfect terrain to bolster their ideologies by, on the one hand, praising the Irish love for the land and, on the other hand, attacking the English "semifeudalistic territorial policies", which they claimed were "typical of every monarchist regime and caused the state of poverty in Ireland" (O Século, 27-01-1882). The republicans criticised monarchist regimes abroad in order to avoid new waves of restrictive press censorships, which would have been inevitable had they condemned the Portuguese monarchist regime directly (Franco, 1993). While the monarchists represented the Irish as indolent and incompetent in 


\section{GEOGRAPHICAL IMAGINATIONS}

order to justify the chaotic state of affairs in Ireland, the republicans used a different strategy. They attacked colonial England for not having taken advantage of the alleged perfect natural setting in Ireland to develop a modern communication and transport infrastructure, thus providing the country with economic activities and the means to prosper (Lavergne, 1867). In keeping with Kiberd's work, as far as the Portuguese republicans were concerned, like the Irish and unlike Portuguese monarchists, colonialism in Ireland took several forms such as political rule from London, economic expropriation by planters who came in several waves of settlement, an accompanying psychology of self-doubt and dependency among the Irish and a further inadequacy of territorial policies that jeopardised the innate quality of the land (Kiberd, 1995).

The rebellious nature of the Irish was proclaimed by both interest groups to be a very particular trait of Irish identity. The monarchists considered it an inglorious trait, while the republicans romanticised it and attempted to nurture it in the Portuguese identity itself (Catroga, 1991). According to the monarchists the Irish rebelled because of an innate characteristic while the republicans saw it as a legitimate reaction to the "exploitation they suffered for centuries in their own land" (O Século, 18-09-1887). According to the republicans, had they been exploited in a space that did not belong to them their reaction would not have been so violent. Thus, rebelliousness in Irish identity was represented as a reflection of spatial occupation. Also, despite sporadic references to the roles of women in Irish nationalist mainstream and rebellious activities, women's efforts were marginalised and restricted (Nash, 1997). In Portugal, as in Irish nationalist and unionist traditions, political action was defined as male and military (Benton, 1996).

Catholic propaganda visualised Ireland as the ideal example of the fight against Protestantism and the creation of a Portuguese national identity moulded upon Catholic principles, especially with the increasing loss of power held by the Church in Portugal since the definitive victory of liberalism in 1834 (Azevedo, 2000). However, religion was represented carefully due to an awkward contradiction. On the one hand, republicans had a natural tendency to produce antiCatholic discourses in Portugal, in accordance with their belief in individual independence of thought (Almeida, 1968). However, in relation to the 'Irish Question', they were forced to defend Irish Catholicism in order to attack England's monarchy (Rosa, 2000). On the other hand, the most conservative, monarchist and anti-Irish authors were closely tied to Portuguese Catholic institutions; although, they felt the need to condemn Irish Catholicism - but not Catholicism in general - in order to defend England (Vargues et al, 1998).

Despite the fact that the representation of religion was used cautiously, Catholicism was one of the main elements of Irish and Portuguese identities that was manipulated. Representing the qualities of the Irish Catholic united Portuguese republicans and Catholics. Defending the Catholic fervour of the Irish implied attacking the Protestant impudence of England, which pleased the Catholics. At the same time, it implied the condemnation of the monarchist structure as a whole, which pleased the republicans. According to both of those propagandistic groups, the landlord in Ireland exemplified the depravity of the English monarchy that continued to 


\section{GEOGRAPHICAL IMAGINATIONS}

massacre the sacred soil of Ireland and for that reason had to be expelled (Cobbett, 1865). In other words, whether the intention was motivated by Catholic or republican propaganda, a negative image of non-catholic England became strong in the Portuguese geographical imagination. That demonised image implied the necessity of a "territorial exorcism of Ireland" that could only be carried out by the "Catholic sons of Ireland" (Regnault, 1842). The rebel spirit of the Irish and their fight for the land was, consequently, justified and more importantly legitimised by Catholic motivation, a fact that was used in Portugal to gather support for the Irish cause. As a consequence, a desire, emanating from the revolutionary impulses that derived from prolonged conflict in Ireland to fashion a completely new society, existed among the Portuguese and Irish.

\section{References}

Almeida, F., 1968. História da Igreja em Portugal; Vol.2; Livraria Civilização Editora; Porto/Lisboa

Arrowsmith, A., 1999. "M/otherlands: literature, gender, diasporic identity"; In Brewster, S; Crossman, V; Becket, F; Alderson, D (Eds.); Ireland in Proximity: History, Gender, Space; Routledge; London/New York; pp.129-144

Azevedo, C, M. (Ed.), 2000. Dicionário de História Religiosa de Portugal; Vol.1-4; Círculo de Leitores; Lisboa

Benton, S., 1996. "Women disarmed: the militarization of politics in Ireland 1913-23"; Feminist Review; Vol.50; s/n; pp.148-172

Bew, P., 1991. Charles Stewart Parnell; Gill and Macmillan; Dublin

Boran, E; et al (Eds.), 2006. Enforcing Reformation in Ireland and Scotland (1550-1700); Ashgate; Aldershot

Brewster, S; et al (Eds.),1999. Ireland in Proximity: History, Gender, Space; Routledge; London/New York

Brown, G; et al., 1993. Discourse Analysis; Cambridge University Press; New York/Melbourne

Canny, N., 2001. Making Ireland British (1580-1650); Oxford University Press; Oxford/New York

Carvalho, R., 1985. História do Ensino em Portugal Desde a Fundação da Nacionalidade Até ao Fim do Regime de Salazar-Caetano; Fundação Calouste Gulbenkian; Lisboa 


\section{GEOGRAPHICAL IMAGINATIONS}

Cobbett, W., 1865. História da Reforma Protestante em Inglaterra e Irlanda - fazendo ver que este acontecimento abateu e empobreceu a maior parte dos habitantes destes paizes, em uma colecção de cartas dedicada a todos os inglezes justos e sensíveis: Nova edição ornada com dezeseis gravuras em cobre que a todos os portugueses para cabal desengano do que é a religião protestante dedica o Padre José de Sousa Amado; Typographia Universal; Lisboa

ConnelL, J, T., 2000. Encontros Com Maria: Aparições de Nossa Senhora; $2^{\text {nd }}$ Ed.; Planeta Editora; Lisboa; [preface by Robert Faricy, Jesuit Priest, original title: Meetings With Mary, Visions of the Blessed Mother]

Connolly, S, J., 1997. "Culture, identity and tradition: changing definitions of Irishness"; In Graham, B (Ed.); In Search of Ireland: A Cultural Geography; Routledge; London/New York; pp.43-63

Connolly, S, J (Ed.)., 1998. The Oxford Companion to Irish History; Oxford University Press; New York

Catroga, F., 1991. O Republicanismo em Portugal: Da Formação ao 5 de Outubro de 1910; Vol.2; Faculdade de Letras da Universidade de Coimbra; Coimbra

Coleman, A., 1980. Eça de Queirós and European Realism; New York University Press; New York

Cousens, S, H., 1961. "Emigration and demographic change in Ireland (1861-1881); Economic History Review; Vol.14; N.2; pp.275-388

Coutinho, L, P., 2003. Do Ultimato à República: Política e Diplomacia nas Últimas Décadas da Monarquia; Prefácio; Lisboa

Cunha, I, F., 1993. "Sobre a estante de Jaime Batalha Reis: o homem e o seu círculo"; Revista da Biblioteca Nacional; Sec.2; N.8(2); Biblioteca Nacional de Lisboa; Lisboa

Curtis, J; et al., 1971. Apes and Angels: The Irishman in Victorian Caricature; Newton Abbot; New York

Davis, N., 1998. Europe: A History; Harper Perennial; London

Donnelly, J, S., 1975. The Land and the People of Nineteenth Century Cork: The Rural Economy and the Land Question; Routledge and Kegan Paul; London

Foster, R, F., 1993. Paddy and Mr. Punch; Penguin books; London 


\section{GEOGRAPHICAL IMAGINATIONS}

Foster, R, F (Ed.)., 2001. The Oxford History of Ireland; Oxford University Press; Oxford/New York

Franco, G., 1993. A Censura à Imprensa (1820-1974); Imprensa Nacional Casa da Moeda; Lisboa

Gonçalves, C., 1917. "A aliança luso-britânica e o domínio colonial português"; Boletim da Sociedade de Geografia de Lisboa; N.10/12; Sociedade de Geografia de Lisboa; Lisboa

Graham, B., 1997. "Ireland and Irishness: place, culture and identity [introduction]"; In Graham, B (Ed.); In Search of Ireland: A Cultural Geography; Routledge; London/New York; pp.1-15

Gregory, D., 1993. "Interventions in the historical geography of modernity: social theory, spatiality and the politics of representation"; In Duncan, J; Ley, D (Eds.); Place/Culture/Representation; Routledge; London/New York; pp.272-313

Hall, S., 1997. "The work of representation"; In Hall, S (Ed.) (1997); Representation: Cultural Representations and Signifying Practices; "Culture, Media and Identities"; Sage Publications; London/New Delhi; pp.13-74

Homem, A, C., 1998. "O avanço do republicanismo e a crise da monarquia constitucional"; In Mattoso, J; História de Portugal: O Liberalismo (1807-1890); Vol.5; Editorial Estampa; Lisboa; pp.109-121; [coordenação de Luís Reis Torgal e João Lourenço Roque]

Howe, S., 2000. Ireland and Empire: Colonial Legacies in Irish History and Culture; Oxford University Press; Oxford/New York

Ingrams, R., 2006. Life and Adventures of William Cobbett; Harper Perennial; London

Kabdebo, T., 2001. Ireland and Hungary: A Study in Parallels with an Arthur Griffith Bibliography; Four Courts Press; Dublin

Kiberd, D., 1995. Inventing Ireland: The Literature of the Modern Nation; Jonathan Cape; London

Knock, T., 1979. A Aparição de Nossa Senhora na Irlanda; s/n

Lavergne, L., 1867. Ensaio Sobre a Economia Rural de Inglaterra; Escócia e Irlanda; Imprensa Nacional; Lisboa; [preface by Latino Coelho and translation by Venâncio Deslandes]

Lee, J (Ed.), 1985. Ireland: Towards a Sense of Place; "The U.C.C.-R.T.E Lectures"; Cork University Press; Cork 


\section{GEOGRAPHICAL IMAGINATIONS}

Livingstone, D, N., 1992. The Geographical Tradition: Episodes in the History of a Contested Enterprise; Blackwell Publishers; Oxford

MacLaughlin, J., 1998. "Pestilence on their backs, famine in their stomachs': the racial construction of Irishness and the Irish in Victorian Britain"; In Graham; Kirldan (Eds.); Culture Theory and Ireland; Macmillan; London

MacPhilpin, J., 1881. História da Aparição de Nossa Senhora na Egreja Catholica de Knock no Condado de Mayo, Provincia de Connaught na Irlanda; Livraria Catholica de Joaquim António Pacheco; Lisboa; [trabalhos de tradução encetados por Fernando Thomaz de Brito]

Marques, A.H.O., 1972. A Primeira República Portuguesa: Para Uma Visão Estrutural; Livros Horizonte; Lisboa

Miné, E.,1983. Eça de Queirós Jornalista; $2^{\text {nd }}$ Ed.; Livros Horizonte; Lisboa

Mitchell, D., 2000. Cultural Geography: A Critical Introduction; Blackwell Publishers; Oxford

Nash, C., 1997. "Embodied Irishness: gender, sexuality and Irish identities”; In Graham, B (Ed.); In Search of Ireland: A Cultural Geography; Routledge London/New York; pp.108-127

"O Comércio do Porto" (1855-1925); Porto

“O Século" (1881-1925); Lisboa

Pires, D., 1996. Dicionário da Imprensa Periódica Literária Portuguesa do Século XX (19001940); Vol.1; Grifo Editores e Livreiros Lda.; Lisboa

Queirós, E., 1970. Letters from England; Ohio University Press; Ohio; [translated from the Portuguese by Ann Stevens]

Queirós, E., 1979. A Emigração Como Força Civilizadora; Perspectivas e Realidades; Lisboa; [prefácio de Raul Rego]

Queirós, E., 1994. Correspondência Consular; Edições Cosmos; Lisboa; [edited by Alan Freeland]

Regnault, E., 1842. História dos Crimes do Governo Inglez desde os Primeiros Assassinatos da Irlanda até ao Envenenamento dos Chins, Vertida em Portuguez por F. e C.; Typographia de M. J. Coelho; Lisboa

Reis, J.B.,1988. Revista Inglesa; "Memória Portuguesa"; Biblioteca Nacional; Publicações D. Quixote; Lisboa; [editing, introduction and notes by Maria José Marinho] 


\section{GEOGRAPHICAL IMAGINATIONS}

Rodrigues, A.G., 1992. A Tradução em Portugal: Tentativa de Resenha Cronológica das Traduções em Língua Portuguesa Excluíndo o Brasil de 1495 a 1950; Vol.2-5; Imprensa Nacional Casa da Moeda; Lisboa

Rosa, V.C., 2000. 'Revista Inglesa': Percursos de Jaime Batalha Reis na Inglaterra Vitoriana; $\mathrm{s} / \mathrm{n}$; Lisboa; [doctoral dissertation]

Samuel, P., 1991. Do Idealismo Republicano ao Manifesto dos Emigrados; Governo Civil do Porto; Porto

Santos, M., 2007. O Império do Outro: Eça de Queirós, Ramalho Ortigão, Batalha Reis, Oliveira Martins e a Inglaterra Vitoriana; Faculdade de Ciências Sociais e Humanas; Universidade Nova de Lisboa; Lisboa; [doctoral thesis]

Tengarrinha, J.,1965. História da Imprensa Periódica Portuguesa; Portugália Editora; Lisboa

Tengarrinha, J.,1989. História da Imprensa Periódica Portuguesa; $2^{\text {nd }}$ Ed.; Caminho; Lisboa

Torgal, L.R. et al., 1998. "Produção e reprodução cultural”; In Mattoso, J; História de Portugal: O Liberalismo (1807-1890); Vol.5; Editorial Estampa; Lisboa; [coordenação de Luís Reis Torgal e João Lourenço Roque]

Vargues, I.N. et al., 1998. "Estruturas políticas: parlamentos, eleições, partidos políticos e maçonarias"; In Mattoso, J; História de Portugal: O Liberalismo (1807-1890); Vol.5; Editorial Estampa; Lisboa; [coordenação de Luís Reis Torgal e João Lourenço Roque] 
GEOGRAPHICAL IMAGINATIONS 


\section{GEOGRAPHICAL IMAGINATIONS}

\section{Representations of space, musical practices and transborder territorialities among Brazil, Argentina and Uruguay}

Lucas Manassi Panitz, Federal University of Rio Grande do Sul; Université Bordeaux 3 lucaspanitz@gmail.com

\section{Introduction}

The ponder upon the relation between music and geographic space, if it's not new, has acquired more importance over the recent years with the renewal of social and cultural geography. Authors like Kong (1995, 1997), Leyshon et al (1998), Lévy (1999) and Raibaud (2006, 2011), among others, are examples of authors of this topic. Considering that, it is needed to visualize music itself as a spatiality and a creator of spatialities and territorialities. On this sense, we may see a group of musicians, their practices and representations on the platino space - a spatial crop where several political, cultural and natural geographic unities overlay, which includes Argentina, Brazil and Uruguay. From the collective acting of these musicians their aesthetic propositions, their songs, their network articulation and their receptivity on cultural politics of regional integration - we can visualize this phenomenon on its geographical dimension. That is, it is sought to comprehend which geographical elements involved in such phenomenon, discussing its contribution in a moment of a South American integration not only by an economic point of view, but also social and cultural. It is my opinion that musical phenomenon under discussion presents itself as a new trans-border cultural territoriality, but it carries ancient elements. Such territoriality requires the existence of a "platino space" is necessary for both social representation and music practices. Composers like Vitor Ramil, Ana Prada, Kevin Johansen, Daniel Drexler, Richard Serraria (among others) are included on this research.

\section{Music and Space: Follow the Represent(actions)}

Music in general, but specially songs - as a literary and musical form - has the capacity of representing the world, creating discourses and bringing new interpretations about this world. . The composer of songs is a social being and his or her expression is not confined only on the artistic context he inhabits. Music talks about society, culture, politics and it is incorporated on the everyday discourses.

Such idea illustrates the importance of thinking in terms of social representation, which is a form of knowledge of reality created by an individual or a group to be shared in a group or among groups of individuals, such as affirmed by Jodolet (2001). Thus, every representation is social, because it is meant to give sense and orientation to human actions. Social representations as "systems of interpretation that rule our relation with the world and with others - guide and organize the conducts and social communications" intervene, therefore, "in varied processes such as the diffusion and assimilation of knowledge, the individual and collective development, 


\section{GEOGRAPHICAL IMAGINATIONS}

the definition of personal and social identities, the expression of groups and the social transformations" (idem:22). Therefore, social representations are more like a work in progress than something tightened; their study focus more on innovation than in tradition, more intensively in an ongoing social life than in an already established social life, such as affirmed by Moscovici (2001). I do not disagree that the act of representing something, according to Marin (apud Lussault, 2007:72) is "l'enonciation puissant d'une absence", but I would complement affirming the act of making something that is not there present has an intrinsic intention with the actor, individual or collective, and its enunciation fulfills a role inside a social and geographical reality. The representations of space, such as we understand here are included on this approach because representing space is a social act that aims to create an idea of space. This idea, elaborated by a social being, communicates values, perceptions and meanings which are always situated historically and geographically. That's important because when we work with representations of space, detaining on the processes of imaginaries and identities that have in space one of its structuring axis inform (1) the origin and the ways representations are negotiated, (2) the geographical contexts that make them arise, (3) the resulting actions from such representations and, with them, we can understand (4) the processes of diffusion of conceptions of space in society and its relation to culture.

Under this perspective, we go apart from a view that evokes the representation of space only as an image of geographical materiality, external to men, but as an act of represent human existence itself, which is inexorably spatial (Lussault, 2007).

This act of representing space is done by language, which is understood not only by writing, but also by speech, gestures, visual and musical shapes, etc. In other words, language is performative. Lussault (2007) reminds that every linguistic act is always a social act imbued with performance and lined with a spatiality. Represent space is, therefore, a spatial practice.

According to Aubert (1991), music is present among all societies, so we can consider it as a immanent characteristic of human species, such as articulated language. "Like language, music is a product of collective experience, answering a group of determinant cultural needs. On this sense, music is certainly a total social fact". (idem:11). Music is the most present artistic product in everyday humans' lives. It has the power of putting in motion a great amount of social and spatial representations. Discussing the ideas of the anthropologist Gregory Bateson, Turino (2008) affirms arts in general have a special form of communication that contains an integrative function - they integrate and unify members of a social group, but also integrate individuals with their own world and space. On this way, art express both social and individual realities and recreates the same reality every moment. Their representations are connected to the world and create it. Or, as Aubert proposes to music (1991:12), "The operating power of music is a currently acknowledged reality. Every musical form is intimately connected to its social environment, what it expresses and transforms at the same time". And, as representations as we understand them, serve to give sense to human actions, it will always be understood as represent(actions), as discourse and practice. In terms of geographical analysis, it is necessary 


\section{GEOGRAPHICAL IMAGINATIONS}

to be aware of the contents of representations of space and practices on space and in what ways they combine on the production - on the current case - of territorialities. Because the musical phenomena geographies and territorializes, it moves. It is necessary, then, a method to the field work that completely considers this phenomenon.

I have visualized a potential study on the proposal of multisited ethnography of Marcus (1995). This author advocates by the necessity of an ethnographic work that participates the flux, the contexts of circulation of subjects and objects from the research; on this author's case, this work methodology is bound to what is called "Anthropology of globalization" or "Anthropology of the contemporary", among other denominations. The author suggests to follow social actors, objects and representations as a way to understand the construction of social facts. Thus, I start from a conception of a multi-situated geographical field work, following the musicians' network in question, registering the representations and practices in order to understand how and through which contexts a musical territoriality is produced.

\section{The Music that geographizes: musical aesthetics from platino space}

Vitor Ramil, Brazilian writer and composer, published an essay called A estética do frio (Ramil, 1993). In this essay, he ponderates about his own musical creation background and attempts to systematize these reflections and creates a contemporary conception of Brazilian music typical from the South. During the period he lived in Rio de Janeiro, in June, Ramil watched the national news. The television program showed images of popular festivals in Bahia in a tropical weather next to images of frost from the winter in Rio Grande do Sul. The negative temperatures and the everyday routine of the people on that environment were shown in a tone that suggested abnormality, as if they were disconnected from Brazil's reality, even close to another country association. Ramil noticed that although the cold temperatures were present in other states, there was a recurrent representation that linked the image of gaucho ${ }^{70}$ to this climatic context. On the same way, beyond representation, the author notices that the cold is indeed conected to people's lives on this place and this would be a defining metaphor for the creation. This artist, then, sought to represent "cold", dwelling on the regional imaginary and his own perception of place. Typical images came out: the gaucho drinking mate and gazing the vastness of pampa ${ }^{71}$, the green fields contrasting the blue sky, few elements composing the landscape. Right after that, the composer traced similarities between the landscape and the rhythm of milonga, creating an analogy between them: "Milonga in a minor tone, reflexive, dense, deep and melancholic. Rigorous on its cadency, ponteio and fraseado; subtle on its oriental sinuous melodic movement" (Ramil, 1993:268). From this conception, Ramil establishes characteristics to his production: "Brazilian rhythm, black, groovy, treated with harshness (the

\footnotetext{
${ }^{70}$ Gaúcho is the denomination for a person Born in Rio Grande do Sul, state located on the furthest South of Brazil. But the name is also used for a cultural type of platino region, which began on $17^{\text {th }}$ century and it lasts until today on the folklore of Brazil, Argentina and Uruguay, even though gaúchos may have distinctive characteristics in each country. The gaucho is known for his peculiar lifestyle of which many mythical representations arose. Milonga and payada, creole heirs of "provençal troubadourism" are two musical manifestations strongly linked with gaucho.

${ }_{71}^{7}$ The Pampa denomination is a quíchua originated word to denominate the "grasslands that are located on Rio Grande do Sul and in the countries of Prata, associating the ocurrence of pasture that are also denominated savannas, steppes or simply Field. (the latter would be the most appropriate term)" (Fontoura, 2008 , p. 1). Pampa, in quíchua, na aborigenous South American language, means "plain area".
} 


\section{GEOGRAPHICAL IMAGINATIONS}

rigor of tango) and planned preciousism. The rhythm like a minouscious thought. [...] The rhythm that brings lightness. Cleaniness. An analogy? Mounts and cliffs from Rio put here and there, criteriously, on the smooth vastness of pampa" (idem). In songs like Milonga em Sete Cidades and Indo ao Pampa (Ramil, 1997), it is noticed the transposition of these ponderations inside the musical creation, equally denoting important elements of geographicity in the terms of Relph (1978) and Dardel (1952). The artist starts from his living space and the interpretation of regional literature and the social imaginary of pampa, of which are translated into sonourous representations linked to this geographical reference.

On the other side of the platino border, the Uruguayan musicians Jorge and Daniel Drexler created the term Templadismo - an allusion to Tropicalismo. In fact, on the core of this conception, as well on the aesthetic of cold, lies a characteristic that follows the lived space, which are the climate and its well-defined seasons and its associated sensations -melancholy, for example. To Daniel Drexler, melancholy is clearly associated to climate and landscap. He also affirms "the Templadismo forms a musical trend in the southern Latin American, which is characterized by no excess, where reign peaceful athmospheres, colors and sounds". Daniel Drexler also explains that the Templadismo denomination came through conversations with his brother Jorge about the aesthetics of cold, tropicalismo and Manifesto Antropófago and it occurred to him, as a joke, to theorize about a pampas' tropicalismo. "If I had to define Templadismo in a few words, l'd say that it is a sort of theorical milestone to the creations (in my case, the creation of songs) about and through the Prata River Bay" (idem). The Argentinian composer Kevin Johansen talks about "Subtropicalismo" and also corroborates to the proposal of Templadismo and the aesthetics of cold. In an interview made for this research, the composer affirms that he recognizes a specific culture in the platino scope and he says that "it is said that from the South of Rio Grande do Sul we are more tangueros, more melancholic [...] I also usually say that we are Subtropicalistas because of the weather firstly because it marks all cultures and secondly because our artistic fathers are Tropicalistas" (Kevin Johansen, interview at july, 2008).

For both, Ana Prada and Kevin, the platino culture expresses itself by diversity, by mixture, by the historical character of ethnic miscegenation and, therefore, of rhythms. Kevin affirms that "the contact with the Atlantic, the mixture of the natives with European and here in the South where the resonance of Africa left its mark and sonority" (Ana Prada, interview at july, 2008). Ana Prada tells that one important charachteristic of Prata culture expresses itself on diversity: "On this variety, melancholy, rhythm and uprooting, as well as nationalism, intolerance (and intolerated), the cold and heat, the shades of grey and colorfulness" (idem).

Through these musicians, we notice, in one hand, the recognition of a historical formation that configures ethnicity and culture on platino space; and, on the other hand, a conception linked on landscapes, highlighting pampa and the subtropical character that imprints this environment. Far from being a deterministic conception of culture, such speeches lead us to consider the 


\section{GEOGRAPHICAL IMAGINATIONS}

entwinement between nature and culture. According to Jovchelovitch (2004:21), "representation is both connected to social and it is linked with the materiality of the world". On this sense, it is impracticable to take into account the representations of musicians in question if the materiality of representation is not taken into account. After all, according to Berque (1998), it is a trait of geographer to take into account the physical material of which each culture imprints its mark, its "graphy" on earth.

Thus, it is noticed a strong geographying dimension on the representations of the artists. They bring elements of geographical space's materiality to the aesthetic creation, making this materiality alive and indispensable on musical conception. Furthermore, we will see how this dimension supports territorializing proposals, aiming the field artists' action on space, which generates specific territorialities.

\section{Music that territorializes: networks, shows and cultural politics}

On this section, I will present elements that takes us to consider a territorializing process of this musical phenomenon. This process points out a questioning of other centralities to cultural manifestations and funds other centers of power where this Music may transit. The geographying representations continue and are added to power dimension on space, which is from practices that lead to a "territorialization".

Vitor Ramil is pointed by many interviewers of the research as the musician that put into manifest the contestation of Brazil's center as a sole space of cultural circulation. By doing so, he took with him not only Brazilians, but Argentineans and Uruguayans to also seek exchanging practices on the region. According to the artist, his album Tambong "promoted an encounter of platino musicians from the South of Brazil, as well as from the Northeast and Center. His motivation was on the determination to subvert a state of things in Brazil that makes its regions to feel marginalized from the hegemony from Brazil's institutional center in many aspects of national life, among them, cultural production" (Ramil, 2004:28). He also defends that Rio Grande do Sul and Porto Alegre are located in a privileged area in order to establish a dialogue between Brazil and Prata, "the meeting of coldness and tropicalness", and he categorically finishes: "We are not in the margin of a center, but on the center of another History" (Ramil, 2004:28).

When he questioned the centrality of Southeastern Brazil in terms of cultural production through representation of a new Center and another History, Vitor Ramil acts discursively, supporting a territorial action that, in fact, he had already put in practice when he returned to Pelotas (inner Rio Grande do Sul), seeking to consolidate a market to his Music in the South and its neighbors. Daniel Drexler contributes with the discussion when he emphasizes the transformation of the feeling of periphery and isolation. 


\section{GEOGRAPHICAL IMAGINATIONS}

I think that one of the most important things is to overcome this situation that we are on the periphery of something. [...] And what I find interesting about what Vitor Ramil says and what we are saying now is that in a certain way it is time to say ok: let's put things in our hands. Let's put this way of living aside, a life that is constantly being traced by what happens on the center (Unimúsica, 2009).

It is noticed that, on this sense, artists seek the building of a new territoriality, a new "center" that enables the reproduction of their works. When they contest "the other center", artists start to organize and guide their actions on a new schedule, which include cities from their partners, as well as new venues and cultural partners. When they organize or take part in shows, samples and seminars that alludes this new centrality, the representation of this territory becomes effective and these events become important landmarks of this territoriality in construction. Spectacles like "Porto Alegre - Montevideo, Sin Fronteras", "Lagunas y Lagoas", "Aires de la pampa alegre", "Yakupampa", "Música de Sul a Sur", "Rumbos, Músicas Del Sur", "Latinoamericana", among others, clearly Express the existence of a lived reality that transposes national borders.

It is necessary to stress the role of the public and private cultural agents towards the affirmation of the representations of this network of musicians. As an example, Festival de Inverno de Porto Alegre affirmed on its release that

(...) the program states once more its platino accent. It is an event that outstands on the city, not only for the attractions, but for the fact of the enjoyment of the specific circumstance of the porto-alegrense winter that originated the attempt to produce an aesthetic of the cold (Vitor Ramil) [...]. We also bet on the cultural integration with our plantino brothers, without forgetting to rescue consecrated national values (Gonzaga, 2010).

In other events like Unimúsica, what calls our attention is the recognition about aesthetic Daniel Drexler's point of view:

Drexler presents pop electroacoustic songs with a clear influence from folkloric genres from Prata river basin, such as milonga pampeana, candombe, chamarrita and the murga montevideana. Since 2005, he uses the term "Templadismo" to refer to a new aesthetic current integrated by Argentinean, Uruguayan and Rio Grande do Sul's musicians that are inspired by the topographic, climatic, demographic and regional reflexes under an open and creative creation, as well as 


\section{GEOGRAPHICAL IMAGINATIONS}

a positive and open attitude in order to absorb the influences of a globalized world (UFRGS, 2009).

Therefore, an influx of conceptions about the aesthetics of cold and Templadismo is seen inside public institutions, either through the recognition of them as conceptions of musicians' integration or through the establishment of a North - or a South, in better words - to programmatic actions in the cultural sphere. The discourse about platino identity is also under discussion, in dialog with the Brazilian identity. Such representations are undeniable in the sense of assumption of a distinguished character seeking dialogue with the countries of Prata in order to formulate an identity that connects with Brazil and a Spanish-speaking America.

Either for the collective shows or the events that discuss the trajectories of Southern music and its identity, even through the cultural events promoted by private or public entities, we noticed a territorializing intention of this musical activity, organizing artists, cultural producers and public around a new circuit of popular transborder music that articulates a network of cities. It is necessary also to consider the musical events because according to Romagnan (2000), music territorializes mostly because of festival and musical animations. It will be important to discuss the notion of event worked by Milton Santos. This geographer affirms that "if we consider the world as a group of possibilities, the event is a veiche of one of these existing possibilities in the world." (Santos, 2009:144)

Considering they don't repeat twice, the events are always new: "When they emerge, they are also proposing a new story", they transform objects giving them new characteristics. [...] they dissolve identities, proposing us other ones, showing that they are not static" (ibidem:146). If we recognize, according to Santos, that there is not an event without actor and without subjects, we visualize musicians in question as the source of creation of representations of space and the music being the vehicle of communication and the event as a becoming of represented space, its possibility of real existence that never fades. The events, in this case, may be of several types. There are events that connect artists with each other through human relations, the bounds of friendship, and the shared landscapes and languages. There are also the musical works merchandising events, where new ideas are broadcasted on television, radio, newspaper, internet sites, releases, photographs, CD covers, etc. During these events, the bounds of friendship stand out, as well as the representations of closeness between regional and national identities. In a third type, the platino space is played on stage; it becomes something complete because it allows to mix in one event musicians and their songs, languages, rhythms, representations of space, empathy with the public and specialized media. During the events, platino space becomes real not only for those who act, but also for the public that engages in performance. In the end, a fourth type of event goes towards cultural public policies. When institutions seek these and other artists to represent regional trans-border integration, they reinforce the scope of action of artists and also the idea of integration they propose, allowing new partnerships and several meetings. There is, however, a multidimensionality of events that 


\section{GEOGRAPHICAL IMAGINATIONS}

bound the individual experiences to collective ones, the public to artists and the cultural politics of music. Each event of these settles space, gradually becoming each node of the network of events as a new centrality. In this way, allying representation and action, musical practices territorializes along with the idea of a platino trans-border space.

In an attempt to explore the symbolic issue of territory, we can affirm this is understood as a place or a collection of places that mobilizes the registers of human and social life; it combines the concrete, material dimensions, their objects and spaces, their practices and social everyday experiences with the dimension of representations - ideas, images, symbols, memories - and power (Di Méo and Buleón, 2007). The territory may be understood also as a social relation with space that presupposes appropriation, occupation, domain and usage. Having in mind that human actions are not homogeneous through space and also that recent transformations of the world allow a communication each time more intense and unequal, it would be pertinent to consider the existence of several network-territories, formed by "lines (fluxes) that bound nodes (poles), never fulfilling space on its group", assuming also that this condition allows many "interstices that offer themselves to other forms of spatial organization" (Haesbaert, 2002:123). Thus, we see that network-territories can be overlapped and their nodes can be in contact or not, according to the nature of territorialities in question.

Here, we assume that territoriality, seen as a spatialized condition of the indiviual's action over the territory, or also as "a primary geographical expression of social power" (Sack, 1986:5). To Sack, the exercise of power in territorial terms involves area classification, means of communication by barriers and land access control. It is necessary, however, to take power into a more broad account. Foucault (1998) helps us to understand power must be considered more as a productive network that goes across the social body than a negative instance that aims repression solely. We could also complement with Arendt, when she says that "power arises there, where people gather and act concretely" (Arendt, 2011:23). From this point of view, I affirm, based on Sack (1986), territoriality is an instrument of maintenance of geographical context, guiding our experience in the world.

This way, it is possible to understand the production of a musical territoriality on platino space as a way to embody an effective flow of cultural agents that enable their own reproduction, independent from other centers of cultural circulation. At the same time this territoriality at course express the production of meaning to artists, helping them to build their experience, also collective, as it is expressed by the composer Richard Serraria in an interview.

We are also realizing Porto Alegre always spent time connecting Brazil, Uruguay and Argentina and we also always felt being isolated, always a litlle... peculiar characters for the rest of Brazil [...] Now with Mercosul we feel that we became a bridge among these cultures, we are beginning a new era of communication, of exchange, breaking 


\section{GEOGRAPHICAL IMAGINATIONS}

with certain prejudices that makes us feel like brothers, that the media and cultural prejudices are weakening (Unimúsica, 2009).

We notice that the geographying registers are mobilized in partnership with territorializing intentions. This means that at the same time artists represents platino space on their aestheticmusical conception, which are the product of cultural matrices and lived experiences, they search for forms of action that allow the instauration of a new centrality, or the legitimating of a space of circulation of the music they create. Of course, through the artists' declarations we can see that they seek not only to overcome professional barriers but also political and cultural ones. They identify geographical, historical and cultural traits on the trans-border space; they identify a moment of political and commercial openness on the region; they identify the need of the actors' organization and represent the space and treat it as a locus of their action. Musicians' mettings, seminars and workshops, provide debates, talks, conversations and exchange of experiences which results in a consensus about the isolated condition and the lack of perspective towards artistic reproduction. It was possible to create a group awareness that lead to action strategies about space.

In this sense, we point out the reflections made by Jovchelovitch (2008) towards the role of communication and social representations and their procedural character. According to the author, the representation "emerges like an mediating structure between the subject-otherobject. It is constituted as work, that is, the representation structures itself on a communicative action that bounds subjects to other subjects and to world-object". The author suggests we have to consider representations as a communicative action in terms of Habermas, because it creates at the same time that builds the participants of the communicative process. When I followed the artists during my research, I have noticed the organization of actions is not made in a sense of political project, like a manifesto, where there is a full convergence of opinions and also a permanent dialogue between partner musicians that seek contact points among their musical productions and their aesthetic conceptions. These dialogues were also built mainly outside formal instances, in rehearsals and several private meetings. Thus, many groups were created in trans-border partnerships involving the organization of gigs and albums.

\section{Popular platino Music: a musical territoriality}

In the previous sections, I have showed how the representations of space are elaborated on the sense of a geographying practice that aims to describe space and be situated on that space. I also intended to establish analogies between the musical composition and landscape, for example. It was discussed some aesthetics or musical proposals are situated on this space and complement each other through the search of common points of representation. Their music is consolidated on platino space and this can be considered as an overlap - not accurate between several geographical units like the landscapes of pampa, Mercosul, Prata river basin, 


\section{GEOGRAPHICAL IMAGINATIONS}

Conosur, among others. The mobilized characteristics to describe this shared place involves the rhythms, the trans-border character, the historical formation of the area, the contiguity of pampa, the climate, the existence of a moment of economical and cultural integration.

Moreover, the process of representation of space is added to territorializing practices. Artists seek a space to make their music be heard. This space is viable due to musical practice itself, living the represented space and also through the questioning of centrality of other musical markets such as São Paulo and Rio de Janeiro, for example, and through the proposal of a new cultural center that gravitates around Porto Alegre, Buenos Aires and Montevideo. When this new territoriality is produced, artists articulate a space of cultural and economical exchange of a trans-border nature. Thus, rhythms, languages and national imaginaries are put on dialogue and converge to a mutual recognition of shared cultural elements that contribute to the creation of new experiences of space and identity hybridism. Therefore, Music has significantly collaborated to the creation of territorialities that surely express the regional integration on Prata, gathering artists, public, cultural agents and culture policies. I understand this musical territoriality (re)composes platino space: it recomposes because it brings to surface the recognition of a shared past, before the establishment of boarders of Nation-States. It composes because the contents of representations and practices has been transformed by contemporaneity and by the current intentionality of the agents.

Platino space becomes possible through micro-integrations that multiply themselves through the actors involved. These micro-integrations are rhizomatic, expanding the network and creating a diversity of contexts able to escape some aesthetic conceptions of platinidade, but still represents a process of a trans-border integration because they include actors of different nationalities. In my opinion, these processes do not contain a statute of exceptions. They concern new forms of territorialities and experiences of space that transcends national borders and are articulated not in some area, but in a network. In methodological terms, the proposal of this multi situated field work was valid and embraced the numerous contexts of artistic creations and identity trading. This work also followed the relationship between musicians with their public and several cultural agents, observing in real time the growth of the network and the representations of space put into dialogue. When we study the representations of space, we understand these are practices: discursive practices and expressions of the lived world of actors and the contexts they engage, the events they organize and the flows they generate. When combining representations and practices in the same analytical movement, following their trajectories, I want to emphasize the procedural and the dynamic character of human territorialities without neglecting both the constitution of subjectivity through language and the geographical importance of flows, including also the perceptions and the lived world. On this way, I believe the geographical study of Music, due to its multidimensionality, may contribute to a reflection of plurality of the geography of humans in contemporaneity. And, above all, it may show the intrinsic relation between action, politics, culture, art and space. 


\section{GEOGRAPHICAL IMAGINATIONS}

\section{References}

Arendt, H., 2011. La condición humana. Madrid: Paidós.

Aubert, L., 1991. Mondes en musique. Genève: Musée d'ethnographie.

Berque, A., 1998. Paisagem-marca, paisagem-matriz: elementos da problemática para uma geografia cultural. In: R.L. Corrêa and Z. Rosendahl, eds., Paisagem, tempo e cultura. Rio de Janeiro. Rio de Janeiro: EDUERJ, pp.84-91.

Dardel, E., 1990. L'homme et la terre: nature de la réalité géographique. Paris: Comité des travaux historiques et scientifiques-CTHS.

Drexler, D., 2009. Micromundo. [1 CD] Porto Alegre: MS Produtora.

Fontoura, L.F.M., 2008. Recordações do Pampa. In: X Encuentro. El mundo como Geografia. Rosario: Centro Humboldt.

Foucault, M., 1981. Microfísica do poder. Rio de Janeiro: Graal Edições.

Gonzaga, S., 2010. Sergius Gonzaga comenta o Festival de Inverno. Prefeitura Municipal de Porto Alegre [online] 1 jul 2010. Available at: $<$ http://www2.portoalegre.rs.gov.br/festinverno/default.php?reg=3\&p_secao=11> [Acessed 30 aug 2010].

Haesbaert, R., 2002. Territórios alternativos. São Paulo: Editora Contexto.

Hall, S., 1997. Representation: Cultural representations and signifying practices. London: SAGE Publications Limited.

Hoy Diário, 2006. Entrevista con Daniel Drexler. [online] Available at: $<$ www.diariohoy.net/notas/verNoticia.phtml/html/228974> [Accessed 30 Jul. 2007].

Jodelet, D., 2001. Representações sociais: um domínio em expansão. In: Representações sociais. Rio de Janeiro: EDUERJ, pp.17-44.

Jovchelovitch, S., 2004. Psicologia social, saber, comunidade e cultura. Psicologia \& sociedade, 16(2), pp.20-31.

Jovchelovitch, S., 2008. Os contextos do saber: representações, comunidade e cultura. Petrópolis: Vozes. 


\section{GEOGRAPHICAL IMAGINATIONS}

Kong, L., 1995. Popular music in geographical analyses. Progress in Human Geography, 19, pp.183-183.

Kong, L., 1997. Popular music in a transnational world: the construction of local identities in Singapore. Asia Pacific Viewpoint, 38(1), pp.19-36.

Lévy, J., 1999. Le tournant géographique: penser l'espace pour lire le monde. Paris: Belin.

Leyshon, A., Matless, D. and Revill, G. eds., 1998. The place of music. New York: The Guilford Press.

Lussault, M., 2007. L'homme spatial: a construction sociale d l'espace humain. Paris: Éditions du Seuil.

Marcus, G.E., 1995. Ethnography in/of the world system: the emergence of multi-sited ethnography. Annual review of anthropology, 24(1), pp.95-117.

Di Méo, G. and Buléon, P., 2007. L'espace social: une lecture géographique des sociétés. Paris: Armand Colin.

Moscovici, S., 2001. Das representações coletivas às representações sociais: elementos para uma história. In: As representações sociais. Rio de Janeiro: EdUERJ, pp.45-66.

Raibaud, Y., 2005. Territoires musicaux en région: l'émergence des musiques amplifiées en Aquitaine. Pessac: Maison des Sciences de l'Homme d'Aquitaine.

Raibaud, Y., 2011. Geographie socioculturelle. L'Harmattan ed. Paris.

Ramil, V., 1993. A estética do frio. In: Nós, os gaúchos. Porto Alegre: Ed. da Univ. Federal do Rio Grande do Sul, pp.262-270.

Ramil, V., 1997. Ramilonga: A estética do frio. [1 CD] Pelotas: Satolep Music.

Ramil, V., 2004. A estética do frio. Pelotas: Satolep Livros.

Relph, E.C., 1979. As bases fenomenológicas da Geografia. Geografia, 4(7), pp.1-25.

Romagnan, J.M., 2000. La musique: un nouveau terrain pour les géographes. Géographie et cultures, (36), pp.107-126.

Sack, R., 1986. Human Territoriality: its theory and history. Cambridge: Cambridge University Press.

Santos, M., 2009. A natureza do espaço: técnica e tempo, razão e emoção. São Paulo: Edusp. 


\section{GEOGRAPHICAL IMAGINATIONS}

Turino, T., 2008. Music as social life: the politics of participation. University Of Chicago Press.

UFRGS., 2009. Unimúsica: cancionistas de hoje. Universidade Federal do Rio Grande do Sul. 1 folder.

UNIMÚSICA, 2009. Encontro com Daniel Drexler - Templadismo. [manuscrypt of conversation] (Personal archive, 04 jun 2009). Porto Alegre: Universidade Federal do Rio Grande do Sul. 
GEOGRAPHICAL IMAGINATIONS 


\section{GEOGRAPHICAL IMAGINATIONS}

Art (f), juvenile, mature, dedicated is looking for space $(\mathrm{m})$ for mutual and allround arrangements. Enriching geography classes through artistic practice

Romy Hofmann, Erlangen Nurnberg University

romy.hofmann@ewf.uni-erlangen.de

\section{Social scenery | the world we live in}

In times of increased flows of media-based information, truths are constantly produced and reproduced. Being up to date about the daily occurrences happening around the globe remarkably illustrates how people are confronted with different realities, watching the news on television, taking a newspaper as an additional medium or listening to one local radio station. The world surrounding us offers a lot of suggestions how to see and interpret our daily environment. This way of attracting, of grabbing our attention nowadays is becoming more and more sophisticated: our senses are increasingly addressed by different media. These do not exclusively spread "beautiful", "nice" pictures, but "ugly" and "repugnant" messages as well. This general trend can be called aestheticisation. Aestheticisation is not primarily about making up new gadgets or beautiful applications to enrich our daily lives. It describes another way of how they appeal to us and how we in turn perceive and make them meaningful. As part of this tendency, we assumedly do not exclusively decide or act according to rational purpose but we are guided by feelings, sounds, smells, colours and so on. Emotional and symbolic messages increase the attractiveness of phenomena (Walter, 2009). Supposedly "objective" factors such as statistics, numbers or size that claim one-dimensional causality cannot persuade equally. This is enforced by constantly and discursively negotiating aesthetics.

Figure. 1: German yogurt advertisement

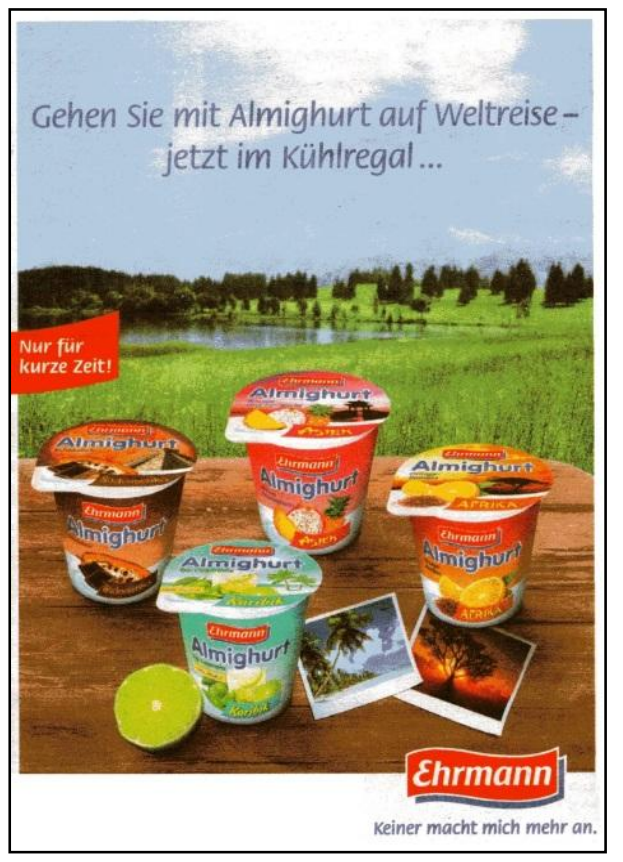




\section{GEOGRAPHICAL IMAGINATIONS}

Cinemas entice people to watch films in three or four dimensions: african landscape can authentically be seen and felt ("african adventure"), we can observe our extraordinary planet from above ("la terre vue du ciel") or plunge into deep sea ("océans"). This does not necessarily imply uniformity nor artificial performance since there are places or subjects we can only grasp in this way. Trips to foreign countries may start right in our living rooms. Yet this tendency has gone even further since media images gain importance compared to the images we actually find in our physical-material environment (Walter, 2009). The excessive use of aesthetics can be defined as "an-aestheticisation" (Welsch, 1990:13) or aestheticisation on the surface (Hoppmann, 2000:63) - leading to the process and state of losing one's ability to feel sensitively because of an aesthetic overload. It takes place on a psychic level and becomes a social phenomenon (Hoppmann, 2000:15).

If we go on a trip around the world with a german dairy, for example, we will visit south america, africa, the caribbean and asia (fig. 1). South america - this is chocolate next to a mayan pyramid; the sunset in africa is accompanied by oranges and tea; in asia we may try pineapple and dragon fruit at the beach; and the caribbean entices us with lime cocktail and palm tree beach. This could probably make a geographer's mouth water. Not just because of the exotic taste of the yogurt but of the geographic references implied. People can even wear paris, new york city, chicago or london tubemap (fig. 2) on their wrist. Styles of clothes are ought to reveal which city people come from: there is "the berlin type", rather casual und informal than "the hamburg style".

Advertisements and products appeal to us, especially our senses and should finally make us consume them. Even more important, they construct a specific reality of geographic locations: when taste is related to specific countries or places become meaningful when having them with us, when actually wearing them. The shopping centre where nice music is been played and where it smells of fresh flowers creates a relaxed atmosphere to encourage consumption. Things or situations take on meaning just in a particular context. Embedding this into the conditions of an increased disposition of experience and pleasure, german sociologist Gerhard Schulze (1992) speaks of an "experience-driven society" ("erlebnisgesellschaft").

However, although further privileging our senses there are sensory perceptions which, to some extent, are still disregarded. The example of smell should make this obvious. ${ }^{72}$ there is no other sensory perception than smell that entails such prejudices (Apin, 2007): we link feelings, experiences, people and objects to different smells, hence categorising and evaluating.

${ }^{72}$ Bischoff (2007, pp. 33-35) explicates the disregard of smells in detail and underlines the necessity of sharpening this sense on the basis of two examples from Frankfurt/Main in Germany. 


\section{GEOGRAPHICAL IMAGINATIONS}

Figure. 2: Aesthetic jewellery: London tubemap cuff (seen on http://www.designhypeinc.com/)

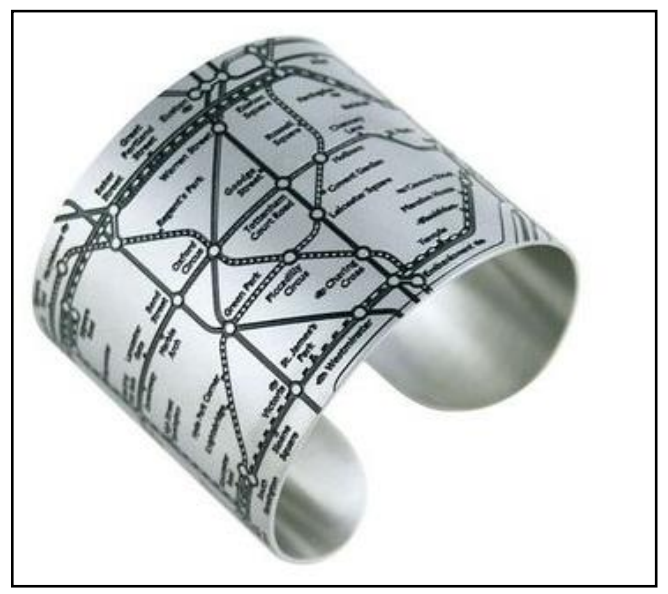

Often, language cannot grasp the variety of smells and associated sensations. Investigating smell is yet emerging as a relatively new discipline, mainly in architecture (Weihser, 2012). Nevertheless, smell has a long history so far. In the United States and United Kingdom during the nineteenth century immigrants underwent 'sanitary salvation' in order to become "civilised" (Henshaw, 2012). Another way of "treating" smells and hence people's perception was undertaken in Madeira in 2006, where a fish market was planned that did not smell of fish at all (Weihser, 2012). It is less surprising that indeed smell has a lot to do with identity: we strongly measure people or circumstances due to our preconceptions: a business man should smell of expensive perfume, whereas pedestrian underpasses or the subway convey a variety of fairly unpleasant odours. Constructing people's identities may reflect upon respective spaces and vice versa. These are geographical imaginations as well. The more intensely these (aesthetic) factors are stressed, the more meaningful things become, with the final effect of delineation or differentiation. We, as responsible and sensible actors should be aware of our senses and the factors influencing our perceptions.

\section{From spaces to places | first approaches to geography}

In the course of aestheticisation, the term "media" refers to an even broader range of factors conveying and constructing information. These "new geofactors" is what new cultural geography is interested in. This perspective in current geography is especially looking at how people assign meaning to things and how this affects the spaces we appropriate. Attaching importance may result in statements of like - dislike - indifference: taking lovely photographs of our environment, frequently visiting places - avoiding streets, writing sceptical guidebooks - thoughtlessly roaming the streets or throwing away litter in parks. The underlying thought is that the world does not merely consist of arbitrarily arranged material artefacts but it is we as central actors who personally make them significant. The things do not do anything. Places thus do not exist 


\section{GEOGRAPHICAL IMAGINATIONS}

before the things: things take on meaning only by processes of individual or social performance. A person eating a "south american" yogurt might do this not because of satisfying his hunger but enjoying the sensation of holiday when consuming it. Other people might have different feelings about the product nor even buy it. Consequently, there cannot be one single truth nor spaces with only one option to use. We recognise different perspectives on our world instead of praising one universal paradigm (Glasze, Hofmann and Uphues, 2012:6). In the course of the cultural turn taking its origin mainly in cultural studies, fixed categories and positivistic concepts became dissolved in the second half of the $20^{\text {th }}$ century. This paradigm shift conceives realities as constantly produced, re-evaluating phenomena such as language or symbols for daily life. There is a variety of turns re-considering their basic principles. The spatial turn is especially relevant not only for geography, but other disciplines dealing with spaces as well. Following this, geography (education) established four concepts of spaces as modes to look at them (Wardenga, 2002).

Geography conventionally conceives spaces as containers that are - metaphorically - filled with elements of the physical-material world, such as streets, people, numbers about the weather, names of places and so on. These structures can be represented in maps, tables or graphs giving a sensation of a clearly conceivable world as it objectively is. Secondly, we think of spaces as systems of spatial relations: the objects and spatial structures are linked together in terms of analysing distances, infrastructure planning or trading connections and commodity flows between two or more countries. These two concepts are extended in the course of a constructivist understanding of spaces. We do not take things for granted in the sense of "it is like this" but we are looking at how things and especially spaces are becoming what we think they are. Spaces are results of individual or social perceptions. People perceive spaces differently, depending on the knowledge, aims, backgrounds they have. Tourists will think of Lisbon in other dimensions than does an inhabitant. Climate researchers will advise local residents in Guatemala to leave the area while they keep on praising the fecund soil there to grow new vegetables. Finally, spaces are considered social constructions. Media is a strong factor producing spaces, be it language, images, photographs, newspapers. The "axis of evil" consisting of North Korea, Iran and Iraq as evil terrorist and dangerous states was labelled by George W. Bush in 2002 and discursively maintained by the media with the effect of powerfully subsisting in our minds. When hearing about Iran few people might think of persian high culture at first sight. Spatial constructions can serve as legitimate factors for various actions, be it war or the construction of contested buildings, for example Hamburg Elbphilharmonie. Thinking of spaces as social constructions, we have to look at how, why and with which consequences they take on this special meaning. These two last conceptions recognise a plurality of spaces. It is important, however, not to fall back into dichotomies praising the last concept of spaces while neglecting the idea of spaces as containers. It should be noted that these concepts need to be 


\section{GEOGRAPHICAL IMAGINATIONS}

thought together since we connect elements of our physical-material environment with individual perceptions, mental images of and actions in spaces.

On the one hand, this (spatial) contingency - at least theoretically - allows for additional appropriation of spaces in our daily lives when appreciating individuality. We just have to challenge underlying norms and values: why do we usually walk on the pedestrian, whereas the streets are only cancelled for cars in case of manifestations? Is it allowed to have breakfast on a public square? These considerations might be helpful in terms of urban planning, where inhabitants, even children, are involved in the planning processes. If some (spatial) realities, as claimed by the media, are discursively repeated and remain unquestioned, they can become accepted in a sense that people see them as binding and the only truth. On the other hand, more options to choose may result in confusion or doubts. Acting in a world where everything seems possible causes uncertainties. After all, there are routines which help finding orientation in our daily lives - routines that need not be challenged.

\section{Art \& geography}

Nowadays, aesthetics is persistently surrounding us, be it in restaurants, train stations, at the barber's or most unusual places like Siemens underground car park in Munich or a museum on germany's highest mountain zugspitze (Rauterberg, 2008:11). It seems as if we are exceedingly requested to think and see aesthetically, to constantly decide what to buy, to eat, to wear by consulting our senses. Following this line of reasoning it is vital to maintain orientation in everyday life. Before reflecting on this question it should briefly be considered which notion of art is applied here.

Attempting at a general definition, art(s) describe(s) a huge array of cultural processes. Those productions can take on different shapes: dance, painting, sculpture, literature, music, photography, architecture and so on. Departing from the notion that art is not primarily functional but rather meeting aesthetic purposes, it matches with the aforementioned tendency towards experience and pleasure. Even functional objects - thinking of furniture - are made for moderately hedonistic reasons in order to make us feel satisfied. Design is in line with promoting pleasure and well-being (Murphy, 2005:1). 


\section{GEOGRAPHICAL IMAGINATIONS}

Figure. 3: is this art? - it's all about the context! (own illustration)

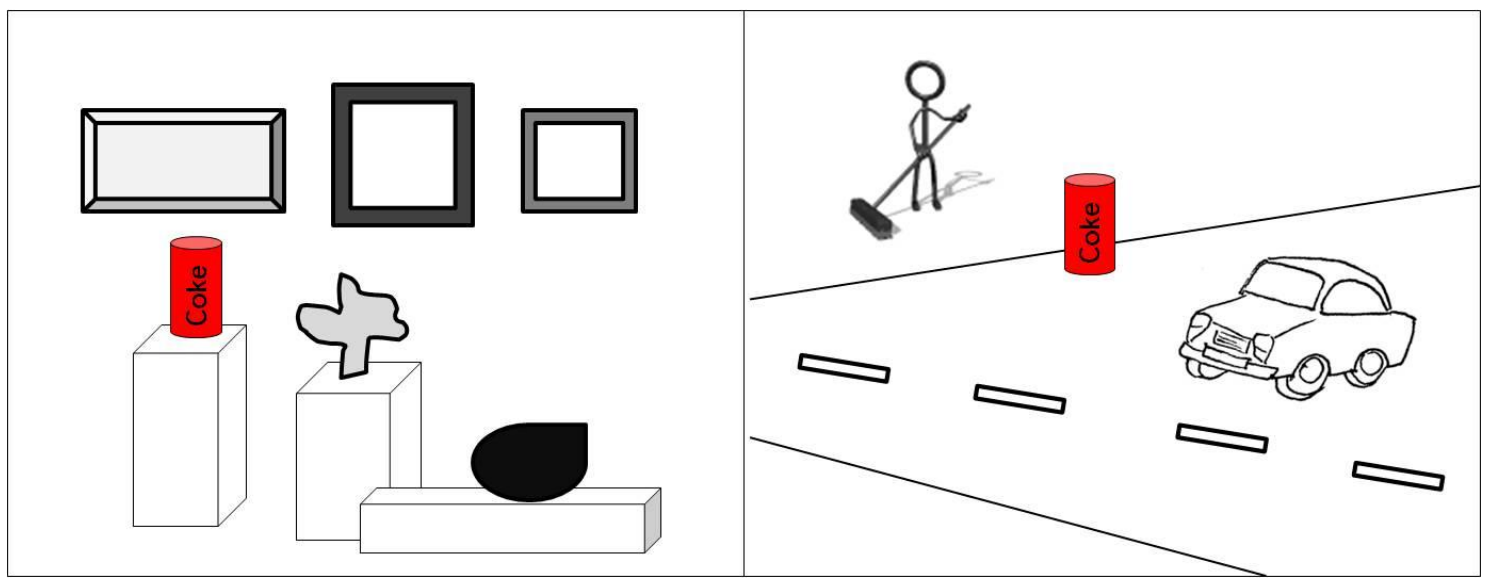

One aspect that should be considered though is the practice and usage of artworks in their relation to spaces. Do people appropriate or think of spaces differently when conceiving them as artistic or aesthetic structures rather than ordinary things? What art finally means to individuals depends on the particular context (see fig. 3).

\subsection{Artistic potentials}

Art is more than just language. It uses and requires other senses than the eyes for looking or fingers for painting. Thinking of the south american yogurt as an artwork in the broader sense, it becomes obvious that art produces symbols: things or actions which emblematically "stand for something". They follow a so called "mode of displaying" (Kathke, 2010): visual communication is prompted by their existence. Often, by merely been shown they stimulate an inner reaction that need not nor cannot always be verbalised by its reader. Even intercultural understanding is said to be made possible via the arts, conceiving them as a "universal language" and praising openness (Gao, 2009).

Art is a mirror of society. This year's biennial arts festival for architecture in Venice brought to the surface that times of financial scarcity and crisis do call for a cultural change even in artistic production, architecture included. For one year, architects have studied everyday life in torre david, a 45-storeyed office building in Caracas that has not been finished yet. The artists' aim was to deduce strategies for renewal and amelioration of living conditions of 750 families, therefore being awarded the "golden lion". It was just the national newspapers that became furious about this incident since they were afraid that a "badge of shame" would be illustrated at the most important architecture exposition (Weissmüller, 2012). Art is indeed and in many ways a highly political issue. An italian group of artists invented a game for iphones with which to critically bring into spotlight the contested resource of cobalt and its excessive usage for technical devices. The players had to push children soldiers on to work in the mines. Following 


\section{GEOGRAPHICAL IMAGINATIONS}

this, Apple Company removed the software from its product line within minutes (Süddeutsche, 2012). Even in terms of music, artists take a leading role in claiming political rights and social improvements. Artistic techniques further display pieces of society. Photography distributes them in an often more aesthetic way than merely watching photos in a photo album. Albert Watson took snapshots of benin cotton farmers being involved in the initiative called "cotton made in Africa". Artistic practice combines aesthetics with the meaningful.

Working in a "shelter" (Biehler, 2004:306), in the sense of a safe space, art(ists) dare(s) to articulate not only critique but judgements more frankly (Tagesspiegel, 2012). In 2010, an art student created a sculpture called "peeing petra". She was an astonishingly authentically looking policewoman crouching down with lowered pants. This artwork could be seen in the exhibition hall in Dresden art academy. To make matters more authentic, they even created a puddle from plastic - because the water they had originally used did harm to the historic floor. The student ultimately won a prize for this (Fries, 2011; Lüpke-Narberhaus, 2011). Art creates intermediary spaces, influences atmospheres and brings irritations into seemingly stable contexts (Biehler, 2004:305). A swiss project investigated to what extent museums and their artworks influenced visitors' emotions (Dradio Kultur, 2009; Rauterberg, 2012). In their psychogeographic study, they found that art is less a matter of rational minds than a bodily experience. Aestheticisation is not far away.

As has become clear from the previous accounts, art offers space for open interpretation. A good artwork is an open artwork leaving space for own and diverse readings (eco, 2002). The approach of aesthetics of reception stresses the individual contribution in the process of reading artworks and thus perceiving them as such. Rooted in literature theory, it was then applied to the arts as well. Aesthetics of reception in the 1970 - understanding Wolfgang Iser (1976) - saw the reader as active part in the constitution of meaning of literary texts. They contain "empty spots" which are to be filled by the reader. In this sense, artists are "crucial producers of urban imaginations" (Nippe, 2011:10), but are not more than stimulators. After all, believing Michel de Certeau $(1988: 16-17 ; 85)$ we are all tactical and creative artists of the everyday life. Via tactically interfering into spatial structures we appropriate spaces individually and are even able to contest the mighty's strategies. This can be seen on a small scale at the memorial for the murdered european jews in berlin: chiefly young people are sitting at or jumping from one stele to the other. The artist's intention, on the contrary, was to commemorate the death of millions of european jews during nazi regime in a place of depression and narrowness. The "gap" between intended and actual use of this place seemingly results from a lack of knowledge by the youngsters. Nevertheless, people are not abandoned from there by force. The artist leaves the appropriation to the people. The "death of the author" (Roland Barthes, 2000; original text: 1968) eclipses the potency of the artist's intentions while emphasising the recipient's own way of reading - not only - artworks. Meaningfulness is produced by the reader. In line with the cultural turn challenging fixed assumptions of beliefs, multiple artistic practices do not rely on normative concepts either. They are seen as open processes that do not fear the unknown or 


\section{GEOGRAPHICAL IMAGINATIONS}

uncertain outcomes. Aestheticisation builds the bridge between geography and art. Artistic productions create multiple spaces which require aesthetic perception in order to comprehend them.

\subsection{Liaison}

Art and geography obviously share some striking similarities. First and foremost, both require the people. Art is operating in spaces while concurrently producing them. These are spaces working as symbolic locations. Whereas until the 1990s artistic productions had to work "together" with the space of reference and even their meaning was determined by it, the "functional space", termed by james meyer began replacing this dependent relation. Artworks were intentionally temporary (Möntmann, 2002:47), either resorting to the physical-material surroundings or not. It is the interaction between observer, artwork and space that constitute the particular place - a place of ephemeral qualities which consists of preliminary un-meaningful matters becoming significant through us (Rottmann, 2003). Fischer-Lichte (2008) describes the fact that artists are more and more producing symbolic events than mere "objects" as "aesthetic of the performative". Significantly, it is not just the artists or geographers who see those potentials in opening the concept of spaces. Even philosophers and sociologists such as Rorty and Luhmann (Besand, 2006) argue accordingly. Be it conscious- or unconsciously, artist do not conceive spaces as strictly physical-material conditions. Rather, "[...] A site may be a group of people, a community“(John Lindell cited in Möntmann, 2002:48). Functional or not, the interest lies in what place is being constructed with which consequences and under which circumstances. In other words, it is about the (geographical) question behind artistic productions.

By the middle of this year hamburg dustmen received wide media coverage. With their action called "tonnographie" (a word creation from german "dustbin" and the suffix "graphy") they created site-specific works being presented in a photography exhibition. They used an 1100 litre-rubbish container as a pinhole camera - with an exposure time of up to 90 minutes. The action was initially planned as a media campaign in order to increase the dustmen's image. The factors contributing to their success were various: the professional group of dustmen implemented a quite new idea that probably nobody else had done before. It was their individual perspectives that came to light, which in turn could even make hamburg inhabitants get to know new places they might have never been before. After all, dustmen cover a large scope of action getting to know the city even under different perspectives. Last but not least, media coverage facilitated promoting the exhibition of their photographs (Hinzundkunzt, 2012). But the most vital consideration was the following: any type of site-specific work does require the knowledge of the special place (Möntmann, 2002:48). Following up Iser's thoughts, the importance of artists/geographers/sociologists as "professional readers" comes up again here. 


\section{GEOGRAPHICAL IMAGINATIONS}

\subsection{Examples}

There might be disagreement about the sense and value of artistic occurrences. When Christo did his coverings with huge scarves in Berlin (1995) and New York (2005) he wanted to sensitise people and raise their awareness on the symbols of policy. Wrapping berlin reichstag, christo redescribed buildings, enveloped their meaning so that people could reappropriate them newly.

In other words: things must be transformed or substituted to change our positions in order to look at them again and see how things are seen from the other perspective and to finally recognise the changes in our perception. Alternative associations should be transferred to the political context (Besand, 2006). People even speak of an ecologic aesthetic because Christo's works do not leave traces other than mental reminders. Artistic phenomena need not necessarily be displayed in public space. Maps alike construct realities by aesthetic/artistic practice. The emotional map of greenwich (fig. 4) displays people's feelings when walking through the town. Technical devices record people's personal sensations and translate them into a map while confirming the graphs with individual explanations. In this case, the graph reaches a peak when the person was having an "argument with mum". The different steps to model the artwork and the product itself are aesthetic in nature. The geographic question behind is how do I feel, perceive a part of the city and why is it like this?

Figure. 4: Emotional Map Greenwich by Christian Nold

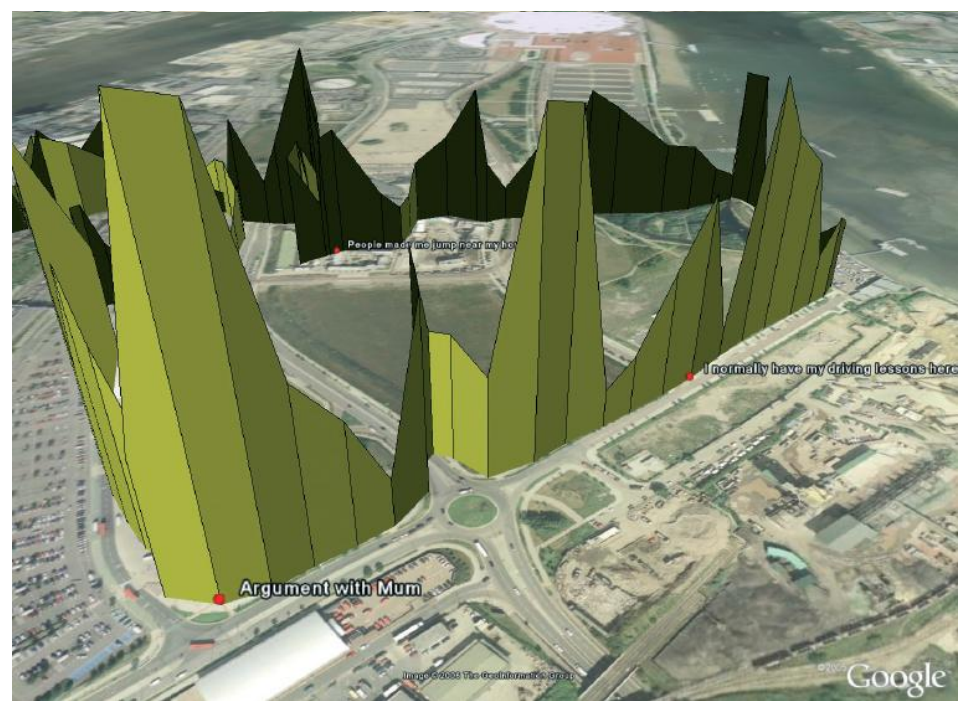

\section{4. $A(r) t$ school}

There are plenty of ways how to do art. Nevertheless, it is not just about the "huge stage" and big artists displaying their work in museums on a global level. The "mean man" (De Certeau, 1988:9) participates in the daily making of spaces as well. Derived from the potentials of artistic 


\section{GEOGRAPHICAL IMAGINATIONS}

interventions the question arising now is which significance art has for students ${ }^{73}$ then, especially in geography classes?

\subsection{Geographic and educational relevance}

Departing from the basic (cl)aim in the particular context of (german) geography education, students' spatial orientation should be fostered. It does not suffice to know how to read maps and decipher their symbols correctly but to acknowledge that spaces are social constructions (see the four concepts of space). The increasing influence of new aesthetic media, such as sounds or smell, plays a vital role in the construction of places. It is an essential precondition to let the students (re)discover their own relation to spaces. This does not mean to constantly report their position in physical spaces via smart phones but to recognise their symbolic standing points which may include opinions and feelings about the locations they frequent or are familiar with. The perception of spaces, for which reasons and with which consequences we appropriate them can be the result of media images. Do I avoid parts of a city because the news about the place make me frightened?

Decision-making competences is what follows from spatial orientation skills. These do not always amount to "real actions" in our environment, but firstly comprise students' mental disposition, awareness of circumstances and willingness to act in spaces as well. These competences involve students' knowledge because aesthetics is not just about observing birds and feeling astonishment. Looking through "aesthetic lenses" can help them acquire knowledge because in this way, by using all their senses, they can better recognise details as well as questioning routines and what seems rather normal to them.

German human geographer Jürgen Hasse (2007:5) understands spatial orientation as aesthetic in nature: it requires both self-reflection and world-reflection, especially in times of increasingly directing and influencing awareness. He (2001:2-5) therefore marks different moments in terms of aesthetic education, starting with raising sensory perception. "perceiving with all senses" suggests corporeality, sharpening feelings and emotions. Sensitising our senses helps expanding the idea of "what is thinkable" (Hasse, 2001:3) - which is not only the objects we see and touch. Self-reflection via sensory awareness includes recognising the plurality of realities wherein my opinion is just one next to others. This point targets at our ability to subjectivity. In a world where we are offered a variety of acting options, we should first and foremost be able to verbally express our own standing point before choosing one option or the other. We should further be aware that aesthetic perception fundamentally does not follow any obligation or purpose: we should not always have expectations about what to see or feel; rather letting our mind open for new experiences. Finally, spatial orientation understood as aesthetic education fosters and claims critical thinking. This does not mean finding mistakes while pointing the finger at people but to allow alternative ways of reasoning, for example by using our senses in order to fill spaces of ignorance. The claim of an "aesthetic look" leads to the emphasis of doing

\footnotetext{
${ }^{73}$ Although the focus is on the students, it concerns us as well.
} 


\section{GEOGRAPHICAL IMAGINATIONS}

something with spaces, not just in them. The daily way to work, going along the streets portrays actions we normally and routinely do in spaces, whereas actions with spaces include feelings, understanding meaning(s) by actively engaging in them. It is not for no reason that john Dewey (1988:47) speaks of experiencing. Incidental experiences, such as enjoying a rich meal, do not account for real experiences unless we are aware of the ingredients, the process of preparation and finally bringing these aspects together in the moment of consumption (Dewey, 1988:61). Only then can this experience be remembered and of long duration. Finally, decision-making competences go beyond mentally roaming spaces in our heads or on paper. Students should be encouraged to actively interfere into spatial structures.

\subsection{Mapping | bridging geography and the arts}

The mapping-approach prolifically bridges art and geography. Where traditional geographic methods do not suffice to grasp the processes of how meaning is attributed to spaces, mapping targets at creative appropriation, be it mentally or physically, of spaces. Often mapping is labelled as "artistic cartography" (Busse, 2007) although the focus is not necessarily on a map. The traditional understanding of maps as objective and real images of the world give way to the notion of subjective and individual spatial readings. As "subjective cartographying" (Möntmann, 2002:48) - stressing the ongoing and active involvement - mapping describes the idea of "cartography of perception and awareness" (Fredric Jameson cited in Möntmann, 2002:48). It is a kind of site-specific work (Möntmann, 2004:16) where students apply rather different artistic research methods, for example drafts, photos, poems, sculptures and so on. In mapping processes we take possession of spaces in order to develop and display the contingent modes of their existence.

\subsubsection{Mapping at school}

Mapping processes are always initiated by recognising our own subjective presumptions and expectations (reconstruction). This step implies the students' increased attentive- and awareness for their everyday lives: understood as a quest, they are consciously searching, but without knowing in advance what this would be. They will however discover things they have not expected (Sabisch, 2007:18). In this way, students access the space in its qualities and atmospheres. They are looking from the distance ("naive view") while effectively sensing, perceiving and being involved in the spatial structures. It is crucial to acknowledge that the very position, opinion, background, feelings - subjectivities - do indeed influence the way students perceive the spaces and if they do at all. Students will investigate spaces and question assumptions taken for granted. This can be done either totally free or with the help of some hints by the teacher. Students should express their opinions, be it verbally, by paintings or writings; even brainstormings prove suitable. Their own beliefs are then broken up during the second step (deconstruction) when discovering new structures (Busse, 2007). In the course of 


\section{GEOGRAPHICAL IMAGINATIONS}

the deeper investigation subjective assumptions are broken up. Additional context information will be helpful in order to back up their knowledge and experiences. Students reflect their own standing point in comparison to others. Following this, newly acquired knowledge and perceptions are translated into the public space ${ }^{74}$ by artistically rearranging it (deconstruction). With the help of a research question students go on to develop an alternative idea of its uses and transform it accordingly. Students are animated to engage in the rupture of "conventional" spatial structures. The aim is not to decorate places and to put new things into them but to give the place another meaning, another way to use or to see it. When mapping spaces students are given the opportunity of self-actualisation: they can narrate their own history of spaces and tell us about themselves (Busse, 2009:38). This third phase of a mapping process always requires people as a public mass. Spatial experiences should be continued together with passer-bys (Busse, 2007:264). The artistic reorganisation ought to disorientate people's views with the aim of initiating processes of critically questioning their beliefs and practices in those spaces.

By now, there are similar terms used to express equal procedures. "hacking"- or "guerrilla"actions are in fashion in bigger and smaller towns. The prefix guerrilla points to the unauthorised practices of putting new structures - lights (lightning), plants (gardening), yarn (knitting), benches (benching) or even others - into public spaces. After all, it is a question of good labelling and promoting. Hacking actions aim at an even more innovative level. The term is employed in a positive and educational sense (Hofmann, Mehren and Uphues, in press): hackers do not merely criticise but want to achieve changes or improvements. There might be many more mapping- or guerrilla-actions in our daily environment we do not even actually make out as such.

Mapping processes in educational contexts can benefit from teachers' qualified contribution. Working with different groups of students facilitates coordination. A reasonably planned temporal frame will allow for completing the single steps. Due to the rather "open" approach of art and the concept of spaces, however, some difficulties might arise before initiating mapping processes at school. On the one hand, the open proceeding encourages free operation whereas on the other hand outcomes cannot strictly be planned.

\section{Mapping | example}

Mapping actions at school can be implemented in any grade, depending on the subject or aims to be achieved. Geography lessons in particular do not only allow for performances within the classroom but site-specific work in the field as well. Mapping processes can start by a previously set question or the students are carefully guided towards the specific matter. One example suitably illustrating the mapping approach is the subject of segregation in cities, especially gentrification. The artistic implementation of this urban development has a famous pioneer, namely american artist Martha Rosler. In her three-part exhibition „if you lived here...”

\footnotetext{
${ }^{74}$ Another kind of mapping action could be done by using music to stimulate changed atmospheres in public spaces. It is possible to do a mapping with a conventional map, either. Students may modify the map in content and/or form and distribute them to the people. They must document their reactions.
} 


\section{GEOGRAPHICAL IMAGINATIONS}

(1989) she brought to light the increasing social differences and segregation going along in New York at the end of the 1980s. She arranged three different thematic exhibition rooms.

The question of public versus private spaces is a controversial one, but is suitable to be discussed, not least because we often accept rules or values. Students are equally able to broach this issue (for details see Hofmann, Mehren and Uphues, in press):

This school unit could start at a public place near the school. For the first phase of reconstruction, students follow the people's actions there. They playfully think about other possible routines the person might follow and how he/she might feel there. Every student writes a quasi-fictitious report from the first-person-perspective and in small groups presents it to the others. In the phase of deconstruction the students will question their previously unreflected statements. Therefore, they do a brainstorming on "public space" and "non-public space", followed by a short discussion concluding what and how a public place might be. Photos of intended but scarcely visible exclusion, such as benches built in circles around trees or single seats - where homeless people are prevented from sleeping - can serve for sensitising the students for exclusion in public spaces. In small groups, they will go to the place a second time and try to identify other intended and unintended ways of excluding groups of people (skaters, old people, the disabled). These are then cartographically fixed and compared. This phase terminates with the groups deciding for one form of exclusion. For the third phase of construction, the students think of a method to make exclusion visible for the general public. Resorting to books and the internet, students inform themselves about the situation of this excluded group. The third phase starts in the classroom where students develop their own artistic idea to interfere into the chosen part of the place. A bench could be decorated with cushions, a blanket and a lamp in order to attract the homeless people to stay there. When having modified the place, the students must observe the passengers' reactions. They can either report their actions by camera, text, video, or directly talk to passer-bys discussing the issue of exclusion of the homeless. Back in the classroom, the hacking action should be reflected and potentials for urban planning be discussed.

Other possible places can be "non-places" (Augé, 2006) such as airports, shopping malls or train stations. These are places without own identity: in times of increased mobility they are frequented without profoundly reflecting about their structures and meaning. Mappings can go beyond site-specific actions, stressing the social significance of geography education. Artistic practice can guide both teachers and students when dealing with multimedia-based and aesthetic perception of the mobile phone, for example. A school unit on the mobile phone can entice students to find their own stance on the usage of this ubiquitous medium within media culture (Brohl, 2007). Billmayer (2011) demonstrates how shopping and consumption can be brought into class. This issue too bears high relevance for geography that is dealing with sustainability, food and clothes, as well as higher-level questions of identification via consumption and lifestyle. 


\section{GEOGRAPHICAL IMAGINATIONS}

\section{Conclusions}

It must be acknowledged, however, that there are also temporary artistic interventions conveying a whiff of spectacular event but that are missing apt backgrounds. Mappings must not be practiced as l'art pour l'art but follow a certain (research) question. They are consciously temporary and call for the "destruction" of the functional place - in order not to impose rigid meanings of it. Mappings are no permanent constructions. Otherwise, they pose the risk of becoming attractions and even leading to gentrifying effects. In order to avoid nuisance mapping actions should always refrain from violence and destruction. There has been a wave of guerrilla- and hacking-actions recently, trying to impose different meanings while selfrepresenting their authors. In the context of geography classes, the mapping approach should be stuck to.

Subsuming these thoughts under the headword of spatial orientation, geography education must not stop at the claim to know the way to school or the nearest supermarket. It is about displaying the extent of possible actions in and encouraging the appropriation of spaces. Artistic practice facilitates orientation in spaces of our society. ${ }^{75}$ it is understood as the ability to read signs and traces as well as producing them on our own. Artistic practice and methods do help grasping geographic issues more profoundly and help facing unknown situations more confidently.

In the special context of education, artistic practice contributes to the free development of the individual; UNESCO road map for arts education states that "[c]ulture and the arts are essential components of a comprehensive education leading to the full development of the individual" (2006:3). For educational applications, the arts need not abandon their idea of playful interventions. Students' decision-making skills can be increased, not just in terms of real actions. These methods help pointing to social grievances and inefficiencies without moralising. Mapping actions imply traits of postirony, which means they combine seriousness and humour. Furthermore, participation in social discourses can be stimulated by these practices since students see that they can change something in their environment. Their skills to evaluate are even fostered to the point of changing their meanings. Students' lifeworlds serve as a perfect linking point because geographic matters can be aggregated to a local level. After all, students have a certain relation to their hometown and this, in turn helps stimulating interests and awareness. For geography as school subject as well, there are several advantages. Students and teachers can see what geography further comprises, recognising its huge social relevance. Artistic approaches offer new ways of practicing field work for example. Last but least, the transfer of methods and subjects to other contexts and school subjects is viable. The blurring of boundaries between the disciplines of geography and the arts benefits both of them.

${ }^{75}$ The following conclusions are drawn from a research project the author has been carrying out in two classes ( $11^{\text {th }}$ grade) in German geography lessons and are based on the respective oral presentation. 


\section{GEOGRAPHICAL IMAGINATIONS}

\section{References}

Apin, N., 2007. Montagsinterview: "neukölln hat den radikalsten duft". Taz, [online] 16 december. Available at: <http://www.taz.de/!9630/> [accessed 23 june 2012].

Augé, M., 2006. Non-places. Introduction to an anthropology of supermodernity. London: verso.

Available at: <http://epub.sub.uni-hamburg.de/epub/volltexte/2009/4041/> [accessed 20 january 2012].

Barthes, R., 2000. Der tod des autors. In: f. Jannidis, ed. 2000. Texte zur theorie der autorschaft. Stuttgart: reclam, pp.185-193.

Besand, A., 2006. Verhüllen oder enthüllen? - ästhetik als herausforderung für sozialwissenschaft und sozialwissenschaftliche bildung, journal of social science education, [online] available at: < http://www.jsse.org/2006/2006-2/pdf/besand-enthuellen.pdf> [accessed 03.05.2012].

Biehler, C, 2004. Ein - räumen - aus - reizen. Bildhauerische maßnahmen am ort und für den ort. In: j. Kettel, ed. 2004. Künstlerische bildung nach pisa. Beiträge zum internationalen symposium "mapping blind spaces. Neue wege zwischen kunst und bildung". Oberhausen: athena, pp.304-313.

Billmayer, F., 2011. Shopping - ein angebot zur entlastung der kunstpädagogik, zeitschrift kunst medien bildung (zkmb), text im diskurs, [online] available at: $<h t t p: / / w w w . z k m b . d e / i n d e x . p h p ? i d=73>$ [accessed 01 september 2012].

Bischoff, W., 2007. Nicht-visuelle dimensionen des städtischen. Olfaktorische wahrnehmung in frankfurt am main, dargestellt an zwei einzelstudien zum frankfurter westend und ostend [pdf] available at: <http://oops.uni-oldenburg.de/volltexte/2009/830/pdf/bisnic07.pdf> [accessed 03.05.2011].

Brohl, C., 2007. Multimedium handy - eine künstlerische forschung [pdf] available at: <http://www.lehrer-online.de/multimedium-handy.php> [accessed 02.09.2012].

Busse, K.-P., 2007. Vom bild zum ort: mapping lernen. Norderstedt: books on demand.

Busse, K.-P., 2009. Kartografieren. In: b. Welzel, ed. 2009. Weltwissen kunstgeschichte: kinder entdecken das mittelalter in dortmund. Norderstedt: books on demand, pp.31-38.

De Certeau, M., 1988. Die kunst des handelns. Berlin: merve.

Dewey, J., 1988. Kunst als erfahrung. Frankfurt am main: suhrkamp. 


\section{GEOGRAPHICAL IMAGINATIONS}

Dradio Kultur, 2009. Kunst macht nervös. Martin tröndle im gespräch mit christoph schmitz. [online] available at: <http://www.dradio.de/dlf/sendungen/kulturheute/992635/> [accessed 06 september 2012].

Eco, U., 2002. Einführung in die semiotik. München: fink.

Fischer-lichte, E., 2008. Ästhetik des performativen. Frankfurt am main: suhrkamp.

Fries, M., 2011. Aufregung um die pinkelnde petra. Zeit online, [online] 11 januar. Available at: http://www.zeit.de/studium/uni-leben/2011-01/walldorf-petra-kunst [accessed 02 march 2012].

Gao, X., 2009. Interkulturelles verstehen durch kunst im zeitalter der globalisierung. Doctoral dissertation at mlu munich [pdf] available at: <http://edoc.ub.unimuenchen.de/10388/1/gao_xuan.pdf> [accessed 03 september 2012].

Glasze, G., Hofmann, R. and Uphues, R., 2012. Stadträume als gesellschaftlich hergestellte räume. Praxis geographie, 1, pp.4-6.

Hasse, J., 2001. Ästhetische bildung. Plädoyer für eine verschränkung von wahrnehmungs- und denkvermögen im lernen [pdf] available at: <http://www.fb16.tudortmund.de/kulturwissenschaft/symposion/hasse.pdf> [accessed 02 june 2012].

Hasse, J., 2007. Ästhetische bildung - eine doppelte perspektive ganzheitlichen lernens [pdf] available at: <http://www.widerstreit-sachunterricht.de> [accessed 20 june 2012].

Henshaw, V., 2012. Shock, stench and filth: smell and historians of the urban environment. Smell and the city blog, [blog] 21 may. Available at: <http://smellandthecity.wordpress.com/2012/05/21/shock-stench-and-filth-smell-and-historiansof-the-urban-environment/> [accessed 10 september 2012].

Hinzundkunzt, 2012. Tonnographie. Fotos aus dem müllcontainer. [online] available at $<$ http://www.hinzundkunzt.de/nachrichten/fotos-tonnografie-stadtreinigung/> [accessed 30 june 2012].

Hofmann, R., Mehren, M. and Uphues, R., (in press): hacking the city. A somewhat different mode of field work. European journal of geography.

Hoppmann, H., 2000. Pro:vision. Postmoderne taktiken in einer strategischen gegenwartsgesellschaft. Eine soziologische analyse. Berlin: wissenschaftlicher verlag berlin.

Iser, W., 1976. Der akt des lesens. Theorie ästhetischer wirkung. München: fink. 


\section{GEOGRAPHICAL IMAGINATIONS}

Lüpke-Narberhaus, F., 2011. Pinkel-polizistin „petra“. "die frauen sind auf meiner seite". Interview mit marcel walldorf. Spiegel online, [online] 12 january 2011. Available at: http://www.spiegel.de/unispiegel/wunderbar/pinkel-polizistin-petra-die-frauen-sind-auf-meinerseite-a-738988.html [accessed 02 march 2012].

Möntmann, N. Ed, 2002. Kunst als sozialer raum. Köln: könig.

Möntmann, N., 2004. Mapping. A response to a discourse. In: n. Möntmann and y. Dziewior, eds. 2004. Mapping a city. Ostfildern-ruit: hatje cantz, pp.14-22.

Murphy, I. L., 2005. An hedonomic evaluation of pleasurable human-technology experience: the effect of exposure and aesthetics on the experience of flow. Doctoral dissertation at university of central florida [pdf] available at: $<$ http://etd.fcla.edu/ct/cfe0000875/murphy_lauren_200512_phd.pdf> [accessed 03 september 2012].

Nippe, C., 2011. Kunst baut stadt. Künstler und ihre metropolenbilder in berlin und new york. Bielefeld: transcript.

Rauterberg, H., 2008. Und das ist kunst? Eine qualitätsprüfung. Frankfurt am main: fischer.

Rauterberg, H., 2012. Wirkung von kunst: und die herzen schlagen höher. Zeit online, [online] 20 april. Available at: <http://www.zeit.de/2012/17/museumbesuch-studie> [accessed 13 may 2012].

Rottmann, A., 2003. Das unendlich kleine. Diskurse über kunst im öffentlichen raum. [online] available at: <http://eipcp.net/transversal/0102/rottmann/de/print> [accessed 03 may 2012].

Sabisch, A., 2007. Inszenierung der suche. Vom sichtbarwerden ästhetischer erfahrung im tagebuch. Entwurf einer wissenschaftskritischen grafieforschung. Bielefeld: transcript.

Schulze, G., 1992. Die erlebnisgesellschaft. Kultursoziologie der gegenwart. Frankfurt am main: campus.

Süddeutsche, 2012. Wirtschaft: kobalt. [online] available at: <http://newsticker.sueddeutsche.de/list/id/1354420> [accessed 12 september 2012].

Tagesspiegel, 2012. „künstler sagen leichter die wahrheit“. Nicola kuhn im interview mit artur zmijewski. Tagesspiegel, [online] 18 january. Available at: http://www.tagesspiegel.de/kultur/kuenstler-sagen-leichter-die-wahrheit/6077960.html [accessed 28 february 2012]. 


\section{GEOGRAPHICAL IMAGINATIONS}

Unesco, 2006. Road map for arts education. The world conference on arts education: building creative capacities for the 21st century [pdf] available at: <http://portal.unesco.org/culture/en/files/40000/12581058115road_map_for_arts_education.pdf/ road+map+for+arts+education.pdf> [accessed 12 september 2012].

Walter, J., 2009. Baukultur als standort- und wirtschaftsfaktor. Hamburg [online]

Wardenga, U., 2002. Alte und neue raumkonzepte für den geographieunterricht. Geographie heute, 23(200), pp.8-11.

Weihser, R., 2012. Smellscapes. Die stadt mit der nase entdecken. Zeit online, [online] 11 september. Available at: http://www.zeit.de/lebensart/2012-08/lust-auf-stadt-smellscapesgeruch-nase [accessed 12 september 2012].

Weissmüller, I., 2012. Hanteln stemmen in der hochhausruine. Süddeutsche zeitung, 30 august. Welsch, W., 1990. Ästhetisches denken. Stuttgart: reclam. 
GEOGRAPHICAL IMAGINATIONS 


\section{GEOGRAPHICAL IMAGINATIONS}

\section{Place, flavors and musicality}

Dariane Raifur Rossi, Federal University of Rio Grande do Sul

dariane.rossi@gmail.com

\section{Introduction}

We currently still face an education based on the transfer of knowledge by a teacher who transfers information from reproduction. The most modern educational theories already indicate the construction of knowledge from students, taking into account their prior experience, empirical knowledge. The current school must mean the themes to be worked from experiences, experimentation, problems which instigate the curiosity in classroom (Freire, 1997; Moran, 2006).

There is a whole dynamical and social school challenging us today, presenting new dilemmas, new forms of teaching and mainly an agile positioning which is set up according to the daily scenario of social, economic and technological changes. This panorama of transformations is present in every field of our lives, and it makes us constantly reflect on the types of values, attitudes and knowledge that guide our life in society.

The following words by Moran (2006:22) sum up the new view of education, an innovative education:

We learn better when we live, experience, feel. We learn when we relate to one another; make bounds; links between what was missing, chaotic, disperse, including them in a new context, giving them reason, a new meaning.

We learn when we discover new dimensions to the meaning before it slips away, when we broaden the surrounding of our understanding, when, much as an onion, we peel new layers that seemed hidden to our perception before, which make us comprehend in another way. We learn when we make bridges between reflection and action, experience and concept, theory and practice; when they both are mutually fed.

We learn when we balance and integrate the sensorial, the rational, the emotional, the ethical, the personal and the social.

We learn from the pleasure, because we enjoy a subject, a media, a person. Games, pleasant environments, positive stimuli can facilitate learning.

We learn more when we can gather all the factors: we have interest, clear motivation; develop habits which facilitate the learning process; and feel good about what we are studying and how we do it. 


\section{GEOGRAPHICAL IMAGINATIONS}

According to the words above and the teachers' teaching practice, an interconnection between geography and other areas of knowledge less fragmented is seek, aiming at a sum of the parts favoring the formation of a set.

Under this view, school provides optimal elements to teaching inter-subjectivity and belonging, that is, an environment where students, through dialog, can create knowledge upon a critical view of their reality.

\section{Justification}

This premise is already present in Geography and in the changes the school has been through in recent years; in order to reformulating educational methods, didactical materials are extremely important for the teacher's work. Didactical material contribute as instruments that enable the planning of good didactical situations, seeking the promotion and extension of student's knowledge, allowing that they develop concepts, problematize issues and articulate contents (Rossi and Rossato, 2007).

From the need of offering a new focus on the study of regional geography in Brazil, a work proposal that favored a different view of the Brazilian culture by means of cooking, hearing and interpretation of music was thought. The "Aprendendo Geografia pelos sabores e músicas do Brasil' (Learning Geography Using Flavors and Music from Brazil) workshop was developed by geography teachers Dariane Raifur Rossi and Maíra Suertegaray Rossato at Colégio de Aplicação da Universidade Federal do Rio Grande do Sul (Laboratory School of the Federal University of Rio Grande do Sul - CAp / UFRGS).

The teaching of geography by flavors and musicality is a contribution to the regional study, as it values a critical reading of the places and their different cultures. The perceptive experience of the student not only in the school and its surroundings, but also in society favors the formation of the feeling of identity, which we relate to the idea of belonging, and this is the intimal exchange relationship of transformations established between an individual and his/her environment.

Demystifying this interrelation is an essential component to building critical citizenship awareness, which is why relating living experiences with school teaching is so important.

In this case, Santos (1997) expresses that the study of the place is essential to the living environments, as it "constitutes the dimension of existence manifested upon the routine shared among different people and is the base to common life." In addition: It concerns a geographical treatment given to the world lived. This treatment has been assuming different dimensions; on the one hand, place is distinguishes from the subjective views connected with emotive perceptions, while in the other hand it concludes all answers and experiences we have in the environments we live in. This implies understanding place by means of our existential needs, 


\section{GEOGRAPHICAL IMAGINATIONS}

namely, location, position, mobility, interaction with objects and/or people. This perspective identifies with our corporality and, from it, our being into the world.

These considerations contribute to the perceptive construction of the subject in his/her reality. Accordingly, pedagogical practices with different languages for the teaching of Geography are proposed to promote the building of concepts by the five senses: hearing, sight, touch, smell and taste.

The work with different representations allows students to know their world and their society by means of practices which privilege cultural, moral and ethical formation, and which promote the intellectual and emotional development, awakening the creativity, autonomy and criticism.

For Tuan (1980), the perception of the senses can be understood as "a set of biological mechanisms which can be influenced by culture and, in this case, the construction of worldviews and the possibility of changing its attitudes to relate to the environment."

Accordingly, the way of understanding the space is related to how each individual perceives his/her place of living.

The discovery of their place into a social and ecological context, and the understanding of their interactivity with these environments are crucial to the formation of an active and participative personality from young students.

It is therefore included in the perspective of cultural geography after the 1970s, when a process of recovery of the cultural approach in geography started to be outlined.

It was no longer about studying the cultural diversity based on their material content, but to admitting that the culture is closely linked to the system of representations, meanings, values which create an identity that is manifested through socially shared creations and expressed spatially, i.e. to admit that the culture in its broadest anthropological sense represents the entire lifestyle of a society, which not only includes the production of material objects, but also a cultural system (ethical, moral values, habits and meanings expressed in social practices), a symbolic system (unifying myths and rites) and an imaginary system, which serves as the link between the last two, therefore forming the locus of space identity of a group (Zanatta, 2008:254).

Therefore, according to Corrêa (2003:13), the concept of culture

$[\ldots]$ is released from the supra-organic vision and from the culturalism, in which the culture is seen according to the common sense and has explanatory power. It is also immunized against the structuralist vision, in which the culture would be part of the "superstructure", being determined by the "base". The culture is seen as reflection, mediation 


\section{GEOGRAPHICAL IMAGINATIONS}

and social condition. It has no explanatory power; on the contrary, it needs to be explained.

In this context, many analytical perspectives have been proposed to understand the intense transformations of geographical space, as well as to guide the work of school geography education required to the formation for critical citizenship. Among them, a critical-oriented perspective which, from the 1990s onwards, acquired significant relevance due to its agreement with the postmodern movement, and the cultural approach. In this approach, one can highlight the interest for the research of a plurality of subjects related to popular culture, folklore, ethnicity, gender, religion, the food/cuisine and the landscape, as well as to different art forms like music, literature and poetry.

According to McDowell (1996:159):

Cultural geography is currently one of the most exciting areas of geographical work. Ranging from the analysis of everyday objects, representation of nature in art and in films to studies of the meaning of landscapes and the social construction of identities based on places, it covers many issues. Its focus includes the investigation of material culture, social customs and symbolic meanings, addressed from a number of theoretical perspectives.

Precursor to the cultural approach, Sauer (1963) understand that the task of geography is conceived as the establishment of a critical system that includes the phenomenology of landscape, in order to capture all the meanings and colors of the varied terrestrial scene. To this author:

There is a strictly geographic way of thinking about culture, which is as the mark of the man's work on the area. We can think of people associated with an area or on an area, how we can think of them as groups associated by lineage or tradition. In the first case, we are thinking about culture as a geographical expression, consisting of shapes that are part of geographical phenomenology (Sauer, 1963:326).

A society's cuisine represents one of the tastiest aspects of a culture, in addition to enable the conduction of a study and an analysis of the history and geography of a place. With the study of its typical cuisine, students will be able to perceive and understand the changes that dishes suffer over time, the discovery of human inventions, the influence that people receive from other people. In addition, cuisine has an affective aspect because the scents and flavors of food bring about pleasant feelings and memories. The social function of the meal is also important 


\section{GEOGRAPHICAL IMAGINATIONS}

because people not only eat for food, but to live with relatives and friends a shared pleasure, a way of being and living (TVE Brasil, 2008).

The use of music connected with the work with food was extremely beneficial, as music is present in our daily lives, expressing feelings on our living space. Music is a cultural representation, allows the everyday knowledge of the most different places and spaces, of societies and social interactions contained in it. The pedagogical construct it offers is learning by restructuring, i.e. a rereading of conceptions of reality. It has an accessible language, because it awakens the sensitivity and works with different intelligences (Rossi and Rossato, 2007).

The integrated pedagogical practice of cooking and music depicts Brazilian places and cultural aspects, awakes curiosity and stimulates the senses of students. On the other hand, building a pedagogical proposal based on sensory experimentation allows teachers to develop a greater referential instrument, able to favor them in developing their teaching process and systematizing the content and information in a more creative manner.

\section{Purposes}

The following objectives have been considered when building the proposal of workshop for the students:

- building the notion of culture as an expression of lifestyles;

- knowing the formation of Brazil from regional cultural differences expressed by cuisine, associated with reading music of many genres;

- comparing aspects of the history and geography of the Brazilian regions;

- valuing and preserving the cultural plurality which characterizes our country

- developing autonomy against proposed educational activities;

- raising awareness about the importance of being responsible for his/her obligations in face of proposed activities;

- relativizing and reflecting critically concepts and information worked in classroom; and

- interpreting different textualities (music, texts, images and maps).

\section{Syllabus}

The objectives proposed in the workshop involved the study of the following contents:

- the Brazilian territorial formation;

- the settlement of Brazil;

- the Brazilian culture according to the food and musicality;

- the ethnic composition of Brazil and its different contributions; and

- the Brazilian regions, its landscapes and features. 


\section{GEOGRAPHICAL IMAGINATIONS}

\section{Contextualizing CAP, project Amora and the workshop's proposal}

The Colégio de Aplicação da Universidade Federal do Rio Grande do Sul (Laboratory School of the Federal University of Rio Grande do Sul - CAp/UFRGS) was founded in April 14, 1954 with the initial priority of serving as internship for teaching degree students, according to the Decree of Law No. 9053, of March 12, 1946.

From the year of its foundation up to 1996, CAp was located in the building of the School of Education (FACED) in the central campus of the University. The transfer of the CAp to Campus do Vale occurred in 1996, where its facilities have broader space and better infrastructure.

Currently, the student body is made up of 658 students, 58 students belonging to EJA (youth and adult education), and the faculty is composed of 90 teachers, including those away for training. The Laboratory School currently has 22 employees of the staff of UFRGS and 16 outsourced employees (including cleaning staff, canteen cooks, guards, electrician, among others).

Students enter the CAp through a public draw for the school years corresponding to each end of school year. These students come from different socio-economic realities and also from other neighboring municipalities. This variety of realities allows the clear perception of different cultures, thereby promoting the enrichment of the practices experienced by students.

The Project Amora is a curricular proposal developed in the $5^{\text {th }}$ and $6^{\text {th }}$ grades of the Middle School of CAp and is intended to build knowledge from the interrelation between the multiple facets of the different areas of knowledge, which provides a broad and inter-relational vision of the reality, also very appreciated by integrating affection and cognition creatively. Accordingly, the syllabus of Project Amora, by its characteristics of flexibility, permits the inclusion of many methodologies and pedagogical resources, favoring communicative, interactive and cooperative processes linked to the new communication and information technologies.

The workshops are part of the activities of Project Amora and are intended to develop thinking skills. These workshops are formed by groups of 15 to 20 students on average with different cognitive styles and learning times, generally indicated by the group of teachers. In these workshops, these students develop specific activities, such as textual production, comic books, cooking, educational games, etc.

The workshops occur in planning cycles - action, observation and reflection -, which gives the opportunity of participants to methodizing on the practices, as well as understanding the relationships collected from data, appreciation and speech developed. In this way, a continuing and mutual interaction between teachers and students is set up to distinguish the occasions in which the contradiction and the balance of what is established collectively can be encompassed.

According to Vigotsky (1984), such an approach favors the extension of the zone of proximal development, insofar as it is an area of social interaction as a decisive element for the development and expansion of the potential of subjects. 


\section{GEOGRAPHICAL IMAGINATIONS}

When creating offers the interdisciplinary work among teachers of the school is also possible, which further enriches the proposal as it fosters the exchange between colleagues with different experiences and provides students with many opportunities to look over certain issues.

In this work mode, the student opts for the subject he/she wants to work; two choices are made during the school year and, therefore, the conduct of the course occurs during one semester. By being subjects of free choice, the groups are usually small and mixed, including students from $5^{\text {th }}$ and $6^{\text {th }}$ grades, allowing a closer work, more focused on the needs and interests of the group.

The workshop "Aprendendo Geografia pelos sabores e músicas do Brasil" (Learning Geography Using Flavors and Music from Brazil) occurred in the second semester of 2007 (9/14 to $12 / 14$ ) at the Laboratory School, using two periods on Fridays in the morning shift, for ten

weeks. Spaces used for the workshop were the kitchen, granted by the initial grades of the school (Project Unialfas), and the classroom of students. In these meetings, these ten students prepared the recipes, tasted them, describing their sensations and perceptions from the experimentation, in addition to becoming aware of different cultural aspects of Brazilian regions. This practice allowed students to approach the cooking universe and discover recipes which mark the trajectory of the Brazilian construction and cultural differences. The inclusion of music was a manner of presenting messages and testimonials of the social reality that each artist reports in his/her musicized poetry about the perceived space, thereby contributing to critical geographic knowledge and social and cultural inclusion facilitator.

When searching the cooking traditions of Brazilian regions, students studied aspects of history and geography at the regional scale. In addition, an activity was set up in which they would learn to value and to preserve the cultural plurality that characterizes our country. The table below expresses in summary the typical recipe and music chosen for each class according to the order they were presented (Table 1). 


\section{GEOGRAPHICAL IMAGINATIONS}

Table 1 - Summary of music and regional typical recipes presented and prepared with the students during the workshop

\begin{tabular}{|c|c|c|}
\hline Region & Music & Dish \\
\hline South & $\begin{array}{l}\text { Desgarrados } \\
\text { (Sérgio Napp and Mário Barbará) }\end{array}$ & $\begin{array}{l}\text { Arroz de china pobre e chimarrão } \\
\text { (a recipe of cooked rice with } \\
\text { sausage) and mate }\end{array}$ \\
\hline North & $\begin{array}{l}\text { Sabor Açaí } \\
\text { (Nilson Chaves and João Gomes) }\end{array}$ & $\begin{array}{l}\text { Castanha-do-pará, bolo de } \\
\text { guaraná e suco de açaí (Brazil } \\
\text { nut, Guarana cake and acai berry } \\
\text { juice) }\end{array}$ \\
\hline Center-West & $\begin{array}{l}\text { Saudade Brejeira } \\
\text { (José Eduardo Morais and Nasr Chaul) }\end{array}$ & $\begin{array}{l}\text { Arroz com pequi (rice with souari } \\
\text { nut) }\end{array}$ \\
\hline Southeast & $\begin{array}{l}\text { Boi } \\
\text { (Zeca Pagodinho) }\end{array}$ & $\begin{array}{l}\text { Tutu de feijão, doce de leite com } \\
\text { coco e caldo de cana (mashed } \\
\text { black beans, dulce de leche with } \\
\text { coconut and sugarcane juice) }\end{array}$ \\
\hline Northeast & $\begin{array}{l}\text { O vaqueiro e o pescador } \\
\text { (Antonio Nóbrega) }\end{array}$ & $\begin{array}{l}\text { Castanha-de-caju, tapioca doce e } \\
\text { suco de caju (cashew nut, sweet } \\
\text { tapioca and cashew juice) }\end{array}$ \\
\hline
\end{tabular}

\section{Description of the methodological proposal of the workshop}

The methodological development to make up this workshop followed the three steps described below. Typically, in each meeting of one hour and a half, the musical analysis, the recipe and the comments of the day were developed.

In the first stage, the students started in the classroom with a regional musical activity, in which they heard and interpreted questions on the music. Following, the song "Sabor Açai" (Acai Berry Flavor) is presented, authored by Nilson Chaves and João Gomes, which was presented to students and from which discussions that addressed cultural, environmental, social and economic aspects related to the extraction of acai palm in northern Brazil were made.

\section{Sabor Açaí}

(Nilson Chaves e João Gomes)

E pra que tu foi plantado

E pra que tu foi plantada

Pra invadir a nossa mesa 


\section{GEOGRAPHICAL IMAGINATIONS}

E abastar a nossa casa

Teu destino foi traçado

Pelas mãos da mãe do mato

Mãos prendadas de uma deusa

Mãos de toque abençoado

És a planta que alimenta

A paixão do nosso povo

Macho fêmea das touceiras

Onde Oxossi faz seu posto

A mais magra das palmeiras

Mas mulher do sangue grosso

$E$ homem do sangue vasto

Tu te entregas até o caroço

E a tua fruta vai rolando

Para os nossos alguidares

$E$ te entrega ao sacrifício

Fruta santa fruta mártir

Tens o dom de seres muito

Onde muitos não têm nada

Uns te chamam de açaizeiro

Outros te chamam juçara

Põe tapioca, põe farinha d'água

Põe açúcar, não põe nada, ou me bebe como um suco

Que eu sou muito mais que um fruto

Sou sabor marajoara

Sou sabor marajoara

The questions proposed and discussed in the group of students were as follows:

1) Which is the region described in the Sabor Açaí song. Justify your answer, indicating elements that support your explanation.

2) Which economic activities particular to the region are represented in the Sabor Açaí song? Justify your answer.

3) What is the role of food in the Sabor Açaí song? Justify your answer. 


\section{GEOGRAPHICAL IMAGINATIONS}

4) What cultural elements of each region can be identified in the Sabor Açaí song? Justify your answer.

5) Choose excerpts of the song that best represent the image below. Justify your answer.

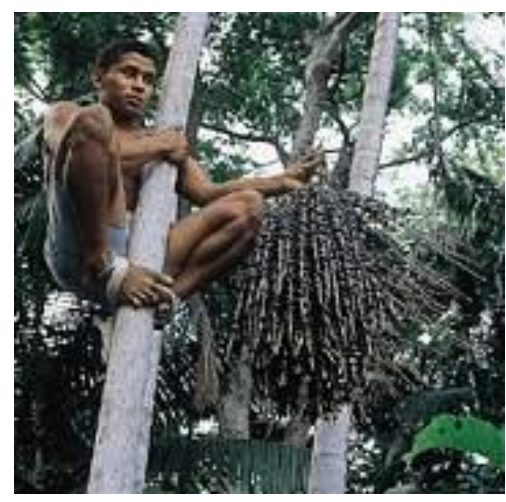

Source:globorural.globo.com

After discussing the lyrics of the song, students received a material on the cultural aspects of the region to be studied and the recipe to be developed on the day. The material on the cultural aspects of each region and the proposed recipe for the day were read and discussed with the group to facilitate the exchange of ideas and clarification of doubts. Still in the classroom, students decided the roles to be developed by each for the production of the recipe and the kitchen cleaning.

In the second stage, the students went to the kitchen wearing mop cap and apron set, washed their hands and get ready to start the recipe. On the kitchen table, they separated, washed, cut each of the ingredients and ordered according to the use in the recipe. In the initial procedure, each student would get one of the ingredients for a teacher who was assisting in the preparation, observed the beginning of preparation and then, individually, each student developed the recipe (Figures $1 \mathrm{a}$ and $1 \mathrm{~b}$ and Annex 1). Participation in the preparation favors the perceptions of scents and textures of the ingredients, as well as the construction of the student's autonomy and criticism. When the preparation is finished, students would serve and taste the finished recipe (Figures $2 a$ and $2 b$ ). They would clean the kitchen and the objects used and return to their classroom. There, they noted down in their gastronomic folders comments on the recipes, indicated on a map the region covered, and always at the end of each meeting, the next region to be studied would be raffled and student be assigned their homework (Figures $3 \mathrm{a}$ and $3 \mathrm{~b}$ ). The homework consisted of small researches on regional legends, customs and trivia, such as the legend of acai berry, which comes from the north through the vision of an indigenous community. To search this legend, students had the opportunity to explore the literary richness of other places and introduce them to the group. See the legend searched by student Géssica on the website www.portalamazonia.globo.com: 


\section{GEOGRAPHICAL IMAGINATIONS}

Before there was the city of Belém, capital of the State of Pará, in the Amazon, a large tribe occupied that region. Food was scarce and life became increasingly difficult with the need to feed all the Indians of the tribe. It was then that the Indian chief of the tribe, called Itaki, made a very cruel decision. He decided that from that day all the children who were born would be sacrificed to prevent an increase of their tribe's Indians. One day, however, the daughter of the cacique, who was called laçã, gave birth to a beautiful girl, who also had to be sacrificed. laçã was desperate and, every night, cried for missing her little girl. For many days the daughter of the Indian chief didn't come out of her tent. In prayer, she asked Tupã to show his father another way to help his people without having to sacrifice the poor children. After that, on a moon night, laçã heard a child crying. She approached the door of her hut and saw her little girl smiling, at the foot of a slender Palm tree. She was amazed at the sight, but soon after threw herself into her daughter's arms, embracing her. Mysteriously, however, the girl disappeared. laçã was heartbroken and cried a lot until she fainted. The next day her body was found, embracing the trunk of the palm. In laçã's face a smile of happiness could be seen and her black eyes stared the top of the palm tree, which was loaded with dark berries. The Indian chief Itaki then order that the berries would be taken in a barrel of wood, which they mashed and obtained a red wine that was called acai, in honor of laçã (which is acai when written backwards). With the acai berry, the Indian chief fed his people and, from that day, suspended his order to sacrifice children.

Reading and discussing the text of the legend presented above was the motto for the tasting activities involving acai juice and some typical products of the northern region, such as Brazil nut and the guarana cake, in addition to stimulating a debate about the influence of indigenous culture in our food and our vocabulary. 


\section{GEOGRAPHICAL IMAGINATIONS}

Figure 1 - The moment in which participating students, duly uniformed, cut the ingredients (a) and prepare the recipe (b).

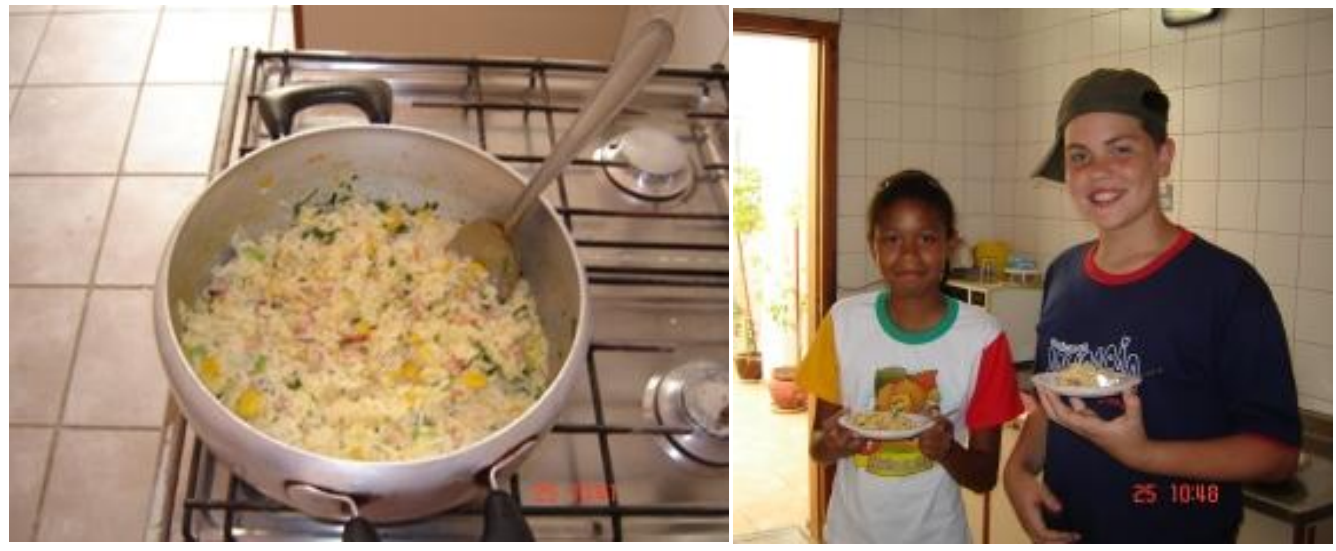

Figure 2 - Recipe of arroz com pequi prepared by students representing the Central-West region cuisine. When the students did the tasting (b).

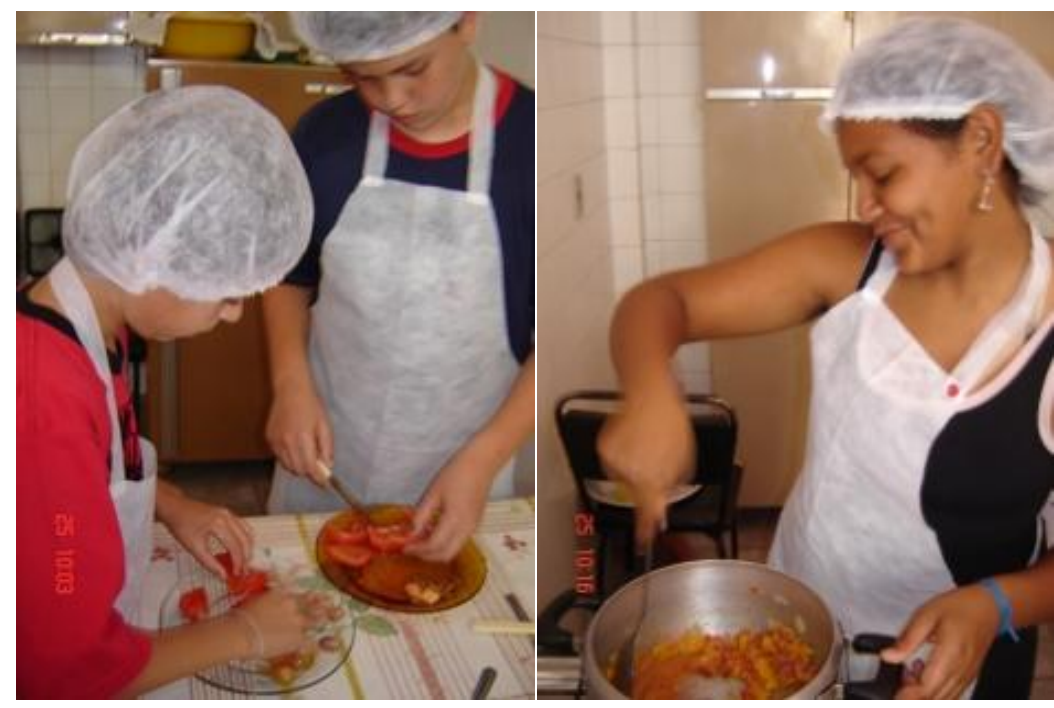

Figure 3 - Moment when students heard and discussed about the songs, in addition to the record of their impressions of tastings in their recipes folder.

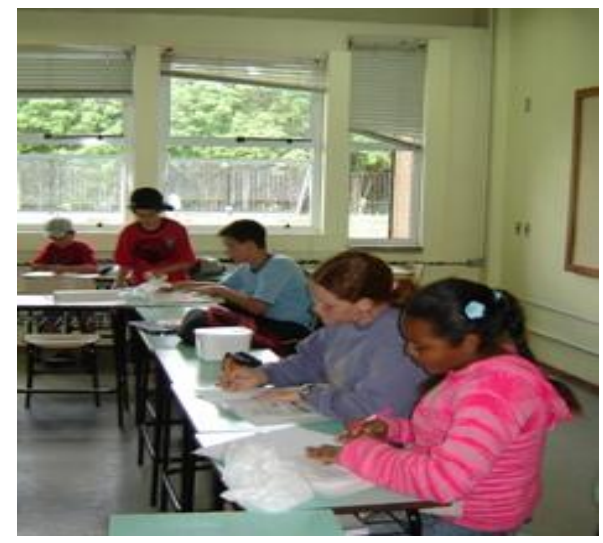




\section{GEOGRAPHICAL IMAGINATIONS}

The third stage was carried out after the study of all Brazilian regions by the students. A map of Brazil separated into five regions with a white track was presented. This track went from the first region that had been studied and finalized in the last region where the regional cultural studies were conducted. This way, the group of students had to create questions and answers about each region from the bibliographic material organized during the meetings, meetings, structure the board, make the dice and create the rules of the game. Then the group met, played the Jogo das regióes e seus sabores (Game of the Regions and Their Flavors) and evaluated the work (Figure 4).

Figure 4 - Image of the Game of the Regions produced by students at the end of the workshop. In this game, the students drew up the questions and the answers on each region from the bibliographic material worked in the classroom, in addition to elaborating the board, the sheets and creating their own rules

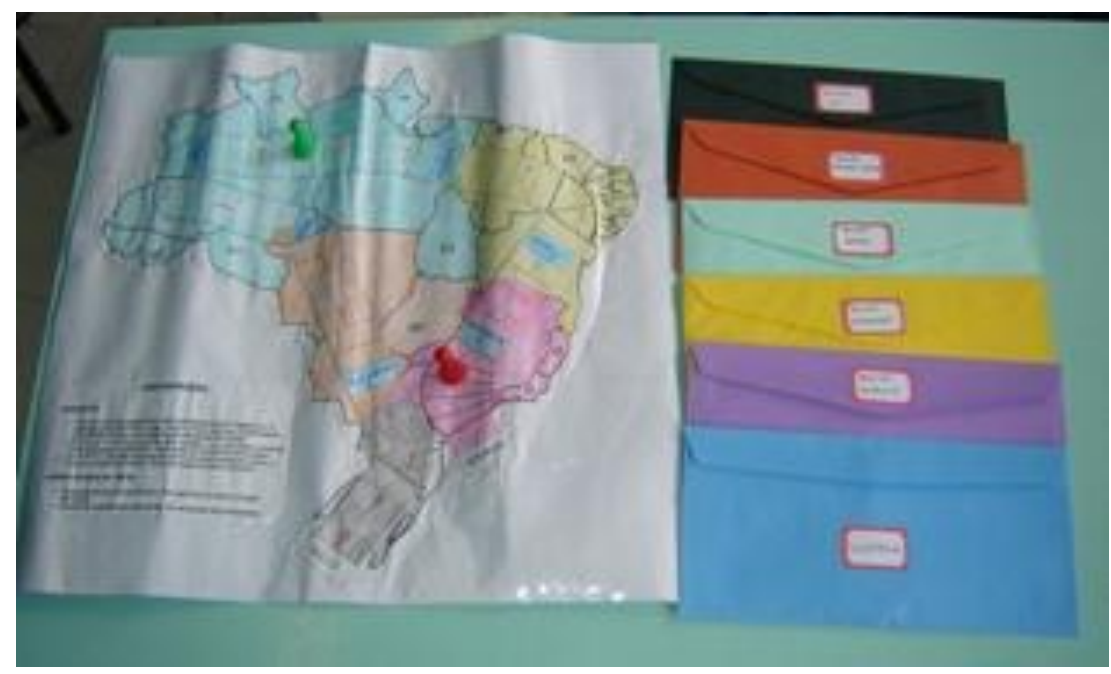

\section{Results obtained}

The development of this workshop brought significant results for the construct of geography teaching and for students' personal and psychopedagogical formation.

Students who participated in the workshop have shown dynamism, participation and interest in carrying out the work. The posture observed was valuation of work from the reception of the proposal and initiative in bringing tips on ingredients, other recipes and, mainly, the reports made to family members and other colleagues about the workshop. In this sense, families participated effectively, as they helped in moments of preparation of proposed tasks and also give the opportunity at home to practice the recipes learned in the workshop practice, encouraging students' creative and autonomous postures.

Another important result was the change of students' behavior perceived by teachers. At the beginning of the workshop, the group was aggressive and unwilling to accept the opinion of colleagues and work together. In the course of work, attitudes have changed to stimulate greater unity and solidarity between them and to value different viewpoints. This transformation 


\section{GEOGRAPHICAL IMAGINATIONS}

was relevant to the strengthening of affective ties and inclusion of students previously excluded from the group for presenting learning and relationship difficulty.

During the period of the workshop students were very frequent and participatory. The approval of such pedagogical proposal was evidenced at the time when students begin to show they want to undertake a new activity with these characteristics, proposing new horizons to be searched, such as the regions of the world through songs and typical dishes.

Regarding the understanding of concepts of geography, the result was fully satisfactory. The folder prepared by students worked as a portfolio of activities, allowing, through the sequential record of the work, the evaluation of the student's constructions during the meetings, as well as their commitment to the subject. Along with the practice developed in the kitchen, oral contributions and posture in classroom, this portfolio composed the evaluation of students during the workshop.

The proposed objectives were met through the understanding of the influences and contributions of different ethnicities in the formation of the Brazilian geographic space and valuation of different regional expressions.

The Brazilian regional cuisine is rich, tasty and varied. Each one of the Brazilian states has typical dishes, prepared according to ancient traditions, which are passed on to each generation. The meaning of food goes beyond the simple act of eating. Many traditions consider the preparation and the meals as a semi-sacred moment that favors the friendship of the people.

Accordingly, the practice of cooking, in addition to contributing to the expansion of the understanding of regional customs and habits through the use of different techniques and ingredients, gave a change for students to have a gastronomic experience different from that of their daily life, therefore craving to discover new flavors.

The presentation of the workshop of different gastronomic realities to the group of students supports the idea of sharpening the palate, awake the curiosity to know new flavors, prepare them and transform the tasting into an enjoyable and educational moment. Together with the preparation of regional dishes, music was used to give more playfulness and joy to teaching and learning.

From musical appreciation, students built the meaning of the concept of soundscape and its importance for the composition of each of the regions studied, as well as they became aware of regional diversities shown in songs or rhythms different from those valued by the media. In this case, the upwelling of fundamental sensibilities for an intelligent listener was evident, able to select rhythms and use the listening to (re)create languages and interrelate places and cultures (Schafer, 1991).

The positive experience of this workshop stimulated the development and completion of two teacher training courses developed in 2008. The first happened in the XXVIII Encontro Estadual de Geografia (XXVIII State Meeting of Geography), in the city of Bento Gonçalves, and the second at the extension course " $O$ mundo na sala de aula: temas contemporâneos $e$ 


\section{GEOGRAPHICAL IMAGINATIONS}

construção de recursos de ensino" (The world in the classroom: contemporary issues and construction of teaching resources), presented in the Laboratory School for undergraduate students and teachers from public and private schools.

\section{Assessment}

It was noted that such an initiative offers much more than a moment of relaxation and establishment of affective ties between teachers and students at the time of learning. It also allows an entire work of interrelationships between the school content and its practical application in daily life of the students. The understanding of the content by the students was evident from the texts built in classroom, oral presentations of tasks, or presentation of regional trivia, musical interpretations and the elaboration of the Jogo das regiões e seus sabores (Game of the Regions and Their Flavors).

The workshop managed to gather the playfulness and the conceptual construction of knowledge. The success of the activities was guided by the form of the thematic approach, which presents issues of our regional diversity that often permeate or do not comply with the geo-political conventions, but should be respected and preserved by forming the Brazilian culture and then be part of the daily life of the students.

We believe that the activity proposed and developed at CAp can be widely applied by teachers, even though it has been developed with a small number of students in our experience, which is not the reality for most teachers in the country. This proposal can be adapted for larger classes, not requiring the use of a kitchen. The teacher makes the choice of ingredients and recipes to be developed based on the reality of their school and according to the themes they want to address.

We believe that proposing challenges to students to allow the exercise of citizenship and active participation in the construction of their culture is fundamental to the pedagogical construction. This proposal assists in demystifying for the student that a cultural form can overlap or be better than another, currently broadly viewed in media.

This work favors a reflection about the modifications and adaptations that our culture and cuisine suffered over time, due to the mixture of black and indigenous heritage with that of the European (Chaves and Freixa, 2007), as well as the influence of these changes on the formation of identity of the subjects and our society. We believe that through this work we can uncover the greatness of our country and rescue a greater social participation and valuation of the origins of our students.

The practice developed in the workshop resulted in the construction of the concept of culture as an expression of lifestyle. Reading and interpreting the lyrics of selected music brought to classroom aspects of landscapes, habits, customs, legends and transformations passed by each region of Brazil. The preparation of dishes and later tasting led to an understanding of the 


\section{GEOGRAPHICAL IMAGINATIONS}

context of appearance of recipes, the reason for using (or not) certain ingredients, thereby developing a different look about cultural differences as a representation of different lifestyles. This experience positively allowed the pursuit of an education proposal that, according to Moran (2006), articulates the sensory, the rational, the emotional, the ethical, the social and the personnel and therefore becomes more effective with regard to the objectives achieved and content built. Here, when we mention the objectives and the content we are indeed talking about geography, but we are also highlighting the overcoming of cognitive and relationship problems, problems that are part of the school context and which teachers must learn to cope with and think about.

\section{References}

Chaves, G. and Freixa, D., 2007. Larousse da cozinha brasileira: raízes culturais da nossa terra. São Paulo: Larousse do Brasil

Correa, R. L. and Rosendahl, z. (Org.), 2003. Introdução à Geografia Cultural. Rio de Janeiro: Bertrand Brasil.

Freire, P., 1997. Pedagogia da Autonomia - Saberes necessários à prática educativa. São Paulo: Paz e Terra.

McDowell, L., 1996. A transformação da Geografia Cultural. In: Gregory, D.; Ron, M.; Graham, S., eds. Geografia Humana: Sociedade, Espaço e Ciência Social. Rio de Janeiro: Jorge Zahar Editor.

Moran, J. M., 2006. Caminhos para a aprendizagem inovadora. In: Moran, J. M.; Masetto, M. T.; behrens, M. A., eds. Novas Tecnologias e Mediação Pedagógica, 12ª ed. São Paulo: Papirus, pp.22-24.

Rossi, D. R.; Rossato,S., 2007. Geografia (em)canto. In: Anais do XXVII Encontro Estadual de Geografia AGB, Porto Alegre: Santa Maria.

Sauer, C., 1963. The Education of a Geographer. In: Leighly, John (ed.). Land and Life :a Selection from the Writings of Carl Ortwin Sauer. Berkeley: University of California Press, pp.389-404.

TVE Brasil, 2008, O ouvido pensante. Available at <http://www.tvebrasil.com.br/SALTO/boletins2001/hge/hgetxt5.html> [Accessed 20 March 2008] Santos, M., 1997. A natureza do espaço: técnica e tempo, razão e emoção. São Paulo: Hucitec. 


\section{GEOGRAPHICAL IMAGINATIONS}

Tuan, Y-Fu., 1980. Topofilia: Um estudo da percepção, atitudes e valores do Meio Ambiente. Tradução: Lívia de Oliveira, São Paulo: Difel.

Vigotsky, L., 1984. A formação social da mente. São Paulo: Martins Fontes.

Zanatta, B. A., 2008. A Abordagem Cultural na Geografia. Temporis(ação) 1(9), p. 249-262. 
GEOGRAPHICAL IMAGINATIONS 


\section{GEOGRAPHICAL IMAGINATIONS}

\section{Birds, Ecology and Landscape: Linking science and art with elementary school children}

Maria João Silva; Dalila Barros; António Alberto Silva, Polytechnic Institute of Porto, inED mjosilva@ese.ipp.pt,dalilabarros@hotmail.com, aasilva@ese.ipp.pt

\section{Introduction}

In different ways, and using different methods and techniques, both art and science aim to perceive the world and to express knowledge about the world. This paper presents a research project that mobilized works of art and their production contexts to enhance science education approaches to the questions: How are birds adapted to their environment? How are birds, place and landscape related?

As follows, and bearing in mind that geography addresses human-environment interactions in the context of specific places and locations (IGUCGE, 1992), the developed research project linked natural sciences (namely Physics and Ecology), art, and their productions spaces to environmental landscapes and to children's learning spaces. Through the linkage of science and art in the experimental science learning of bird ecology, the research project presented in this paper aimed at developing observation, creative imagination, perseverance and critical thinking in the context of elementary school science curriculum.

Leonardo $\mathrm{Da}$ Vinci artefact and artworks were used in the mentioned research project to motivate children and to illustrate the importance of perseverance and accuracy in art and science. Being a painter, a sculptor and at the same time a scientist and a technologist, Da Vinci was a precursor in dealing with the links between art and science (Cachapuz, 2007). This author explains that his goal in exploring the links between art and science is interdisciplinarity in education.

In an unpredictable and changing world, interdisciplinary study encourages students to choose new areas for personal study and to become independent, lifelong learners who have learned not only how to learn but also how to assess and value their own thinking, imagination, and ingenuity in decision-making situations (Ontario Ministry of Education, 2002).

The research project, which is presented in this paper, was developed as an interdisciplinary project of the Master in Experimental Science Teaching of the School of Education of the Polytechnic Institute of Porto. It included two case studies that were developed in a school of a rural zone of the north of Portugal with two groups of elementary school children, in the context of the activities of a school communication project.

Following David Harvey, Doreen Massey, and Edward Soja, for whom space is constitutive of and constituted by social relations, in this research project, the educational spaces are considered not as entities, but as active processes (Pykett, 2012). In this way, the reflexive space of learning was created by children and teacher, aiming at integrating children's everyday spaces of learning and leisure, as well as the production spaces of science and art. 


\section{GEOGRAPHICAL IMAGINATIONS}

This paper includes six sections. The first one is this introduction that is followed by the theoretical framework. The third section presents the method used in the presented research project. Subsequently, the fourth section presents and discusses the results. The fifth section includes the conclusions of the two case studies and the final section consists of the bibliographic references.

\section{Theoretical framework}

The Portuguese elementary school curriculum emphasises the value of creative imagination in art, but not in science. It also mentions the importance of promoting interdisciplinarity. Nevertheless it doesn't facilitate the creation of any links between art literacy and science literacy in the first six years of scholarity.

\subsection{Interdisciplinarity in elementary schools}

Interdisciplinary interaction can allow students to understand the meaning of their learning activities and may simplify the integration of learning processes and of knowledge (Lenoir, 2006). This author also emphasizes that stratification of subjects and the reduction of curriculum to "basic skills" - such as reading, writing and counting and nowadays socialization - can represent important obstacles to interdisciplinarity (Lenoir, 2006). "To deal with today's issues, students also require interdisciplinary skills. Using models and prototypes, students can simulate ideas and test variables to produce new products or perspectives or find and implement solutions that go beyond established disciplines" (Ontario Ministry of Education, 2002).

The use of interdisciplinarity in elementary education is supported for diverse learning approaches such as: the theory of Multiple Intelligences that emphasizes the different dimensions of intelligence and the importance of gather different media, different subjects, and different approaches to potentialize the diversity of possible combinations of such dimensions that students can present in a classroom; the concepts of Situated Learning and Learning Communities (Brown, Collins, and Duguid, 1989 ; Lave and Wenger, 1991 ; Figueiredo and Afonso, 2005) that highlight the need for rich, real and meaningful learning contexts.

In order to produce those meaningful learning contexts, schools' spaces should be lived, represented, transformed and recreated by children and teachers in a territorialisation process (Lopes, 1994). In this constructivist context it is also relevant to mention that interdisciplinarity can approach complexity and in this way facilitate the individual and collective development of competences such as thinking, experimenting and communicating (Carbó Cortina, Pigrau Solé, and Tarín Martínez, 2010). 


\section{GEOGRAPHICAL IMAGINATIONS}

\subsection{Art and Science in elementary schools: imagination and critical thinking}

It has been argued that ecological literacy should be promoted in a wide variety of subject areas such as the arts, in order to widen affective approaches to environmental education (Inwood, 2007). One possible approach, which requires not only art making but also critical thinking is to develop art as research, where art education inquiry concentrates on learning that is connected to other disciplines (Stokrocki and Delahunt, 2008). These authors present a case study where the animé Nausicaa was discussed and super bugs were made to empower children to reinterpret bug powers and learn about ecology (Stokrocki and Delahunt, 2008).

In the context of Quebec elementary schools, Lenoir (2006) calls attention to two aspects that can constitute obstacles to the development of interdisciplinary didactic approaches, and consequently obstacles to didactic approaches linking science and art education:

- Natural sciences can be used abbreviated as a strategy to teach the mother language and are therefore reduced to mere raw materials;

- The stratification of school subjects in the curriculum can lead to a depreciation of the arts, which however offer a different way of construction and expression of reality as well as a means of entering into relation with reality.

Art can be a starting point to deal with observation in science, namely in what concerns the relations between observation and theory (Cachapuz, 2007), since scientific observation includes noticing, theoretical expectations, observational records, and productive dispositions (Eberbach, Crowley, 2009).

Art can also contribute to develop imagination, which is very important for new hypotheses (Richmond, 1984). Science can use the art ideas as inspiration for articulate problems and ideas for critical examination" (Richmond, 1984).

Critical and creative thinking are common to art and science. Rationality in science aims to eliminate error, and it is used to guide and evaluate practice (Richmond, 1984). Rationality in art points out the weaknesses of imagination and encourages imagination to create worlds that momentarily defy (rational) articulation.

\subsection{Colour and flight in bird ecology}

Birds' beauty, namely in what concerns their colours, flight dynamics, and songs (not approached in this paper) have inspired painters, writers, photographers, and influenced the sense of the world of people in general, in a way that led to the creation and extended use of the term birdscapes. Birdscapes are present in multiple everyday educative spaces, such as gardens, parks, and zoos. This research project addresses such landscapes, mobilizing environmental, cultural and aesthetical approaches (Domingues, 2001). 


\section{GEOGRAPHICAL IMAGINATIONS}

"Birds are the most colorful land vertebrates, with diverse plumages, representing (to human eyes) almost every color imaginable" (Stoddard and Prum, 2011). These colours play an important role in birds' ecology and have different functions, from crypsis and camouflage to social signalling and mate choice (Stoddard and Prum, 2011). Birds can see many more colours than humans can, because they have additional colour cones in their retina that are sensitive to ultraviolet range (Phys.org, 2011). Birds can even see many more colours than they have in their plumage (Phys.org, 2011). Colours in birds are the result of pigmentary and structural phenomena.

Flight is another important aspect of birds' ecology, being fundamental for diverse tasks such as searching, catching and carrying preys, avoiding predators, and migrating. The two main features that birds have for flight are wings and feathers (Raptor Research Foundation, 2012). Some feather colours are iridescent, being created by prism-like structures in the feathers (Phys.org, 2011).

\section{Method}

The research work presented in this paper is qualitative and integrates two case studies developed in an elementary school of a rural zone in the north of Portugal during the school year 2011/2012, with two groups of 10 (first case study) and 13 children (second case study) of the $5^{\text {th }}$ and $6^{\text {th }}$ grade. The case studies were developed as facultative workshops in the context of a science communication project.

The teacher that designed and implemented the workshops was also a researcher, and author of this paper, and it was not responsible for any curricular unit of the participants. This way, the developed research included two case studies but was designed to incorporate some of the characteristics of the action-research methodology.

Aiming at studying the interactions between the participants and the contexts, as well as the participants' views of the studied problem, qualitative data were collected by the teacher/researcher. Data collection included participant observation, interviews, audio and photographic recordings of the workshop activities as well as the codices, used as portfolios, in which children were invited to record their observations and thoughts.

The first case study aimed at motivating children to bird ecology through the use of Leonardo Da Vinci artefacts and artworks, while the second case study was centred on the study of light and colour, using the topic "colours of bird feathers" as a materialization.

In the next section, those two case studies will be presented and discussed. Although the collected qualitative data were analysed using content analysis techniques, the results of such analysis aren't exhaustively presented in this paper. The presentation of the two case studies, although informed by the results of the content analysis, rather makes use of multimodal narrative strategies (Lopes et al., 2010). 


\section{GEOGRAPHICAL IMAGINATIONS}

\section{Results and Discussion}

\subsection{Case study 1 - From Art to Science Teaching}

The workshops of the first case study included the following activities:

- Exploration of Leonard Da Vinci work in diverse books;

- Observation and setup of models of Da Vinci machines, including models of the paddle boat, the tank and the flying machine;

- Discussions and experiments around the topic "What makes flying possible?";

- Wings and feathers: observation and representations;

- Flight, feathers and friction;

- Analysis of birds' regurgitations;

- Creation of a bird.

These workshop activities, namely the ones centred on Da Vinci work, were implemented aiming at communicating to children that: perseverance and persistence are fundamental in artistic and scientific work; and that accuracy is necessary to produce useful representations.

Figure 1 - Children observing books on Da Vinci works

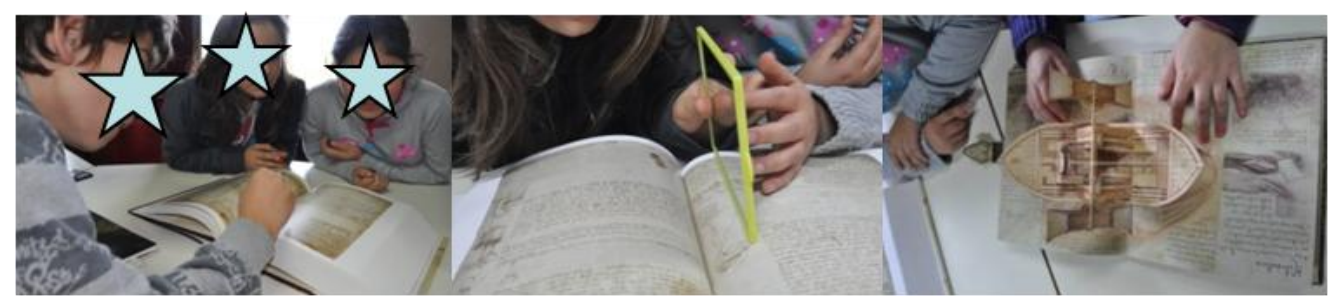

The observation of Da Vinci codices made it clear to children that the visual richness and the accuracy in representations make it possible to convey an impressive amount of information. Children recognized that in order to represent observations, thoughts and conclusions it is not enough to record them. The way we organize information matters. They exemplify with the differences between an organized and an unorganized notebook or portfolio. "It is not possible to understand the second one". "It is something that shouldn't happen when we want to discover new things".

Children also observed "mirror writing" often used in Da Vinci codices and reflected on the roles of codes in communication safety. The observation of Da Vinci paintings and codices motivated children to value the way of registering (see figure 2). 


\section{GEOGRAPHICAL IMAGINATIONS}

Figure 2 -Annotation made by one child in the codice

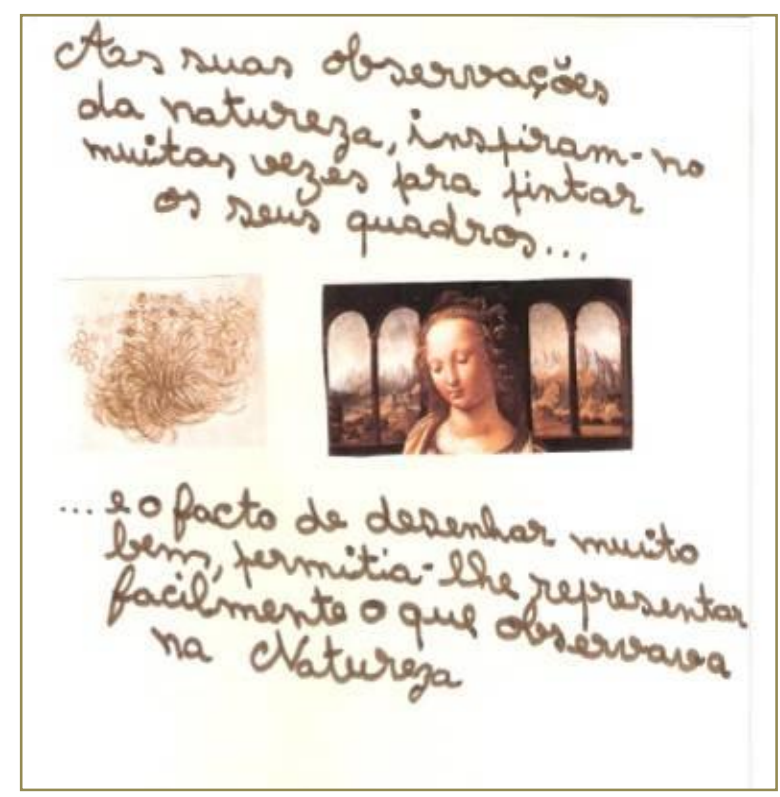

The setup of the models of the Da Vinci machines wasn't an easy task. This was a surprise for children. They initiated the task in such an unorganized way that frustration came, and children began to give up. The teacher/researcher called their attention for the importance of a careful reading of the instructions and of the need of following them step by step. With a little help from the teacher/researcher, they were able to set up the models in an autonomous way. They analysed in small groups the functioning of the machines and discussed their conclusions with the colleagues and the teacher/researcher.

Figure 3 -“What makes flying possible?" : Exploring, experimenting and registering

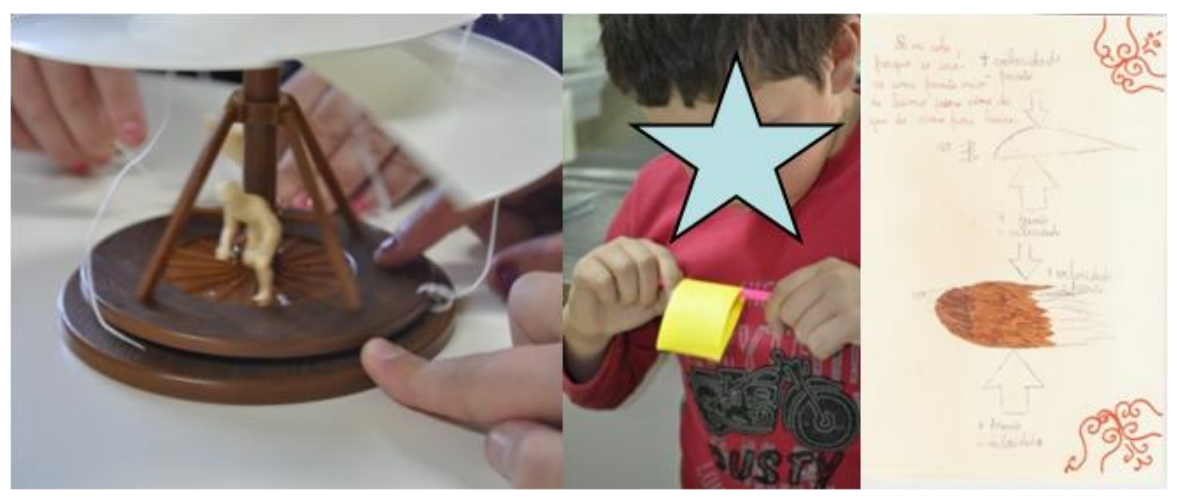

Using the flying machine model, the teacher/researcher introduced the topic "What makes flying possible?". A set of experiments were implemented by children to test principles, such as the Bernoulli Effect, and to explore the forces that make it possible to fly. These experiments were implemented with diverse wing models and the similarities between the airplanes' shape and wings and the birds' shape and wings. 


\section{GEOGRAPHICAL IMAGINATIONS}

Subsequently, children were invited to observe, using their senses and tools such as binocular loupes, a diversity of birds of prey feathers. They observed the diverse feathers (from nocturnal and diurnal birds) and analysed their observations enthusiastically.

They showed evidences of critical thinking in the observation and analysis of the feathers' structure and in relating such structure with the presence/absence of friction and the noisy/silently flight of diurnal/nocturnal birds of prey. Children noticed that the feathers of the diurnal birds of prey have "voided holes" that should cause more friction and therefore noise.

Figure 4 - Using the binocular loupes to observe birds of prey feathers

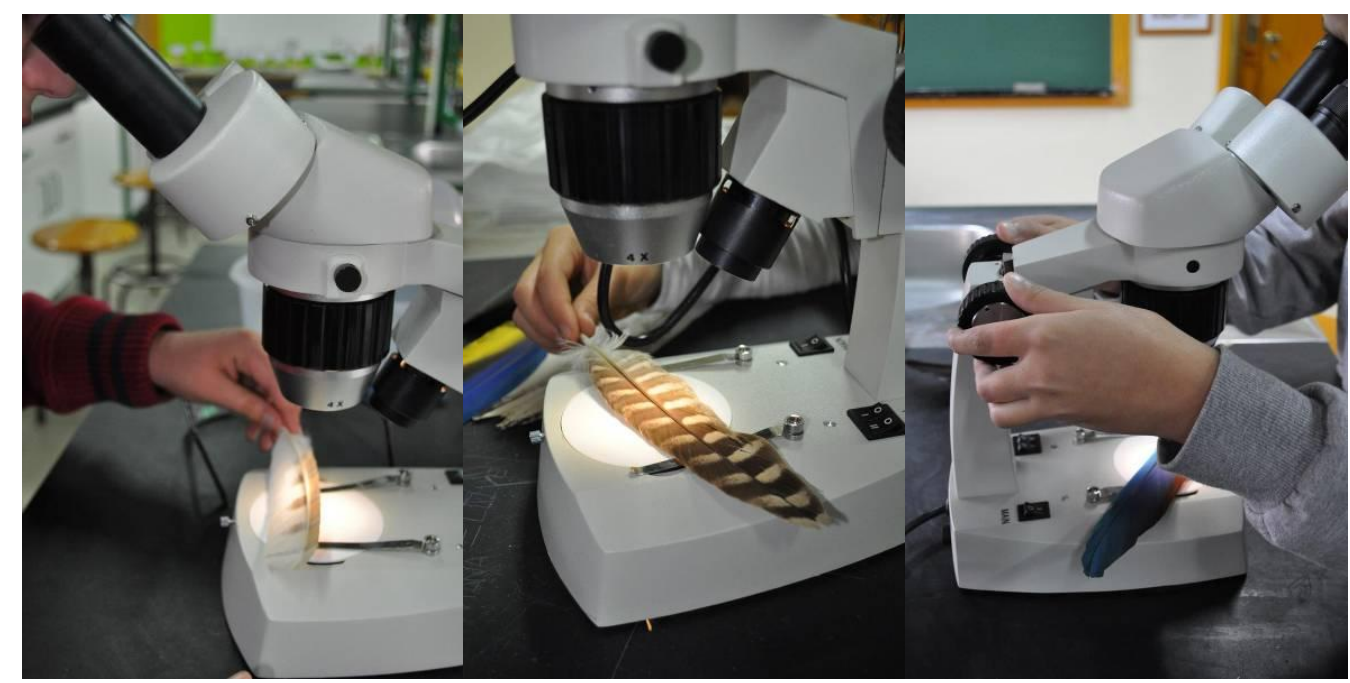

Children tried to draw their observations, using analytic observation and critical thinking. For instance, one student expressed the intention of drawing an eagle with the colours of the feather that he was observing. However, because he concluded that the feather belonged to a nocturnal bird of prey, he finally decided not to draw an eagle (a diurnal bird of prey). They pointed out the errors and limitations of the representations that they have created, and sometimes they even feel frustration when they were not able to draw in a better way.

Figure 5 - Drawing feathers: sight drawing and drawing at transparency

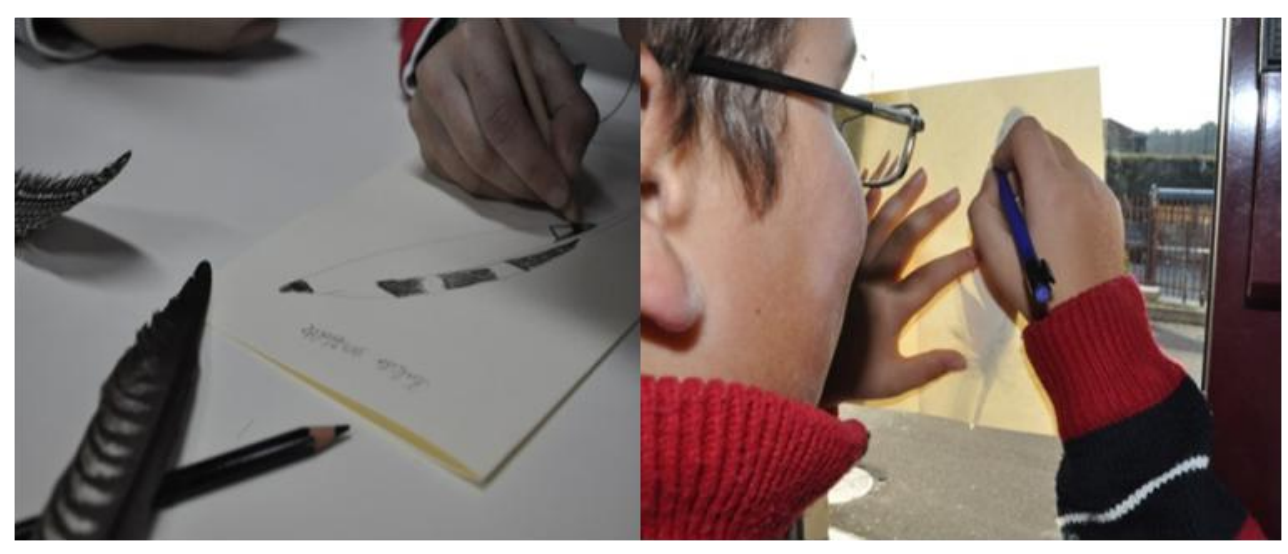




\section{GEOGRAPHICAL IMAGINATIONS}

The development of analytic observation was also visible in the birdwatching stories told by children in the following weeks. Some of the children informed the class about the talks with their families on the name of the birds that they could observe everyday, their behaviours and conservation.

The following activity was the laboratory analysis of regurgitations of diurnal and nocturnal birds of prey. During the analysis of regurgitations, the teacher/researcher discussed with the students the importance of georeferencing the collected pellets and of characterizing each place of collection. In this activity, children were stimulated to conclude that through the study of pellets it is possible to know a bird's diet and relate it to its habitat.

This activity was the basis of the debate on the topic "What does a bird need to survive"?, namely in what concerns the kinds of birds' beaks, feet and legs. In this context, the similarities between the feet of the swimming birds and the paddles of Da Vinci paddle boat were noticed. In the subsequent activity, adapted from (REWHC, 2003) children were invited to create a bird in a landscape, using the paper collage technique. They created diverse birds by choosing the habitat, the nourishment, the head, the body, and the legs. After the creation of his/her bird, each child assesses the probabilities of the bird survival, using a table provided by the teacher/researcher.

Figure 6 - The results of the creation of a bird by a child, before and after survival assessment

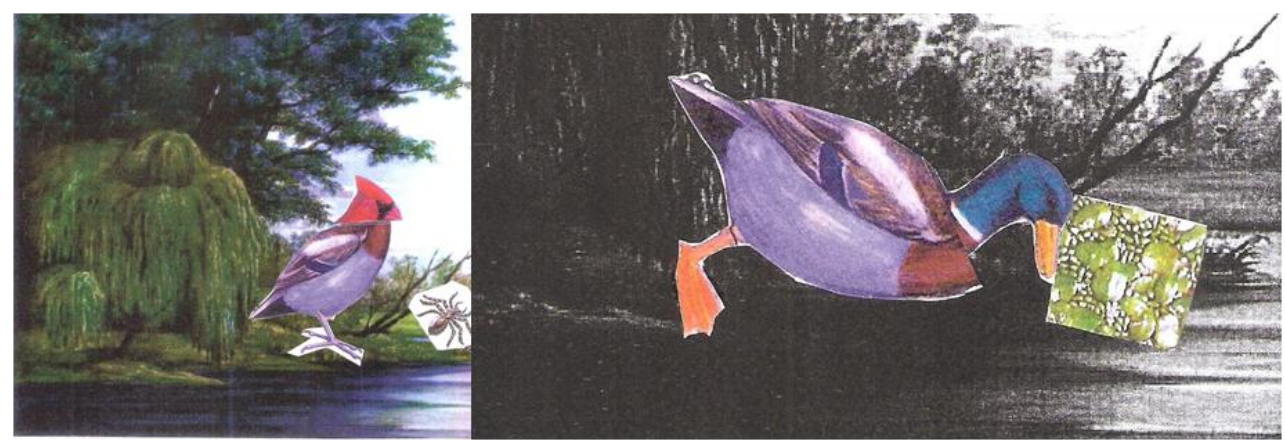

Some of the children started the creation of the bird using personal aesthetic criteria. However, using the assessment table, one child assessed his creation (Figure 6) saying that the bird cannot survive in the water (inadequate body and legs) and cannot get enough food (the beak is adequate to eat seeds, insects, spiders...). After the assessment of the survival probabilities, this child was able to write the reasons for the failure and created another bird, which was adapted to the chosen environment (Figure 5).

In this first case study, the learning space was multidimensional. Although the activities took place in a science education space (school lab), a diversity of interrelated spaces were mobilized, such as art spaces (for instance, through Da Vinci codes and the models of the Da Vinci machines), as well as ecosystems and their diurnal and nocturnal dimensions (for instance, through birds' feathers and the birdwatching stories). 


\section{GEOGRAPHICAL IMAGINATIONS}

\subsection{Case study 2 - Light and Colours of Birds' Feathers}

The workshops of the second case study included the following activities:

- Assessment of the previous workshops;

- Links between art and science;

- "Why are feathers so colourful?"

- White light decomposition and composition;

- Experiments on objects' colours;

- The case of the colours of birds' feathers;

- Colours in paintings and in nature.

The activities of this second case study were designed to deepen the learning of light and colour, through the study of feathers' colours and of the roles of those colours in habitats and landscapes. In the first activity, the children that have participated in the first case study shared the already developed activities with the new colleagues.

Table 1 - Children's vision of the relationships between art and science, before and after the second case studies' activities

\begin{tabular}{|c|c|c|c|c|c|c|c|c|}
\hline \multirow{3}{*}{ Categories } & \multicolumn{8}{|c|}{ Number of answers } \\
\hline & \multicolumn{2}{|c|}{$\begin{array}{l}\text { Associated to } \\
\text { art }\end{array}$} & \multicolumn{2}{|c|}{$\begin{array}{l}\text { Associated to } \\
\text { science }\end{array}$} & \multicolumn{2}{|c|}{$\begin{array}{l}\text { Associated to both } \\
\text { domains }\end{array}$} & \multicolumn{2}{|c|}{$\begin{array}{l}\text { Not associated } \\
\text { to any of the } \\
\text { two areas }\end{array}$} \\
\hline & Before & After & Before & After & Before & After & Before & After \\
\hline It requires effort & 1 & -- & 5 & -- & 5 & 12 & 2 & 1 \\
\hline It is interesting & -- & -- & 5 & 1 & 5 & 12 & 3 & -- \\
\hline It is fun & 4 & -- & -- & -- & 7 & 13 & 2 & -- \\
\hline It requires accuracy & 4 & -- & 3 & -- & 3 & 13 & 3 & -- \\
\hline $\begin{array}{l}\text { Tries to understand } \\
\text { reality }\end{array}$ & 2 & -- & 9 & 3 & -- & 10 & 2 & -- \\
\hline It requires imagination & 12 & 1 & 1 & -- & -- & 12 & -- & -- \\
\hline It requires criativity & 10 & 1 & 3 & -- & -- & 12 & -- & -- \\
\hline Any one can do it & 8 & 3 & 2 & -- & 3 & 10 & -- & -- \\
\hline It improves citizens life & 2 & -- & 8 & 4 & 1 & 9 & 2 & -- \\
\hline $\begin{array}{l}\text { Sentences written by } \\
\text { students }\end{array}$ & -- & -- & -- & -- & -- & -- & 13 & 13 \\
\hline
\end{tabular}

Following the references made by children to Da Vinci works, in the second activity, children were asked about the relationships between science and art. It was asked to children to relate a 


\section{GEOGRAPHICAL IMAGINATIONS}

set of statements to art, to science or to both. This task was repeated at the end of this second case study.

The analysis of children's answers (summarized in Table 1) makes it clear that imagination and creativity were at first mainly associated to art, while science was the one associated to the understanding of the reality and to the improvement of citizens' life. After the activities children found more similarities between science and art than at the beginning of the study.

The following activities were centred on the questions: How and why do we see colours? Why are feathers so colourful? Since children pointed out that to see an object it is necessary to illuminate it, an experiment was developed to study the composition of the white light: an optical prism was used to see the dispersion of the white light. Afterwards, a set of experiments was implemented to explore the addition of colours, including an experiment in which white light was created using blue, red and green radiations. Subsequently, it was experimentally explored how light influences the colour of translucent and opaque objects, as well as how filters act in the subtractive composition of colours. These experiments were followed by a discussion on colour, light and pigments. The colours of bird feathers were then analysed, emphasising that pigments act like light filters, conditioning in this way the colours of the feathers.

Based on the observation of the painting of David Hockney (1977) "Self portrait with blue guitar", it was possible to analyse the addition of colours in painting and specifically in pointillism. This analysis made it possible to introduce the camouflage phenomenon. Some of the students have observed, in the context of the first case study, the superposition effect of the yellow and blue feathers of the Blue-and-Yellow Macaw (Ara ararauna), making it difficult to distinguish them in the green foliage. As it is discussed by children and teacher and audiorecorded:

Teacher - This superposition of colours, in this kind of painting, also occurs in nature. Do you remember our visit to Santo Inácio Zoo?

A- Yes.

Teacher - Those birds...the macaws had that strong blue and strong yellow.

(in the meanwhile, the children made a lot of questions about the paintings. After answering to the questions, the teacher/researcher return to the camouflage subject).

Teacher - We were talking about the blue pigments of this painting and I was asking if you remember what happened when the macaws that have that strong colours...

E - They have pigments.

Teacher - When they flight to the trees... do you remember what happened?

$E$ - The pigments were not so blue, anymore...

I- They were lighter.

E - They were farther. When they are quiet, the pigments are closer. When they open the wings, the pigments move apart.

Teacher - That is true. But, when we were seeing the bird show... 


\section{GEOGRAPHICAL IMAGINATIONS}

I - I know. It's because the upper part of the feathers is darker. But when they open the wings, just like...our arm, they are lighter.

Teacher - When they flight to the trees, we couldn't see them in the foliage.

$B$ - The leaves were green.

Teacher - The leaves were green. But the macaws were not green.

A-Camouflage!...

Teacher - Exactly. But how, with those bright colours...

$B$ - They get the leaves' colours.

Teacher - But how?

$B$ - With the feathers.

Teacher-But how?

$L-I$ know.

I- As they were in contact with another colour...

E-Pigments. By the union of the pigments that...

$B-$ l know.

$A-B l u e$ with yellows gets green.

Teacher - (smiling) What happens to our eyes? It's similar to what happen when we see this kind of painting.

I- When it [the macaw] is closer, we see the separated colours. But when it is farther, we see them in a different way.

(...) Teacher - But there is still another phenomenon. As D was saying [that when seeing the painting through another perspective] he saw a wave that he doesn't see when the painting was illuminated in a different way. It also happens with the feathers.

[The teacher gave some Blue-and-Yellow Macaw feathers to children.]

Teacher - Look. You can see the bright colours. Really bright.

D- Yes.

Teacher - Now, look. When I observe from here [the teacher was looking to a feather that was receiving light from the other side], they seem black.

[Children observed the changing of the colours, while handling the feathers to modify the way they were illuminated]

Teacher - This way, when the birds move, in the foliage, the colour changes... and creates a sensation...

$B-$ an illusion.

Teacher-Exactly. It's one trick that they have to guarantee the camouflage.

This example was used to trigger off the exchange of ideas about other camouflage situations. To continue the study of the feathers' colours, a new set of experiments was implemented. These experiments aimed the exploration of the optical phenomena that are responsible for the iridescent colours of birds' feathers: diffraction and interference/iridescence. 


\section{GEOGRAPHICAL IMAGINATIONS}

Figure 7 - Observing the white light through a diffraction grid and the interference of waves in the school pond

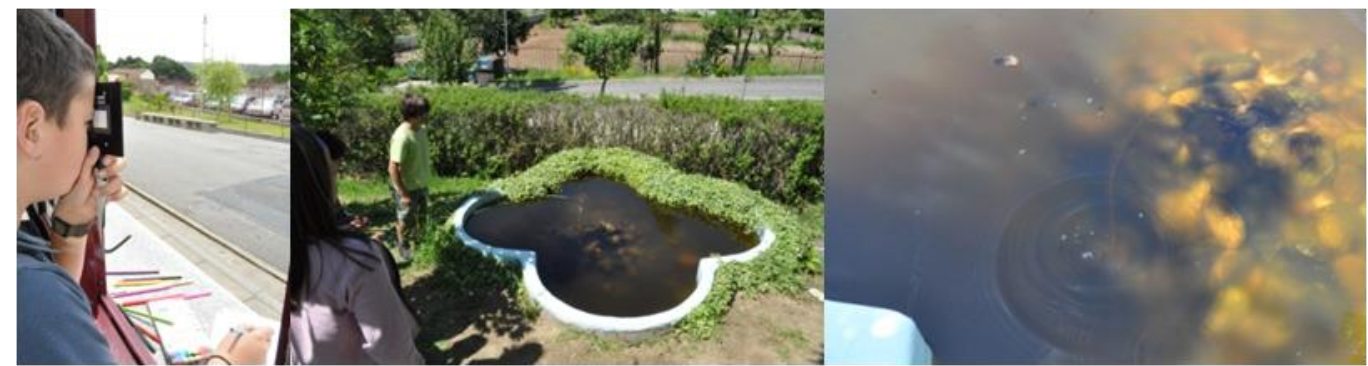

Children explored those optical phenomena by observing: white light through a diffraction grid and through a film of nail varnish; the interference of mechanical waves in the school pond; the white light waves' interference in a film of soap and in a DVD; the iridescence in birds' feathers.

Figure 8 - Annotations made by children in their codices
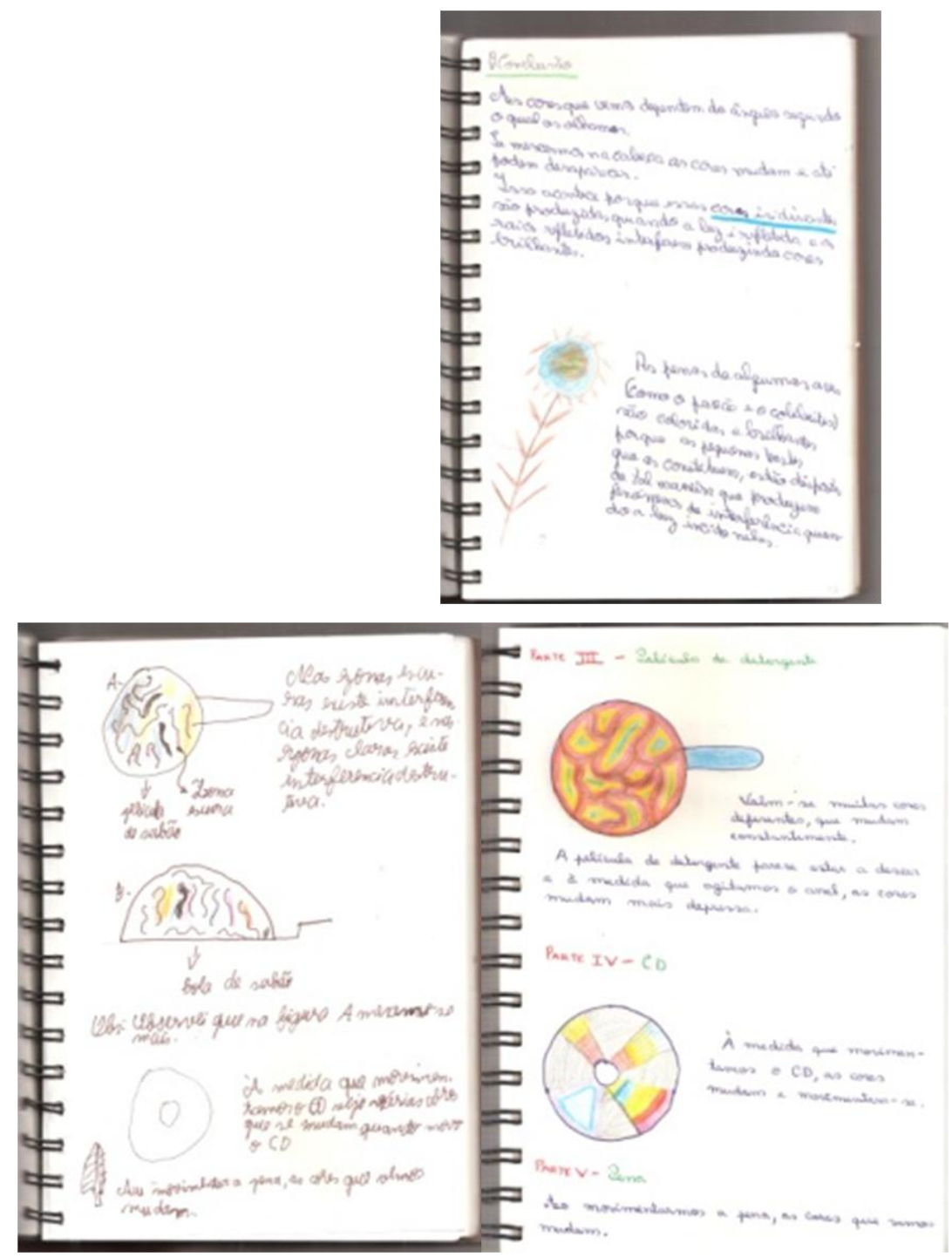


\section{GEOGRAPHICAL IMAGINATIONS}

Figure 9 - A page of a codice and annotations in a worksheet
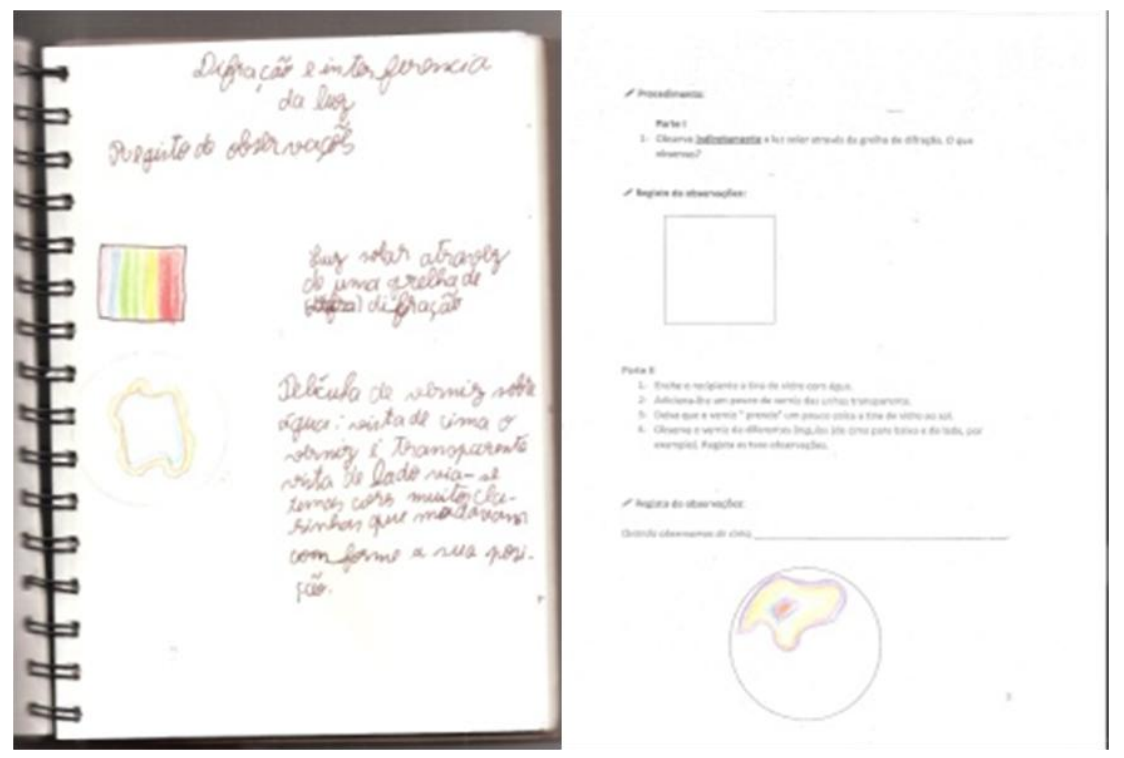

Once more, in this second case study, the learning space was multidimensional. The school was an integrative space that attended to diverse children's spaces, formal (school science lab) non formal (schoolyard), and informal (birdwatching spaces) local (school or way from home to school) or far-away (Zoo). All those spaces were physically or conceptually visited, building new learning geographies.

\section{Conclusions}

This paper presented two case studies developed to link science and art in the experimental science learning of bird ecology. These two case studies explored new education spacialities, acknowledging the importance of considering the contexts or uneven geographies of schooling in which people learn (Pykett, 2009).

In the first case study, children were invited to observe and analyse a set of Da Vinci paintings and to set up models of Da Vinci machines, such as the flying machine. These activities made it possible to children to investigate, in a participatory way, how birds can fly (through the development of a set of experiments), as well as to relate the flight and nourishment of birds to diverse habitats and landscapes (through the analysis of regurgitations and the "creation" of a bird).

In this first case study, it was possible to observe evidences of improvement in children competences related to analytic observation, critical thinking and accuracy of representations. Those evidences are reified in children codices. During the development of the experiments, the classroom discussions and the "creation" of a bird, children showed evidences of development of conceptual and procedural knowledge in what concerns the analysis of landscapes and of the adaptations of birds to those landscapes. 


\section{GEOGRAPHICAL IMAGINATIONS}

The use of Da Vinci's work, and of its production context, to the study of birds' ecology, was motivating to all the participants in this case study. The use of codices, as portfolios, influenced the conceptual analysis developed by students. The didactic methods used in this case study facilitated the development of scientific competences by children and contributed to the improvement of science literacy and art literacy. Children were involved in the tasks and showed interest in artistic and scientific issues, while linking art and science spaces.

In the second case study, the learning activities included: the observation of paintings; the analysis of the techniques used to produce specific colour effects in landscape representations; and a subsequent set of experimental learning activities to explore processes and properties related to light and colour. These diverse learning activities allowed children to observe, explore, analyse, reflect and communicate about light and colours in paintings and in environment, about pigments and structural colours of the birds' feathers, as well as to relate these characteristics to the processes of bird adaptation to environment, and specifically to landscapes, with an emphasis in camouflage. This way, through the practices of children and teacher, the spaciality of those education activities was developed, making use of children's everyday spaces and of rather new learning spaces, such as the school science lab and the Zoo.

This second case study also made it possible to confirm that it is feasible to link art and science to develop observation (reified in children's codices), creative imagination, perseverance and critical thinking (as can be verified in the analysis of dialogues and debates) in the context of elementary school science curriculum, and in particular in the study of bird adaptation to environmental landscapes. In addition, at the end of this case study, children recognized more similarities and links between art and science than at the beginning of the case study.

\section{References}

Brown , J. S. , Collins , A. and Duguid , P. , 1989. Situated cognition and the culture of learning. Educational Researcher, 18 ( 1), pp. $32-41$.

Cachapuz, A., 2007. Arte y Ciência: ¿Que papel juegan en la educación en ciencias?

Revista Eureka sobre Enseñanza y Divulgación de las Ciencias, 4 (2), pp. 287 - 294.

Carbó Cortina, V.; Pigrau Solé, T. and Tarín Martínez, R. M., 2010. The Role of Thinking, Experimenting and Communicating in the Science Lab [online]. eLearning Papers, 20. Available at: <www.elearningpapers.eu> [Accessed 30 October 2011].

Domingues, A., 2001. A Paisagem Revisitada. Finisterra, 36(72), pp. 55-66.

Eberbach, C. and Crowley, K. (2009). From Everyday to Scientific Observation: How Children Learn to Observe the Biologist's World. Review of Educational Research, 79 (1), pp. 39-68. 


\section{GEOGRAPHICAL IMAGINATIONS}

Figueiredo , A. D. and Afonso , A. P., 2005 . Context and Learning: A Philosophical Framework . In: A. D. Figueiredo and A. P. Afonso eds. 2005. Managing learning in virtual settings: the role of context. Information Science Publishing (Idea Group), pp. 1-22.

Gardner , H., 1999 . Intelligence reframed: multiple intelligences for the 21st Century. Basic Books.

International Geographic Union Comission on Geographical Education (IGUCGE), 1992. International Charter on Geographical Education. Nürnberg: Selbstverlag des Hochschulverbandes fur Geographie and ihre Didaktik. Available at: < http://www.igucge.org/charters_1.htm> [Accessed 23 May 2013].

Inwood, H., 2007. Artistic Approaches to Ecological Literacy: Developing Eco-art Education in Elementary Classrooms, Marilyn Zurmuehlen Working Papers in Art Education, 2007 (1), Article 6. Available at: <http://ir.uiowa.edu/mzwp/vol2007/iss1/6> [Accessed 21 September 2012].

Lave, J. and Wenger , E., 1991. Situated learning: legitimate peripheral participation. Cambridge: University of Cambridge Press.

Lenoir, Y., 2006. Practices of Disciplinarity and Interdisciplinarity in Quebec Elementary Schools: Results of twenty Years of Research. Journal of Social Science Education, 5 ( 2), pp. 19-36.

Lopes, J. T., 1994. A Animação no Espaço Escolar Urbano: Um Estudo sobre Práticas Culturais Estudantis. Sociologia, Série I, volume 3, 73-138.

Lopes, J. B., Cravino, J. P., Silva, A. A., Viegas, C., Cunha, A. E., Saraiva, E. et al., 2010. Investigação sobre a mediação de professores das Ciências Físicas em sala de aula. Vila Real: Universidade de Trás-os Montes e Alto Douro.

Ontario Ministry of Education, 2002. Ontario Curriculum Grades 11 and 12 Interdisciplinary Studies. Available

at: <http://www.edu.gov.on.ca/eng/curriculum/secondary/interdisciplinary1112curr.pdf> [Accessed 21 September 2012].

Phys.org, 2011. Birds' eye view is far more colorful than our own. Available at: <http://phys.org/news/2011-06-birds-eye-view.html>. [Accessed 21 September 2012].

Pykett, J., 2009. Pedagogical Power: lessons from school spaces. Education, Citizenship and Social Justice, 4(2), 103-117. 


\section{GEOGRAPHICAL IMAGINATIONS}

Pykett, J., 2012. Making Youth Publics and Neuro-Citizens: Critical Geographies of Contemporary Educational Practice in the UK. In: P. Kraftl, J. Horton and F. Tucker, eds., 2012. Critical Geographies of Children and Youth: Policy and Practice. Bristol: Policy Press, pp. 27-42.

Raptor Research Foundation, 2012. Birds and Their Feathers. Available at: $<$ http://www.raptorresearchfoundation.org/education/feather-facts> [Accessed 21 September 2012].

Raytheon Employees Wildlife Habitat Council (REWHC), (2003). Create-a-Bird: A cut-n-paste activity. Available at: http://rewhc.org/downloads/adaptation.pdf. [Accessed 30 October 2011].

Richmond, S.,1984. The Interaction of Art and Science. Leonardo, 17 (2), pp. 81-86.

Stoddard, M.C. and Prum, R.O., 2011. How colorful are birds? Evolution of the avian plumage color gamut. Behavioral Ecology, 22, pp. 1042-1052.

Stokrocki, M. L. and Delahunt, M., 2008. Empowering Elementary Students' Ecological Thinking Through Discussing the Animé Nausicaa and Constructing Super Bugs. Journal for Learning through the Arts, 4(1), Available at <http://escholarship.org/uc/item/1cm011rg> [Accessed 21 September 2012]. 
GEOGRAPHICAL IMAGINATIONS 


\section{GEOGRAPHICAL IMAGINATIONS}

\section{Spatial representations of squatter settlement in visual narratives of brazilian films: a comparative cinematic landscape analysis of black orpheus, city of god and elite squad I\& II}

Juliana Cunha Costa, Jacobs University Bremen

hello.juliana@gmail.com

\section{Cinema and cultural geography: an introduction}

As stated by Hall (1997:2) "'culture' is one of the most difficult concepts in the human and social sciences and there are many different ways of defining it". Describing this word "[...] is a complex and difficult task which has produced a range of very different definitions" (Grang, 2008:1). According to Mitchell (2000:12) culture has no ontological basis, and the common usage of this word brings this concept to an empty abstraction "[...] an abstraction that has no referent in the material world".

Previous cultural studies concentrated their efforts on describing the singular characteristics of societies according to different kinds of nations and languages. "These types of researches "[...] focused on the differences or similarities between national and racial/ethnic groups, which treated cultures as monolithic entities" (Hong, 2009:3). Nevertheless, Hall (1997) highlighted the "cultural turn" as a significant boundary in the social and human sciences, since "meaning" was presented as an important tool in describing culture. Consequently "[...] culture is concerned with the production and the exchange of meaning [...] between the members of a society or group" (Hall, 1997:2).

For the purpose of appreciating one of the several denotations of culture, Hong (2009) provides one model with four hypotheses: first, culture transports the idea that the physical and the social environments create certain types of knowledge; second the knowledge is shared between members of a community and "[...] it is transmitted across generations" (ibid:4); third the shared knowledge is converted as truth among individuals of this community; and lastly when the individual is exposed in two diverse cultural groups, he/she can "[...] acquire the shared knowledge of both cultures" (ibid).

Finally, Hong (2009) combines knowledge into the networks of knowledge; which consists of an amalgamation of individual behaviors, cognitions and affections, together with the interactions among other people from the same community, transmitted from one generation to the next. This "transmission" of knowledge is understood by Hall (1997) as the diversity of sharing the meaning. In here "[...] culture depends on its participants interpreting meaningfully what is happening around them, and 'making sense' of the world" (Hall, 1997:3).

The cultural approach in the geographic science, has presented its development based on studies of representation, as it "[...] connects meaning and language to culture" (Hall, 1997:15). Claval (2008) emphasized, that the access to the "reality" was also possible throughout the representations and images of the world. The early modern cultural geography had its first 


\section{GEOGRAPHICAL IMAGINATIONS}

advent in the late $19^{\text {th }}$ century, when scholars based their works on descriptive analyses of the space; during the $20^{\text {th }}$ century they had gradually introduced the analytical investigation of the space by means of establishing relation among culture, nature, region and landscape (Oakes and Price, 2008, pp. 6-7). Particularly, in the beginning of the 1970's geographers disseminated and extended the debates about cultural geography with the support of cultural studies. This scientific discipline had defined itself as a significant subject inside of the huge area of the Geography sciences and "[...] cultural geography has begun to assume a more central position in the current rethinking of human geography" (Jackson, 1989:1).

Oakes and Price (2008:80) indicate that some memorable scholars as Jackson, Ratzel, de la Blache, Sauer, Hoskins and Zelinsky built a firm foundation on significant directions that shaped cultural geography as a coherent subfield of geography. The geographic theories were sustained by the phenomena of cultural characteristics that influenced the configuration of the space, for example, while referring to the studies of phenomenology (Claval, 2008). In addition to that, geographers were supported by previous studies when dealing with social and cultural contexts and presenting human spatiality through the manifestations expressed in many cultural forms such as: literary book, painting, spectacle, religious ritual, music, photography and film.

The uncountable approaches to interpret the space guided by images seemed to be a stimulating course that has permitted cultural geographers to analyze films as a technique to understand how filmmakers make use of the geographical space in order to construct their narratives and contribute to influence the perception of the "real world". Furthermore, Azevedo (2006) identifies films portraying landscape as a cultural representation of its nature and space; in her analysis, moving images can also contribute to the expansion of the debate in the fields of cultural geography and visual studies.

Jordan-Bychkov and Domosh (1999:29) believe, that "landscape mirrors culture, and the cultural geographer can learn much about a group of people by carefully observing the landscape". The filmmakers select a certain landscape by (re-) constructing a representation of the place and its cultural group, this (re-) presentation is disseminated worldwide and the viewers will identify a cultural group throughout the landscape.

Slums are not a new element in contemporary Brazilian films as the "Cinema Novo of the 1960s contrasted the optimism and enthusiasm of Juscelino Kubitschek's developmentist period with a debate over important 'national questions,' such as the country's dispossessed in the rural and urban settings" (Oliveira, 2008:46). "The fascinating quality of the geography and landscape of the sertão finds its urban counterpart in the outskirts and slums. They cause fascination as well as horror and repulsion, contradictory feelings which films have never ceased to note and express" (Bentes, 2003:129).

Consequently, based on these assumptions, the present work will introduce a comparative cinematic landscape analysis of the Brazilian filmmaking through the visual narratives that reproduce daily life in the Brazilian slums in the following four films: Black Orpheus (Camus, 1959, Brazil, France, Italy), City of God (Meirelles, 2002, Brazil), Elite Squad (Padilha, 2007, 


\section{GEOGRAPHICAL IMAGINATIONS}

Brazil) and Elite Squad: The enemy within (Padilha, 2010, Brazil). These films carry different spatial representation of Brazilian squatter settlements; these landscapes are frequently symbolic and are part of a social formation of the "real world".

This work is systematized into five sections. The first section provides an overview of the concept of narrative and visual narratives in order to develop a better understanding of film narrative forms. The second section analyzes narrative forms through the cinematic codes in Brazilian films. The third section presents the cinematic landscape as a spatial representation of slums while the fourth section carries the cinematic landscape analysis of Black Orpheus, City of God and Elite Squad I \& II. Finally, the final section offers more generalized conclusions.

\section{Narrative and visual narratives of moving images}

According to Barthes $(1966,1996)$, narrative can be articulated in a variety of genres and media. It can be presented via verbal, non-verbal, static, and finally, moving images, or through some combination of each. The author argues that narratives exist in any kind of human productions, artistic, or related to everyday life, as in films, news, stories, histories, paintings, photographs, etc. In conformity with Newcomb (2004:416) "a fundamental characteristic of narrative $[\ldots]$ is the arrangement of events in time". "For a film to be a 'narrative' it must present us with a series of events in ways that imply connections between one event and the next".

Moreover, in this infinite variety of forms, it is present at all times, in all places, in all societies; indeed narrative starts with the very history of mankind; there is not, there has never been anywhere, any people without narrative; all classes, all human groups, have their stories, and very often those stories are enjoyed by men of different and even opposite cultural backgrounds (Barthes, 1966, 1996:46).

The narrative in the literally works, for example, in books was the main source for geographers to explore the landscape, however, Grang (1998) pointed out that geographers may gain from other media, such as visual and audio materials, with the intention of observing cultural ideas of a landscape produced and reproduced within these audio visual narratives. "Film can have obvious connections to literature - most clearly where films are made of books" (Grang, 1998:82). Films are a good manner to understand visual narratives since:

Visual narratives can be defined as a visual that essentially and explicitly narrates a story where - Visual signifies - something that can be seen using the human eye. Story signifies - a series of events linked by causality, temporality or sequence or the order of occurrence. Narrative signifies - the act of telling a story or the story 


\section{GEOGRAPHICAL IMAGINATIONS}

itself or the order of presentation (Pimenta and Poovaiah, 2010:30).

As stated by Schirato and Webb (2004) the visual narrative transports the notion of reading a visual text, in this case, a picture, a moving image or any visual object; which contains a space, a story or a frame of information that operates within a social context. It is important to remember that those visuals also require techniques to convey their stories through conventions known by a group from a certain society. It is not only the common sense appeal that supports the viewers to recognize the plot or the context of an image. The applied techniques in the visual narratives can also determine messages to the viewers, for example, the light structures to draw attention to a particular piece in an image and the depiction of a human expression of happiness, anger or sadness (Schirato and Webb, 2004).

Visual signs can represent several meanings; this is why they must be connected with a frame of story that aims to denote a specific logic. Filmmakers make use of culture specific codes in their visual narratives to tell a story that is represented by the visual sign and might be interpreted by the viewers as the "corrected" or "intended" visual narratives. Pimenta and Poovaiah (2010) underlined that the visual narratives are divided into three instances: static, dynamic and interactive. In the first, the image is static, for example in a comic strip, but the eyes and the mind are in movement. The dynamic visual narrative is the ability of constantly changing images; for example, any moving image, as a film "[...] typically consists of a number of still images that is run at high speed giving the impression of temporal movement. The story is constructed before the eyes of the spectator. Actors, scenes, duration of the event, actually physically move in time; albeit in a linear fashion" (Pimenta and Poovaiah, 2010:38). Finally, the interactive visual narrative involves interaction with the viewers, such as in an electronic video game.

\subsection{Genre and film narrative forms}

It is believed by Newcomb (2004) that narrative and genre hold a representative place in all forms of literature and also in the contemporary studies about media. Since they are instruments by which the human being can experience the world through the re-construction, rearrangement and re-imagination of their stories in the space. "Genre theory began with Aristotle, who built on Plato's distinction between imitation and description and thus went far beyond the Greek practice of classifying poetry mainly by its metrical form" (Kearns, 2009:201-202). Nonetheless, Chamberlain and Thompson $(1998,2009)$ draw attention to the point that genre is not a simple concept to discuss, since this term is quite new in the field of social science; and it has a long and mostly confusing history both in literature and in visual arts. Newcomb (2004) continues to report that narrative and genre are also instruments which systematize and guide experience and knowledge. These concepts act as a structure for meaning in all kinds of nonfictional and fictional contents. 


\section{GEOGRAPHICAL IMAGINATIONS}

According to Pramaggiore and Wallis (2005) the interpretation of films is mainly based on five components: narrative form, mise-en-scène, cinematography, editing and sound. As a means to comprehend the categories of narratives in film or literary types, Newcomb (2004) underscored the importance of genre as a system of classification in the narrative forms. It is through imitation of the real life that "Aristotle distinguished three literary types - epic, lyric, and dramatic - according to the means of imitation (melodrama, language, rhythm)" (Kearns, 2009:201-202). Furthermore, Gancho (2002) believed that these three categories consist of literary forms; in her analysis, the first one is the fictional narrative, which is structured upon history, films are included in this category; the second is a genre which belongs to lyrical poetry; and lastly, the theatrical drama, related to theater narratives, tragedy and comedy.

As identified by Gancho (2002) each narrative is structured by five elements: plot, character, time, space and narration. The plot does not necessarily reflect the "realistic" universe; however it must be verisimilar to the "reality". "The cinema constructs and legitimates an idea of the real. Realism is not a form of mimetic transparency that spontaneously reproduces the external world, rather verisimilitude is an "effect" (Barthes 1989) produced by the artful arrangement of signifying elements within a text according to specific conventions (MacCabe 1993)" (Peckham, 2004: 422).

Regarding narratives, the verisimilitude occurs when in a plot exists a cause that triggers a consequence. It is necessary to take into account the structuring constituent of the narrative, otherwise stated, the conflict in order to appreciate the organization of the facts in a plot. Conflict is a component of narrative that opposes to other elements, it creates a tension that will organize the facts in the narrative; it can be man versus man, man versus nature or man versus self. Finally, in terms of structure, the conflict is responsible to determine five parts of the plot. These are: exposition or introduction; rising action; climax - the most intense part of the story, it can be physically or emotionally; falling action and lastly the conclusion, this last one can be represented as a resolution or a catastrophe.

The second element of the narrative is the character; he, she or it can be the protagonist, the antagonist or the adjuvant. The protagonist is the central person, classified between hero and anti-hero, the antagonist is the villain and the adjuvant is the secondary character. The third element of the narrative is the time, the facts of the plot connect different time layers: historical period, duration of the history, chronological or physiological time. The last one mentioned does not occur in a logical order of begging, middle and end. The space, which is the fourth element, represents the geographical location and it is divided between physical and physiological spaces; the latter refers to the ambience in which the characters are involved, it can be the socioeconomic, moral or psychological environment; the "[...] ambience is the concept that connect time and space" (Gancho, 2002:17). Lastly the narration is the main element that organizes all other elements in the narrative. 


\section{GEOGRAPHICAL IMAGINATIONS}

Cinematic narration is arguably the most sophisticated of all narrative media, because it is 'multi-track,' both visual and audio. This enables films to co-opt the communicative capabilities of a whole host of other media and forms. For example, films have linguistic communication through the presence of dialogue or voice- on the sound-track, or the inclusion of printed text within the image (such as intertitles, shots of newspapers, books, letters etc.) (Speidel, 2006:2).

\section{Understanding narrative forms through cinematic codes in brazilian films}

Film studies refers to the science of interpreting a film, however it does not seem so trivial as "reading is often defined as interpreting symbols in relation to intended meanings" (Gaffney and White, 2006, 2009:8). While film narratives "[...] organize stories according to sets of conventions, which are understood by filmmakers" (Speidel, 2006:3), film viewers must read and recognize them as a sequence of events. This identification occurs as a response to the viewer's experience of their "real world" and also by their contextual understanding of other representations formed through watching other fictional or non- fictional contents (Speidel, 2006).

Cinematic codes refer to a set of tools used by filmmakers, based on the sets of conventions, in order to construct their narratives. These codes, presented in the film narratives, can be detected through the technique of interpreting the film language: while visual codes is divided into mise-en-scène, cinematography and editing; audio codes are divided into speech, music and noise; nevertheless this paper does not aim to articulate a discussion regarding audio narratives (Speidel, 2006). All elements of cinematic codes play an important role in film narratives, nevertheless, this paper will focus exclusively on mise-en-scène, since "each elements of the mise-en-scène [...] influences the viewer's experience of the story, characters, space, and time" (Pramaggiore and Wallis, 2005:60).

Here mise-en-scène is composed by six elements: setting, property, costume and make-up, performance, lighting and special effects; the latter mainly refers "[...] to image manipulations that change the appearance of other aspects of mise-en-scène" (Speidel, 2006:17); thanks to the digital technology innovations it was possible to advance with the techniques of image manipulation, please refer to the Figure-1. Cinematography will be defined by (Speidel, 2006:14) as "all those elements of cinematic expression which are performed or controlled by the camera. These include framing and shot scale, camera angle and movement, and depth of field and focus". Lastly, editing involves the joining together of these separated six elements pieces. Pramaggiore and Wallis (2005) summarize that in the post production period, special effects are added and cinematography and editing refined. 


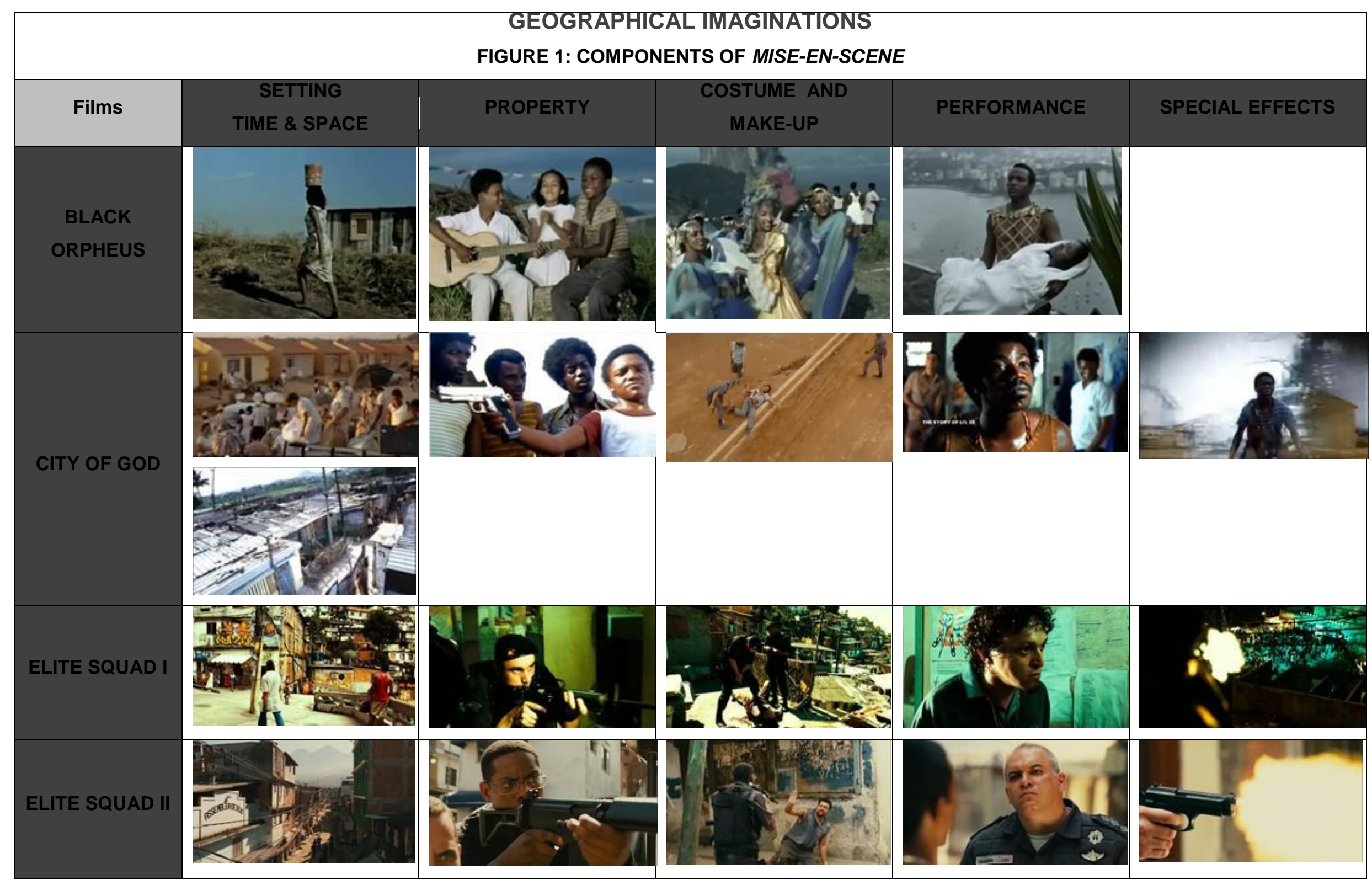




\section{GEOGRAPHICAL IMAGINATIONS}

The concept of mise-en-scène or 'staging in action', which originated in the nineteenth-century theater refers in film studies to the constituent elements that compose a shot and create a specific 'screen space'. Amongst other prerequisites [...] setting is a crucial aspect of mise-en-scène. The setting is sometimes privileged as the leading character in a film, functioning not merely as an incidental background for the main action, but as an expressive component of the narrative itself (Peckham, 2004:420).

Setting denotes the location where the film's action take place, it can be real or imaginary, predominantly generated by computer software; settings can be inside of buildings or outdoors, , work or public spaces, it can be spacious or overcrowded (Pramaggiore and Wallis, 2005). "The settings given to us during the openings to some films may leave us with more questions and not place us within a particular world with quite the same certainty" (Gaffney and White, 2006, 2009). Since, the setting does not infers that a geographic space should be represent at the first moment; nevertheless it suggest authenticity or spatial qualities, since the primary function of a setting is to combine time and space on the narratives (Speidel, 2006). "Directors sometimes choose to use settings that work against expectations" (Pramaggiore and Wallis, 2005:63) it is the case of the film Black Orpheus, in which poor houses in Rio's favelas take place as settings of the musical narrative fiction between a singer and his beloved, Orpheus and Eurydice.

Property is any moveable objects within the set or used by a characters in the film; it can carry high symbolic weight and functioning as source of connotative expression or not. Property also operates as iconographic demonstrations of genre, once weapons and police cars are central to crime drama films such as Elite Squad I and II. Property "[...] play a key role in suggesting a whole array of meanings beyond what is shown; they are a rich, and extremely economic, source of connotative expression" (Speidel, 2006:11). The contrast between Elite Squad I and II and City of God shows, even though all of these movies depict squatter settlements of Rio de Janeiro, that the properties in the scenes are different. The three films above are filled with guns and weapons in contrast to the Black Orpheus, where the guitar is the main property: "Orpheus; he it is who makes the sun rise every morning, as he sings and strums his guitar", even when Orpheus is dead "[...] one of the children picks up his guitar to play as the sun rises on another day" (Owen Lee, 1961:311).

In the sequence symbolic meaning is also expressed by costume and make-up, as well as cultural connotations that reinforce preconceived stereotypes as other graphic properties in the scene; they indicate the personality and the social status and milieu of the character, as well as, provide evidence concerning determined time and space (Pramaggiore and Wallis, 2005). The differences between the characterization of a police officer and a criminal suspect in films as Elite Squad I and II is clearly well-marked; on the one hand, the first group is depicted on screen with their black and intimidating uniforms, and on the other hand criminals are most of the time portrayed with their dirty streetwear costumes. In Black Orpheus the costumes reinforce the 


\section{GEOGRAPHICAL IMAGINATIONS}

golden age of Rio de Janeiro's carnival in the favelas when Orpheus "[...] costumed as the sun" and Eurydice "[...] as the night" (Owen Lee, 1961:311).

Performance is the richest area of cinematic expression, it encompasses facial expression, body posture and movement; performance also depends of many factors to result in a convincing narrative, since the actor's performance is highly connected to different kind of storylines. Many theater's directors are invited to be a part of the producers team, since there are responsible to guide and train actors according to their methods of realistic performances. "Fátima Toledo, a Brazilian acting coach whose participation in the casting of City of God cannot be overlooked, had herself developed an original method to extract realistic performances out of non-professional actors, especially for television" (Durão, Felix and Pontes, n.d.:8-9). The film City of God was one of the precursors in using favela dwellers as unprofessional actors to performer themselves in Meireles' narratives of City of God in order to preserve the realistic aspect; this method was also applied in films as Elite Squad I and II, since the director José Padilha selected some police officers from BOPE (Batalhão de Operações Policiais Especiais eng._Special Police Operations Battalion) to perform by themselves during the chasing scene in favelas.

\footnotetext{
Meirelles declared in several interviews that from the beginning of the production his aim was to achieve a kind of realism that could rival the novel's, and that this could only be achieved on the screen through spontaneous acting: 'I wanted the audience to look at Lil' Zé and actually see the real Lil' Zé, and not an actor playing a role. The idea was to have these unknown actors in order to eliminate the filter, to let the spectator have a direct relationship with the character (Durão, Felix and Pontes, n.d.:8-9).
}

Finally, lighting "[...] illuminates the set and the actors and can be designed to create certain moods and effects" (Pramaggiore and Wallis, 2005:77). It can generate an esthetic effect of shadow and light and create a special atmosphere. In the film City of God different colors are applied to represent the same space, however, to distinguish different periods of time. For example, the first period of the film depicts the 1960s - the moment in which the northeast population of Brazil arrives to the City of God, this moment also describes the beginning of the City of God's population expansion - "this is the age of innocence of City of God and hence the use of golden colors and much light to depict a relaxed tempo, cozy houses, streets full of happy kids, and so on" (Bülent, 2004:2). Moreover, in the second period of the film, the 1970s, the colors get darker and grey "[...] crime and perversion increase, but communal ties continue to exist [...] the favela becomes a zone of indistinction between law and unlaw, city and nature, peace and war" (ibid). In the third and last period, the 1980s "[...] colors turn all gray and, ceasing to have any referent any longer, violence takes the form of a pure, naked violence; everybody becomes homo sacer" (ibid). 


\section{GEOGRAPHICAL IMAGINATIONS}

\section{Cinematic landscape as a spatial representation of squatter settlement}

Cinematic landscapes can also be constructed - that is, formed from the conscious and intentional isolation and emphasis of topographic detail, and/or the application of mediumspecific techniques and technologies (choices of perspectives and lenses, editing, optical, filters, computer-generated or -enhanced imagery) (Harper and Rayner, 2010:22).

According to Lefebvre (2006) the concept of landscape has different meanings. In consonance with Jackson (1989:13) the essay "The Morphology of Landscape" wrote by Sauer (1925) emphasized the landscape as a "[...] strictly geographic way of thinking of culture". According to Sauer's concept, many of the world boundaries are more cultural than physical. "The same physical environment has given rise to quite different cultural landscape because of different cultural processes in each area" (Jackson, 1989:14). Landscape was defined by Sauer (1925, 2008:98) as a term that "[...] denotes the unit concept of geography, to characterize the peculiarly geographic association of facts [...] It may be defined, therefore, as an area made up of a distinct association of forms, both physical and cultural". Mitchell (2005:49) defined that landscape "[...] refers to a form of representation, both as an art and as a complex system of meaning". In conformity with the Brazilian geographer Santos (1991:61, translated by the author) "everything that we see, what our vision can reaches, is the landscape. The landscape can be defined as the domain of the visible, what the vision embraces. It is not only formed of volume, but also of colors, movements, smells, sounds and etc". What Santos (1988) stated concerning as concept of landscape was quite similar to the definition of cultural landscape designed by Jordan-Bychkov and Domosh (1999:29) as the "[...] visible, material landscape that cultural groups create in inhabiting the Earth".

Cultures shape their own landscapes out of the ram materials provided by the earth. Every inhabited area has a cultural landscape, fashioned from the natural landscape, and each uniquely reflects the culture that created it [...] every cultural landscape is an accumulation of human artifacts, some old and some new (Jordan-Bychkov and Domosh 1999: 29-30).

Based on above mentioned definitions, the concept of landscape seems undoubtedly to be a fertile ground for Cultural Geography in order to explore cultural studies, since "[...] the cultural landscape is rich in symbolism and visual metaphor" (Jordan-Bychkov and Domosh 1999:175). The cultural landscape is a key element in any visual narrative; once the filmmakers can achieve a greater realism of the filming locations, then the space reproduced in their narratives preserves the aspect of verisimilitude with the "real" scenery. Harper and Rayner (2010) believe that the filmmakers can be compared with mapmakers, once they have tools to guide the audience to a quite familiar or newly discovered landscape, "both maps and films assume and position audiences, ideologically as well as geographically" (ibid:15). In consequence, maps and films encompass the selection, inclusion, omission and invention of objects in a space.

If we consider landscape as a symbolic system (Crang, 1998), a cinematic landscape is much more symbolic than a purely spatial background that supplements the visual description of actions and events in a narrative (Lefebvre, 2010). In order to comprehend the meaning of cinematic landscape, Lukinbeal (2005:3) quoted Jackson's (1979) ideas, of the interrelationship 


\section{GEOGRAPHICAL IMAGINATIONS}

between landscape and theater, as a human control of the space/stage; as, the "theater is a staged production with a set of socially and artistically determined rules [...] humans control and design the landscape as if it were a theatrical stage [...] theater imparts the human ability to see ourselves as occupying the center of the stage". Moreover, he reinforced that Jackson's essay was the basis for a debate regarding to cinematic landscapes; since, theater can be considered an artistic predecessor of cinema. "With its emphasis on the visual, the spectacular and male control of the stage, this metaphor emphasizes landscape and cinema as a cultural production, a space that is mediated by power relations" (Lukinbeal, 2005:4).

Harper and Rayner (2010:16) go further in their analysis and specify that a "[...] cinematic landscape is the imposition of order on the elements of landscape, collapsing the distinction between the found and the constructed". The authors attract attention to the fact, that a cinematic landscape is not constantly a reproduction, but it can be a discovered, or even an invented landscape shaped by filmmakers' imagination, as seen on the example of two science fiction films Avatar (Cameron, 2009, USA) and The Matrix (Wachowski and Wachowski, 1999, USA). These films projected two fantastic landscapes which do not exist in the real world; nevertheless they were shaped as a similar association to the real world. Since, any kind of cinematic landscape depicts a symbolic landscape that is recognized by the audience and "[...] frequently contribute to social formation, impacting upon human association and societal norms" (Harper and Rayner, 2010:16).

According to Harper and Rayner, (2010:17) the cinematic landscape assumes position of "representation" in a film narrative, "[...] representation is produced by selection or construction, or an amalgam of these, and these landscape have corresponding degrees of authenticity and originality". As mentioned by Lefebvre (2006:8) "cinematic landscape is a multifaceted and pluridisciplinary spatial object whose meanings and representations extend from real-life environments to art". Lukinbeal (2005:8), strengthen that the repetition of a particular area depicted by films or television programs as icon of a geographical location has the autonomy to "[...] create a representational legacy that works to construct and establish a cognitive map, a sense of place". Hall (1997) undertakes that:

Representation is the production of the meaning of the concepts in our minds through language. It is the link between concepts and language which enables us to refer to either the 'real' world of objects, people or events, or indeed to imaginary worlds of fictional objects people and events (Hall, 1997:17).

Each of these theoretical positions makes an important contribution to the understanding of cinematic landscape of favelas as its spatial representation. Four selected Brazilian films have in common the depiction of Brazilians slums as a background in their visual narratives. Nevertheless, the favelas' landscapes, illustrated in these films, are "[...] largely based on the narrow landscape definition on the basis of human intervention" (Harper and Rayner, 2010:17). These landscapes had changed over the years, since they are composed of several elements that interact among them and create an overall conception of this sociocultural construction. 


\section{GEOGRAPHICAL IMAGINATIONS}

Technically speaking, the cinematic landscapes, in these Brazilians films, indicate the symbolic representation or the real perception of the favelas by the audience. Every individual has a different way of perceiving these places, which depends on his/her socioeconomic status as well as on the degree of their relationship with their environment; this is the difference between the person, that only experience slums through television and films imageries, and the favela dwellers. The cinematic landscape of the squatter settlement in visual narratives of Brazilian films is nothing more than the filmmakers' "representation" of their experiences with the "world". Furthermore "a depicted cinematic landscape appears purely as a realist recorded however, it is a cinematic element aesthetically manipulated (Harper and Rayner, 2010:16).

According to Davis (2006:22) in the $18^{\text {th }}$ century the squatter settlements were defined as the places "[...] characterized by an amalgam of dilapidated housing, overcrowding, disease and poverty". Moreover in the $19^{\text {th }}$ century U.S Americans defined this area as occupied by a squalid and criminal population. Furthermore, the author condenses the meaning of squatter settlements by referring to the definition formally embraced at the United Nations meeting in 2002, in the city of Nairobi, Africa: as a place "[...] characterized by overcrowding, poor or informal housing inadequate access to safe water and sanitation, and insecurity of tenure [...] restricted to the physical and legal characteristics of the settlement [...] although it equates under most circumstances to economic and social marginality" (Davis, 2006:23). Nonetheless, the same social commentator adverted that this new urban order is compelled by the increasing inequalities within and between cities of different sizes and economic specializations. A report produced by Share the World's Resources (2010:1) reinforced that "[...] most of the world's urban population, most of its largest cities and most of its urban poverty is now located in Africa, Asia and Latin America".

Several writers have referred to various local names given to squatter communities: colonias proletarias in Mexico, barriadas brujas in Panama, ranchos in Venezuela, barriadas in Peru, callampas in Chile, cantegriles in Uruguay, favelas in Brazil, and, in other places, marginal areas, clandestine urbanizations, barrios of invasion, parachutists, phantom towns, etc (Mangin, 1967:65).

In Brazil, the city expansion - being the result of a rapid demographic increase - and the disorganized urbanization - caused by the local community's self-planed irregular settlements had generated an informal and disordered growth in the urban cities during the 1960s and 1970s. Moreover, the immigration flow of poor, rural citizens to the surroundings of the big cities of São Paulo and Rio de Janeiro and the large number of people living in the same urban areas began the development of squatter settlements in Brazil. Slums have been part of Rio de Janeiro's landscape for more than a century, and most of them have increased since the 1960's. An example might be the neighborhood Morro da Providência, which was registered as the first slum founded in 1880s (Perlman, 2009).

The favelas settings have played important and distinct roles in the film Black Orpheus in contrast to City of God and Elite Squad I and II. The Brazilians slums represent main settings for development of the narratives in the four selected films; nonetheless, they gained different meanings. In consequence, beliefs and feelings, which viewers associate to the representation 


\section{GEOGRAPHICAL IMAGINATIONS}

of a setting, may not fill their expectations, since "[...] the significance of that environment in a film depends on the way it functions in the narrative and relates to other visual techniques" (Pramaggiore and Wallis, 2005:65).

\section{Cinematic landscape analysis of black orpheus, city of god and elite squad i \& ii}

The film Black Orpheus was an adaptation of the Greek myth of Orpheus and Eurydice; and the main setting of the narrative was located in the favela Morro da Babilônia in the Leme neighborhood in Rio de Janeiro (Gates, 2011). The French director Marcel Camus received from the president Juscelino Kubitschek full governmental support to produce the film however, Grasse (2004:293) alleged that "[...] the film remains a vehicle for an otherwise Brazilian project" and carries a certain Eurocentric vision of a modernist negrophilia in an exotic carnivalesque black community. "The film stresses favelados as '... carefree, full of boundless energy and rhythm, with an unfettered zest for life"' (Mangin, 1967:73). As seen in Figure 2, the slum dwellers live in "[...] a kind of romantic masochism of misery that finds an escape through art, popular culture, carnival and samba" (Bentes, 2003:129). Race and social equality play an important role in the visual narrative of this film, since the hero "[...] black Orpheus and his community illustrated an utterly fictional, utopian citizenship of inclusion" (Grasse, 2004:301) in the midst of a Brazilian racist society in the 1950s.

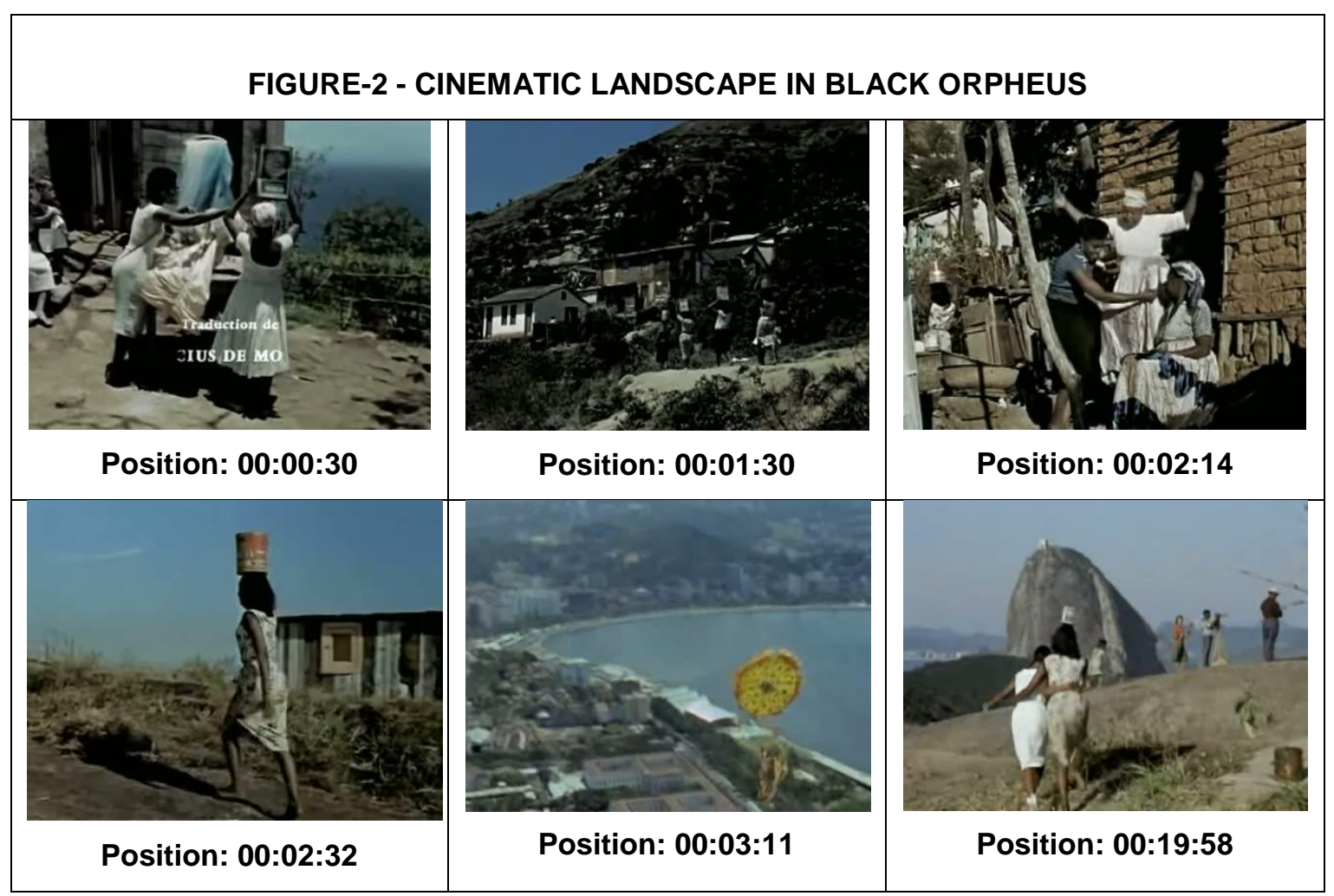




\section{GEOGRAPHICAL IMAGINATIONS}

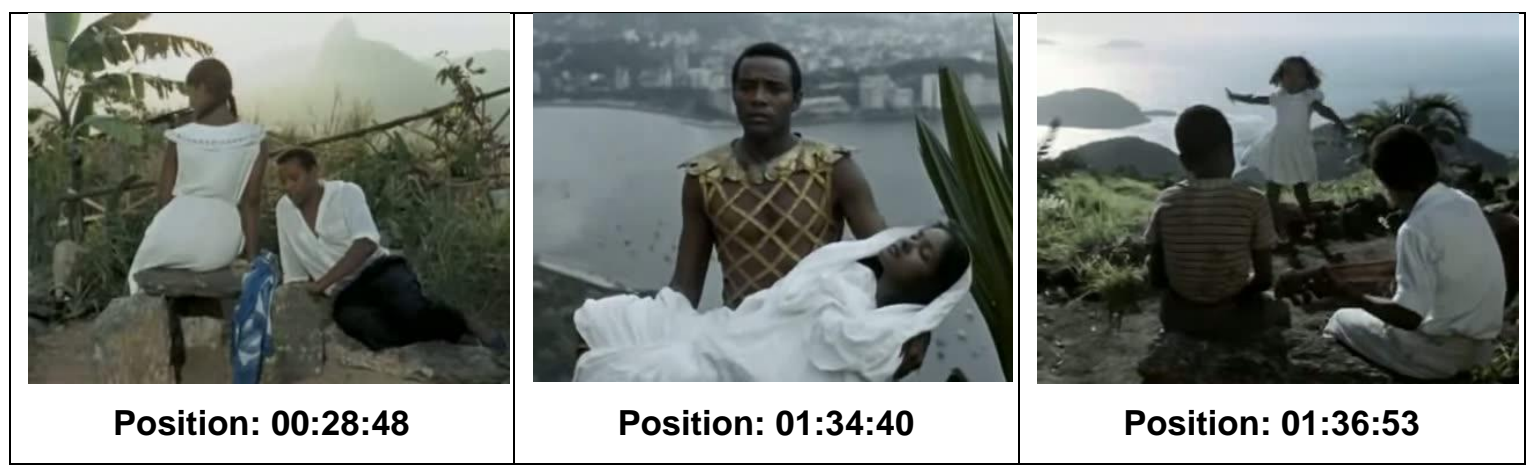

Glauber Rocha, for one, was acutely aware of the way Brazilian films were often consumed in Europe, and of Europeans' habit of turning to the culture of the underdeveloped world to satisfy their nostalgia for primitivism (Bentes, 2003:87).

Grasse (2004) pointed out that the Bossa Nova was imposed as a background music in order to depict the life in favelas of Rio de Janeiro, nevertheless "[...] this place was rooted in samba during carnival, and a highly regarded cultural authority linked to that popular music" (ibid:292) instead of the rhythm developed amongst the white middle class in the southern part of Rio de Janeiro during the 1950s. He also highlighted that Bossa Nova was introduced to international audience through this film and Camus was responsible to support the musical careers of composers and performers such as, Antonio Carlos 'Tom' Jobim the distinguished compositor, together with Vinícius de Moraes, of the international successful music Ipanema Girl (Garota de Ipanema).

According to Bentes (2003) the director of Black Orpheus neglected all historical and social contexts through the fact that has created an unreasonable non-realistic geography; colors, black cast, music instruments and carnivalesque allegories, which are the elements of the miseen-scène and portray the life in an unsubstantiated favela of Rio de Janeiro. The city "[...] is a cinematic construction, a juxtaposition of postcards" (Bentes, 2003:134), which presents the favela landscape "[...] as a mythical and paradisiacal place where poverty is glamorous, even desirable, where nature and culture are one, where poor dwellings, the barracos, look charming and the backdrop is a touristy landscape of the Guanabara Bay" (ibid.). The visual elements of the film reinforce Favela as a representation of the lost paradise, an exuberant landscape, where the community of 'noble poor' lives a modest but happy life in dignified poverty (Bentes, 2003).

Daily life is transformed into celebration and playful time. In the film, misery is transubstantiated into 'primitivism' and 'archaism'. In fact, misery is not an element in the film. The characters live in a 'primitive' way, but misery has disappeared under the veil of a non-problematic poverty (Bentes, 2003:134-135).

As opposed to the film Black Orpheus which represented the Cinema Novo movement, City of God and Elite Squad I \& II formed the part of the new generation or the renaissance represented by the National cinema which opened the floor to a wide range of techniques, genres, styles and approaches in the mid-1990s. The contemporary cinema represents "[...] urban and rural life from a perspective of the disenfranchised marginalised fringes of society" 


\section{GEOGRAPHICAL IMAGINATIONS}

(Shaw and Dennison, 2007:101). Notwithstanding, the society and the media in general "[...] started to pay attention to the favela only when the kidnappings and the cocaine business started" (Nagib, 2003:164), which problems have affected directly everyday life of middle class. City of God is based on the novel written in 1997 by Paulo Lins and directed by Fernando Meirelles and Kátia Lund. The book is the result of research in a poor housing project; this novel is grounded on the interviews and data collection related to the drug traffic organization and its connection to the history of the shantytown City of God in the 1970s-80s. The film is divided into three parts; the first one reproduces the arrival of poor immigrants coming from the Northeast area of Brazil and the relocation of a quota of the socially excluded population to the place called City of God in the beginning of the 1960s. The actual representation of a squatter settlement has been illustrated in the second and third part of the film, by showing unplanned settlements and lack of adequate infrastructure. As the continuation, in the beginning of the 1980s, according to the film audiovisual narrative, the City of God became the most unsafe area of Rio de Janeiro.

In this film, as illustrated in Figure - 3, the life in Brazilian's urban shantytowns is presented with an extraordinary degree of realism. This was possible while the "language of slums" has been applied as the official language in the film. The non-professional cast consisting of a slum residents performed in such a way that often shocked the audience; the modern cinematic techniques, the frenetic rhythm, and the "[...] digital editing, in the style of an advertisement video" (Shaw and Dennison, 2007:103) constitute the important factor of the films' realism. According to Oliveira (2008) City of God inaugurated the term of "esthetic of violence"; since the representation of favelas' landscapes and their elements formed part of the visual narrative. This representation of violence in shantytowns is considered as a pure spectacle for voyeuristic audiences. City of God portrayed the inner workings of gangland culture in 3 different favelas with the intention to "[...] make middles-class Brazilian aware of the realities of life on their doorsteps (Shaw and Dennison, 2007:103-104). "As the film progresses the idyllic neighborhood starts to change into the contemporary idea of what a favela is supposed to be. A cramped area filled with little shacks, gangs, thieves, dirty little children and a lot of excessive violence" (Hulshof, 2011:57). However, the narrative still brings the idea of hope when they "[...] continued to use the favela as a place of misery and violence from which sometimes something good derives" (ibid). 


\section{GEOGRAPHICAL IMAGINATIONS}

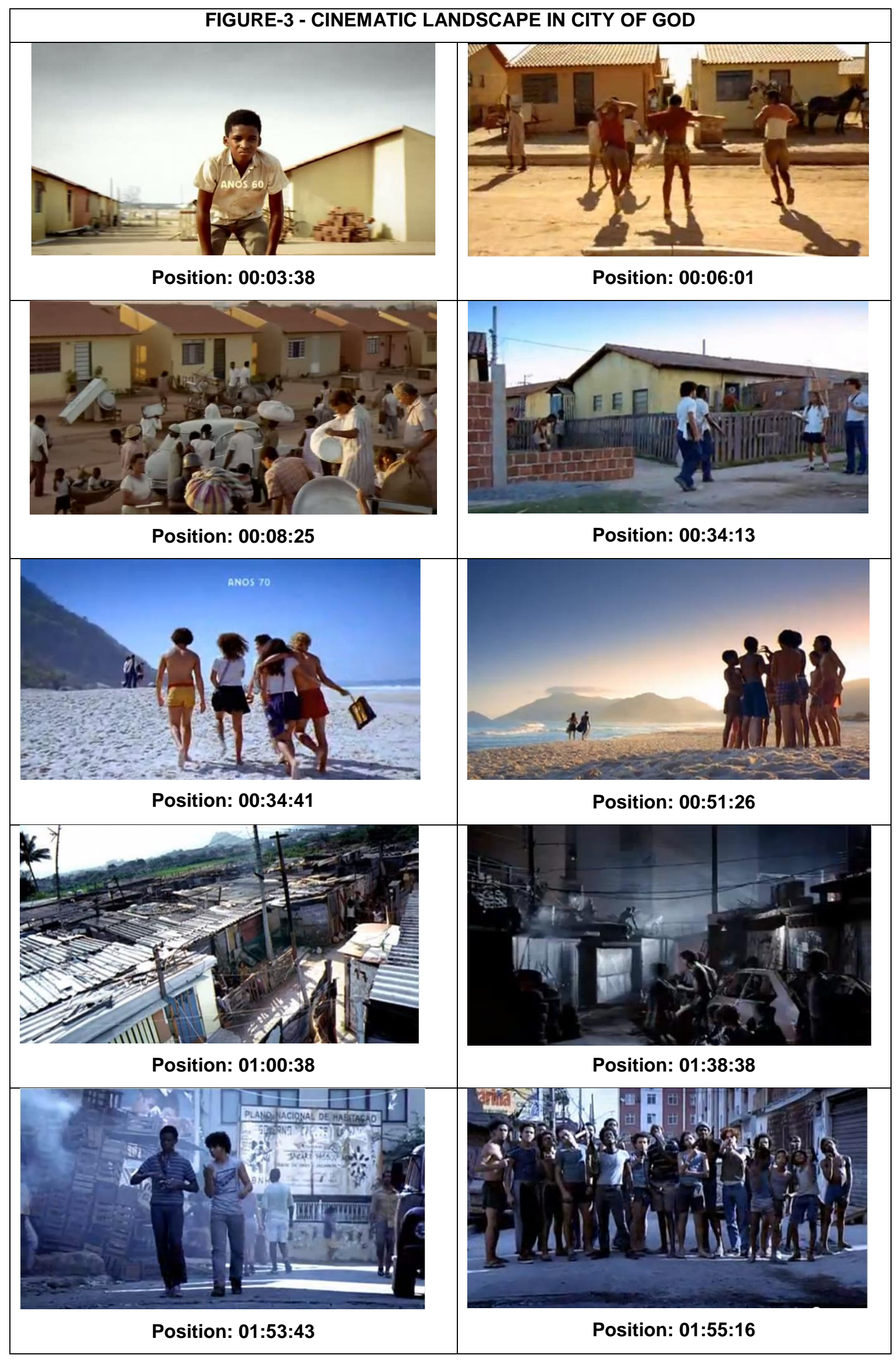




\section{GEOGRAPHICAL IMAGINATIONS}

Different from City of God, which depicts slums as the foreground of the battlefield among drug gangs, Elite Squad I and II showed this environment as a battleground between drug traffickers and police squads. In both Elite Squads, please refer to the Figure 4 and Figure 5, the narration is conducted by the protagonist, the law enforcement agent,Nascimento; he "[...] imposes a dizzying pace on his narrative. The whole plot and the characters of the film have their actions foreseen by this hidden voice that is revealed in the diegesis through the irregular web of the favela" (Saldanha-Álvarez, 2011:24). On the one hand, the first film presents him as the leader of a Military Police Swat Team well known as BOPE and conducts a dangerous mission to clear Brazilian shantytowns from the drug trafficking, since the Pope John Paul II was arriving to Rio de Janeiro (ANCINE, 2008). On the other hand, the second film shows the enemies of Nascimento as "[...] not primarily the drug traffickers but other players connected to globalization [...] standing out among others is the real estate developer and corrupt politicians who lead the assault on the urban territory" (Saldanha-Álvarez, 2011:18).

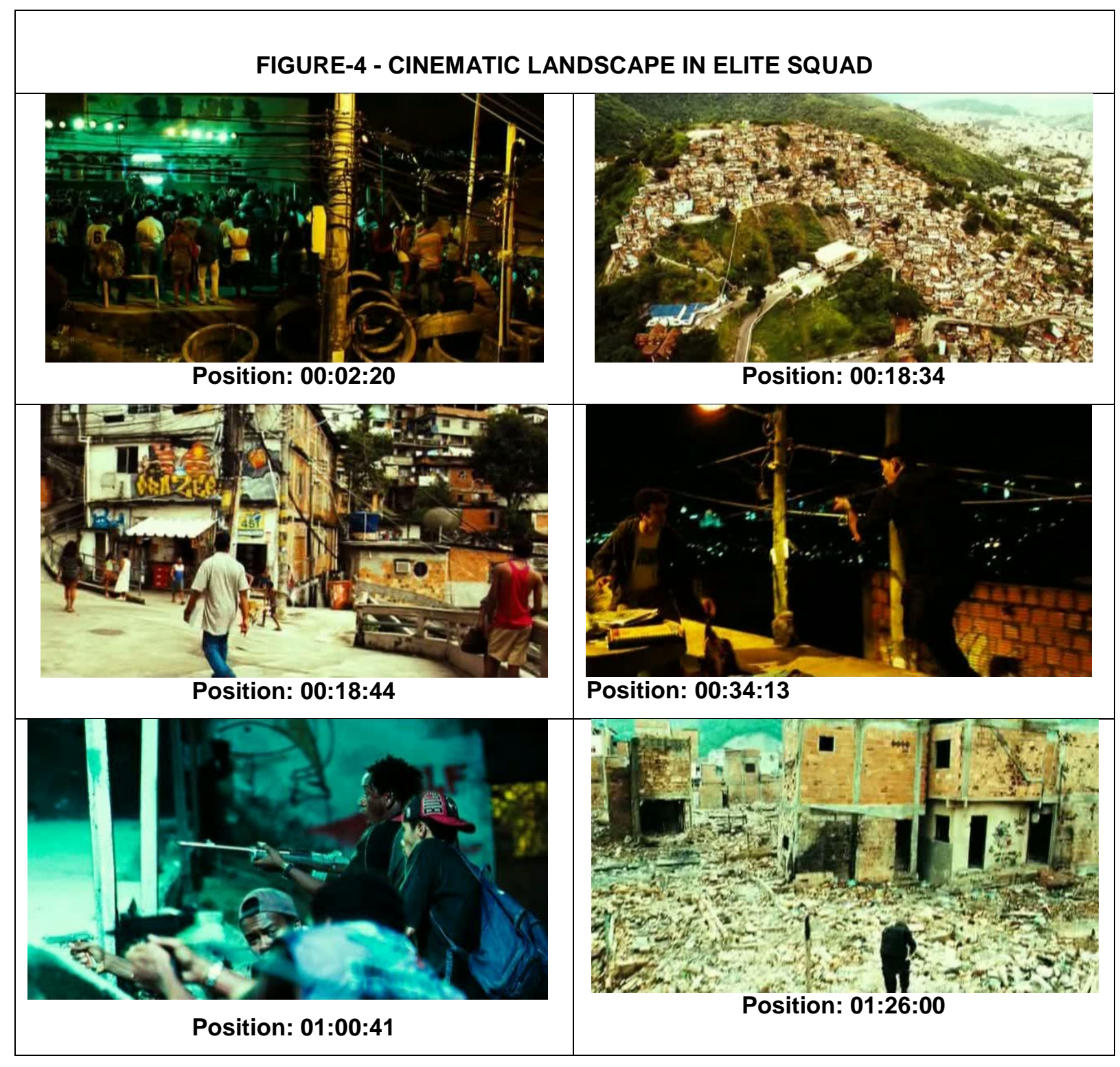




\section{GEOGRAPHICAL IMAGINATIONS}

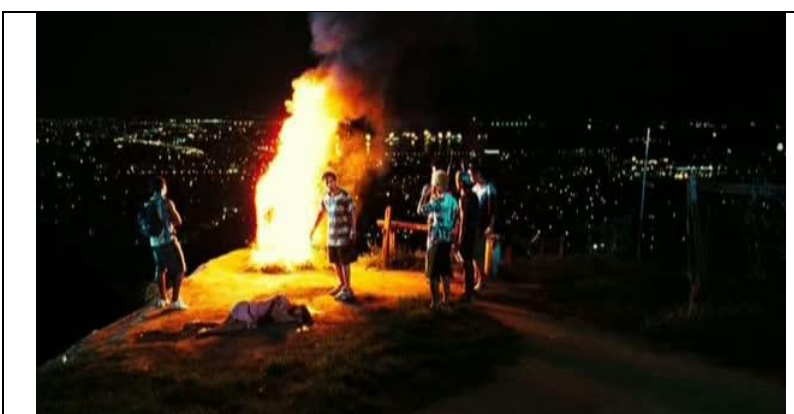

Position: 01:38:10

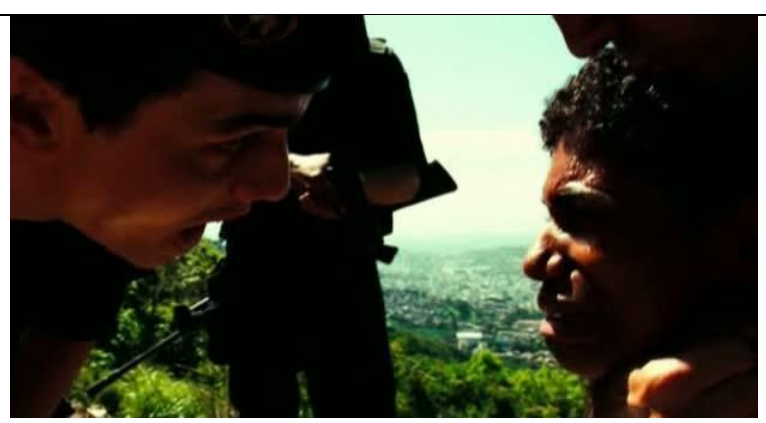

Position: 01:47:44

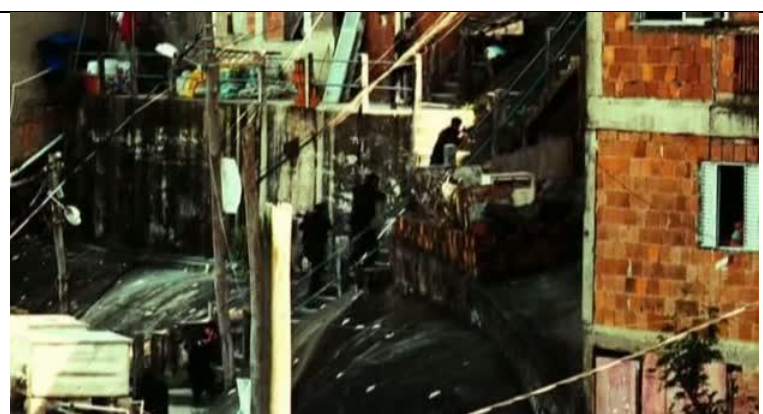

Position: 01:45:43

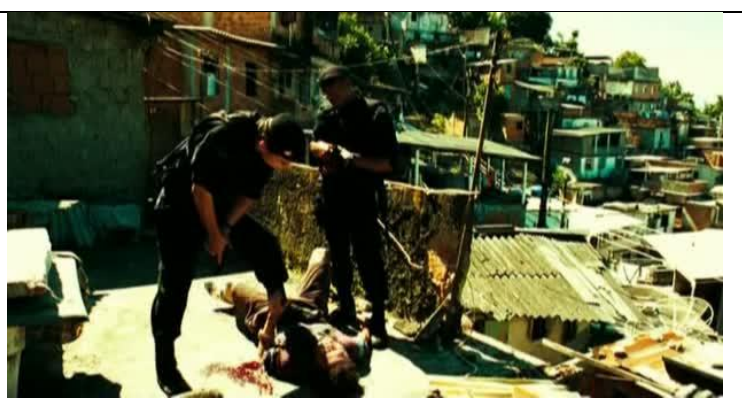

Position: 01:49:50

FIGURE-5 - CINEMATIC LANDSCAPE IN ELITE SQUAD: THE ENEMY WITHIN

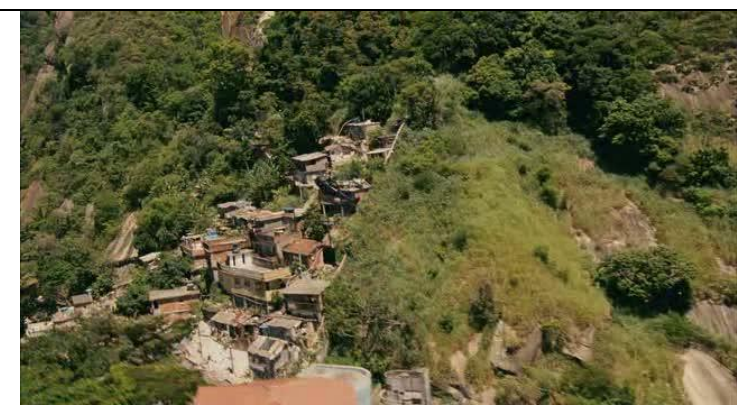

Position: 00:38:31

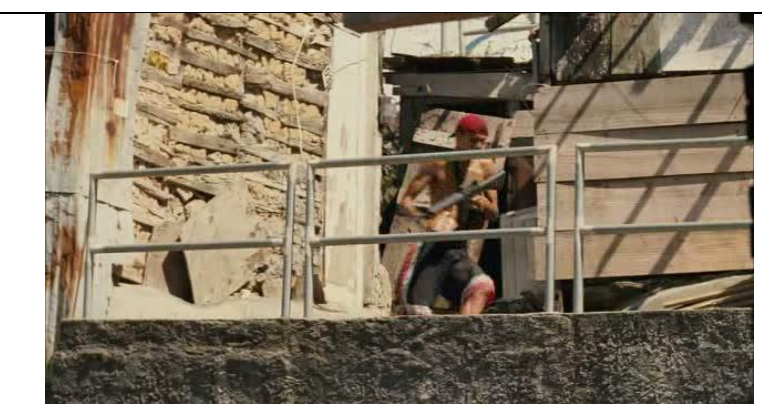

Position: 00:38:55

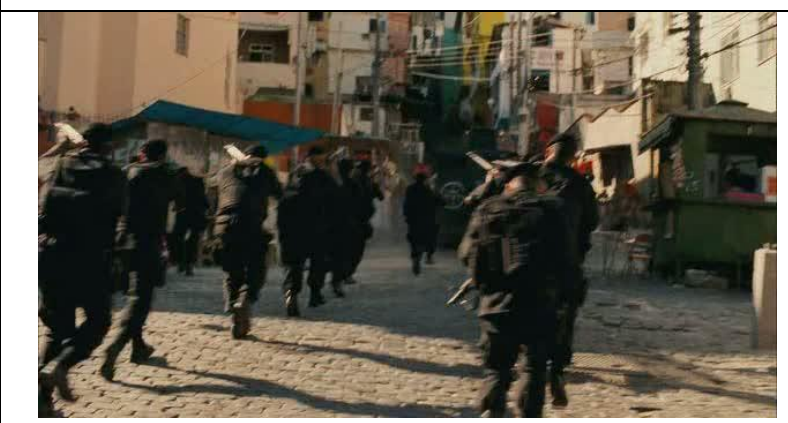

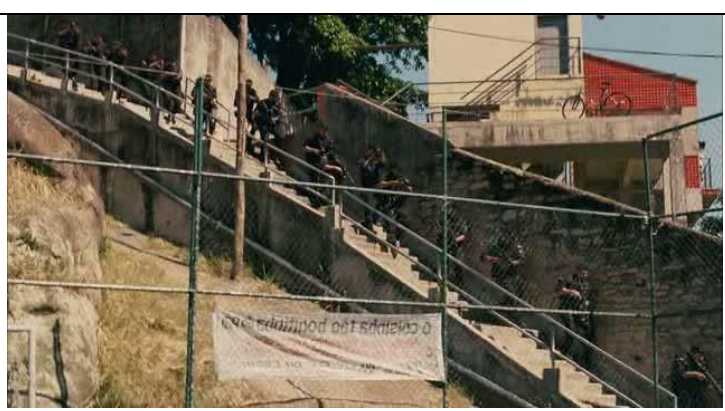

Position: 00:38:42

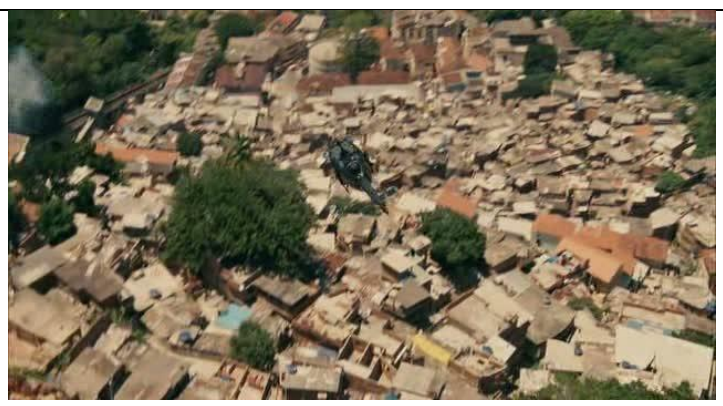

Position: 00:39:04

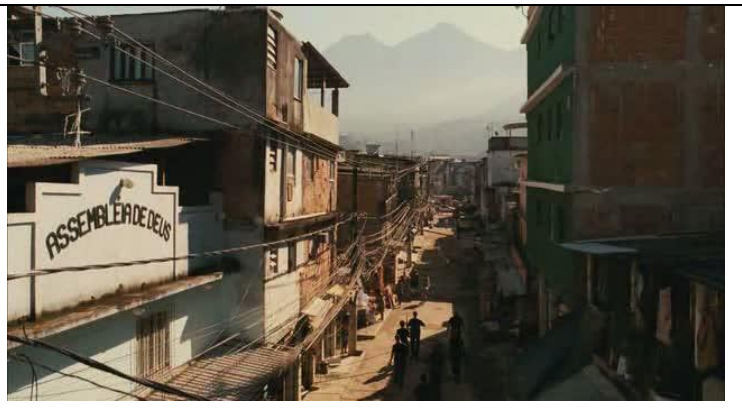

Position: 00:45:09 


\section{GEOGRAPHICAL IMAGINATIONS}

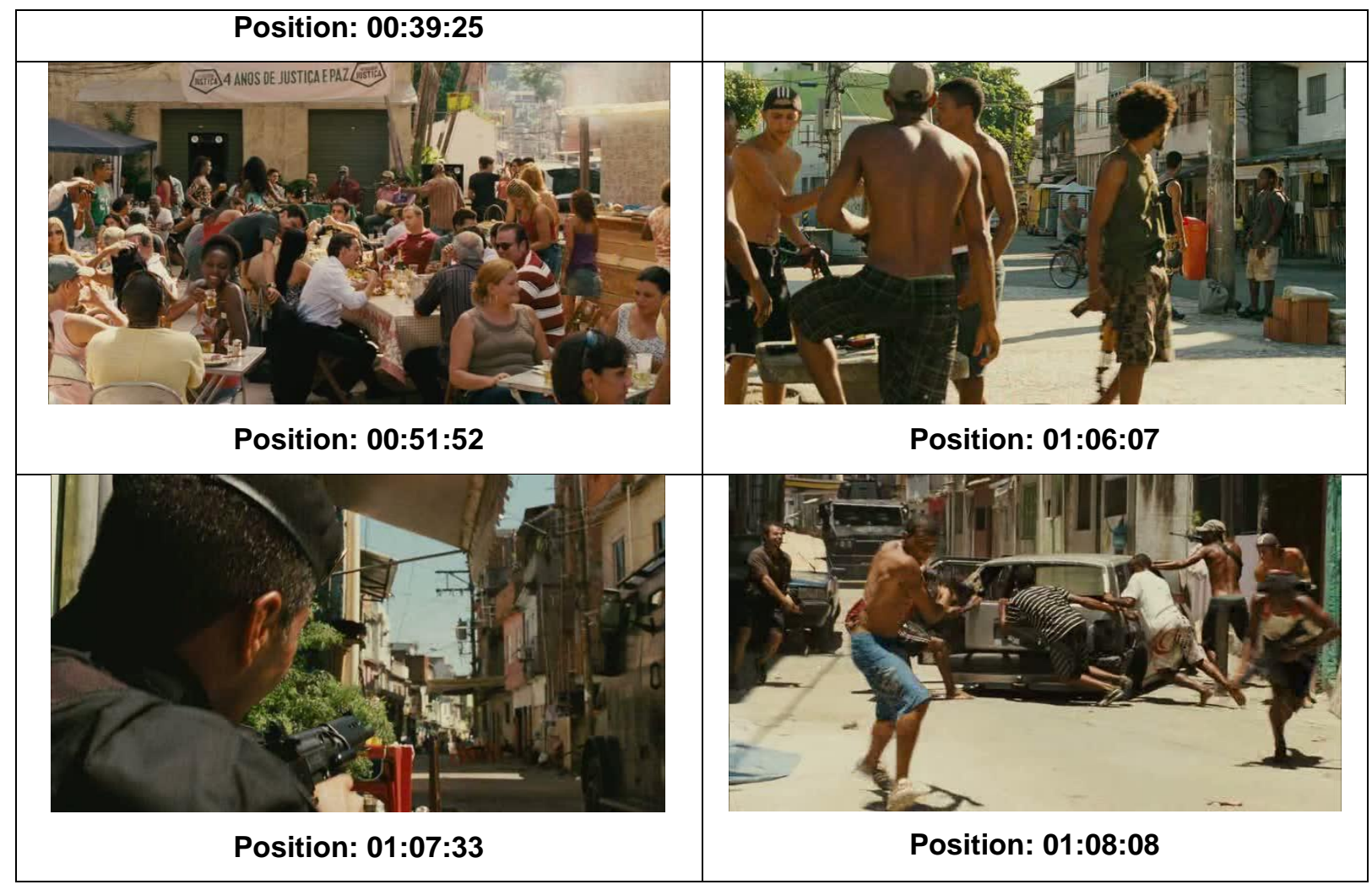

This new type of urban criminal who holds the practice of the favelas and of the city is fiercely imbued with the spirit of profit and earnings on the margins of the system These are MP soldiers or ex-policemen or even soldiers of the armed forces, who have demobilized but still use weapons, training and violence to dominate a defenseless community. Their action takes place on the hillsides or the secret plots of the distant suburbs (Saldanha-Álvarez, 2011:18).

Nevertheless, in Elite Squad I and II, shantytowns are still represented as the environment controlled by drug traffickers, which play a significant role in the narrative as community leaders as well as enemies of the State. The practice of torturing criminals commonly used by BOPE is a point that raises question why are they considered heroes for their attitudes towards criminals. "The film also has been controversial because it seems to approve of the harsh and violent activities of the BOPE in the communities" (Alves and Everson, 2011:224).

Shaw and Dennison (2007) identified the phenomenon of "voyeuristic audience" who admires film contents showing the life in slums' landscapes as a foreground for the confrontation between two groups: police versus criminals. Elite Squads also maintained the same pattern. Saldanha-Álvarez (2011:25) alleges both films to "[...] evoke a nervous, tense and dynamic sense of modern urban life in Brazil" and the audience of these films "[...] applauded some of the most violent scenes were satisfied in their visceral desire for hyper stimulus and sensationalism" (ibid).

Life in Rio de Janeiro or in large Brazilian cities has changed the subjectivity of the anxious public of the asphalt and the hillside, overexcited by constant exposure to the danger seen in the film, which includes the daily life of the city (Saldanha-Álvarez, 2011:25-26). 


\section{GEOGRAPHICAL IMAGINATIONS}

\section{Conclusion}

The cultural approach in geography was based and developed on studies of representation, since it combines meaning and language. After the 1970s cultural studies played an essential role in geographical science. Theories were supported on phenomenon of cultural characteristics and its spatiality could be expressed through a vast range of artistic forms as: painting, photography, music, moving images, etc. The numerous techniques applied to interpret the space via moving images, permitted cultural geographers to investigate films and to comprehend the way in which filmmakers appropriate the geographical space in order to construct their visual narratives. The viewers' perception of the "real world" occurs by the interpretation of a tangible visual sign which carries several meanings and, it must be linked to the frame of information to denote its specific interpretation. It is through culture specific code through which visual narratives tell a story and viewers interpret them as the "precise" or "envisioned" visual narratives. Filmmakers create visual narratives that are understood by the spectators by means of verisimilitude connected with their personal experience of the space.

The cinematic codes are tools applied by filmmakers based on a set of conventions. Convincingly, the cinematic codes are characterized as a powerful approach adopted by the filmmakers to reproduce or even to create certain cultural landscape; nonetheless, "[...] as representation, landscape is also ideology. It is a specific way of seeing; that is while landscape signifies the look of the land, it also signifies a specific way of looking at the land" (Mitchell, 2000:50). Mitchell is referring to the multiple forms of perception that each person has to perceive the world through representation of a landscape. Crang believed, that "film permitted the new spaces of observations; it created impossible visions that contrasted with previous ways of seeing" (Crang, 1998:82). It is clearly well marked that the same geographic landscape can be virtually experienced from different perspectives. Since the techniques of the cinematic codes have been applied by filmmakers in their visual narratives, a cultural landscape can be revealed, reinvented or even created throughout new conventions of representations (Harper and Rayner, 2010).

Moreover, the aesthetic treatment of a landscape involves selection, interpretation, omission and invention of a geographical ambience constructed by the filmmakers' visual perception. Usually, the cinematic landscape seems to be "real", nevertheless, this selected space should not be considered as real, but as a stereotyped representation of the "reality". Film itself contributes to the definition of a national landscape through the common sense imaginaries. The representations of favelas' landscape were transformed over the past decades of the $20^{\text {th }}$ century. It was presented in Black Orpheus (1959) as an enjoyable place to a degraded location in City of God (2002) and in Elite Squad I \& II (2007) and (2010). It is unquestionable, that films as a cultural product, visually (re)construct the "popular imaginary" of a particular landscape and distributes it to a large audience without a deep critical analysis. On the one hand, foreigners' perception help to develop an idea of squatter settlement as an exotic and paradisiacal place in which poor and socially excluded individuals seems to accept their living conditions. On the other hand, the new generation of film collaborates to reinforce the idea of an awful landscape 


\section{GEOGRAPHICAL IMAGINATIONS}

inhabited by degenerated people. However, most of them lack in debate the existence of an extreme social inequality in Brazil that forms part of a social excluded population.

\section{References}

Alves, M. H. M and Evanson, P., 2011. Living in the Crossfire: Favela Residents, Drug Dealers and Police Violence in Rio de Janeiro. Philadelphia: Temple University Press.

ANCINE (Agência Nacional do Cinema - Ministério da Cultura - Governo Federal)., 2008.

Cinema Brasil: Catálogo de Filmes. Brasília. Brazil. Available at: <http://www.ancine.gov.br/sites/default/files/catalogo-cinemabrasil/Catalogo_MRE2007.pdf>

Azevedo, A. F., 2006. Geografia e cinema: representações culturais de espaço lugar e paisagem na cinematografia portuguesa. PhD Thesis. University of Minho.

Barthes, R., 1989. The reality effect. In: tr. Howard, R,. Berkeley: The rustle of language, University of California Press, pp.141-148.

Barthes, R., 1996. Introduction to the structural analysis of narratives. In: Onega, S. \& García Landa, J. Á. (eds). Narratology. London: Longman. First publication as "Introduction a l'a analysé structurale du recit 1966.

Bentes, I., 2003. The sertão and the favela in contemporary Brazilian film. In: L. Nagib., ed., The New Brazilian Cinema. London: IB Tauris, pp.121-137.

Bülent, D., 2004. City of God. CITY, Vol 9(3), Department of Sociology, Lancaster. Available at: $<$ http://www.lancs.ac.uk/fass/sociology/papers/diken-city-of-god.pdf>

Chamberlain, $\mathrm{M}$ and Thompson, P. eds. 2009. Narrative and genre: Contexts and types of communication. 2nd ed. New Brunswick: Transaction Publishers.

Claval, P., 2008. Uma, ou algumas, abordagem(ns) cultural(is) na geografia humana?. In: A. Serpa, ed. Espaços culturais: Vivências, imaginações e representações. Salvador: Edufba, pp.13-29.

Crang, M. 1998. Cultural geography. London: Routledge

Davis, M., 2006. Planet of Slums, New York: Verso.

Durão, F. A., Felix, J. C and Ponte, C. A., n.d. Realism and reality of blood: City of God 10 years later. Available at: http://www.brown.edu/Departments/Humanities_Center/events/documents/FabioDuraoarticle.pd $f$ 


\section{GEOGRAPHICAL IMAGINATIONS}

Gaffney, F and White, J. eds., 2009. AS Film studies: The essential introduction. 2nd ed. New York: Routledge.

Gancho, C. V., 2004. Como analisar narrativas. São Paulo: Ática

Gates, H. L,. 2011. Black in Latin America. New York and London: New York University Press.

Grasse, J., 2004. Conflation and Conflict in Brazilian Popular Music: Forty Years between 'Filming' Bossa Nova in "Orfeu Negro" and Rap in "Orfeu". Popular Music, Vol. 23, No. 3 (Oct., 2004), pp. 291-310. Available through Cambridge University Press. Website <http://www.jstor.org/stable/3877504> [Accessed 9 September 2012]

Hall, S. ed, 1997. Cultural representations and signifying practices. London: Open University Press.

Harper, G and Rayner, J. eds., 2010. Cinema and landscape. Bristol, U.K: Intellect Books

Hong, Y. ed,. 2009. A dynamic constructivist approach to culture: Moving from describing culture to explaining culture. In: Wyer, R. S. Jr., Chiu, C., \& Hong, Y. eds. Understanding culture: theory, research and application. New York: Psychology Press, pp.3-23.

Hulshof, E., 2011. The Depiction of Evil in Brazil's Cultural Products. MA. The Universiteit Utrecht. Available at: <http://igitur-archive.library.uu.nl/student-theses/2011-0928200552/Hulshof,\%20E.pdf> [Accessed 05.01.2012]

Jackson, P., 1989. Maps of meaning. An introduction to cultural geography. London: Unwin Hyman

Jordan-Bychkov, T. G and Domosh, M. eds., 1999. The human mosaic: A thematic introduction to cultural geography. 8th ed., Dallas: Longman.

Kearns, M., 2012. Genre theory in narrative studies. In:. ed. D. Herman., M, Jahn and M-L, Ryan, eds. The Routledge encyclopedia of narrative theory. New York: Routledge, pp.201-205.

L. Nagib., ed. 2003. Death on the beach - the recycled utopia of Midnight. In: L. Nagib., ed., The New Brazilian Cinema. London: IB Tauris, pp.157-174.

Lefebvre, M., 2006. Landscape and film. New York: Routledge.

Lukinbeal, C., 2005. Cinematic Landscapes. Journal of Cultural Geography, 23:1, pp.3-22.

MacCabe, C., 1993. Realism and the cinema: notes on some Brechtian theses. In: A. Easthope, ed., Contemporary film theory. London: Longman, pp.53-67.

Mangin, W., 1967. Latin American Squatter Settlements: A Problem and a Solution. Latin American Research Review, Vol. 2, No. 3 (Summer, 1967), pp. 65-98. Available through The 


\section{GEOGRAPHICAL IMAGINATIONS}

Latin American Studies Association. Website <http://www.jstor.org/stable/2502178> [Accessed 9 September 2012]

Mitchell, D., 2000. Cultural geography: A critical introduction critical introductions to geography. Oxford, UK: Blackwell.

Mitchell. D., 2005. Landscape. In: D, Atkinson., P, Jackson., D. Sibley and N. Washbourne. eds., Cultural Geography: A Critical Dictionary of Key Concepts. London: I.B. Tauris

Newcomb, H., 2004. Narrative and genre. In: J.D.H. Downing., D. McQuail., P. Schlesinger and Ellen Wartella. Eds. The Sage handbook of media studies. Thousand Oaks: Sage, pp. 413-428.

Oakes, T. S., and Price, P. L. eds., 2008. The cultural geography reader. London and New York: Routledge.

Oliveira, E. K. F., 2008. An ethic of the esthetic: Racial representation in Brazilian cinema today. Vanderbilt e-Journal of Luso-Hispanic Studies. pp.43-51. Website < http://ejournals.library.vanderbilt.edu/ojs/index.php/lusohispanic/article/view/3218/1422>

[Accessed 9 September 2012]

Owen Lee, M., 1961. Orpheus and Eurydice: some modern versions. The Classical Journal, Vol. 56, No. 7 (April 1961), pp. 307-313. Available at: http://www.jstor.org/stable/3294869

Peckham, R. S., 2004. Landscape in film. In: S. James., J.S. Duncan., N. C. Johnson. and R.H. Schein., eds., A Companion to Cultural Geography. Oxford and Malden, MA: Blackwell. pp.420429.

Perlman, J., 2009. Favela: Four decades of living on the edge in Rio de Janeiro. New York: Oxford University Press.

Pimenta, S. and Poovaiah, R., 2010. On defining visual narratives. In: ed. R., Poovaiah, Design Thoughts. August 2010; IDC, IIT Bombay, Mumbai, India. Available at: <http://www.idc.iitb.ac.in/resources/dt-aug-2010/On\%20Defining\%20Visual\%20Narratives.pdf>

Pramaggiore, M and Wallis, T., 2005. Film: A critical introduction. 2nd ed. London: Laurence King Publishing.

Saldanha-Álvarez, J. M.,2011. A city shaped by crime? A representation of spaces and urban planning and environment of the city of Rio de Janeiro as shown on the movie Elite Squad, by Jose Padilha. Urbana Affaires and Public Policy, v. XII, pp.1-33.

Santos, M., 1991. Metamorfoses do espaço habitado. São Paulo: HUCITEC

Sauer, C., 2008. The Morphology of Landscape. In: T. S. Oakes and P. L. Price., eds., The cultural geography reader. London and New York: Routledge. 


\section{GEOGRAPHICAL IMAGINATIONS}

Schirato, T., and Webb, J., 2004. Understanding the visual. London: Sage.

Share The World's Resources., 2010. The Seven myths of 'slums' challenging popular prejudices about the world's urban poor. United Kingdom - Share The World's Resources,

$\begin{array}{lllll}\text { London. } & \text { Retrieved, } & \text { January, } & \text { 2012, from }\end{array}$ http://www.stwr.org/downloads/pdfs/7_myths_report.pdf

Shaw, L and S. Dennison., 2007. Brazilian National Cinema (National Cinemas). London: Routledge.

Speidel, S., 2007. Film form and narrative. In: J, Nelmes., ed. An introduction to film studies, 4th ed. London and New York: Routledge. 
